\title{
Religions and Psychotherapies
}

\author{
Edited by \\ Prof. Dr. Klaus Baumann and Prof. Dr. Frank-Gerald B. Pajonk
}

Printed Edition of the Special Issue Published in Religions

MDPI www.mdpi.com/journal/religions 
Prof. Dr. Klaus Baumann and Prof. Dr. Frank-Gerald B. Pajonk (Eds.)

\section{Religions and Psychotherapies}


This book is a reprint of the Special Issue that appeared in the online, open access journal, Religions (ISSN 2077-1444) from 2011-2012 (available at:

http://www.mdpi.com/journal/religions/special_issues/religions-psychotherapies).

\section{Guest Editors}

Klaus Baumann

Caritaswissenschaft und Christliche Sozialarbeit, Theologische Fakultät

Albert-Ludwigs-Universität Freiburg, Germany

Frank-Gerald B. Pajonk

Praxis Isartal, Kloster Schäftlarn, Germany

Klinik für Psychiatrie und Psychotherapie, Georg-August Universität Göttingen, Germany

\section{Editorial Office}

MDPI AG

Klybeckstrasse 64

Basel, Switzerland

\section{Publisher}

Shu-Kun Lin

\section{Managing Editor}

Jeremiah R. Zhang

\section{Edition 2014}

MDPI • Basel $•$ Beijing $•$ Wuhan $•$ Barcelona

ISBN 978-3-906980-77-5 (Hbk)

ISBN 978-3-906980-78-2 (PDF)

\footnotetext{
Articles in this volume are Open Access and distributed under the Creative Commons Attribution license (CC BY), which allows users to download, copy and build upon published articles even for commercial purposes, as long as the author and publisher are properly credited, which ensures maximum dissemination and a wider impact of our publications. The book taken as a whole is (C) 2014 MDPI, Basel, Switzerland, distributed under the terms and conditions of the Creative Commons by Attribution (CC BY-NC-ND) license (http://creativecommons.org/licenses/by-nc-nd/4.0/).
} 


\section{Table of Contents}

List of Contributors

V

Preface XV

Editorial

Religions 2014, 5(3), 871-875; doi:10.3390/rel5030871

XVI

http://www.mdpi.com/2077-1444/5/3/871

\section{Review Section}

\section{René Hefti}

Integrating Religion and Spirituality into Mental Health Care, Psychiatry and

Psychotherapy

Religions 2011, 2(4), 611-627; doi:10.3390/rel2040611 ....

http://www.mdpi.com/2077-1444/2/4/611

\section{Sylvia Mohr}

Integration of Spirituality and Religion in the Care of Patients with Severe Mental Disorders

Religions 2011, 2(4), 549-565; doi:10.3390/rel2040549

http://www.mdpi.com/2077-1444/2/4/549

\section{Lauren Mizock, Uma Chandrika Millner and Zlatka Russinova}

Spiritual and Religious Issues in Psychotherapy with Schizophrenia: Cultural Implications and Implementation

Religions 2012, 3(1), 82-98; doi:10.3390/rel3010082 36

http://www.mdpi.com/2077-1444/3/1/82

\section{Lone Overby Fjorback and Harald Walach}

Meditation Based Therapies-A Systematic Review and Some Critical Observations

Religions 2012, 3(1), 1-18; doi:10.3390/rel3010001

http://www.mdpi.com/2077-1444/3/1/1

\section{Section of Original Papers}

\section{Eunmi Lee, Anne Zahn and Klaus Baumann}

"Religion in Psychiatry and Psychotherapy?" A Pilot Study: The Meaning of Religiosity/Spirituality from Staff's Perspective in Psychiatry and Psychotherapy

Religions 2011, 2(4), 525-535; doi:10.3390/rel2040525 
Maigenete Mengesha and Earlise C. Ward

Psychotherapy with African American Women with Depression: Is it okay to Talk about Their Religious/Spiritual Beliefs?

Religions 2012, 3(1), 19-36; doi:10.3390/rel3010019.

http://www.mdpi.com/2077-1444/3/1/19

\section{Eckhard Frick}

Transforming Losses-A Major Task of Spiritually Integrated Psychotherapy

Religions 2011, 2(4), 659-675; doi:10.3390/rel2040659

http://www.mdpi.com/2077-1444/2/4/659

\section{Mevludin Hasanović, Osman Sinanović, Izet Pajević and Mark Agius}

The Spiritual Approach to Group Psychotherapy Treatment of Psychotraumatized Persons

in Post-War Bosnia and Herzegovina

Religions 2011, 2(3), 330-344; doi:10.3390/rel2030330

http://www.mdpi.com/2077-1444/2/3/330

\section{Eliezer Witztum and Daniel Stein}

Suicide in Judaism with a Special Emphasis on Modern Israel

Religions 2012, 3(3), 725-738; doi:10.3390/rel3030725

http://www.mdpi.com/2077-1444/3/3/725

\section{Harald Walach, Marie-Louise Gander Ferrari, Sebastian Sauer and Niko Kohls}

Mind-Body Practices in Integrative Medicine

Religions 2012, 3(1), 50-81; doi:10.3390/rel3010050 146

http://www.mdpi.com/2077-1444/3/1/50

\section{Dwight Judy}

Transpersonal Psychology: Mapping Spiritual Experience

Religions 2011, 2(4), 649-658; doi:10.3390/rel2040649

http://www.mdpi.com/2077-1444/2/4/649

\section{James M. Wilce}

Sacred Psychotherapy in the "Age of Authenticity": Healing and Cultural Revivalism in Contemporary Finland

Religions 2011, 2(4), 566-589; doi:10.3390/rel2040566 189

http://www.mdpi.com/2077-1444/2/4/566 


\section{List of Contributors}

Mark Agius is a Visiting research Associate at the department of Psychiatry University of Cambridge, and a Clare College Research Associate in Clare College Cambridge. He is also an Honorary Associate Specialist in South Essex Partnership University Foundation Trust. He has published widely on Early Intervention in Psychosis, PTSD, and Bipolar Disorder.

He has a research interest in Transcultural Psychiatry and in how religion, theology and Philosophy interface with Psychiatry.

Klaus Baumann (born 1963) has been a full professor for Caritas Science and Christian Social Work at Freiburg University's Faculty of Theology since 2004 which he has served as Dean from March 2010 to September 2014. From 2002 to 2004 he had been a professor for applied human sciences at the Faculty of Theology at Paderborn (Germany). He is a Catholic priest and practicing psychological psychotherapist, graduated as STD from the Pontifical Gregorian University in Rome in 1996, where he had also completed his studies of psychology and psychotherapeutic training. From October 2012 to March 2014 he accepted an Internal Senior Research Fellowship of the Freiburg Institute for Advanced Studies (FRIAS) as part of an interdisciplinary research group focused on Spirituality and Religiosity in Medicine (www.nersh.org), especially on patients with chronic diseases.

Dwight Judy, Ph.D., is Professor Emeritus of Spiritual Formation at Garrett-Evangelical Theological Seminary in Evanston, Illinois, U.S.A., and retired United Methodist minister. Previously, he served on the faculty of the Institute of Transpersonal Psychology and is a past president of the Association for Transpersonal Psychology. Dwight sees individuals in spiritual direction and has offered retreats on contemplative prayer and Christian spirituality since 1979. He is author of six books including Discerning Life Transitions: Listening Together in Spiritual Direction (Spiritual Directors International Imprint) and Christian Meditation and Inner Healing. Dwight and his wife, Ruth, are parents of two grown sons.

Marie-Louise Gander Ferrari (born 1973, Switzerland).1993-1999: medical school of the University of Geneva, Switzerland. 2000-2007: training years for becoming Speciality doctor in General Internal Medicine and Psychosomatic Medicine.

2007-2008: research assistant funded by a grant from the Swiss National Science Foundation at the University of Northampton, UK with Prof. Harald Walach. Study about the 
effects of mindfulness meditation on the physiological stress system. 2008-2011: Oberärtzin (Consultant) in psychosomatic medicine at the University Hospital, Inselspital, in Bern under Prof. Roland von Känel. 2011: birth of her son. 2011-2013: maternity leave and move to Edinburgh, Scotland, UK. 2013 up to now, Staff grade doctor in General Medicine at the Western General Hospital in Edinburgh, UK.

Lone Overby Fjorback is currently the leading clinical consultant at the Research Clinic for Functional Disorders and Psychosomatics, Aarhus University Hospital and director for Danish Center For Mindfulness (www.mindfulness.au.dk), Aarhus University.

She has created a mindfulness approach to treat patients who experience multiple, persistent, and disabling physical symptoms that cannot be explained by a well-defined medical or surgical condition. Used is an empirically defined definition bodily distress syndrome (BDS), which includes various conditions such as fibromyalgia, chronic fatigue syndrome, and somatization disorder. Also mindfulness was tested in a randomized trial including 119 patients, and mindfulness was found to produce improvements within the range of those reported with CBT (e.g. Fjorback et al, Journal of Psychosomatic research). The economic effects of mindfulness are evaluated by the use of original register data from the 119 enrolled patients and a matched control group of 5950 individuals. Mindfulness had substantial socioeconomic benefits over the control condition (e.g. Fjorback et al, Journal of Psychosomatic research).

Eckhard Frick (born 1955) holds a professorship of Spiritual Care at the Medical School, University of Munich and teaches psychosomatic anthropology at the Jesuit Munich School of Philosophy. He is a Jesuit, Catholic priest, psychiatrist, and practicing Jungian psychoanalyst.

Mevludin Hasanović is neuropsychiatrist, subspecialist of social psychiatry and group analyst. He graduated on the Sarajevo University School of Medicine (1982). He completed Specialization and Postgraduate study at the Zagreb and Tuzla Universities. At the University of Tuzla he obtained PhD and associate professorship (2009). He teaches in University of Tuzla on Medical School and on Educational and Rehabilitational School, also on University of Zenica, School of Social Pedagogy. Mevludin Hasanović is one of founders of Tuzla users’associations: „Fenix“, „Nada (Hope)“ and „Stećak“. Member of Editorial board of journals “Acta Medica Saliniana”, „Journal of Neurology \& Stroke“ and “Acta Medica Academica”. He published more than 200 scientific and professional papers in the field of 
psychiatry and mental health care in the International Journals, Congress publications and as book chapters in the national and international books and textbooks. With supporters he established medical assisted treatment of heroin addicts with buprenorphine+naloxone (Suboxone) method in BH. He coordinates education in Eye Movements Reprocessing and Desensitisation (EMDR) education in $\mathrm{BH}$. He coordinated several international research projects. Mevludin Hasanović is interested in clinical work and research in the fields: clinical aspects of psychosocial trauma, family medicine, traumatic stress syndrome, war veterans and civilian victims of war as well as children and adolescents, the role of spirituality and religiosity in the promotion and preservation of mental health and clinical methods of EMDR, neuroimaging of brain cortex, opiate substitution treatment with buprenorphine+naloxone (Suboxone).

René Hefti, M.D., graduated from the medical school at Zurich University in 1987; completed residencies in internal medicine and cardiology in Switzerland, Austria and Jemen from 1988 - 1998; did an additional training in psychosomatic medicine and existential psychotherapy from 1994 - 2002 and became head of the psychosomatic department of the Clinic SGM Langenthal, Switzerland. 2005 Dr. Hefti founded the Research Institute for Spirituality and Health (www.rish.ch) and initiated the European Conferences on Religion, Spirituality and Health (www.ecrsh.eu). His research interests include religion as a stress buffering "agent” and the integration of spirituality into an extended bio-psycho-social model. Since 2006 Dr. Hefti is lecturer for psychosocial medicine at the University of Bern, Switzerland, also teaching clinical skills and the integration of spirituality into clinical practice (e.g. taking a spiritual history).

Niko Kohls is a professor for health sciences at the University of Applied Sciences in Coburg, Germany. Niko has been researching the relationship between spirituality, mindfulness and health as well as the underlying psychophysiological pathways for almost 20 years. Niko obtained his diploma (Dipl. Psych) in 1998 and his PhD in 2004 from the University of Freiburg and received his habilitation in 2012 from the University of Munich. In October 2013, he has received the Amalia-Award for "New ways of Thinking” in the category of science that was awarded by a German philanthropic network, the Weimarer Visionen.

He was named a Fellow in the Samueli Institute’s Center for Brain, Mind and Healing in 2007. Having established an independent research group "Psychophysiology of Consciousness: Spirituality, Mindfulness, Quality of Life and Health” at the Generation 
Research Program of Ludwig-Maximilians-University, Niko has set up several projects that are dedicated to scrutinizing the impact of saluogenetic interventions in different contexts such as schools, universities, workplace or the military. He is currently responsible for the scientific evaluation of a large project in Germany that investigates the impact of mindfulness based interventions at the workplace with regard to stress, creativity, decision making and social and moral competencies.

Eunmi Lee, Ph.D., was born in South Korea in 1981, where she received degrees as social worker (MA) and speech therapist (BA). In 2006 she began to study Caritas Science and Christian Social Ethics at the Faculty of Theology, University of Freiburg, Germany, where she got her MA in 2009 and her Ph.D. in 2013. She has been working as research assistant of the project "religiosity/spirituality in psychiatry and psychotherapy" since 2008. At present, her main research is focusing on professionals in mental health with regard to religions/spirituality.

Maigenete Mengesha holds a Masters in Counseling Psychology and a $\mathrm{PhD}$ in Psychology from the University of Wisconsin Madison. As a qualitative researcher, her dissertation focused on the role of spirituality in the relief seeking experiences of women with depression. She operates from a Multicultural, Humanistic, and Systems approach in her clinical work as she helps people heal through difficult life events. She has worked with a racial and ethnic diverse population in community mental health, hospitals, and behavioral health settings. Her work includes, individual, couples, families and groups. Dr. Maigenete Mengesha is currently a post-doctoral fellow at Wellness House, in Hinsdale Illinois, where she does psycho-oncology focused counseling and actively works to address health disparity issues in the cancer support communities in the greater Chicagoland area. Dr. Mengesha also teaches in the psychology department at Aurora University.

Uma Chandrika Millner, Ph.D. works as a Research Associate at Boston University Center for Psychiatric Rehabilitation. Social justice and multiculturalism form the foundations of her work. Her clinical and research interests focus on trauma, vocational psychology, psychodynamic psychotherapy and the intersection of contextual factors and mental health.

Lauren Mizock is Assistant Professor of Psychology at Worcester State University. Dr. Mizock is also a licensed psychologist in Massachusetts and carries a small private practice in 
Cambridge, MA. Her clinical and research focus is in issues of culture and stigma across topics of serious mental illness, racism, transgender mental health, women's mental health, and size acceptance.

Sylvia Mohr, Ph.D., is a CBT psychotherapist and a researcher at the Department of Mental Health and Psychiatry of the University Hospitals of Geneva. She has been involved for more than 20 years in the care of people suffering from severe mental disorders. Grounded on her clinical work, her research focuses on taking into account healthy spirituality and religiousness as a positive resource to cope with psychosis, as well as spiritual suffering. She especially contributed to disentangle psychopathology from spirituality and religiousness in psychosis. She is collaborating to the implementation of spirituality and religiousness assessment in routine practice in ambulatory care.

Izet Pajevic is currently a Chair of the Department for Psychiatry in Tuzla. He received his Master's degree in the "Islamic way of life as a factor of mental stability" from the School of Medicine University of Tuzla in 1999, and a Ph.D. with his dissertation on "The impact of religiosity on mental health in adolescents” in 2003. After completing his Ph.D., Izet was assistant professor at the School of Medicine, University of Tuzla where he taught neuropsychiatry with medical psychology. Since 2008 he is associate professor who teaches Psychiatry with medical psychology, Psychology \& Communication, Neuropsychology, and Psychiatric Nursing within the undergraduate courses. Also, he teaches postgraduate courses in Clinical Research at the School of Medicine Tuzla, and Psychology in Clinical Practice at the Philosophy Faculty - Department of Psychology. From 2005 to 2007 he taught Religion and Health at the Nursing Faculty Zenica. Since 2006 he teaches undergraduate courses in Psychopathology, Social pathology, Community Mental Health, Self-protection methods and Treatment Programming at the Islamic Faculty Zenica, and since 2010 a postgraduate course in Socio-pedagogical Treatment at the Department of Social pedagogy of the University Zenica. He gained a title Primarius Doctor in 2003, and he is a board-certified subspecialist in clinical psychiatry $(\mathrm{MoH}, 2011)$. His clinical and research interest include the clinical psychiatry, adolescent psychiatry, and psychology of religion. He has published over 200 scientific and professional papers. Izet is the author of several book chapters and editor of several books. He currently serves as the president of the Association of Psychiatrists in Bosnia and Herzegovina. He is member of Presidencies of Psychiatry Association in BosniaHerzegovina, Association of Child and Adolescent Psychiatry in Bosnia-Herzegovina, 
Association for Biology Psychiatry and Psycho-pharmacotherapy, and Tuzla Canton Association of Psychiatrists.

Frank-Gerald Bernhard Pajonk is an experienced specialist in psychiatry and psychotherapy (Behavioral Therapy and Logotherapy according to V. Frankl) and a Professor of Psychiatry. He graduated as medical doctor from the Ludwig-Maximilians University Munich, Germany, in 1993. He received his training and worked thereafter at the Medical Schools and Departments of Psychiatry and Psychotherapy of the Universities of Munich, Hamburg and Homburg, and as Medical Director of Dr. Fontheim's Hospital for Mental Health. In addition he has been a Benedictin monk and is a catholic deacon. Currently he is working in a private practice at the Monastery of Schäftlarn and teaches at the University of Göttingen.

He is renowned for both his clinical and scientific work. His research in the past years has focused on psychiatric emergencies, the neurobiology of exercise and resilience in stressful environments. For many years he is heading the interdisciplinary research group "Emergency Psychiatry”. Being an expert in demand for differentiating spiritual experiences from psychopathologically relevant symptoms, he is dedicated to integrate spiritual aspects to psychotherapy according to the needs of the patients.

Zlatka Russinova, Ph.D., is a Research Associate Professor in the Department of Occupational Therapy at the Boston University Sargent College of Health and Rehabilitation Sciences and a Senior Research Associate at the Center for Psychiatric Rehabilitation. Her research focuses on examining various dimensions of the process of recovery from serious mental illness, including the role of religion and spirituality in promoting recovery.

Sebastian Sauer was born in Bamberg, Germany, in 1978. He received his "Diplom” (MSc equivalent) from the University of Koblenz-Landau in 2005. In 2009, he completed his PhD program, and in 2014 he completed the "Habilitation", while he was working as a research fellow at the LMU in Munich (Germany). After having received the Diplom, he was working as business consultant and later as head of departmental for personnel training, knowledge management, and strategy at the medical services of the compulsory health insurance in Bavaria. Sebastian now works as a researcher and lecturer at the FOM University of Applied Sciences. Hit research interests include psychometrics and mindfulness. In his ever-vanishing spare time, Sebastian enjoys the outdoors. As of March 2013, he is the father of the Cutest 
Baby Ever. Sebastian has (co-)authored about 30 publications, and in 2006, he was presented with the research award of the Society of Meditation and Meditation Research (Germany) for his Diplom Thesis. In 2006, he has been selected as a Scholar of the Brain, Mind, and Healing Program of the Samueli Institute, Alexandria, VA (USA).

Osman Sinanović (born1952, Duboštica, Bosnia and Herzegovina), became Master of Medical Science (MrSc), at Medical Faculty, University of Tuzla in 1983, and Doctor of Medical Science (PhD), at Medical Faculty, University of Zagreb in 1989. Since 1980 he works in University Clinical Center Tuzla. He performed different functions within his profession, and currently he is head of department for neurophysiology and neuromuscular diseases of Clinic for Neurology of University Clinical Centre Tuzla, Heard of cathedra for Neurology, professor of neuropsychiatry and medical psychology on Faculty of Medicine, University of Tuzla. Perennial lecturer at the School of Medicine and Faculty of Education and Rehabilitation Sciences and the Nursing High School of the University of Tuzla, in the cases of neuropsychology, neurology and psychiatry, medical psychology, the psychology of communication, and on the post-graduate study of School of Medicine, School of Education and Rehabilitation, School of Natural Science and Philosophy at the University of Tuzla the subjects of scientific writing and research methodology. He was guest professor on faculty of medicine, University of Ulm, and currently he is guest professor on Faculty of Medicine, University of Osijek.

Daniel Stein, M.D., completed his medical training at the Hadassah University Hospital in Jerusalem, Israel. He is a certified psychiatrist, and child and adolescent psychiatrist in Israel. Since 1998, Dr. Stein is the director of the Pediatric Psychosomatic Department, The Edmond and Lily Safra Children's Hospital, The Chaim Sheba Medical Center, Tel Hashomer, Israel. He is an Associate Professor (Clinical) at the Department of Psychiatry, Head of the Section of Child and Adolescent Psychiatry, and instructor at the School of Psychotherapy, all at the Sackler Faculty of Medicine, University of Tel Aviv, Tel Aviv, Israel. His main topics of interest include child and adolescent psychiatry, eating disorders, psychosomatic disorders, psychological complications of medical disorders, and suicidology. Prof. Stein has an extensive knowledge and expertise in psychodynamic psychotherapy and cognitive behavioral therapy as well as in psychopharmacotherapy in both children/adolescents and adults. He is a member of numerous scientific international organizations and a reviewer in numerous scientific journals, has participated in many international conferences, and has won several 
scientific awards. He is the co-founder and past deputy chairman of the Israeli Academy of Eating Disorders. Prof. Stein has written more than 140 articles and book chapters published in prominent international journals and books. He is has recently completed, as a co-editor, the publication of the two of three books on eating disorders. Lastly, from 2001 onwards, including 2013, Prof. Stein constantly appears in the list of the best Israeli child and adolescent psychiatrists, published yearly by the daily Israeli newspaper “Maariv.”

Harald Walach is Professor of Research Methodology in Complementary Medicine and Director of the Institute of Transcultural Health Studies at the European University Viadrina in Germany. Here he also leads a Masters Program in Cultural Sciences-Complementary and Alternative Medicine, designed as a further education programme for doctors, pharmacists, and others with a health background.

Holding a PhD in Clinical Psychology (1990) and a PhD in History and Theory of Science (1995), his interests are wide ranging. His original research in complementary medicine - in areas such as homeopathy, acupuncture, spiritual healing, and placebo effects - were motivated by his interest in healing processes and mechanisms. Derived from this is his interest in the interface between mind and body and a culture of consciousness and its effects on health. Mindfulness research and research in spiritual healing, as well as intentional processes, are a natural consequence. He has embarked on a theoretical understanding of such generic healing processes in collaboration with physicists in more recent developments. He has contributed to the transpersonal psychology literature, has translated one of the least known but most influential medieval mystical writers, the Carthusian Hugh of Balma, into German and is keenly interested in the link between spiritual practice or meditation and health and healing in a generic sense.

Earlise Ward is a Licensed Psychologist and an Associate Professor at University of Wisconsin-Madison School of Nursing. She is also a research investigator at the WisconsinMadison, Institute for Clinical and Translational Research - Collaborative Center for Health Equity (CCHE). CCHE is home to the University of Wisconsin-Madison Health Equity and Leadership Institute (HELI)

As a researcher and licensed psychologist, Dr. Ward has witnessed first-hand in her clinical practice the impact of mental health disparities among African Americans. Her program of research focuses on developing and testing culturally appropriate mental health interventions for African American adults with depression. 
Dr. Ward has expanded her research on an international level. In particular, she is collaborating with researchers in the US Virgin Islands and Ghana, Africa, to develop and test culturally specific behavioral treatments for depression. She is also presently expanding her research domestically to focus on treating depression in American Indian elders

Dr. Ward is passionate and committed to improving mental health outcomes and quality of life for racial and ethnic minorities struggling with depression, as well as all individuals experiencing mental illness. She believes that providing culturally sensitive care is important for everyone regardless of race, ethnicity and nationality.

James M. Wilce is Professor of Anthropology at Northern Arizona University and the author of four books, including Language and Emotion (Cambridge, 2009), and numerous articles in journals such as Comparative Studies in Society and History, Current Anthropology, Emotion Review, American Ethnologist, Medical Anthropology Quarterly Journal of Linguistic Anthropology, and (with co-author Janina Fenigsen) Semiotica. He has lived in Bangladesh and Finland, conducting discourse-centered ethnographic studies of illness and healing.

Eliezer Witztum, M.D. is a Professor in the Division of Psychiatry, Faculty of Health Sciences, Ben-Gurion University of the Nege and Director of Psychotherapy School. He specializes in cultural psychiatry, trauma and bereavement, strategic and short-term dynamic psychotherapy treatment of pedophilia and in the history of psychiatry. He has written more than 200 scientific publications. His recent books included 'Sanity and Sanctity', 'Soul, Bereavement and Loss' (Hebrew) and 'King Herod: A Persecuted Persecutor: A Case Study in Psychohistory and Psychobiography'. Together with Professor Lerner (in Hebrew, 2009) and 'Genius and Insanity. Outlines concerning the analysis of the relationship between psychopathology and creativity as shown in the examples of separate individuals in Russia of the XIX century' (in Russian 2011) and 'Working with the Bereaved Multiple Lenses on Loss and Mourning' (2012) with Professor Rubin and Dr. R. Malkinson.

Anne Katharina Zahn, Dr., graduated from the medical school at Freiburg University in 2005; completed residencies in psychotherapy and psychiatry university Hospital Freiburg and Neurology and became a head doctor on an open ward 2014.

Her research interests include religion and spirituality and their role for patients in psychiatric and neurological settings. She has lead projects getting more understanding about how therapists and staff members see this topic as well as patients. Following the question if 
an integration into clinical therapy in seeing the client as a physical emotional and spiritual being is wanted and how it can be approached. She is also active in research on body psychotherapy and guiding a study on clients with insomnia. 


\section{Preface}

As guest editors, we are grateful for the initiative of Editor in Chief Prof. Dr. Peter Iver Kaufman (Richmond VA, USA) and of Managing Editor Mr. Jeremiah R. Zhang (Beijing, China) of "Religions" to provide a book edition of our Special Issue "Religions and Psychotherapies". The download statistics of this open access issue underlines the growing relevance and timeliness of thorough research into the many dimensions implied by the relationship between religions and psychotherapies. Far from dealing with these dimensions exhaustively, the papers give plenty of food for thought and hopefully stimulate further research in an as yet very open and controversial field. We thank all the authors and coauthors for agreeing to the print publication of their papers and Laura Wagner and others from the MDPI team for their valuable help.

Freiburg/ Göttingen (Germany), September 2014

Klaus Baumann and Frank-Gerald B. Pajonk 


\section{Editorial}

\section{Religions and Psychotherapies—Special Issue}

The birth of modern psychotherapies - along with the birth of psychology as a science on one side and with psychoanalysis, other depth-psychological treatments and behavioral therapies in addition to medical treatments of psychological disorders on the other side-in the 19th and 20th centuries was accompanied by positivistic and mechanistic paradigms underlying empirical research and claims of scientific dignity [1]. Affirmations which could not be tested or observed empirically had to be excluded from science-including any kind of metaphysics and religious belief, notwithstanding pioneering studies by William James [2], Granville Stanley Hall, James Henry Leuba and Edwin Diller Starbuck [3] for psychology in general and for psychology of religion(s) in particular. In particular, the critique of religions by Sigmund Freud has continuously exerted a strong impact in the fields of psychiatry and psychotherapies; in addition, regarding psychodynamics and symptoms of psychic disorders, religious phenomena in the lives of patients may be just as affected as other cognitive and emotional aspects and behaviors [4]. Consequently, religious experience and religious behavior of patients in psychiatry and psychotherapies have rarely been object of research and teaching apart from predominantly symptomatic and pathogenic perspectives [5].

In the last three decades, however, starting from the USA, a growing interest and increasing activities in research and application as to the role of religiosity and spirituality in health care, oncology, and mental health can be observed. In recent years, a variety of papers have addressed the shift to a more positive reception of religion and spirituality for mental health, also addressing the ambiguity between these two disciplines and life domains [6-8]. It seems that the historical tension between mental health and religious professionals is making a shift towards inter- and transdisciplinary collaboration and mutual respect [9]. The vast majority of studies have shown that participation in religious and spiritual behavior strengthens protective factors for mental health which, if addressed properly, turn out to be helpful for treatment.

A systematic review of clinical studies found good evidence that religious involvement is correlated with better mental health in the areas of depression, substance abuse, and suicide, some evidence in stress-related disorders and dementia and insufficient evidence in bipolar disorder and schizophrenia [10]. For many other mental disorders and psychiatric conditions, such as anxiety disorders, obsessive-compulsive disorders, trauma-related disorders, personality disorders or eating disorders, research is on the way; however, it is too early to draw conclusions in terms of evidence.

Without doubt, religious or spiritual beliefs have an impact on some of the most important questions in psychiatry and psychotherapy, such as insight into illness or need for treatment, the use of mental health care services, coping strategies, therapeutic relationship, and treatment adherence. They are related to greater forgiveness and to reduced hostility and self- 
harm [11,12]. They may influence quality of life and well-being despite psychiatric symptoms. People with spiritual beliefs have a different stigma tolerance towards people with mental health and a different sense of control over important areas of life, a discrepancy that becomes even bigger when investigating strict atheists or agnostics in contrast with believers [13]. Moreover, last but not least, certain religious and spiritual practices found their ways as "techniques" into psychotherapy, such as mindfulness-based cognitive therapy or elements of dialectic-behavioral therapy (DBT; cf. [4], pp. 110-11).

The special issue "Religions and Psychotherapies", which closed in summer 2012, intended to attract reviews, theoretical and clinical original studies on questions regarding the relationship between religions and psychotherapies. We invited scholars, researchers and practitioners to contribute to interdisciplinary dialogues regarding the role of (various) religious attitudes of clients/patients/therapists in (various) psychotherapeutic treatments, religious doctrines and interpretations with regard to psychic disorders, psychotherapeutic metapsychologies regarding religions and religious attitudes, religious practices and coping with psychic stress and disorders. This special issue set out to include both general and basic principles/issues as well as specific questions regarding treatments and methods.

Twelve of the submitted articles passed the peer review, including four review papers. These consider the integration of religions and spiritualities into mental health care, psychiatry and psychotherapy in general (René Hefti) and into the care of patients with severe mental disorders in particular (Sylvia Mohr), religious and spiritual issues in psychotherapies with patients with schizophrenia (Lauren Mizock, Uma Chandrika Millner and Zlatka Russinova) and a critical review of meditation based therapies (Lone Overby Fjorback and Harald Walach).

Eight original papers provide an impressive range of topics in the vast field of research, which can be regarded as religious or spiritual notwithstanding the ongoing lack of consensual definition of these terms. Which attitudes and attributions prevail among the psychiatric staff (physicians, nurses, other therapists) with regard to the role of religions and spiritualities of their patients and of themselves in treatment (Eunmi Lee, Anne Zahn and Klaus Baumann)? What are the roles, implications or potentials of religions and spiritualities in the treatment of African American women with depression (Maigenete Mengesha and Earlise C. Ward), in mourning and transforming losses (Eckhard Frick), in group psychotherapy treatment of psychotraumatized persons in post-war Bosnia and Herzegovina (Mevludin Hasanović, Osman Sinanović, Izet Pajević and Mark Agius) or in suicidality in Judaism as compared to other religious denominations (Eliezer Witztum and Daniel Stein)? What about therapies or therapeutic approaches which in different ways are using religious and/or spiritual convictions or practices, as presented in this special issue by the papers on mind-body practices in integrative medicine (Harald Walach, Marie-Louise Gander Ferrari, Sebastian Sauer and Niko Kohls), on transpersonal psychology trying to map spiritual experiences (Dwight Judy), and on "sacred" psychotherapy in the "age of authenticity" in contemporary Finland (James M. Wilce)?

Far from being representative, these precious pieces of research and theoretical efforts offer glimpses into an increasingly important and vibrant field of research aiming at a better 
service for the patients in psychiatry and psychotherapies in a responsible attention to, reflection and integration of relevant religious and spiritual issues. Such responsible efforts of integration would rather favor than undermine professional neutrality (in the sense of abstaining from any kind of manipulation) and counteract the widespread ongoing neglect of such existential issues which is mirrored in significant biases on the side of the professionals in psychiatry and psychotherapy [14]. In this sense, we welcome recent developments like the foundation of a new section on religiosity and spirituality in the German DGPPN in September 2013. Also in 2013, the American Psychological Association published a handbook on Psychology, Religion and Spirituality [15], followed in 2014 by a German reader on psychotherapy and spirituality [16], postulating that psychotherapists meet their patients' religious and spiritual attachments with empathic appreciation and respect, in line with the ethical principles of psychologists and code of conduct of the American Psychological Association [17] and with the recommendations for psychiatrists on spirituality and religion released by a position statement of the (British) Royal College of Psychiatrists [18].

Further research and therapy improvements may be encouraged by these developments both in research and in professional societies. As editors of this special issue, we are grateful to all researchers who submitted their papers, to all reviewers, and to the effective and efficient editorial support provided by Jerry Zhang and his team from RELIGIONS.

Klaus Baumann and Frank-Gerald B. Pajonk Guest Editors 


\section{Conflicts of Interest}

The authors declare no conflict of interest.

\section{References and Notes}

1. Baumann, Klaus. "The Birth of Human Sciences, especially Psychology." In L'uomo moderno e la Chiesa - Atti del Congresso (Analecta Gregoriana, 317). Edited by Paul Gilbert. Rome: Gregorian \& Biblical Press, 2012, pp. 391-408.

2. James, William. The Varieties of Religious Experience. A Study in Human Nature. New York: Simon \& Schuster, 1997 (first ed. 1902).

3. Huxel, Kirsten. Die empirische Psychologie des Glaubens. Historische und systematische Studien zu den Pionieren der Religionspsychologie. Stuttgart: Kohlhammer, 2000.

4. Baumann, Klaus. "Remarks on Religions and Psychiatry/ Psychotherapies." In Spiritualität und Gesundheit. Spirituality and Health. Ausgewählte Beiträge im Spannungsfeld zwischen Forschung und Praxis. Selected Contributions on Conflicting Priorities in Research and Practice. Edited by René Hefti and Jacqueline Bee. Bern: Peter Lang, 2012, pp. 99-118.

5. Baumann, Klaus. "Zwangsstörungen und Religion aus heutiger Sicht." Fortschritte der Neurologie Psychiatrie 75 (2007): 587-92.

6. Aist, Clark S. "The recovery of religious and spiritual significance in American Psychiatry." Journal of Religion and Health 51, no. 3 (2012): 615-29.

7. Pargament, Kenneth I., and James W. Lomax. "Understanding and addressing religion among people with mental illness." World Psychiatry 12, no. 1 (2013): 26-32.

8. Greenberg, David. "Religion and mental health: A double-edged sword or a life-giving medicine?" World Psychiatry 12, no. 1 (2013): 40-41.

9. Lawrence, Ryan E., Kenneth A. Rasinski, John D. Yoon, and Farr A. Curlin. "Religion and beliefs about treating medically unexplained symptoms: a survey of primary care physicians and psychiatrists." The International Journal of Psychiatry in Medicine 45, no. 1 (2013): 31-44.

10. Bonelli, Raphael M., and Harold G. Koenig. "Mental disorders, religions and spirituality 1990 to 2010: A systematic evidence-based review." Journal of Religion and Health 52, no. 2 (2013): 657-73.

11. Enright, Robert D., and Richard P. Fitzgibbons. Helping Clients Forgive: An Empirical Guide for Resolving Anger and Restoring Hope. Washington DC: American Psychological Association 2000.

12. Seligman, Martin E.P. Authentic Happiness: Using the New Positive Psychology to Realize Your Potential for Lasting Fulfillment. New York: The Free Press 2002.

13. Weber, Samuel R., Kenneth I. Pargament, Mark E. Kunik, James W. Lomax, 2nd, and Melinda, A. Stanley. "Psychological distress among religious non-believers: a systematic review." Journal of Religion and Health 51, no. 1 (2012): 72-86. 
14. Lee, Eunmi, and Klaus Baumann. "German Psychiatrists' Observation and Interpretation of Religiosity/ Spirituality." Evidence-Based Complementary and Alternative Medicine 2013 (2013): Article ID 280168. doi.10.1155/2013/280168.

15. Pargament, Kenneth I., ed. APA Handbook of Psychology, Religion and Spirituality. Washington, DC: American Psychological Association, 2013.

16. Utsch, Michael, Raphael M. Bonelli, and Samuel Pfeifer. Psychotherapie und Spiritualität. Mit existentiellen Konflikten und Transzendenzfragen professionell umgehen. Heidelberg: Springer, 2014.

17. American Psychological Association. "Ethical Principles of Psychologists and Code of Conduct. Including 2010 Amendments.” Available online: www.apa.org/ethics/code/ index.aspx (accessed on 19 July 2014).

18. Cook, Cristopher H. Recommendations for Psychiatrists on Spirituality and Religion. Position Statement PS03. London: Royal College of Psychiatrists, 2011.

Reprinted from Religions. Cite as: Baumann, K.; Pajonk, F.-G.B. Religions and Psychotherapies-Special Issue. Religions 2014, 5, 871-875. 




\title{
Review Section
}

\section{Integrating Religion and Spirituality into Mental Health Care, Psychiatry and Psychotherapy}

\section{René Hefti}

\begin{abstract}
Integrating spirituality into mental health care, psychiatry and psychotherapy is still controversial, albeit a growing body of evidence is showing beneficial effects and a real need for such integration. In this review, past and recent research as well as evidence from the integrative concept of a Swiss clinic is summarized. Religious coping is highly prevalent among patients with psychiatric disorders. Surveys indicate that $70 \%-80 \%$ use religious or spiritual beliefs and activities to cope with daily difficulties and frustrations. Religion may help patients to enhance emotional adjustment and to maintain hope, purpose and meaning. Patients emphasize that serving a purpose beyond one's self can make it possible to live with what might otherwise be unbearable. Programs successfully incorporating spirituality into clinical practice are described and discussed. Studies indicate that the outcome of psychotherapy in religious patients can be enhanced by integrating religious elements into the therapy protocol and that this can be successfully done by religious and non-religious therapists alike.
\end{abstract}

Reprinted from Religions. Cite as: Hefti, R. Integrating Religion and Spirituality into Mental Health Care, Psychiatry and Psychotherapy. Religions 2011, 2, 611-627.

\section{Spirituality in Mental Illness and Psychiatric Disorders}

Spiritual approaches to mental illness are still at their infancy, certainly in Europe. There is an ongoing controversy on whether or not to integrate spirituality into the treatment of persons suffering from mental illness, mainly due to concerns about harmful side effects from encouraging and supporting religious involvement. On the other hand, a growing body of evidence is showing beneficial outcomes of religious and spiritual approaches to psychiatric disorders. Spirituality can be seen as a unique human dimension [1], making life sacred and meaningful [2], being an essential part of the physician-patient-relationship [3] and the recovery process $[4,5]$.

Persons suffering from mental illness emphasize that understanding one's problems in religious or spiritual terms can be a powerful alternative to a biological or psychological framework. Although reframing the issue in this manner may not change reality, having a higher purpose may make a big difference in an individual's willingness to bear pain, to cope with difficulties, and to make sacrifices. Given the fact that people with serious mental illnesses already struggle against widespread prejudice and discrimination, it would seem important to maintain or strengthen 
people's existing religious affiliations and support systems as part of their treatment or rehabilitation plan [2].

Lindgren and Coursey [6] interviewed participants in a psychosocial rehabilitation program: $80 \%$ said that religion and spirituality had been helpful to them. Trepper et al. [7] found that participants experiencing greater symptom severity and lower overall functioning are more likely to use religious activities as part of their coping. Symptom-related stress leads to greater use of religious coping, a phenomenon that has also been shown in other studies [8,9]. Baetz et al. [10] demonstrated among psychiatric inpatients that both public religion (e.g., worship attendance) and private spirituality were associated with less severe depressive symptoms. Religious patients also had shorter lengths of stay in the hospital and higher life satisfaction.

Koenig, George, and Peterson [11] followed medically ill elderly persons who were diagnosed with a depressive disorder and found that intrinsic religiosity (following religion as an "end in itself," rather than as a means to another end) was predictive of shorter time to remission of depressive disorder, after controlling for multiple other predictors of remission. Pargament [12,13] has extensively studied the role of religious coping methods in dealing with stress. He found consistent connections between positive styles of religious coping and better mental health outcomes. Religious coping styles such as perceived collaboration with God, seeking spiritual support from God or religious communities, and benevolent religious appraisal of negative situations have been related to less depression [11], less anxiety [14] and more positive affect [15].

\section{A Holistic and Integrative Framework for Therapy}

\subsection{The Extended Bio-Psycho-Social Model}

In psychiatry and psychosomatic medicine, the bio-psycho-social model introduced by George L. Engel in 1977 [16], is the predominant concept in clinical practice and research. It shows that biological, psychological and social factors interact in a complex manner in health and disease. In the extended bio-psycho-social model [17], religion and spirituality constitute a fourth dimension (Figure 1). This holistic and integrative framework is a useful tool to understand how religion and spirituality influence mental as well as physical health. Interactions with the biological, psychological and social dimension constitute the distinct disciplines of "biology of religion", psychology of religion and sociology of religion. The extended bio-psycho-social model illustrates that a holistic approach in mental health has to integrate pharmacotherapeutic, psychotherapeutic, sociotherapeutic and spiritual elements. 
Figure 1. Extended bio-psycho-social model integrating religion/spirituality as a fourth dimension.

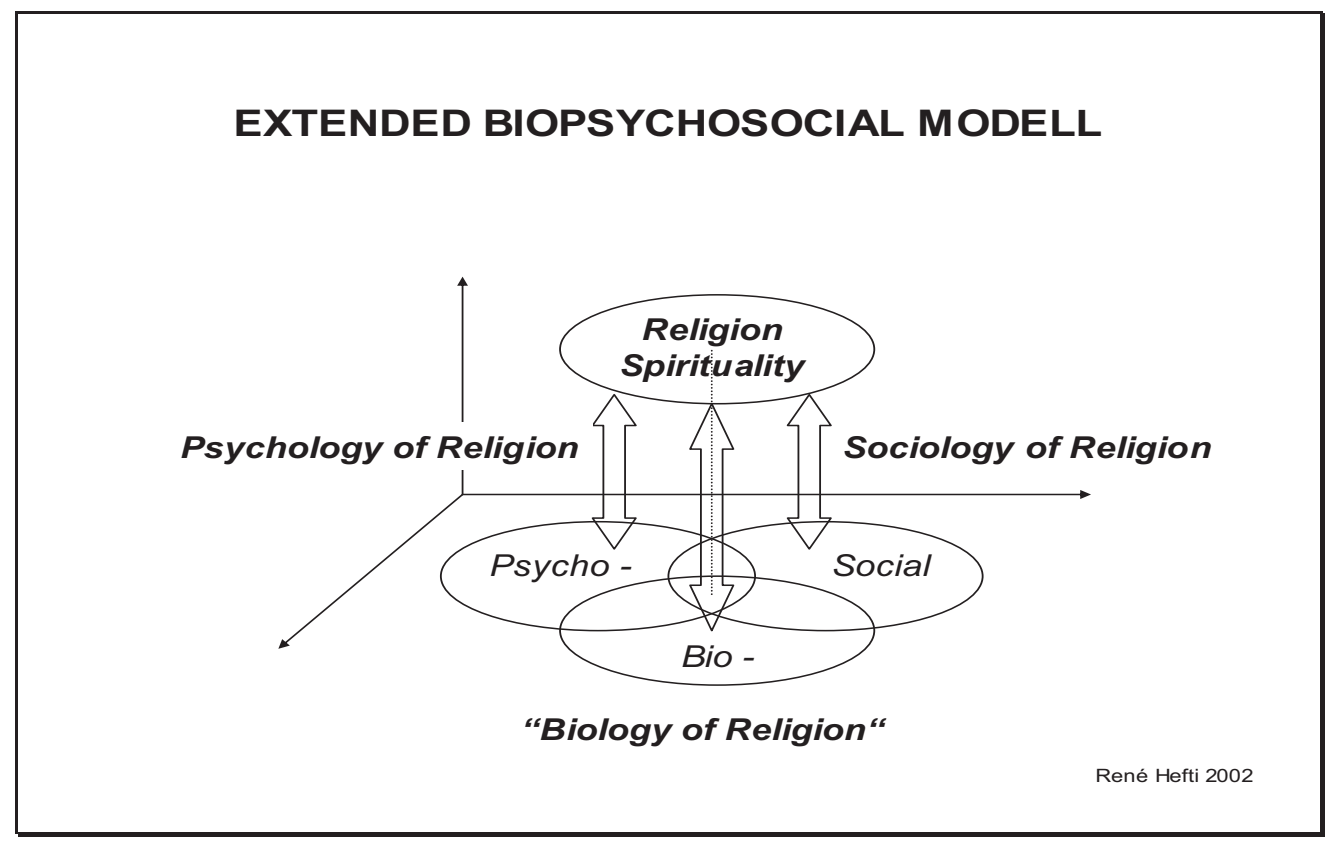

\subsection{Religion and Spirituality as Resource or Burden}

Religion and spirituality can have beneficial or adverse effects on health. In general, people who are more religious report better physical health, psychological adjustment, and lower rates of problematic social behavior [18-21]. Spirituality strengthens a sense of self and self-esteem [22,23], of feeling more like a "whole person" and of being valued by the divine (as part of creation, as a "child of God"), countering stigma and shame with positive self-attributions and, by all of this, reinforcing "personhood" [24].

Spirituality is associated with decreased levels of depression [25], especially among people with intrinsic religious orientation based on internalized beliefs [26]. Spirituality correlates with lower levels of general anxiety [27] and with positive outcomes in coping with anxiety [28]. Higher levels of spirituality among individuals recovering from substance abuse are related to optimism and resiliency against stress [29], and spiritual coping methods are found to have positive effects for persons diagnosed with schizophrenia [30]. Participation in spiritual and religious activities helps to integrate individuals into their families [31].

Religion and spirituality also deliver social and community resources [22,23] which are enhanced by the "transcendent nature" of the support. Belonging to and finding acceptance in a religious community may have special importance for people who are often rejected, isolated, or stigmatized [32]. Spiritual experiences facilitate the development of a fundamental sense of connectedness. Religion and spirituality also foster a sense of hope and purpose, a reason for being, 
as well as opportunities for growth and positive change [5,23,33]. These are ways in which patients have expressed their experience of enhanced personhood or empowerment.

Aside from the beneficial effects, it is important to be aware of the "negative" influence religion and spirituality can have on mental health outcomes and recovery. Negative religious coping involves beliefs and activities such as expressing anger at God, questioning God's power, attributing negative events to God's punishment, as well as discontent with religious communities and their leadership. Negative religious coping has been linked to greater affective distress, including greater anxiety, depression and lower self-esteem [34]. Religious struggles involving interpersonal strain rather than social support and conflicts with God rather than perceived collaboration have been linked to higher levels of depression and suicidality [35]. Negative experiences with religious groups can aggravate feelings of rejection and marginalization [36].

Unfavorable religious convictions can intensify excesses of self-blame and perceptions of unredeemable sinfulness. If they are woven into obsessive or depressive symptom patterns, they can be even more distressing. Furthermore, emotional struggles and feelings of rejection can be reinforced by religious communities who see mental disorders as signs of moral or spiritual weakness or failure. Prayer or other religious rituals can become compulsive and interfere with overall daily functioning [7]. Finally, beliefs involving themes of divine abandonment or condemnation, unrelenting rejection, or powerful retribution may make recovery seem unattainable or unimportant [37].

\section{The Key Roles of Religious and Spiritual Coping}

\subsection{Findings from the Literature}

Several surveys showed a high prevalence of religious coping among patients with severe and persistent mental illness. Tepper et al. [7] investigated 406 patients at one of thirteen Los Angeles County mental health facilities. More than 80 percent of the participants used religious beliefs or activities to cope with daily difficulties or frustrations. A majority of participants devoted as much as half of their total coping time to religious practices, with prayer being the most frequent activity. Specific religious coping strategies, such as prayer or reading the Bible, were associated with higher SCL-90 scores (indicating more severe symptoms), more reported frustration, and a lower GAF score (indicating greater impairment). The amount of time that participants devoted to religious coping was negatively related to reported levels of frustration and scores on the SCL-90 symptom subscales. The results of the study suggest that religious activities and beliefs may be particularly important for persons who are experiencing more severe symptoms, and increased religious activity may be associated with reduced symptoms over time.

This is not only true in the United States but also in Europe. The findings of Tepper et al. have been replicated by Mohr et al. in Geneva, Switzerland [38]. Semi-structured interviews focused on religious coping were conducted with a sample of 115 outpatients with psychotic illness at one of Geneva's four psychiatric outpatient facilities. For a majority of patients, religion instilled hope, purpose, and meaning in their lives (71\%), whereas for some, it induced spiritual despair (14\%). Patients also reported that religion lessened (54\%) or increased $(10 \%)$ psychotic and general symptoms. Religion was found to increase social integration (28\%), although on occasion led to 
social isolation $(3 \%)$. It reduced $(33 \%)$ or increased $(10 \%)$ the risk of suicide attempts, reduced $(14 \%)$ or increased $(3 \%)$ substance use, and fostered adherence to $(16 \%)$ or was in opposition to $(15 \%)$ psychiatric treatment. The results highlight the clinical significance of religion and religious coping for patients with schizophrenia, encouraging integration of spirituality into the psychosocial dimension of care.

Huguelet et al. from the same public psychiatric outpatient department in Geneva investigated spirituality and religious practices of outpatients $(\mathrm{N}=100)$ with schizophrenia and compared them with their clinician's knowledge of patients' religious involvement [39]. Audio-taped interviews were conducted about spirituality and religious coping. The patients' clinicians $(\mathrm{N}=34)$ were asked about their own beliefs and religious activities as well as their patients' religious and clinical characteristics. A majority of the patients reported that religion was an important aspect of their lives, but only 36 percent of them had raised this issue with their clinicians. Fewer clinicians were religiously involved, and, in half the cases, their perceptions of patients' religious involvement were inaccurate. Some patients considered treatment to be incompatible with their religious practice, but clinicians were seldom aware of such conflicts.

\subsection{Clinical Experience and Qualitative Research}

The findings about religious coping reflect the experiences made at a clinic for psychosomatics, psychiatry and psychotherapy in Langenthal, Switzerland (www.klinik-sgm.ch). For a majority of the patients, religious or spiritual coping is an essential part of their coping behavior. Religion provides patients with a framework to cope with disease-related struggles. Existential needs such as being secure, valued and having meaning [40] are addressed by clinicians and pastoral counselors-despite and beyond psychiatric conditions. Two examples of open, unstructured interviews performed with depressed patients at the clinic as part of a qualitative study [41] illustrate this:

First example: A 32-year-old male patient is married and has a one-year-old son. He has been working in the same company for many years and is a member of a Protestant Church. He was hospitalized because of a severe depressive episode. How did he use religious coping to overcome his depression?

A. By reading scriptures/psalms: "Reading psalms helped me a lot to feel closer to God in difficult times. I realized that others (the writers of the psalms) also had to cry and felt desperate in their situation. They argued with God and pleaded to him."

B. By getting spiritual support: "In the very dark moments, when I felt totally lost and abandoned by God, I couldn't cope with my situation anymore. I couldn't fight negative thoughts about the future and myself. I needed somebody from outside to tell me that these are lies, that I am not abandoned either by God or by my family, that I am not worthless but loved."

Second example: A 65-year-old female patient grew up in a small country village. She had five brothers and sisters. Her father was an alcoholic. The patient left home at an early age. Her first marriage collapsed because of her husband's alcoholism. They had two children. After the divorce, the patient experienced her first depression. Later, she married again and became a member of a 
Methodist Church (after a religious conversion). Depressive episodes became less frequent and less severe. What helped the patient to cope better with depression?

A. Controlling depression by faith/prayer: "When I feel sad and my thoughts become gloomy, when I wake up early in the morning and can't sleep anymore, then I go outside into nature and speak with God, thanking him for being in control and for not letting me go down."

B. Not asking why: "In past times I always began to ask why, why did I marry this man, why did God let this happen? But this made things worse. Today I stop this kind of thinking and focus on God."

\section{Mental Health Care Programs Integrating Religion and Spirituality}

In the following paragraphs, four mental health care programs integrating religion and spirituality into a mental health care setting are summarized. A more detailed description of these programs can be found elsewhere [42].

\subsection{Therapy Group on Spiritual Issues at Cambridge Health Alliance Belmont}

The first therapy group on spiritual issues was started by Nancy Kehoe in 1981 in the department of psychiatry at Cambridge Health Alliance and Harvard Medical School, Belmont, Massachusetts [43]. She felt the need to provide seriously mentally ill persons with an opportunity to explore religious and spiritual issues in relation to their mental illness. At first, the idea of having such a group generated anxiety, fear, and doubt among staff members. It brought out the ambivalence that many mental health professionals have about religious issues, an ambivalence reflected in Gallup poll findings [44]. In addition, Bergin and Jensen's work [45] has highlighted the marked difference between the religious beliefs and practices of the general population and those of the mental health professionals. Staff training and instruction alleviated some staff concerns about Kehoe's group. However, the long-term success of the group has been the strongest factor in staff acceptance. Group rules contributing to its success are tolerance of diversity, respect of others' beliefs, and a ban on proselytizing. Another factor is that membership is open to all, regardless of religious background or diagnosis.

\subsection{Spirituality Group at the Hollywood Mental Health Center Los Angeles}

In a standard psychosocial rehabilitation program emphasizing skills training, psycho-education, and cognitive behavioral treatment [46], a spirituality group was offered as a 60-min optional weekly session [47] in the same time slot as the regular standard group. Each session focused on a topic of interest (e.g., forgiveness). Spiritual interventions included discussing spiritual concepts (e.g., helping participants to see their self-worth based in God's promises), encouraging forgiveness, referring to spiritual writings (e.g., the story of the prodigal son, Luke 15, 11-32), listening to spiritual music, and encouraging spiritual and emotional support among the group members (e.g., praying for one another).

The general purposes of the interventions were to help participants understand their problems from an eternal, spiritual perspective, to gain a greater sense of hope, to emotionally forgive and 
heal past pain, to accept responsibility for their own actions, and to experience and affirm their sense of identity and self-worth. Participants were also encouraged to connect with their faith communities.

All 20 participants $(100 \%)$ in the spirituality group achieved their treatment goals, compared to 16 out of 28 people $(57 \%)$ in the non-spirituality group. The difference in goal attainment between the two groups was highly significant $(p=0.0001)$. One participant with a 30 -year history of agoraphobia and daily panic attacks shared that she was able to "push away" the symptoms by utilizing a combination of prayer and relaxation techniques. Participants as a group stated that sensing God's presence helped to lessen feelings of sadness, calm fears and anxieties, deal with forgiveness and resolve daily problems. The findings from the Wong study suggest that inclusion of spirituality in psychiatric rehabilitation is a promising approach.

\subsection{Spirituality Matters Group at the Nathan Kline Institute New York}

The Spirituality Matters Group (SMG) was developed in 2001 at the Clinical Research Evaluation Facility of the Nathan Kline Institute for hospitalized persons with persistent psychiatric disabilities [48], following the rationale that spiritual support fosters the recovery process. SMG is distinct from comparable groups in its multidisciplinary leadership that focuses on integrating spiritual/religious, psychological and rehabilitative perspectives. The SMG is made up of self-referred persons who join three group co-leaders (representing psychology, pastoral care and rehabilitation) in exploring non-denominational religious and spiritual themes designed to facilitate comfort and hope, while addressing prominent therapeutic concerns. Patients are told this group "focuses on the use of spiritual beliefs for coping with one's illness and hospitalization". The highly-structured group format accommodates cognitive deficits and limited social skills that are prevalent in persons with persistent psychiatric disabilities.

During each session's initial phase, new members are introduced, the group's purpose reviewed, the multi-religious and non-denominational nature of the group affirmed, and spirituality defined as "personal beliefs and values related to the meaning and purpose of life, which may include faith in a higher purpose or power." In the middle phase, a topic with a related group activity is presented. Topics are selected by leaders on a rotating basis and carefully prepared so that both negative and positive emotions are addressed. Group members are encouraged to share how the topic has relevance to the perception of their illness, previous behavior patterns, treatment failures, and future goals. In the ending phase, group members summarize the session's emergent themes and new learning's.

Group activities are: 1. Readings from the Book of Psalms [49]. Psalms evoke the full range of human emotions from thanksgiving and praise to anger, fear, desperation, despair, abandonment, hope and protection. Reading selected Psalms emphasizes the universal nature of experiencing conflicts and struggles in daily life, while focusing on elements of faith that maintain strength and perseverance during these difficulties. 2. Reciting prayers together that are familiar and common reinforce individuals' existing religious and spiritual practices. 3. Writing prayers helps improve self-awareness of one's needs and allows articulation of one's experiences in a setting that brings comfort and a sense of closure. 4. Reading spiritual stories allows group members to identify personal values. 
Most of these group activities can be understood as emotion-focused coping [50]. It includes cognitive reframing, social comparisons, minimization ("looking on the bright side of things"), and behavioral efforts to feel better (exercise, relaxation, meditation). Emotion-focused coping is useful when a situation cannot be changed, but only the emotional response can be changed, which is self-affirming and empowering. This coping style can co-exist with problem-focused approaches.

\subsection{Spiritual Issues Psychoeducational Group at Bowling Green State University}

The program was a seven-week semi-structured, psycho-educational intervention at the Psychology Department of Bowling Green State University Ohio [51]. Two doctoral students in clinical psychology served as ongoing facilitators for each group session (1.5 h). Participants discussed religious resources, spiritual struggles, forgiveness, and hope. The intervention was designed to provide new information about spirituality to participants and to allow them to share experiences and knowledge. An additional goal was to present a more inclusive set of spiritual topics to clients with severe mental illness (Table 1).

Group members were recruited through referrals from mental health workers at a local community mental health center. Potential members participated in individual interviews to determine whether their needs, expectations and level of functioning were appropriate for the group. One third of the group members reported a diagnosis of schizophrenia, one third indicated a diagnosis of depression, and one-third reported personality disorders as their primary diagnosis. In terms of religious affiliation, thirty percent identified themselves as Roman Catholic while all others were affiliated with Protestant denominations. Seventy percent indicated that they attend church on a weekly basis. 
Table 1. Overview on the seven-week, semi-structured psycho-educational program.

\begin{tabular}{|c|c|c|}
\hline Week & Topic & Description \\
\hline 1 & Introduction & $\begin{array}{l}\text { Facilitators give group members an overview of the group format and the topics. } \\
\text { In addition, the group rules were reviewed and group members share their } \\
\text { "personal spiritual journey" [43]. }\end{array}$ \\
\hline 2 & $\begin{array}{l}\text { Spiritual } \\
\text { Resource }\end{array}$ & $\begin{array}{l}\text { This session is intended to elicit members' ideas of personal and community } \\
\text { spiritual resources [12]. The session begins by providing the group with } \\
\text { definitions and examples of spiritual resources. The potential barriers to utilizing } \\
\text { these resources are explored and discussed. }\end{array}$ \\
\hline 3 & $\begin{array}{l}\text { Spiritual } \\
\text { Strivings }\end{array}$ & $\begin{array}{l}\text { The primary objective is to have group members explore ways to create and } \\
\text { achieve meaningful, realistic goals related to their spiritual journey. Facilitators } \\
\text { discuss the importance of having strivings [52]. To promote discussion, group } \\
\text { members generate personal lists of their strivings. }\end{array}$ \\
\hline 4 & $\begin{array}{l}\text { Spiritual } \\
\text { Struggles }\end{array}$ & $\begin{array}{l}\text { The overall goal is to emphasize the importance of expressing thoughts and } \\
\text { feelings about spiritual struggles, validate and normalize anger with God or the } \\
\text { Church, and reframe struggles as a time of personal growth. }\end{array}$ \\
\hline 5 & $\begin{array}{c}\text { Forgiveness } \\
\text { of Others }\end{array}$ & $\begin{array}{l}\text { Group members discuss the definition of forgiveness. Then they reflect on } \\
\text { incidents in their life when they were hurt by another person or institution. } \\
\text { Finally, steps towards forgiveness are briefly outlined [53]. }\end{array}$ \\
\hline 6 & Hope & $\begin{array}{l}\text { The primary goal is to explore spiritual strategies that can be used to hold on to } \\
\text { hope [54]. Group members talk about the meaning of hope and reasons to retain } \\
\text { hope. Major pathways used to foster hope are rituals, hymns, trusting that God } \\
\text { has a greater purpose, and supporting each other. }\end{array}$ \\
\hline 7 & Wrap-up & $\begin{array}{l}\text { In the final session, the two permanent facilitators review the topics covered by } \\
\text { the group and solicit feedback from group members. Emphasis is placed on } \\
\text { maintaining confidentiality. }\end{array}$ \\
\hline
\end{tabular}

In conclusion, this intervention provided a safe environment for those with severe mental illness to discuss spiritual concerns. This unique intervention appeared to be highly valued by participants. Community mental health professionals may feel that it is not their place to employ a spiritual issues group in a publicly funded agency. Yet Richards and Bergin [55] note that there "are no professional ethical guidelines that prohibit therapists in civic settings from discussing religious issues or using spiritual interventions with clients." In fact, they assert, it is unethical to derogate or overlook this dimension. With some training in the area of serious mental illness and spiritual concerns, professionals from diverse areas of training could lead such "spirituality groups".

\section{Integrating Religion and Spirituality into Psychotherapy}

\subsection{The Holistic Concept of a Swiss Clinic}

The Clinic SGM Langenthal for psychosomatics, psychiatry and psychotherapy has integrated religion and spirituality into the therapeutic concept from the beginning. The theoretical framework for this integration is the extended bio-psycho-social model [17] as described earlier in this article. In mental as well as in physical illness, there is always an existential and therefore spiritual dimension which should be explored, because it will influence therapy in an explicit or implicit way. For this reason, a short spiritual history is taken from every patient to assess the relevance of 
spirituality in the patient's life and illness. A special emphasis lies on identifying spiritual resources and burdens. If religion or spirituality is relevant for a patient, it is important to understand how he/she wants to implement this dimension into therapy and what the therapist's role should be.

A patient can, as an example, integrate spiritual goals into his/her treatment plan: e.g. regaining hope and meaning; strengthening the relationship with God to better cope with mental illness; persevering in difficult psychosocial circumstances; resolving anger, frustration or disappointment towards God; understanding why God allows bad things to happen in a patient's life, working towards forgiveness in broken relationships; and being more aware of God's presence and guidance in daily life. Spiritual goals are discussed in the interdisciplinary team, of which the pastoral counselor is a full member. It is important that spiritual goals are in line (do not conflict) with other treatment goals. "Spirituality" can be used (or misused) to escape from difficult circumstances. This would not be supported in the therapeutic context.

For many years, the clinic offers psycho-educational group meetings focusing on the integration of therapeutic and spiritual aspects, and emphasizing the benefit and importance of religious and spiritual coping $[7,12,38,51]$. Topics of these psycho-educational group meetings are: Developing a positive perspective for life despite illness and limitations, coping with fear and depression, listening to the Book of Psalms, developing a spiritual identity ("I called you by your name"), fostering personhood, and reflecting on healthy and unhealthy religious and spiritual beliefs.

The integration of spiritual issues into psychotherapy [24] represents a further aspect of the clinic's holistic concept. A patient in a psychotic state felt energized by God's overwhelming presence in his mind and body. The therapist challenged this "spiritual perception" during the psychotherapeutic consultation, and asked for other possible explanations. If a patient has unhealthy beliefs, it is important to challenge them from a spiritual as well as a psychotherapeutic point of view. Further topics are feelings of guilt, being rejected or abandoned by the divine, working towards forgiveness.

\subsection{The Impact of Religiosity on the Outcome of Psychotherapy in a Inpatient Sample}

To evaluate the impact of religiosity on the outcome of psychotherapy, a longitudinal study with a pre-post-design has been conducted at the clinic in Langenthal, Switzerland [56]. The rationale behind this investigation was that religiosity can be conceptualized as a personal resource for religiously oriented patients [57], and that the activation of this resource may support therapeutic processes [58] and improve health outcomes. In the newer literature on empirically validated mechanisms of change in psychotherapy, personal resources seem to play an important role. According to Klaus Grawe, "resource activation" is a key mechanism of change [59] and also an important factor for the improvement of subjective well-being [60]. In psychosomatic and psychiatric patients' religious behaviour, experience and thinking may be particularly important for well-being. According to Howard et al. [61], the improvement of subjectively experienced wellbeing is associated with reduction in symptomatic distress, and the latter is associated with changes of life functioning.

The sample consisted of 189 inpatients from the clinic for psychosomatics, psychiatry and psychotherapy in Langenthal. Data was collected as a standard quality management procedure. The mean age was 43 years. More than two thirds of the patients were female. The mean duration of 
treatment was 70 days. There were some chronically ill patients with a long history of suffering. To assess religiosity, the Munich Motives for Religiosity Inventory (MMRI) was used, a measure developed by Grom, Hellmeister, and Zwingmann [62]. The questionnaire consists of eight subscales that cover different motives of intrinsic religiosity: Moral self-control $(\alpha=0.76)$, cooperative control of significant life events $(\alpha=0.75)$, passive control of significant life events $(\alpha=0.81)$, justice or reward for actions $(\alpha=0.79)$, positive self-esteem $(\alpha=0.85)$, gratitude a nd worship $(\alpha=0.89)$, prosocial attitude and behavior $(\alpha=0.84)$, and readiness to reflection $(\alpha=0.71)$. The eight dimensions were theoretically derived from psychological motivational theories (e.g., self-efficacy, prosocial behavior).

To assess mental health, the well-known Symptom Check List (SCL-90-R, Derogatis 1977) was adopted, focusing on the Global Severity Index scale (GSI) as a measure of total symptom distress. Subjective well-being (SWB) has been measured with a four-item scale including items on distress ("At the present time, how upset or distressed have you been feeling?"), energy and health ("At the present time, how healthy and fit have you been feeling?"), emotional and psychological adjustment ("At the present time, how well do you feel that you are getting along emotionally and psychologically?"), and current life satisfaction ("At the present time, how satisfied are you with your current life?").

To evaluate whether intrinsic religiosity does change during treatment paired sample $t$-tests was performed on MMRI measures. Table 2 shows means and standard deviations of MMRI subscales pre- and post-treatment as well as pre-post differences calculated with paired sample $t$-tests. Five subscales of the MMRI showed significant pre-post differences, at which "cooperative control", "passive control" and "positive self-esteem" demonstrated the largest changes. All subscales with the exception of "moral self-control" and "justice or reward for actions" increased in numbers. Religiosity was found to be significantly changed during treatment.

Table 2. Changes of religiositiy (Munich Motives for Religiosity Inventory (MMRI) subscales) during treatment.

\begin{tabular}{cccc}
\hline MMRI subscales & $\begin{array}{c}\text { Pretest } \\
\boldsymbol{M}(\boldsymbol{S D})\end{array}$ & $\begin{array}{c}\text { Posttest } \\
\boldsymbol{M}(\boldsymbol{S D})\end{array}$ & $\boldsymbol{t}(\mathbf{1 8 8})$ \\
\hline Moral self-control & $4.46(1.02)$ & $4.37(1.06)$ & 1.58 \\
Cooperative control & $4.16(1.02)$ & $4.39(0.99)$ & $3.76^{* * *}$ \\
Passive control & $3.99(1.09)$ & $4.22(1.07)$ & $3.42^{* * *}$ \\
Justice/reward for actions & $2.89(1.34)$ & $2.84(1.33)$ & 0.68 \\
Positive self-esteem & $4.75(1.04)$ & $5.03(1.03)$ & $4.89 * * *$ \\
Gratitude and worship & $4.47(1.08)$ & $4.65(1.13)$ & $2.87^{* *}$ \\
Prosocial attitude/behavior & $4.49(1.08)$ & $4.54(1.13)$ & 0.83 \\
Readiness to reflection & $4.13(1.03)$ & $4.28(1.04)$ & $2.33^{*}$ \\
Religiosity (MMRI mean) & $\mathbf{4 . 1 7 ( 0 . 7 8 )}$ & $\mathbf{4 . 2 9}(\mathbf{0 . 8 2})$ & $\mathbf{2 . 8 9 * *}$ \\
\hline
\end{tabular}

To examine the degree of change of religiosity, symptomatic distress and subjective well-being during therapy, effect sizes $\left(\mathrm{ES}_{\text {pre }}=\right.$ Diff pre-post $\left./ \mathrm{SD}_{\text {pre }}\right)$ have been calculated. The mean of all MMRI subscales was used as an integrated measure of religiosity. Subjective well-being $\left(\mathrm{ES}_{\mathrm{pre}}=1.34\right)$ and symptomatic distress $\left(E S_{\text {pre }}=0.81\right)$ showed substantial changes over the treatment period, while 
changes in religiosity were small $\left(\mathrm{ES}_{\text {pre }}=0.15\right)$. This was expected because religiosity can be conceptualized as a personality characteristic/trait and is quite stable.

Pre-test correlations (Table 3) demonstrate that patients with higher religiosity tend to have better well-being. Religiosity is not associated with symptomatic distress at pre-test assessment. In contrast, subjective well-being was significantly and negatively associated with symptomatic distress, showing that patients with higher symptomatic burden have poorer well-being.

Post-test correlations (Table 4) exhibit basically the same pattern of relationship between religiosity, subjective well-being and symptomatic distress. The association between religiosity and subjective wellbeing was stronger and highly significant. In contrast to the pre-test findings there was a small but slightly significant negative correlation between religiosity and symptomatic distress.

Table 3. Pre-test correlations between religiosity, well-being and distress.

\begin{tabular}{cccc}
\hline Variable & $\mathbf{1}$ & $\mathbf{2}$ & $\mathbf{3}$ \\
\hline 1. Religiosity (MMRI mean, $\mathrm{t} 1$ ) & $(0.93)$ & & \\
2. Subjective wellbeing (SWB, t1) & $0.17^{*}$ & $(0.82)$ & \\
3. Symptomatic distress (GSI, t1) & -0.08 & $-0.43^{* * *}$ & $(0.97)$ \\
\hline
\end{tabular}

Note. $\mathrm{N}=189$, reliabilities (Cronbach's $\alpha$ ) in brackets; ${ }^{*} p<0.05$, *** $p<0.001$.

To predict subjective well-being on post-test assessment, a hierarchical regression analysis was performed. In the first step, initial scores of subjective well-being, symptomatic distress, and initial MMRI mean scores were entered simultaneously as independent variables. In the next step, difference scores of symptomatic distress and difference scores of the MMRI mean were supplied. The results are summarized in Table 5. The first step explained $12 \%$ of the variance in subjective well-being. The second step explained another $38 \%$ of the variance. The standardized regression coefficients demonstrated that religiosity and also changes in religiosity play a significant role in predicting subjective well-being and lowering symptomatic distress.

Table 4. Post-test correlations between religiosity, well-being and distress.

\begin{tabular}{cccc}
\hline Variable & $\mathbf{1}$ & $\mathbf{2}$ & $\mathbf{3}$ \\
\hline 1. Religiosity (MMRI mean, t2) & $(0.95)$ & & \\
2. Subjective wellbeing (SWB, t2) & $0.35 * * *$ & $(0.79)$ & \\
3. Symptomatic distress (GSI, t2) & $-0.15^{*}$ & $-0.58 * * *$ & $(0.97)$ \\
\hline Note. $\mathrm{N}=189$, reliabilities (Cronbach`s $\alpha$ ) in brackets; * $p<0.05, * * * p<0.001$.
\end{tabular}

Table 5. Intrinsic religiosity predicting subjective well-being ( $\mathrm{t} 2)$.

\begin{tabular}{ccc}
\hline Variable & $\Delta \mathbf{R 2}$ & $\boldsymbol{\beta}$ \\
\hline Step 1 & 0.12 & \\
Subjective well-being (SWB, t1) & & $0.24 * * *$ \\
Symptomatic distress (GSI, t1) & & $-0.48 * * *$ \\
Religiosity (MMRI mean, t1) & & $\mathbf{0 . 2 2} * * *$ \\
Step 2 & 0.38 & \\
$\Delta$ Symptomatic distress ( $\Delta \mathrm{GSI})$ & & $-0.70 * * *$ \\
$\Delta$ Religiosity ( $\Delta$ MMRI mean) & & $\mathbf{0 . 2 4} * * *$ \\
All variables & 0.50 & \\
\hline
\end{tabular}


Note. $\beta=$ Standardized regression coefficients; ${ }^{* * *} \mathrm{p}<0.001$

First, the findings support the idea that religious faith is an important resource for religiously oriented patients [57] and is associated with therapeutic outcomes. Second, findings show that significant changes in subjective well-being are associated with religiosity. These results, then, provide empirical evidence that favors the integration of religious behavior, experience, and thinking into psychotherapy in order to enhance treatment outcomes in psychosomatic and psychiatric (in)patients.

\subsection{Religious Patients Benefit from Religious Therapy by Religious and Non-Religious Therapists}

There are only few studies which investigate the outcome of "religious therapies" [63-65]. The integration of religious elements into psychotherapy is typically used for religious patients. Rebecca Probst from the Department of Counseling Psychology, Portland, conducted a comparative study of the efficacy of religious and non-religious cognitive-behavioral therapy with religious and non-religious therapists on religious patients with clinical depression [65]. She hypothesized that religious cognitive-behavioral therapy (RCT) might be more effective for religious patients than standard cognitive-behavioral therapy (CBT) because of higher consistency of values and frameworks. Religious cognitive-behavioral therapy (RCT) gave religious rationales for the procedures, used religious arguments to counter irrational thoughts, and used religious imagery procedures according to a manual published by Probst 1988 [66]. Furthermore, the study was designed to determine whether non-religious therapists could successfully implement religious cognitive-behavioral therapy (RCT).

Focusing on pre- and post-treatment results, Probst et al. found that religious individuals receiving religious cognitive-behavioral therapy (RCT) reported more reduction in depression (BDI) and greater improvement in social adjustment (SAS) and general symptomatology (GSI, SCL-90-R) than patients in the standard cognitive-behavioral therapy group (CBT). Individuals in the pastoral counseling treatment group (PCT), which was included to control for the nonspecific effects of the treatment delivery system, also showed significant improvement at post-treatment and even outperformed standard CBT. This finding was similar to the results obtained with a nonclinical population [67].

The most surprising finding in the Probst study was a strong therapist-treatment interaction. The group showing the best performance on all measures was the RCT condition with the non-religious therapists (RCT-NT), whereas the group with the worst pattern of performance was the standard CBT with the non-religious therapists (CBT-NT). There was less difference in performance between the cognitive-behavioral therapy conditions for the religious therapists (RCT/CBT-RT). This pattern of therapist-treatment interaction suggests the following: 1. Effectiveness of CBT for religious patients delivered by non-religious therapists can be enhanced significantly by using a religious framework. 2. Impact of similarity of value orientation of therapists/therapy and patients on outcome of therapy seem to suggest that neither extreme value similarity nor extreme value dissimilarity facilitates outcome. Value similarity must be defined as a combination of the personal values of the therapist and the value orientation of the treatment. The RCT conditions with 
religious therapists and standard CBT with non-religious therapists show the most value similarity. Neither of them, however, showed high performance and was particularly relevant in this study.

\section{Conclusions for the Integration of Religion and Spirituality into Therapy}

The studies reviewed in this article support the integration of religion and spirituality into mental health care, psychiatry and psychotherapy. Many patients want service providers to address spiritual and religious issues during therapy [68]. Some fear that clinicians will "reduce" or "trivialize" their beliefs or that they will see them as a sign of pathology. This requires clinicians to take a respectful and individualized approach to patient's spiritual and religious background [69].

To develop competence in integrating religion and spirituality into mental health care, clinicians (including psychiatrists, psychotherapists, social workers, and psychiatric nurses) need professional training pertinent to the particular service setting [70]. Such training has to address the following topics: (1) Understanding the ways in which religion and spirituality relate to patients' overall well-being, evaluating whether patients' particular expression of spirituality is helpful or harmful for the recovery process. (2) Taking a spiritual history, developing the ability to talk with patients about spirituality in a manner that is neither intrusive nor reductive but which communicates respectful openness to a patient's unique spiritual experiences, both positive and negative. (3) Supporting religious and spiritual coping, e.g., prayer and meditation, reading psalms or other religious/spiritual literature, attending religious services. (4) Considering counter transference reactions that can be influenced by the therapists' religious or spiritual experiences [71]. (5) Delivering social and community resources, providing opportunities to expand the connections between religious or spiritual activities in the community and in the mental health program itself. (6) Learning when and how to make referrals to religious professionals, to faith-based programs or to centers of spiritual activity.

Mental health care programs integrating spiritual issues range from short-term psycho-educational groups to open-ended discussions of "religious issues" and the way they relate to mental health concerns. Programs illustrate possible forms of integration. For psychotherapy, the Probst study [65] as well as the Azahr studies [63,64] clearly indicate that the outcome in religious patients can be enhanced by integrating religious elements into therapy and that this can be successfully done by religious and non-religious therapists alike. Further studies need to investigate this promising area.

\section{References}

1. Frank1, V. Men's Search for Meaning; Washington Square Press: New York, NY, USA, 1984.

2. Blanch, A. Integrating religion and spirituality in mental health: The promise and the challenge. Psychiatr. Rehabil. J. 2007, 30, 251-260.

3. Matthiews, D.A. The Faith Factor: Proof of the Healing Power of Prayer; Penguin Books: New York, NY, USA, 1998.

4. Russinova, Z.; Blanch, A. Supported spirituality: A new frontier in the recovery-oriented mental health system. Psychiatr. Rehabil. J. 2007, 30, 247-249.

5. Fallot, R.D. Spirituality and religion in recovery from mental illness. New Dir. Ment. Health Serv. 1998, 80, 25-33. 
6. Lindgren, K.N.; Coursey, R.D. Spirituality and serious mental illness: A two-part study. Psychosoc. Rehabil. J. 1995, 18, 93-111.

7. Tepper, L.; Rogers, S.A.; Coleman, E.M.; Malony, H.N. The prevalence of religious coping among persons with persistent mental illness. Psychiatr. Serv. 2001, 52, 660-665.

8. Koenig, H.G. Religious coping and depression in elderly hospitalized medically ill men. Amer. J. Psychiat. 1992, 149, 1693-1700.

9. Chang, B.H. Religion and mental health among women veterans with sexual assault experience. Int. J. Psychiat. Med. 2001, 31, 77-95.

10. Baetz, M.; Larson, D.B.; Marcoux, G.; Bowen, R.; Griffin, R. Canadian psychiatric inpatient religious commitment: An association with mental health. Can. J. Psychiatr. 2002, 47, 159-166.

11. Koenig, H.G.; George, L.K.; Peterson, B.L. Religiosity and remission of depression in medically ill older patients. Amer. J. Psychiat. 1998, 155, 536-542.

12. Pargament, K. The Psychology of Religion and Coping: Theory, Research, and Practice; Guilford Press: New York, NY, USA, 1997.

13. Pargament, K. The bitter and the sweet: An evaluation of the costs and benefits of religiousness. Psychol. Inq. 2002, 13, 168-181.

14. Pargament, K.; Koenig, H.G.; Perez, L.M. The many methods of religious coping: Development and initial validation of the RCOPE. J. Clin. Pyschol. 2000, 56, 519-543.

15. Bush, E.G.; Rye, M.S.; Brant, C.R.; Emery, E.; Pargament, K.; Riessinger, C.A. Religious coping with chronic pain. Appl. Psychophysiol. Biofeedbac. 1999, 24, 249-260.

16. Engel, G.L. The need for a new medical model: A challenge for biomedicine. Science 1977, 196, 129-136.

17. Hefti, R. Unser Therapiekonzept. Infomagazin 2003, 5, 12-13.

18. Miller, W.R.; Thoresen, C.E. Spirituality and health. In Integrating Spirituality into Treatment: Resources for Practitioners; Miller, W.R., Ed.; American Psychological Association: Washington DC, USA, 1999.

19. Mulligan, R.; Mulligan, T. The science of religion in health care. Veterans Health Syst. J. 1999, 55-57.

20. Richards, P.S.; Bergin, A.E. Toward religious and spiritual competency for mental health professionals. In Handbook of Psychotherapy and Religious Diversity; Richards, R., Bergin, A., Eds.; American Psychological Association: Washington, DC, USA, 2000; pp. 3-26.

21. Seybold, K.; Hill, P. The role of religion and spirituality in mental and physical health. Curr. Directions Psychol. Sci. 2001, 10, 21-24.

22. Longo, D.A.; Peterson, M.S. The role of spirituality in psychosocial rehabilitation. Psychiatr. Rehabil. J. 2002, 25, 333-340.

23. Sullivan, W.P. Recoiling, regrouping, and recovering: First-person accounts of the role of spirituality in the course of serious mental illness. New Dir. Ment. Health Serv. 1998, 80, 25-33.

24. Anthony, W.A. The principle of personhood: The field's transcendent principle. Psychiatr. Rehabil. J. 2004, 27, 205.

25. Cosar, B.; Kocal, N.; Arikan, Z.; Isik, E. Suicide attempts among Turkish psychiatric patients. Can. J. Psychiatr. 1997, 42, 1072-1075. 
26. Mickley, J.; Carson, V.; Soeken, L. Religion and adult mental health: State of the science in nursing. Issues Ment. Health Nurs. 1995, 16, 345-360.

27. Bergin, A.E.; Masters, K.S.; Richards, P.S. Religiousness and mental health reconsidered: A study of an intrinsically religious sample. J. Couns. Psychol. 1987, 34, 197-204.

28. Jahangir, F. Third force therapy and its impact on treatment outcome. Int. J. Psychol. Relig. 1995, 5, 125-129.

29. Pardini, D.; Plante, T.G.; Sherman, A. Strength of religious faith and its association with mental health outcomes among recovering alcoholics and addicts. J. Subst. Abuse Treat. 2001, $19,347-354$.

30. Walsh, J. The impact of schizophrenia on clients' religious beliefs: Implications for families. Fam. Soc. 1995, 76, 551-558.

31. MacGreen, D. Spirituality as a coping resource. Behav. Ther.1997, 20, 28.

32. Fallot, R.D. Spirituality in trauma recovery. In Sexual Abuse in the Lives of Women Diagnosed with Serious Mental Illness; Harris, M., Ed.; Harwood Academic Publishers: Amsterdam, The Netherlands, 1997; pp. 337-355.

33. Onken, S.J.; Dumont, J.M.; Ridgway, P.; Dornan, D.H.; Ralph, R.O. Mental Health Recovery: What Helps and What Hinders? National Association of State Mental Health Program Directors (NASMHPD). Res. Rep. 2002, 1-103.

34. Exline, J.J.; Yali, A.M.; Lobel, M. When God disappoints: Difficulty forgiving God and its role in negative emotion. J. Health Psychol. 1999, 4, 365-379.

35. Exline, J.J.; Yali A.M.; Sanderson, W.C. Guilt, discord, and alienation: The role of religious strain in depression and suicidality. J. Clin. Psychol. 2000, 56, 1481-1496.

36. Bussema, K.E.; Bussema, E.F. Is there a balm in Gilead? The implications of faith in coping with a psychiatric disability. Psychiatr. Rehabil. J. 2000, 24, 117-124.

37. Exline, J.J. Stumbling blocks on the religious road: Fractured relationships, nagging vices, and the inner struggle to believe. Psychol. Inq. 2002, 13,182-189.

38. Mohr, S.; Brandt, P-Y.; Borras, L.; Gilliéron, C.; Huguelet, P. Toward an integration of spirituality and religiousness into the psychosocial dimension of schizophrenia. Am. J. Psychiatr. 2006, 163, 1952-1959.

39. Huguelet, P.; Mohr, S.; Brandt, P-Y.; Borras, L.; Gillieron, C. Spirituality and religious practices among outpatients with schizophrenia and their clinicians. Psychiatr. Services 2006, 57, 366-372.

40. Längle, A. The art of involving the person-fundamental existential motivations as the structure of the motivational process. Eur. Psychother. 2003, 4, 25-36.

41. Schmidt, T.; Adami, S. Depression und Glaube-eine qualitative Studie an der Universität Freiburg; Diplomarbeit: Freiburg, Germany, 2008.

42. Hefti, R.; Integrating Spiritual Issues into Therapy. In Religion and Spirituality in Psychiatry; Huguelet, P., Koenig, H.G., Eds.; Cambridge University Press: New York, NY, USA, 2009; pp. 244-267.

43. Kehoe, N.C. A therapy group and spirituality issues fro patients with chronic mental illness. Psychiatr. Services 1999, 50, 1081-1083. 
44. Gallup, G. The Gallup Poll: Public Opinion; Scholarly Resources: Wilmington, DE, USA, 1994

45. Bergin, A.E.; Jensen, J.P. Religiosity of psychotherapists: A national survey. Psychotherapy 1990, 27, 3-7.

46. Reger, G.; Wong-McDonald, A.; Liberman, R. Psychiatric rehabilitation in a community mental health center. Psychiatr. Serv. 2003, 54, 1457-1459.

47. Wong-McDonald, A. Spirituality and psychosocial rehabilitation: Empowering persons with serious psychiatric disabilities at an inner-city community program. Psychiatr. Rehabil. J. 2007, 30, 295-300.

48. Revheim, N.; Greenberg, W.M. Spirituality matters: Creating a time and place for hope. Psychiatr. Rehabil. J. 2007, 30, 307-310.

49. Weintraub, S.Y. From the depths: Psalms as a spiritual reservoir in difficult times. In The Outstretched Arm; National Center for Jewish Healing of JBFCS: New York, NY, USA, 1999.

50. Folkman, S.; Chesney, M.; McKusick, L.; Ironson, G.; Johnson, D.S.; Coates, T.J. Translation coping theory into an intervention. In The Social Context of Coping; Eckenrode, J., Ed.; Plenum Press: New York, NY, USA, 1991.

51. Phillips, R.S.; Lakin, R.; Pargament, K. Development and implementation of a spiritual issues psychoeducational group for those with serious mental illness. Community Ment. Health J. 2002, 38, 487-496.

52. Emmons, R.A. The Psychology of Ultimate Concerns; The Guilford Press: New York, NY, USA, 1999.

53. Enright, R.D.; Fitzgibbons, R.P. Helping Clients Forgive. An Empirical Guide for Resolving Anger and Restoring Hope; American Psychological Association: Washington, DC, USA, 2000.

54. Yahne, C.E.; Miller, W.R.; Evoking Hope. In Integrating Spirituality into Treatment; Miller, W.R., Ed.; American Psychological Association: Washington, DC, 1999; pp. 217-233.

55. Richards, P.S.; Bergin, A.E. A Spiritual Strategy for Counseling and Psychotherapy; American Psychological Association: Washington, DC, USA, 1997.

56. Allemand, M.; Kliegel, M. Religiosity and its relation to therapeutic changes in subjective well-being and mental health in a Swiss inpatient sample. Paper presented at the Psychology of Religion Conference, Glasgow, UK, 28-31 August 2003.

57. Koenig, H.G.; Pritchett, J.T. Religion and psychotherapy. In Handbook of Religion and Mental Health; Koenig, H.G., Ed.; Academic Press: San Diego, CA, USA, 1998; pp. 323-336.

58. Plante, T.G.; Sherman, A.C. Faith and Health: Psychological Perspectives; Guilford Press: New York, NY, USA, 2001.

59. Grawe, K. Psychologische Therapie; Hogrefe: Göttingen, Germany, 1998.

60. Grawe, K.; Grawe-Gerber, M. Ressourcenaktivierung. Ein primäres Wirkprinzip der Psychotherapie. Psychotherapeut 1999, 2, 63-73.

61. Howard, K.I.; Lueger, R.J.; Maling, M.S.; Martinovich, Z. A phase model of psychotherapy outcome: Causal mediation of change. J. Consult. Clin. Psychol. 1993, 61, 678-685.

62. Grom, B.; Hellmeister, G.; Zwingmann, C. Münchner Motivationspsychologisches Religiositäts-Inventar (MMRI). Entwicklung eines neuen Meßinstruments für die 
religionspsychologische Forschung. In Religion und Religiosität zwischen Theologie und Psychologie; Henning, C., Nestler, E., Eds.; Lang: Frankfurt am Main, Germany, 1998; pp. 181-203.

63. Azahr, M.; Varma, S.L.; Dharap, A.S. Religious psychotherapy in anxiety disorders. Acta Psychiat. Scand. 1994, 90, 1-3.

64. Azahr, M.; Varma, S.L. Religious psychotherapy in depressive patients. Psychother. Psychosom. 1995, 63, 165-168.

65. Propst, L.R.; Ostrom, R.; Watkins, P.; Dean, T.; Mashburn, D. Comparative efficacy of religious and nonreligious cognitive-behavior therapy for the treatment of clinical depression in religious individuals. J. Consult. Clin. Psychol. 1992, 60, 94-103.

66. Probst, L.R. Psychotherapy in a Religious Framework: Spirituality in the Emotional Healing Process; Human Sciences Press: New York, NY, USA, 1988.

67. Propst L.R. The comparative efficacy of religious and nonreligious imagery for the treatment of mild depression in religious individuals. Cognitive Ther. Res. 1980, 4, 167-178.

68. D'Souza, R. Do patients expect psychiatrists to be interested in spiritual issues? Australas. Psychiatr. 2002, 10, 44-47.

69. Plante, T.G. Integrating spirituality and psychotherapy: Ethical issues and principles to consider. J. Clin. Psychol. 2007, 63, 891-902.

70. Fallot, R.D. Spirituality and religion in recovery: Some current issues. Psychiatr. Rehabil. J. 2007, 30, 261-270.

71. Koenig, H.G. Spirituality in Patient Care: Why, How, When and What; Templeton Foundation Press: Philadelphia, PA, USA, 2002; p.165. 


\title{
Integration of Spirituality and Religion in the Care of Patients with Severe Mental Disorders
}

\section{Sylvia Mohr}

\begin{abstract}
Spirituality and religiousness (S/R) are resources for finding meaning and hope in suffering and have been identified as key components in the process of psychological recovery. However, religion may also be associated with psycho-pathology, suffering and non-adherence with psychiatric treatment. Based on a literature review, this paper examines how $\mathrm{S} / \mathrm{R}$ can be integrated in the treatment of patients with serious mental illness. We implemented a pilot "Spirituality and Recovery Group" designed to (1) help patients to resort to S/R as a means of recovery; (2) work on resolving conflicts between $\mathrm{S} / \mathrm{R}$ and life issues and treatment; and (3) provide information on $\mathrm{S} / \mathrm{R}$ in the context of psychosis. Preliminary results are presented.
\end{abstract}

Reprinted from Religions. Cite as: Mohr, S. Integration of Spirituality and Religion in the Care of Patients with Severe Mental Disorders. Religions 2011, 2, 549-565.

\section{Abbreviations \\ S/R: Spirituality and Religion}

\section{Introduction}

Over the last decade, the interest in spirituality in psychiatric care has dramatically increased. Indeed, numerous studies demonstrated correlations between mental illness states and levels of spirituality or religiosity. Those relationships are mainly positive, but not always [1]. According to patients and mental health and religious professionals, spirituality and religion (S/R) often play a key role in the recovery process from serious mental illness. S/R may strengthen a sense of self and self-esteem, may involve coping responses that alleviate distress, may be connected to important sources of social and community support and may be the basic sense of hope. However, S/R sometimes hinder recovery by increasing psychopathology (anxiety, depression, delusion) or by rejecting people with mental health problems from religious communities. Patients would like their $\mathrm{S} / \mathrm{R}$ to be assessed and taken into account in their care [2].

Psychological recovery indicates the development of a fulfilling life and a positive sense of identity founded on hopefulness and self-determination. It has recently been recognized as an organizing principle in the systems of care for people who manage mental illness [3]. In psychiatric services oriented toward the promotion of recovery, a person-centered diagnosis is a crucial step for identification of disorders and helps to provide a treatment according to individual needs and values. Such a diagnosis includes both illness aspects (clinical disorders, disabilities and risk factors) and positive health status domain (remission/recovery, functioning and preventive factors). In the diagnostic process, the personal narrative of illness (such as suffering, values and cultural 
experience of illness and care) and of health (such as quality of life, values and cultural formulation of identity and context) are central [4]. A specific contribution from cultural psychiatry resides in the examination of the interaction of illness explanatory models of patients and clinicians in a clinical setting. Explanatory models are beliefs about the nature, the name, the cause, the expected course and the desired treatment for an episode of illness. Explanatory models are influenced by culture, but vary largely among individuals of the same cultural background. Indeed, explanatory models are ways of organizing reality, influenced by context, shifting over time, and often including more than one model [5]. The western explanatory models of mental illness are not universal concepts of psychopathology. It is probable that in all cultures, you can find the belief that malign spiritual forces cause psychiatric illness. Such beliefs influence patterns of help-seeking and adherence to treatment. According to the availability and cost-effectiveness of spiritual treatments, up to 70 percent of the patients will use one or more spiritual treatment before seeking professional help [6]. Moreover, it makes it difficult to disentangle positive symptoms from spiritual experiences (e.g., hearing voices, visions, ecstatic states, trances), especially for people with schizophrenia. Some religious coping behavior may be misdiagnosed as being symptomatic of psychopathology $[7,8]$.

Cultural contexts also influence the integration or the exclusion of $\mathrm{S} / \mathrm{R}$ into psychiatric services. For example, in England, religion has been considered as consoling and therefore chaplains have been systematically included in the staff of psychiatric hospitals since 1890; whereas in France, over the same period of time, religion has been considered as harmful, encouraging delusions and hallucinations, and therefore excluded from psychiatric hospitals [6]. Today, with increased knowledge about $\mathrm{S} / \mathrm{R}$ and mental illness, it is time to overcome this dichotomous vision of religion as harmful or helpful toward an understanding of the complexity of relationships between various aspects of $\mathrm{S} / \mathrm{R}$ and mental illnesses. Such differences also introduce specificities of the integration of $\mathrm{S} / \mathrm{R}$ into treatment according to various mental disorders and various struggles encountered by the patients.

There is no consensus about what spirituality is. Religion is easier to define, as it refers to a social group. Religion involves affiliation and identification with a religious group, cognitive factors-beliefs, and emotional and experiential factors [6]. A literature review of medical and psychological journals produced four models of spirituality: (1) A traditional-historical version of spirituality which defines a subset of deeply religious people; (2) A modern version of spirituality which includes religion but expands beyond it. Spirituality is as a general feeling of closeness and connectedness to the sacred, i.e., divine being or object or a sense of ultimate reality of truth. However, people may search for the sacred outside of an established religious tradition, being "spiritual but not religious"; (3) An expanded modern version of spirituality which includes also positive psychological states (purpose and meaning in life, connectedness with others, peacefulness, harmony and well-being) and (4). A modern clinical version of spirituality which also integrates secular concepts like hope, in order to include everyone [9]. In that sense, based on the sacred object, four types of spirituality were defined: religious spirituality (a sense of closeness and connection to the sacred as described by a specific religion (e.g., Judaism, Christianity, Islam, Buddhism) a particular "God or Higher Power"; humanistic spirituality (a sense of closeness and connection to humankind, often involving feelings of love, altruism, or reflection); nature 
spirituality (a sense of closeness and connection to the environment or to nature) and cosmos spirituality (a sense of closeness and connection with the whole creation) [10].

The integration of $\mathrm{S} / \mathrm{R}$ into mental health care needs to be especially sensitive and respectful to the cultural context. The first step is a systematic inclusion of a $S / R$ assessment into the diagnosis process. Due to the vagueness of the definition of spirituality, this assessment has to be a clinical interview with open questions and not a standardized questionnaire. In this review, we will first present how to conduct a $S / R$ assessment and then various models of integration of $S / R$ into therapies, with an extended focus on group treatments. We will then present preliminary results of our pilot "Spirituality and Recovery Group".

\section{Spiritual Assessment}

The importance of $\mathrm{S} / \mathrm{R}$ is a phenomenon that is poorly acknowledged by clinicians [11]. The assessment of spiritual needs and by whom and how the patient wants those needs to be addressed is an essential part of care management $[12,13]$. In a study evaluating the concordance between a psychiatric rehabilitation program and patients' goals, $22 \%$ of patients set $\mathrm{S} / \mathrm{R}$ goals for the ongoing year, yet they perceived offered services as insufficient toward those goals [14]. Once a patient expresses spiritual concerns and wishes to discuss them with the clinician, a more extensive assessment has to be conducted. Numerous scales have been developed to investigate $S / R$, as it is a multi-dimensional phenomenon [15]. Topics of special interest are those related to mental health states, like relationship with the transcendent, religious orientation and motivation, religious support and religious struggle [16]. For example, in order to assess $\mathrm{S} / \mathrm{R}$ among outpatients with psychosis in Geneva, Switzerland, we developed a semi-structured interview. The open questions were based on the "Multidimensional measurement of religiousness/spirituality for use in health research", focused on behavioral, psychological, and social mechanisms of S/R, which may have an effect on physical and mental health [17], the "Religious coping index" [18], and a questionnaire on spiritual and religious adjustment to life events [19]. This assessment tool was adapted to a variety of spiritual beliefs (pathological or not), linked to different religious traditions (Judaism, Christianity, Islam, Buddhism and minority religious movements), various types of spiritual/religious coping [20]. This clinical interview consists of two parts: 1- A part about the religious and spiritual history (family background and religious education; as well as changes of spirituality and religiousness, especially in relationship with mental illness); the current spiritual and religious beliefs and practices (private and collective); and the subjective importance of spirituality in daily life and to give meaning to life. 2- A part that concerns spiritual/religious coping; i.e., the subjective importance of $\mathrm{S} / \mathrm{R}$ in giving meaning to the illness, to cope with symptoms, to get comfort, coping style, support from the religious community; and the synergy between $\mathrm{S} / \mathrm{R}$ and adherence to psychiatric care (medication and psychotherapy). The second part does not concern patients for whom $S / R$ is absent or marginal. For them, secular sources of hope and meaning are asked. This $\mathrm{S} / \mathrm{R}$ assessment was well accepted by patients and elicits major spiritual themes which may be integrated into care: support positive coping; work on identity and values; differentiate delusion from faith and work on this issue; mobilize the patient toward clergy, chaplains, or a religious community; work on negative religious coping; and work on representations of psychiatric disorder and treatment from a religious perspective [21]. 
Spiritual assessment leads to elicit spiritual needs and the type of $S / R$ intervention needed. In some spiritual groups, patients pray together $[22,23]$, some groups are led by both mental health and religious professionals [22,24], some secular therapies use Buddhist principles [25,26], others are religiously oriented $[27,28] . \mathrm{S} / \mathrm{R}$ is a very sensitive area; the patient has to be informed of the above-mentioned $\mathrm{S} / \mathrm{R}$ characteristics before any referral.

\section{Models of Integration of Spirituality and Religion into Psychiatric Care}

Integration of $\mathrm{S} / \mathrm{R}$ into psychiatric care ranges from referral to chaplain, exploration of spirituality in individual and group psychotherapies, bringing in spiritual concepts and practices into psychotherapies, to holistic care programs.

Mental illness and its treatment present different kinds of theological challenges to different religious traditions, and then spiritual needs to be addressed specifically [29]. When a patient expresses spiritual needs and wants them to be addressed by a religious professional, the integration of spirituality requires a collaboration with the chaplaincy service or other relevant religious people. Religious professionals are not mental health professionals. Their mission is to help their community's members to know God. However, mental health and religious professionals share the same commitment toward alleviation of patients' suffering, with mutual respect for the distinctive resources each partner brings to the helping process.

Individual psychotherapies may be more easily tailored to meet the special needs of patients than group therapies. In order to integrate spirituality into the treatment, therapists need to be open, sensitive and willing to learn about the role spirituality plays in the life of their patients. Each theoretical model of individual psychotherapy may integrate spirituality. In the domain of cognitive behavior therapies, this integration is documented in protocols of treatment. For example, the Christian accommodative cognitive behavior therapy for depression is adjusted for Christian patients. This therapy retains the main features of the existing secular theory yet places the therapy in a religious context. Techniques such as cognitive restructuring and guided imagery depends on Biblical teaching and religious imagery. The effectiveness of this treatment was demonstrated by several studies with outpatients, for both religious and nonreligious therapists. Indeed, therapists do not need to share the same religious background. Christian accommodative cognitive therapy also exists for other disorders, such as anxiety and eating disorders [28]. Under the same principles, cognitive behavior therapy is also accommodated for other religious traditions: Islam, Buddhism and Taoism [28]. In Saudi-Arabia, a Muslim accommodative individual Cognitive Behavior Therapy was also designed to help Muslim in-patients with schizophrenia to cope with their auditory hallucinations [30]. The cognitive behavior therapy for depression has also been augmented by a focus on existential issues (hope, meaning, acceptance and forgiveness) for patients of various beliefs systems [31].

Holistic programs for severe mental illness integrate psychiatric treatment with a religious tradition as a whole person care setting. For example, the Windhorse Therapy is based on Buddhist principles and Western psychology to create individually tailored therapeutic living environments, in order to reduce the chaos and confusion of mental disturbance and improve life functioning [32]. Another example is a Christian psychiatric hospital in Switzerland which offers spiritual individual and group treatments based on the belief that mental illness always implies an existential or 
spiritual dimension. The individual spiritual treatment goals are elicited for each patient by a spiritual assessment. Spiritual treatments include a psycho-educational group focusing on coping with life and mental illness, a spiritual singing and music group, spiritual art therapy, spiritual counseling and psychotherapy, pastoral care and patient libraries [33].

Psychiatric services, predominantly in the USA, attempt to integrate spirituality into group therapies. Group psychotherapies provide unique treatment resources for severe mental disorders. Indeed, sharing their experiences with other patients reduces isolation and offers invaluable social support that also facilitates recovery. Therefore, we will now focus on models of integration of spirituality into psychotherapy groups for severe mental illness.

\section{Models of Integration of Spirituality into Psychotherapy Groups for Severe Mental Illness}

In the domain of substance use disorders, there is a long tradition of including spirituality into treatment. The dependence on a substance includes craving and impaired control over substance-related behavior. Those aspects are the target of both Buddhist and theistic spiritualities, with some commonalities (compassion to self and others) and differences (development of meditation to deal with craving and dependence on substance vs. dependence on God). The twelve-step program Facilitation for Alcoholism, created in 1935, has been well studied and demonstrated its efficacy in numerous clinical trials [28]. This inter-faith program encouraged clients to view alcoholism as a spiritual and medical disease. Its goals are to foster acceptance of the disease of alcoholism, develop a commitment to attend Alcoholics Anonymous, and begin working through the 12 steps. According to the original founders, those steps include that the persons admit their lack of power over alcohol; believe in a greater Power that could restore their sanity; make the decision to turn their lives over the care of God as the persons understand Him; make a moral inventory; admit to God, to themselves and other their wrongs; be ready to let God remove their defects of character and shortcomings; list all persons they had harmed and make amendments to them; continue to make a personal inventory and admit when they are wrong; through prayer and meditation improve contact with God and His will and then carry this spiritual awakening to alcoholics and practice these principles in all their life domains. This program has largely been accommodated all over the world to other substance dependencies, as well as to specific monotheistic faiths (Judaism, Christianity and Islam) [34].

The spiritual self-schema (3-S) therapy, a spirituality focused cognitive-behavioral psychotherapy for the treatment of addiction disorders, integrates Buddhist psychological principles and practices [26]. Addiction is the result of over-learned maladaptive behavioral sequences that supplant almost all others, which frequently result in harm to self and others. In 3-S_therapy, those behaviors are referred to as the addict self. The goal is therefore to help drug users to make a shift from the habitual activation of the maladaptive and potentially destructive addict self-schema to a self-schema that fosters mindfulness, compassion, and doing no harm to self and others, i.e., the spiritual selfschema. This therapy does not impose or endorse Buddhism as an alternative religion, but rather, tailors the therapy to each patient's own $\mathrm{S} / \mathrm{R}$ in defining the spiritual self-schema. Throughout the 12 -session group therapy, patients practice mindfulness meditation and work systematically to develop the 10 traditional Buddhist qualities (generosity, morality, renunciation, wisdom, effort, tolerance, truth, strong determination, loving kindness, equanimity) — and four additional spiritual 
qualities (gratitude, courage, forgiveness, and serenity). With a great majority of Christian patients, this program demonstrates its efficacy for reduction of impulsiveness and drug intake, as well as an increase of spiritual and religious practices.

Another example is a theistic spirituality group for women hospitalized in a center for severe eating disorders [27]. The foundations of theistic psychotherapy are grounded in the worldview of the major theistic world religions, including Judaism, Christianity, and Islam. The core assumptions of this approach are that God exists, that human beings are the creations of God, and that there are unseen spiritual processes by which the link between God and humanity is maintained. It assumes that patients who have faith in God's healing power and draw upon the spiritual resources in their lives during psychological treatment will receive added strength to cope, heal, and grow. In that perspective, several of the core struggles in eating disorders have a spiritual nature. Almost all women with eating disorders have lost touch with their sense of spiritual identity and worth. They often feel unworthy, unlovable, and incapable. They may also struggle with negative images of God, fear of abandonment by God, guilt and shame. The major goal is to help women with eating disorders to affirm their spiritual identity and worth as creations of God. The thematic of the open group sessions concern faith in God, spiritual identity, grace, forgiveness, repentance and overcoming adversity.

For severe mental illness, especially psychotic disorders, spiritual groups in US psychiatric services emerged only several decades after spiritual groups for addiction. Indeed, even now, the prevalence of hallucinations and delusions with religious contents bias mental health professionals toward a reduction of $\mathrm{S} / \mathrm{R}$ in psychopathology of patients with schizophrenia [35]. The groups reviewed are presented in Table 1.

The Nancy Kehoe's pioneering work initiated in 1980 had to wait almost 20 years to be published $[24,36]$. She is a nun and a psychologist, underlining that individuals are more than their mental illness. With a member of staff, she has leads an open group of discussion on spiritual issues for out and in patients with chronic mental illness for 25 years. The group offers a place where patients have the opportunity to explore ways in which their beliefs and practices help or hinder them in coping with mental illness. Membership is voluntary. The group is open to all, regardless of diagnosis or religious background. Patients have to accept the group rules of tolerance of diversity, respect and a ban on proselytizing. About a third of patients choose to participate in the weekly group (Christians, Muslims, Buddhists, Jews, and atheists). The average duration of participation is of two to three years. The group fosters tolerance, acceptance of other's views, selfawareness, and thoughtful examination of belief systems, opportunities to apply spirituality and values to life questions. At first, the idea of having such a group generated anxiety, fear, and doubt among staff members. However, staff training and the long-term success of the group foster staff acceptance. Indeed, more than a hundred patients have attended the group without exacerbation of delusions and promotion of recovery. No empirical outcome data is available.

Table 1. Spiritual Groups for severe mental disorders.

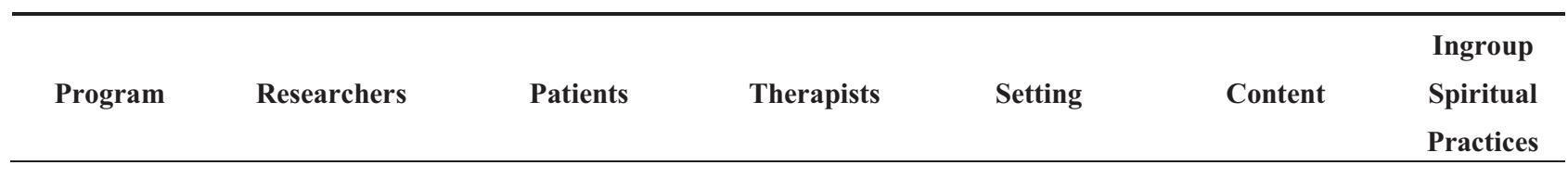




\begin{tabular}{|c|c|c|c|c|c|c|}
\hline $\begin{array}{c}\text { Spiritual } \\
\text { Beliefs and } \\
\text { Values } \\
\text { Group }\end{array}$ & $\begin{array}{c}\text { Kehoe (1999, } \\
\text { 2007) }\end{array}$ & $\begin{array}{l}\text { Out patients with } \\
\text { severe mental } \\
\text { disorders }\end{array}$ & $\begin{array}{l}\text { A nun and a } \\
\text { mental health } \\
\text { professionnal }\end{array}$ & $\begin{array}{l}\text { Weekly open } \\
\text { ongoing group }\end{array}$ & $\begin{array}{c}\text { Discussion on } \\
\text { beliefs and values }\end{array}$ & None \\
\hline $\begin{array}{l}\text { Spirituality } \\
\text { Group }\end{array}$ & $\begin{array}{c}\text { Wong- } \\
\text { McDonald (2007) }\end{array}$ & $\begin{array}{l}\text { Out patients with } \\
\text { severe mental } \\
\text { disorders }\end{array}$ & $\begin{array}{l}\text { Two mental } \\
\text { health } \\
\text { professionals }\end{array}$ & $\begin{array}{l}\text { Weekly open } \\
\text { ongoing group }\end{array}$ & $\begin{array}{l}\text { Discussion on } \\
\text { spirituality and } \\
\text { recovery }\end{array}$ & None \\
\hline $\begin{array}{l}\text { Spirituality } \\
\text { Matters } \\
\text { Group }\end{array}$ & $\begin{array}{c}\text { Revheim and } \\
\text { Grenberg }(2007 \text {, } \\
\text { 2010) }\end{array}$ & $\begin{array}{l}\text { Inpatients with } \\
\text { schizophrenia }\end{array}$ & $\begin{array}{l}\text { A chaplain, a } \\
\text { psychologist } \\
\text { and a mental } \\
\text { health prof. }\end{array}$ & $\begin{array}{l}\text { Weekly open } \\
\text { ongoing group }\end{array}$ & $\begin{array}{l}\text { Structured group } \\
\text { focus on recovery }\end{array}$ & $\begin{array}{c}\text { Prayer and } \\
\text { spiritual } \\
\text { stories }\end{array}$ \\
\hline $\begin{array}{c}\text { The } \\
\text { Spirituality } \\
\text { Group } \\
\text { Meetings }\end{array}$ & $\begin{array}{c}\text { Galanter, } \\
\text { Dermatis, et al. } \\
\text { (2011) }\end{array}$ & $\begin{array}{c}\text { In and out } \\
\text { patients with } \\
\text { severe mental } \\
\text { disorders }\end{array}$ & $\begin{array}{l}\text { A psychiatrist } \\
\text { and a mental } \\
\text { health prof. }\end{array}$ & $\begin{array}{l}\text { Weekly open } \\
\text { ongoing group }\end{array}$ & $\begin{array}{l}\text { Semi-structured } \\
\text { focus on coping } \\
\text { with the illness }\end{array}$ & None \\
\hline $\begin{array}{c}\text { Spiritual } \\
\text { Issues } \\
\text { Psychoeducat } \\
\text { ional Group }\end{array}$ & $\begin{array}{l}\text { Phillips, } \\
\text { Lakin et al. } \\
\text { (2002) }\end{array}$ & $\begin{array}{l}\text { Out patients with } \\
\text { severe mental } \\
\text { disorders }\end{array}$ & $\begin{array}{l}\text { Two clinical } \\
\text { psychologists }\end{array}$ & 7-sessions & $\begin{array}{c}\text { psycho- } \\
\text { educational group }\end{array}$ & Prayer \\
\hline $\begin{array}{c}\text { Spiritual } \\
\text { Coping } \\
\text { Module }\end{array}$ & $\begin{array}{l}\text { Weisman de } \\
\text { Mamani, } \\
\text { Tuchman, } \\
\text { Duarte (2010) }\end{array}$ & $\begin{array}{l}\text { Relatives of } \\
\text { people with } \\
\text { schizophrenia }\end{array}$ & $\begin{array}{c}\text { Two cognitive- } \\
\text { behavior } \\
\text { therapists }\end{array}$ & 3-sessions & $\begin{array}{c}\text { psycho- } \\
\text { educational group }\end{array}$ & None \\
\hline
\end{tabular}

In a psychosocial rehabilitation program of a community mental health center, patients choose each week to participate in the "Spirituality Group" or in a skill-training group [37]. Lead by two mental health professionals, this open group is aimed at enhancing the recovery process, defined as personal goal attainment. Each session focuses on one topic of interest determined periodically with participants. Spiritual interventions include discussing spiritual concepts, encouraging forgiveness, referring to spiritual writings, listening to spiritual music, encouraging spiritual and emotional support among the Spiritual Group members. The general purpose of the interventions were to: help participants to understand their problems from a spiritual perspective; gain a greater sense of hope; emotionally forgive and heal from past pain; accept responsibility for their own actions; experience and affirm their sense of identity and self-worth; encourage to connect with their faith communities for social and spiritual support. About half of the patients participate regularly in the group, essentially Christians. All of the 20 participants reached their personal goals, in comparison to $57 \%$ of a group $(n=16)$ who did not participate. Indeed, when persons in recovery begin to conceptualize various aspects of life within a spiritual context, they often find a new orientation to the world and a new motivation and direction for living.

In a state-hospital inpatient unit, the "Spirituality Matters Group" is proposed for patients with schizophrenia $[22,38]$. This weekly group is open and lead by three professionals representing psychology, pastoral care and rehabilitation. The group lasts for several years, self-referred patients are from various religious backgrounds (Christianity, Islam, Judaism, other religions or without religion) and commit to attendance throughout their whole hospital stay (from 3 to 7 months). The group is recovery-focused on the use of spiritual beliefs for coping with one's illness and 
hospitalization, exploring nondenominational religious and spiritual themes designed to facilitate comfort and hope, while addressing prominent therapeutic concerns. The format of the group is highly structured in order to accommodate for cognitive deficits and limited social skills prevalent in persons with persistent psychiatric disabilities. Each session begins with members' presentation, reminder of objectives (using spiritual beliefs to cope with daily stressors and for support with behavioral changes) and the multi-religious and nondenominational nature of the group with a definition of spirituality (personal beliefs and values related to the meaning and purpose of life, which may include faith in a higher purpose or power). To foster respect and communication, a ritual of reading the covenant written by group members is instituted. Then, one leader, on a rotating basis, introduces a specific theme (e.g., loneliness, hope, forgiveness, patience), group members are encouraged to share how the topic has relevance to their own perception of illness, previous behavior patterns and treatments failures and future goals. When a situation cannot be changed, emotion-focused coping is attempted. One leader is familiar with the individual treatment plans, to insure integration with other clinical programming for goal attainment. The discussion is followed by pre-planned group activity relating to the topic (e.g., reading Psalms, spiritual stories from a variety of faith perspectives, narratives of spiritual struggle, reading and writing prayers). The group ends by a summary and a prayer for peace. The duration of the experience of leading this group and the satisfaction of patients suggest its therapeutic value. A cross-sectional comparison of 20 self-attendees to the spiritual group versus 20 non-attendees shows that attendees are more hopeful and report more positive religious and spiritual coping with their symptoms and disabilities [22].

The seven-session semi-structured "Spiritual Issues Psychoeducational Group" is designed for outpatients with severe mental illness, treated in a community health center [23]. The goals are to provide new information about spirituality to participants; to allow them to share experience and knowledge to present spiritual topics such as spiritual strivings, spiritual struggles and hope. Ten patients with severe mental disorders (schizophrenia, depression and personality disorders) participated and were satisfied. Before that, patients were interviewed to determine the fitness of the indication, and to accept the rules of respecting others' spiritual beliefs, not proselytizing, and not engaging in spiritual activities. All were religious Christians of various denominations, members of a religious community. The group was led by two clinical psychologists. Every session was organized in a psychoeducational format in which information on specific topics were presented, followed by a discussion on the issue. The themes of the session were (1) interactions between spirituality and mental illness; (2) personal and community spiritual resources; (3) the exploration of ways to create and achieve meaningful and realistic goals related to their spiritual journey; (4) the expression of spiritual struggles with God and with Church, and active coping by a visualization of a Spiritual Being taking away their struggle; (5) forgiveness; (6) the exploration of spiritual strategies to keep hope alive (e.g., hymns, reading the Bible, trusting that God has a greater purpose, supporting each other) and suggestion of the serenity prayer; (7) review of the topics and feed-back.

For the relatives of the patients with schizophrenia, a three-session Spiritual Coping module has been added to a psycho-education program [39]. It is aimed at helping the family members of any religious backgrounds to tap into their spiritual or existential beliefs in functional ways. The group 
is led by cognitive behavior therapists. Handouts are used to facilitate the discussion. First, families explore their beliefs or disbeliefs about God, their community religious supports, their notions of morality, and meaning or purpose in life. Then the concepts of forgiveness, empathy, appreciation and peace are discussed. Lastly, family members are encouraged to engage in spiritual practices that are considered as meaningful and therapeutic for them.

Those experiences appear to be promising according to clinicians [23,36,39], as well as outcome measurements [22,37], and need to be implemented on a larger scale. Therefore, training of future psychiatrists and mental health professionals on $\mathrm{S} / \mathrm{R}$ is necessary. In a teaching hospital, education about spirituality includes the animation of "The Spirituality Group Meetings", beginning with a teacher of the Spirituality Center Faculty, and subsequently with another mental health staff member [40]. The spiritual group is implemented in psychiatric units, as well as ambulatory centers for addiction, with 117 self-referred patients with severe mental disorders (65\% psychosis, 21\% affective disorders and/or 35\%.substance use disorders). The open group is semi-structured aiming to encourage patients to discuss their own experience of spirituality and how it relates to their coping with illness. This is done by addressing one spiritual topic (importance of spirituality in daily life, $\mathrm{S} / \mathrm{R}$ coping, $\mathrm{S} / \mathrm{R}$ community, the role of spirituality in recovery, forgiveness, gratitude, and altruism) by brief information, followed by open questions and a reflecting period.

Some therapies integrate practices rooted in religious traditions, without integration of the spirituality of those traditions. For example, dialectical behavior therapy (DBT) combines acceptance and change through the principle of dialectical progress, with the use of standard cognitive-behavioral techniques for emotion regulation and reality-testing, as well as mindfulness and meditative exercises derived from Buddhism to treat borderline personality disorders. Those practices do not involve any religious concepts. They aimed to foster the capacity to pay attention, non-judgmentally, to the present moment; about living in the moment, experiencing one's emotions and senses fully, yet with perspective. DBT involved both individual and group therapy. The individual component focused on harmful behaviors to self or others, therapy-interfering behaviors and improvement of overall quality of life. In a group context, participants learn to use mindfulness skills, interpersonal effectiveness skills, emotion regulation skills, and distress tolerance skills. DBT has been experimentally demonstrated to be generally effective in treating borderline personality disorders [41,42]. DBT appears to be effective also for post-traumatic stress disorder [43] and substance abuse [44]. The Buddhist meditation practice of mindfulness is also used as a therapeutic tool to cognitive-behavior therapies for psychotic disorders. It is even one of the six key components of the Acceptance and Commitment Therapy [45]. In order to alleviate the distress of positive psychotic symptoms, mindfulness was offered as an alternative response to complement existing coping strategies in a six-session group format [46]. The Buddhist practice of loving-kindness meditation is used in the same way to cope with the negative symptoms of schizophrenia [25]. Those authors developed a six-session group therapy with a secularized version of the lovingkindness meditation practice to cultivate and focus attention on kindness toward self and others. The group is led by a psychotherapist with extensive meditation experience. An outcome evaluation of 16 outpatients showed an increase of positive emotions, self-acceptance, satisfaction with life and decrease of anhedonia. No information was available about the religious affiliations. 
This kind of use of religious practices is not considered as spiritual by their authors. However, it may be a challenge to use it with orthodox religious theist patients and need cultural sensitivity [47].

\section{The Pilot "Spirituality and Recovery Group" in a Public Ambulatory Psychiatric Unit in Geneva, Switzerland}

The integration of $\mathrm{S} / \mathrm{R}$ in psychiatric care needs to be sensitive to the cultural context. The public psychiatric outpatients' facilities offer long-term treatment, primarily for patients with a diagnosis of schizophrenia, bipolar disorder, severe depressive disorder, or personality disorder. The multidisciplinary teams are composed of a first-line psychiatrist, who can be assisted by nurses, social workers, and psychologists, if necessary. Patients receive psychotherapy, somatic treatments, and rehabilitation as needed. Several psychotherapeutic groups are offered for patients with a specific focus on delusions, hallucinations, social skills, self-affirmation, and self-esteem. A chaplain service is offered for inpatients. Chaplains are not employed by the psychiatric service, but by their churches. They cannot therefore be involved as co-leader in spiritual groups, like some US spiritual groups [22,24]. Geneva, Switzerland, is an international and multicultural city, in our secular psychiatric service, $60 \%$ of outpatients with schizophrenia are Christians [48]. In such a context, there is no place for spiritual and accommodative group therapies linked with a religious tradition for religious patients. Some US interfaith spiritual groups introduce spiritual practices in their setting [22,23]. Based on recovery principles, we prefer to work on establishing bridges with chaplains and religious communities, rather than to annex spiritual practices. Indeed, on one hand each religious tradition has its unique specificity [29] and, on the other hand, people with severe mental disorders suffer too often from social isolation.

Given the clinical significance of $\mathrm{S} / \mathrm{R}$ for patients with schizophrenia (i.e., the salience of positive and negative spiritual/religious coping and its associations with psychopathology, psychosocial functioning, substance use, suicidal attempts, adherence to psychiatric treatment [20,49-51]; the reciprocal influences of the illness and the spiritual journey [52,53]; and the role of spirituality in recovery [20,35], we planned a pilot spiritual group for those patients.

The goals of this eight-session semi-structured group are to (1) foster leaning on spirituality to cope with the illness and to recover; (2) address potential deleterious aspects of spirituality; and (3) support social integration of patients in their religious communities. This inter-faith group has specific rules of respecting other people's spiritual beliefs, not proselytizing, not engaging in spiritual activities. These rules aimed to create a respectful climate of sharing between the participants.

Patients were referred by their psychiatrist for an assessment to determine whether their needs and expectations were an indication for the group. All participants considered spirituality of great importance. They were from various religious traditions (Christians of diverse denominations, Muslims, Jews), yet seldom involved in a religious community. Their main objectives were predominantly to (1) decrease feelings of loneliness through sharing spirituality with others; and (2) clarify the confusing overlap between psychotic symptoms and spirituality. The group was led by two clinical psychologists who shared briefly their own religion and spirituality at the first session dedicated to personal spiritual history. The minimal therapists' disclosure was chosen according to our experience in conducting spiritual assessment of people with schizophrenia. Indeed, half of these patients asked the interviewer about his/her spirituality and religion, a brief 
answer fostered trust. Some leaders of spiritual groups took the same stance $[22,23,36]$, while others gave no information. In each session, a topic was presented, followed by a discussion on the issue. The themes of the session were (1) the variety of spiritual beliefs and religious practices; (2) how spirituality and religion may help to alleviate or increase symptoms of the illness; (3) how to disentangle spiritual experience from psychotic experience; (4) how to conciliate spiritual meaning of the illness and psychiatric care; (5) other people's influence in spiritual journey and relationships with religious community members and religious professionals; (6) the interrelations between spiritual history and mental illness; (7) spirituality and recovery; (8) review of the topics and feed-back.

We conducted this spiritual group three times. All of the participants regularly attended the group except for one patient who dropped out after the first session because he was too suspicious to share this topic in a group format. The procedure of indication for the group, as well as agreement to group rules may explain this assiduity. Another factor was the intense nature of the group discussion with deep exchanges among all participants which included existential issues about the meaning of life and death, suffering, self-identity and relationships with God and other spiritual figures, as well as theological questioning. Each participant was acknowledged and sustained in his/her coping resources and knowledge. The group program consisted of seven sessions. In the first session, each member defined the meaning of $\mathrm{S} / \mathrm{R}$ and conveyed the subject of representations of God or other spiritual figures as well as the relationship of the individual with those figures. This theme was then included in the two next spiritual groups. In the second session, topics as spiritual and religious coping were discussed and members exchanged views about changing coping strategies according to their symptoms levels. In their period of deepest suffering, they may feel abandoned by God, feel persecuted by demons, be in a great confusion, unable to discern psychotic from spirituality experience, or find in God or another spiritual figure the unique lasting comforting relationship. In the third session, the aim was to disentangle psychotic experience from spirituality. Interestingly, exchanges alleviated the intense loneliness felt by patients. Indeed, patients avoided talking about this topic with their psychiatrist, fearing increase of medication or imposed hospitalization, as well as with religious professionals, fearing stigma and rejection. Such thematic elicit deep emotions of fear, anger, guilt and shame. The fourth session aimed to explore spiritual meaning of the illness, the thematic of good and evil, sin and guilt. The discussion led to contemplate benevolent spiritual reappraisal. The fifth session was dedicated to the influence of other people on their spiritual journey. Some participants had experienced rejection and stigmatization by mental health professionals and/or religious professionals. However, those exclusions may also be due to lack of communication skills. It is noteworthy that some patients acknowledged the key role of religious professionals in helping them deal with suffering. The sixth session was planned to be dedicated to changes in religion/spirituality over life, particularly in the context of one's psychiatric disorder which is a thematic already discussed in the earlier sessions. We expanded a tool designed to measure suffering by a pictorial representation of the self and the illness [54] in including S/R. Patients had to place the illness and S/R with regards to their self on a blank sheet representing their whole life. Representations were discussed in the group, increasing awareness of the interactions between the self, $\mathrm{S} / \mathrm{R}$ and the illness. Then, in order to promote the recovery process, patients had to imagine where illness and $S / R$ would be if they recovered. This introduced the seventh session dedicated to spirituality and recovery. The concept of psychological 
recovery and the key process (hope, sense of self, meaning of life, responsibility, and personal objectives) are discussed. We invited a patient for whom spirituality and religious involvement played a central role in his life and who recovered despite persistent delusions and hallucinations. His testimony instilled hope for the participants. During the seven sessions, theological questions emerged; hence we invited a theologian and psychologist to respond to these queries. This approach valued patients' questioning and fostered their curiosity to search how those issues are considered in their own religions. The group ended by an overview of the fulfillment of patients' goals and a feed-back about the group experience. Even though their goals were attained, patients wished the group to go on in order to elaborate addressed topics, as well as to discuss new ones, for example, sexuality and spirituality, theodicy, forgiveness. They appreciated the practical exercise of pictorial representation and they wished to have more written materials to sustain discussions. The group was well accepted by participants; they valued the freedom of expression, trust and confidentiality. Furthermore, they expressed a wish to have such a group during the turbulent episodes of hospitalizations. They especially appreciated guest interventions. The Spiritual and Recovery group was not at all aimed to replace the absence of involvement in a religious community, but rather to sustain mobilization toward the participants' religious communities. It was a time of reflection, development and exchange of the members' spiritual journeys. The personal appraisals of the group led some patients to adopt specific intervention according to their needs, i.e., self-affirmation training group, reference to chaplain, cognitive group therapy for delusions, cognitive group therapy for hallucinations, individual psychotherapy, etc.

\section{Discussion}

This review on integration of $\mathrm{S} / \mathrm{R}$ into psychiatric care of people with severe mental disorders, especially psychosis, shows promising results. However it also underlines obstacles and limitations that need to be addressed.

None of these spiritual groups appeared to induce worsening of psychotic symptoms, even with patients presenting delusions and hallucinations with religious contents, as commonly feared by mental health professionals. This fear is often an obstacle to the integration of $\mathrm{S} / \mathrm{R}$ in psychiatric services. To overcome the reluctance of mental health professionals, training, including the experience of co-animation of spiritual groups, proves its efficiency [24,40]. The well-known under investment in $\mathrm{S} / \mathrm{R}$ by mental health professionals is not an obstacle for this training, while non-religious therapists perform as well as religious therapists [28], and they usually bring strong values of compassion and openness into care, interested in training on spiritual assessment [11,21]. In that context, training and research on clinical outcomes of spiritual groups are crucially needed. Such research has to show its efficacy (i.e., the treatment works in more than one psychiatric service), its specificity (i.e., the treatment works better than an alternative treatment for a particular disorder), its ability to produce clinically significant changes maintained over time, and its matching to patients characteristics [28]. No empirical research on the spiritual groups reviewed for severe mental illnesses met these criteria. All participants were voluntary in attending spiritual groups. Randomization would seem rather unethical for such researches, but it may be replaced by a waiting list protocol. 
Most of the spiritual groups are open; participants can attend for several months or even up to several years $[22,24,37,40]$. Our eight-session spiritual group experience, points out the need for an ongoing group for patients with severe mental illness. Indeed, such a brief intervention initiates exchanges that patients wish to pursue, stimulates unexpected new topics to address; and only slightly touches the process of recovery. In order to improve the spiritual group, giving time to patients to explore and elaborate on spirituality and recovery is needed, as it deals with the whole person's identity, not only coping with symptoms. People recovered from severe mental illness underline that recovery involves the whole-person and place spirituality as the core of identity. Such a process needs time, effort, and the experience of loving relationships [55].

An ongoing spiritual group also leaves the opportunity to adapt the major spiritual approaches used to other mental disorders, similar to how long lasting experiences in spirituality and substance misuse was disseminated to severe mental disorders [40]. For example, in our spiritual group, some patients bring distressful representations of God (e.g., an over-demanding God, a punishing God, a terrifying, an abandoning God). A 14-session Spirituality Group, lead by a clinical psychologist and a chaplain, focused on this thematic in a psychiatric hospital unit for patients with borderline personality disorder. This group provides an opportunity to explore and discuss each other's representation of God, thus potentially facilitating modifications toward a more integrated and benevolent image [56]. About half of the people with severe mental illness experience childhood trauma [57]. Some spiritual groups target the specificity of abuse and trauma-related disorders, for example the inter-faith eight-session spiritually integrated intervention for female survivors of sexual abuse [58], and the interfaith eight-session spirituality group for veterans [59]. Trauma survivors have to deal with the evil acts, as a witness, a victim and/or a perpetrator. Evil may be seen as belonging to the nature of human beings, to the Divine, or as a singular entity (a demon, the Devil, Satan, etc.) [60]. Spiritually integrated interventions could help trauma survivors to more effectively use their spiritual practices and beliefs to make new meaning of the traumatic experience and thus foster recovery. Manualized spiritually integrated psychotherapies with specific targets (i.e., severe medical illness, divorce, social anxiety, transgressions by others, etc.) [61] may be precious sources of inspiration to address the various problems encountered by people with severe mental illness.

Another adaptation lies in providing material that takes into account cognitive limitations often encountered in severe mental disorders.

\section{Conclusions}

Integrating spirituality into the care of people with severe mental disorders has to consider the cultural context of the psychiatric service, the characteristics of $S / R$ of each patient as well as pathological specificities. Spiritual group therapies do not increase psychopathology and seem to address patients' spiritual needs and foster recovery. However, wider implementations and clinical research are needed.

\section{Acknowledgments}


The author gratefully acknowledges $\mathrm{Ph}$. Huguelet for his medical support in creating the Spirituality and Recovery Group, as well as his valuable advice and comments in revising this manuscript.

\section{References}

1. Koenig, H.G. Handbook of Religion and Mental Health; Academic Press: San Diego, CA, USA, 1998.

2. Fallot, R.D. Spirituality and religion in recovery: some current issues. Psychiatr. Rehabil. J. 2007, 30, 261-270.

3. Sowers, W. Transforming systems of care: The American Association of Community Psychiatrists Guidelines for Recovery Oriented Services. Community Ment. Health J. 2005, 41, 757-774.

4. Salloum, I.M.; Mezzich, J.E. Outlining the bases of person-centred integrative diagnosis. J. Eval. Clin. Pract. 2011, 17, 354-356.

5. Weiss, M.G.; Somma, D. Explanatory models in psychiatry. In Textbook of Cultural Psychiatry; Bhugra, D., Bhui, K., Eds.; Cambridge University Press: Cambridge, UK, 2010; pp. 127-140.

6. Loewenthal, K.M. Spirituality and Cultural Psychiatry. In Textbook of Cultural Psychiatry; Bhugra, D., Bhui, K., Eds.; Cambridge University Press: Cambridge, UK, 2010; pp. 59-71.

7. Mohr, S.; Borras, L.; Betrisey, C.; Brandt, P.-Y.; Gillieron, C.; Huguelet, P. Delusions with religious content in patients with psychosis: how they interact with spiritual coping. Psychiatry 2010, 73, 158-172.

8. Menezes, A., Jr.; Moreira-Almeida, A. Religion, spirituality, and psychosis. Curr. Psychiatr. Rep. 2010, 12, 174-179.

9. Koenig, H.G. Concerns about measuring "spirituality" in research. J. Nerv. Ment. Dis. 2008, 196, 349-355.

10. Worthington, E.L., Jr.; Hook, J.N.; Davis, D.E.; McDaniel, M.A. Religion and spirituality. J. Clin. Psychol. 2011, 67, 204-214.

11. Borras, L.; Mohr, S.; Gillieron, C.; Brandt, P.Y.; Rieben, I.; Leclerc, C.; Huguelet, P. Religion and spirituality: How clinicians in quebec and geneva cope with the issue when faced with patients suffering from chronic psychosis. Community Ment. Health J. 2009, 46, 77-86.

12. Sims, A. Spiritual aspects of management. In Textbook of Cultural Psychiatry; Bhugra, D., Bhui, K., Eds.; Cambridge University Press: Cambridge, UK, 2010; pp. 434-444.

13. Wallace, C.J.; Lecomte, T.; Wilde, J.; Liberman, R.P. CASIG: A consumer-centered assessment for planning individualized treatment and evaluating program outcomes. Schizophr. Res. 2001, 50, 105-119.

14. Lecomte, T.; Wallace, C.J.; Perreault, M.; Caron, J. Consumers' goals in psychiatric rehabilitation and their concordance with existing services. Psychiatr. Serv. 2005, 56, 209-211.

15. Hill, P.; Hood, R. Measures of Religiosity; Religious Education Press: Birmingam, AL, USA, 1999. 
16. Hill, P.C.; Pargament, K.I. Advances in the conceptualization and measurement of religion and spirituality. Implications for physical and mental health research. Am. Psychol. 2003, 58, 64-74.

17. Institute Fetzer. Multidimensional Measurement of Religiousness/Spirituality for Use in Health Research; US Department of Health and Human Services: Kalamazoo, MI, USA, 1999.

18. Koenig, H.; Parkerson, G.R., Jr.; Meador, K.G. Religion index for psychiatric research. Am. J. Psychiatr. 1997, 154, 885-886.

19. Pargament, K.I.; Koenig, H.G.; Perez, L.M. The many methods of religious coping: Development and initial validation of the RCOPE. J. Clin. Psychol. 2000, 56, 519-543.

20. Mohr, S.; Brandt, P.-Y.; Borras, L.; Gillieron, C.; Huguelet, P. Toward an integration of religiousness and spirituality into the psychosocial dimension of schizophrenia. Am. J. Psychiatr. 2006, 163, 1952-1959.

21. Huguelet, P.; Mohr, S.; Betrisey, C.; Borras, L.; Gillieron, C.; Marie, A.M.; Rieben, I.; Perroud, N.; Brandt, P.Y. A randomized trial of spiritual assessment of outpatients with schizophrenia: Patients' and clinicians' experience. Psychiatry 2010, 62, 79-86.

22. Revheim, N.; Greenberg, W.M.; Citrome, L. Spirituality, Schizophrenia, and State Hospitals: Program Description and Characteristics of Self-Selected Attendees of a Spirituality Therapeutic Group. Psychiatr. Q. 2010, 81, 285-292.

23. Phillips, R.E., 3rd; Lakin, R.; Pargament, K.I. Development and implementation of a spiritual issues psychoeducational group for those with serious mental illness. Community Ment. Health J. 2002, 38, 487-495.

24. Kehoe, N.C. A therapy group on spiritual issues for patients with chronic mental illness. Psychiatr. Serv. 1999, 50, 1081-1083.

25. Johnson, D.P.; Penn, D.L.; Fredrickson, B.L.; Kring, A.M.; Meyer, P.S.; Catalino, L.I.; Brantley, M. A pilot study of loving-kindness meditation for the negative symptoms of schizophrenia. Schizophr. Res. 2011, 129, 137-140.

26. Margolin, A.; Schuman-Olivier, Z.; Beitel, M.; Arnold, R.M.; Fulwiler, C.E.; Avants, S.K. A preliminary study of spiritual self-schema $(3-\mathrm{S}(+))$ therapy for reducing impulsivity in HIV-positive drug users. J. Clin. Psychol. 2007, 63, 979-999.

27. Richards, P.S.; Smith, M.H.; Berrett, M.E.; O'Grady, K.A.; Bartz, J.D. A theistic spiritual treatment for women with eating disorders. J. Clin. Psychol. 2009, 65, 172-184.

28. Hook, J.N.; Worthington, E.L., Jr.; Davis, D.E.; Jennings, D.J., 2nd; Gartner, A.L. Empirically supported religious and spiritual therapies. J. Clin. Psychol. 2010, 66, 1-27.

29. Shuman, J.J. Theological perspectives on the care of patients with psychiatric disorders. In Religion and Spirituality in Psychiatry; Huguelet, P.; Koenig, H., Eds.; Cambridge University Press: New York, NY, USA, 2009; pp. 19-30.

30. Wahass, S.; Kent, G. Coping with auditory hallucinations: A cross-cultural comparison between western (British) and non-western (Saudi Arabian) patients. J. Nerv. Ment. Dis. 1997, 185, 664-668.

31. D'Souza R.F.; Rodrigo A. Spiritually augmented cognitive behavioural therapy. Australas. Psychiatr. 2004, 12, 148-152. 
32. Knapp, C. Psychiatric treatments involving religion: Psychiatric care uning Buddhist principles. In Religion and Spirituality in Psychiatry; Huguelet, P.; Koenig, H., Eds.; Cambridge University Press: NewYork, NY, USA, 2009; pp. 317-331.

33. Hefti, R. Integrating spiritual issues into therapy. In Religion and Spirituality in Psychiatry; Huguelet, P., Koenig, H., Eds.; Cambridge University Press: New York, NY, USA, 2009; pp. 244-267.

34. Cook, C.C.H. Substance misuse. In Spirituality and Psychiatry; Cook, C., Powell, A., Sims, A., Eds.; The Royal College of Psychiatrists: London, UK, 2009; pp. 139-168.

35. Mohr, S.; Huguelet, P. The relationship between schizophrenia and religion and its implications for care. Swiss Med. Wkly. 2004, 134, 369-376.

36. Kehoe, N. Spirituality groups in serious mental illness. South Med. J. 2007, 100, 647-648.

37. Wong-McDonald, A. Spirituality and psychosocial rehabilitation: empowering persons with serious psychiatric disabilities at an inner-city community program. Psychiatr. Rehabil. J. 2007, 30, 295-300.

38. Revheim, N.; Greenberg, W.M. Spirituality matters: Creating a time and place for hope. Psychiatr. Rehabil. J. 2007, 30, 307-310.

39. Weisman de Mamani, A.G.; Tuchman, N.; Duarte, E.A. Incorporating Religion/Spirituality into treatment for serious mental illness. Cogn. Behav. Pract. 2010, 17, 348-357.

40. Galanter, M.; Dermatis, H.; Talbot, N.; McMahon, C.; Alexander, M.J. Introducing Spirituality into Psychiatric Care. J. Relig. Health 2011, 50, 81-91.

41. Lynch, T.R.; Trost, W.T.; Salsman, N.; Linehan, M.M. Dialectical behavior therapy for borderline personality disorder. Annu. Rev. Clin. Psychol. 2007, 3, 181-205.

42. Linehan, M.M.; Comtois, K.A.; Murray, A.M.; Brown, M.Z.; Gallop, R.J.; Heard, H.L.; Korslund, K.E.; Tutek, D.A.; Reynolds, S.K.; Lindenboim, N. Two-year randomized controlled trial and follow-up of dialectical behavior therapy vs therapy by experts for suicidal behaviors and borderline personality disorder. Arch. Gen. Psychiatr. 2006, 63, 757-766.

43. Wagner, A.W.; Rizvi, S.L.; Harned, M.S. Applications of dialectical behavior therapy to the treatment of complex trauma-related problems: When one case formulation does not fit all. J. Trauma. Stress 2007, 20, 391-400.

44. Dimeff, L.A.; Linehan, M.M. Dialectical behavior therapy for substance abusers. Addict. Sci. Clin. Pract. 2008, 4, 39-47.

45. Tai, S.; Turkington, D. The evolution of cognitive behavior therapy for schizophrenia: Current practice and recent developments. Schizophr. Bull. 2009, 35, 865-873.

46. Chadwick, P.; Hughes, S.; Russell, D.; Russell, I.; Dagnan, D. Mindfulness groups for distressing voices and paranoia: A replication and randomized feasibility trial. Behav. Cogn. Psychother. 2009, 37, 403-412.

47. Hathaway, W.; Tan, E. Religiously oriented mindfulness-based cognitive therapy. J. Clin. Psychol. 2009, 65, 158-71.

48. Huguelet, P.; Mohr, S.; Borras, L.; Gillieron, C.; Brandt, P.Y. Spirituality and religious practices among outpatients with schizophrenia and their clinicians. Psychiatr. Serv. 2006, 57, 366-372. 
49. Borras, L.; Mohr, S.; Brandt, P.Y.; Gillieron, C.; Eytan, A.; Huguelet, P. Religious beliefs in schizophrenia: Their relevance for adherence to treatment. Schizophr. Bull. 2007, 33, 1238-1246.

50. Huguelet, P.; Borras, L.; Gillieron, C.; Brandt, P.Y.; Mohr, S. Influence of spirituality and religiousness on substance misuse in patients with schizophrenia or schizo-affective disorder. Subst. Use Misuse 2009, 44, 502-513.

51. Huguelet, P.; Mohr, S.; Jung, V.; Gillieron, C.; Brandt, P.Y.; Borras, L. Effect of religion on suicide attempts in outpatients with schizophrenia or schizo-affective disorders compared with inpatients with non-psychotic disorders. Eur. Psychiatr. 2007, 22, 188-94.

52. Mohr, S.; Borras, L.; Rieben, I.; Betrisey, C.; Gillieron, C.; Brandt, P. Y.; Perroud, N.; Huguelet, P. Evolution of spirituality and religiousness in chronic schizophrenia or schizo-affective disorders: a 3-years follow-up study. Soc. Psychiatr. Psychiatr. Epidemiol. 2010, 45, 1095-103.

53. Huguelet, P.; Mohr, S.; Gillieron, C.; Brandt, P.Y.; Borras, L. Religious explanatory models in patients with psychosis: A three-year follow-up study. Psychopathology 2010, 43, 230-39.

54. Buchi, S.; Sensky, T. PRISM: Pictorial Representation of Illness and Self Measure. A brief nonverbal measure of illness impact and therapeutic aid in psychosomatic medicine. Psychosomatics 1999, 40, 314-20.

55. Fallot, R.D. Spiritual and religious dimensions of mental illness recovery narratives. New Dir. Ment. Health Serv. 1998, 80, 35-44.

56. Goodman, G.; Manierre, A. Representations of God uncovered in a spirituality group of borderline inpatients. Int. J. Group Psychother. 2008, 58, 1-15.

57. Alvarez, M.J.; Roura, P.; Oses, A.; Foguet, Q.; Sola, J.; Arrufat, F.X. Prevalence and clinical impact of childhood trauma in patients with severe mental disorders. J. Nerv. Ment. Dis. 2011, 199, 156-61.

58. Murray-Swank, N.A.; Pargament, K.I. God, where are you?: Evaluating a spirituallyintegrated intervention for sexual abuse. Ment. Health. Relig. Cult. 2005, 8, 191-203.

59. Harris, J.I.; Erbes, C.R.; Engdahl, B.E.; Thuras, P.; Murray-Swank, N.; Grace, D.; Ogden, H; Olson, R.H.; Winskowski, A.M.; Bacon, R.; Malec, C.; Campion, K.; Le, T. The effectiveness of a trauma focused spiritually integrated intervention for veterans exposed to trauma. J. Clin. Psychol. 2011, 67, 425-38.

60. LaPierre, L.L. A theory about the nature of Evil. J. Pastoral Care Counsel. 2008, 62, 99-111.

61. Pargament, K.I. Steps toward a More Spiritually Integrated Psychotherapy. In Spiritually Integrated Psychotherapy; The Guilford Press: New York, NY, USA, 2007; pp. 319-46. 


\title{
Spiritual and Religious Issues in Psychotherapy with Schizophrenia: Cultural Implications and Implementation
}

\section{Lauren Mizock, Uma Chandrika Millner and Zlatka Russinova}

\begin{abstract}
The topics of spirituality and psychotherapy have often been controversial in the literature on schizophrenia treatment. However, current research indicates many potential benefits of integrating issues of religion and spirituality into psychotherapy for individuals with schizophrenia. In this paper, implications are presented for incorporating spiritual and religious issues in psychotherapy for individuals with schizophrenia. A background on the integration of spirituality into the practice of psychotherapy is discussed. The literature on spiritually-oriented psychotherapy for schizophrenia is provided. Clinical implications are offered with specific attention to issues of religious delusions and cultural considerations. Lastly, steps for implementing spiritually-oriented psychotherapy for individuals with schizophrenia are delineated to assist providers in carrying out spiritually sensitive care.
\end{abstract}

Reprinted from Religions. Cite as: Mizock, L.; Millner, U. C.; Russinova, Z. Spiritual and Religious Issues in Psychotherapy with Schizophrenia: Cultural Implications and Implementation. Religions 2012, 3, 82-98.

\section{Introduction}

The topics of spirituality and psychotherapy have often been controversial in the literature on schizophrenia treatment [1,2]. Some practitioners have argued that religion had no space in the psychotherapy setting given a need to be grounded in science. However, current research indicates many potential benefits of integrating issues of religion and spirituality into psychotherapy for individuals with schizophrenia with regards to promoting motivation, wellbeing, resilience, and cultural aspects of one's identity [3,4]. In this paper, implications are presented for incorporating spiritual and religious issues in psychotherapy for individuals with schizophrenia. To achieve this goal, a background on the integration of spirituality into the practice of psychotherapy is discussed. Next, the literature on spiritually-oriented psychotherapy for schizophrenia is provided. Clinical implications are offered with specific attention to issues of religious delusions and cultural considerations. Lastly, steps for implementing spiritually-oriented psychotherapy for individuals with schizophrenia are delineated to assist providers in carrying out spiritually sensitive care.

\section{Spirituality and Psychotherapy}

Inclusion of spirituality and religion in psychotherapy practice has been a relatively recent development [5]. Professional and scientific psychology during the twentieth century intentionally excluded issues of religion or spirituality from psychotherapy [6]. In the psychotherapy literature prior to the 1990s, issues of religion and spirituality would, most frequently, be indexed in relation 
to particular kinds of psychopathology such as religious delusions in schizophrenia [7]. Moreover, the positive association between religious and spiritual issues and mental health was rarely mentioned.

Prominent scholars, such as Sigmund Freud, John Watson, and Albert Ellis expressed minimal interest in the study or practice of religion (see Plante, [6]; e.g., Ellis, [8]; Freud, [9]; Watson, [10]). In fact, Freud [9] referred to religion as an "obsessional neurosis" (p. 43) and even systematically rejected the contention by C. G. Jung [11], that the capacity for religious feeling and imagery was as basic as sexuality. Despite further interest of major theorists, such as William James, Alfred Adler, and Gordon Allport, in the connection between spirituality and psychology, the field continued to distance itself from this topic (see Plante, [6] for review; e.g., Allport, [12]; James, $[13,14])$. These scholars purported that psychotherapy practice should be grounded in scientific theory and research. In addition, the constructs of spirituality and religion were not easily measurable and did not lend themselves adequately to such scientific rigor [6].

However, the past two decades have witnessed a sea of change in the scientific interest in religion and spirituality. Between the years 2000 and 2006, 8,193 articles addressing religion and spirituality from a variety of theoretical and empirical perspectives were published compared to 3803 such articles published over the course of sixty years from 1900 to 1959 [15]. Yet, little consensus has been reached about how to define religion and spirituality and how to distinguish one concept from the other [16-18]. While one prominent set of researchers conceive of religion as the broader term, inclusive of spirituality [18-20], another group of scholars view spirituality as the broader of the two concepts, inclusive of religion [21,22]. Moreover, a third group of authors view religion and spirituality as separate but overlapping constructs [23]. In this paper, we adhere to the broader understanding that religion tends to be associated predominantly with institutional representation of the divine while spirituality tends to be identified primarily with individual experience of the transcendent [17].

Within the broader health perspective on religion and spirituality [23], there have been growing efforts to incorporate spiritual perspectives in the context of psychotherapy [24-26]. The burgeoning interest in the health and mental health benefits associated with spirituality and religion may be attributed to several factors.

First, religion and spirituality have recently been established as important motivating forces in people's lives [27]. The majority of the population in the world considers themselves as being significantly influenced by spirituality or religion [28]. In fact, the majority of the general public in the United States identify as spiritual, if not religious. The 2008 American Religious Identification Survey [29] found that almost $80 \%$ of the population in the United States professed to a particular religious affiliation. This finding was further substantiated by a recent Gallup poll [30] where 80\% of U. S. residents reported that religion was at least fairly important in their lives while $54 \%$ of the same described religion as being very important.

Second, a body of recent research has noted some positive impact of spirituality on wellbeing. Across a broad array of cultural settings and populations, religion and spirituality have often been found to be contributing factors to life satisfaction, sense of personal efficacy, successful coping, and self-esteem [31-35]. Religion and spirituality have been identified as important factors in mental health, including in the recovery from serious mental illnesses [36-38]. 
Third, advances in positive psychology $[39,40]$ as grounded in humanistic and existential thinking shifted the focus from pathology to healthy communities. Positive psychology is focused on increasing the potential for life enjoyment and the promotion of resiliency in the face of problems or stressors experienced by a person [41]. In essence, the lens of positive psychology moves away from mental illness being viewed as harmful and stigmatizing to tracking the positive aspects of mental illness. Interventions are targeted towards health promotion rather than the treatment and cure of pathological conditions. From the perspective of enhancement of wellbeing, positive psychology recognizes that spirituality, among other positive psychological characteristics, may grow out of experiences of having a mental illness [42]. The field of positive psychology also encourages the scientific study of religious and spiritual development as a contributory factor to positive development in adulthood. For example, spirituality and religiousness are associated with higher-order cognitive functions, which involve meaning-making processes, moral judgment, and complex problem-solving skills [31].

Fourth, the emergence of the field of multicultural counseling, contextualized in rapidly shifting cultural trends, re-integrated religion and spirituality as central concepts in psychotherapy practice [43]. The multicultural movement focused on awareness and sensitivity to cultural diversity, an important aspect of which is religious and spiritual practice [44]. The movement brought to light that people vary widely on spiritual and religious dimensions in a pluralistic society. This body of research further illuminated that religious populations preferred spiritually integrated care over conventional psychological services [45]. Simultaneously, the shifting cultural milieu in the United States in the 1960s and 1970s and large-scale shifts in immigration brought about increased awareness of diversity along with exposure to Eastern religion and philosophy. More recently, technological advances in the past two decades have contributed to increased globalization and fostered proliferation in the information exchange especially with regard to culture-specific values and contextual factors that contribute to mental health and well-being.

These factors not only explain recent scientific interest in understanding the positive impact of spirituality and religion on wellbeing, but also underline the value of addressing issues of spirituality in psychotherapy with some of the most challenging mental health conditions. In this paper, we attempt to address the implications of incorporating spiritual and religious issues specifically in the psychotherapy treatments of individuals with schizophrenia.

\section{Spiritually-Oriented Psychotherapy for Schizophrenia}

\subsection{Schizophrenia and Psychotherapy}

Multiple meta-analyses have demonstrated that a significant number of therapy approaches and interventions for the symptoms of schizophrenia have been effective $[1,3]$. However, the practice of psychotherapy for individuals with schizophrenia has still been controversial in the literature due to questions of the effectiveness of psychotherapy for schizophrenia, especially in acute cases [1,2]. In addition, the recovery and rehabilitation model of care for individuals with serious mental illnesses has often overlooked the resource of individual psychotherapy [4]. This omission may be due to the peer support focus of the recovery movement given the history of injustices committed by professional providers [46]. 
There are a number of benefits of psychotherapy for schizophrenia. For one, psychotherapy can provide a space for people with schizophrenia to explore their goals to increase life satisfaction while living with mental illnesses [4]. Some of these goals include lessening the impact of the illness on self-esteem and sense of self, enhancing adaptive coping strategies, and supporting preventative efforts to alter the course of the illness [3]. In addition, psychotherapy can facilitate the construction of a fuller, richer personal narrative of recovery from the illness that is free from stigma [47]. Psychotherapy can also include the technique of metacognition, i.e., reflecting on one's thinking, to encourage a flexible, dynamic thought process in the face of psychosis [4].

These positive outcomes have been acknowledged across several therapeutic orientations, including psychodynamic, supportive, and cognitive behavioral therapy (CBT) [48]. Specifically, psychodynamic therapy has demonstrated benefits in focusing on interpersonal relationships, self-knowledge and exploration, as well as a focus on resolving conflicts [49]. Supportive therapy has also been found to be efficacious when working with individuals with schizophrenia in providing reassurance, reflective listening, offering suggestions, and focusing on present symptoms [3]. Cognitive behavioral approaches have offered benefits in social skills training and coping strategy development [3]. Lastly, a branch of cognitive behavioral therapy, Acceptance and Commitment Therapy, uses techniques of mindfulness and meditation to take a non-judgmental attitude towards psychotic thoughts of not acting on the thoughts or believing them to be true [50].

More recently, there have been attempts to develop therapy approaches that specifically address spiritual issues. Spiritually augmented CBT (SACBT) was developed at the University of Sydney and is a 10-16 session approach used with individuals with mental illnesses to draw from the cognitive component of CBT to address the individual's belief system and enhance thoughts and feelings related to acceptance, hope, achieving meaning and purpose, as well as forgiveness [51]. The behavioral component of SACBT utilizes exercises in prayer, rituals meditation, and relaxation. Spirituality groups for individuals with mental illness in inpatient and outpatient treatment centers have been also gaining popularity [52,53]. For example, Kehoe [52] reported from her eighteen years of experience that spirituality-based group therapy provided an important venue for people with serious mental illness to explore issues related to religion and spirituality. Effectively guided by an open-minded and nonjudgmental therapist, the group fostered tolerance, acceptance of alternative viewpoints, and careful examination of belief systems. Kehoe noted that the group also provided necessary opportunities to apply spirituality and values to important life questions.

\subsection{The Role of Spirituality in Psychotherapy for Schizophrenia}

Spirituality has often been identified as a crucial resource for coping with schizophrenia [38,54]. In particular, the recovery and rehabilitation movement has highlighted the integral role of spirituality for the holistic and overall functioning of individuals affected by the most disabling mental illnesses $[55,56]$. The recovery model is an approach to mental illness that focuses on the process of living a satisfying life of wellbeing and autonomy, as opposed to the traditional treatment focus on symptom elimination [57]. Recovery from serious mental illness has been presented as a spiritual process in itself and a journey of facing spiritual questions about relationships to God, reasons for the illness, and finding a place in the world [55]. 
According to several studies, a range of $30 \%-90 \%$ of people have reported spirituality and religion to be one of the most important parts of recovery from mental illnesses [37]. Many people with schizophrenia report an increase of faith after a psychotic episode and the use of religious coping and seeking spiritual guidance to deal with the symptoms of the illness [38,54,55]. Many individuals have reported a benefit from knowing they can still have authentic connections to God despite a diagnosis of schizophrenia [55]. Deegan [47] put forth the controversial notion that for many people in recovery from schizophrenia, psychotic thoughts may even help to access spirituality.

Religion and spirituality are uniquely personal processes that deserve novel attention to the individual story of each person with schizophrenia [58]. People with schizophrenia may even define their experiences of religion and spirituality differently from one another [17]. In addition, some research suggests that religiousness in individuals with schizophrenia is representative of the rest of the population, although religious coping may be different [55]. For example, they may be less participatory in community spiritual events, most likely due to fear of ostracization [58].

There is a clear importance of integrating spirituality into recovery-oriented treatment models of care for people with schizophrenia [56]. However, it is still underrepresented in the recovery literature and often neglected in clinical care $[38,56]$. Many people with schizophrenia do not disclose their religious or spiritual beliefs to their providers partially out of fear of being labeled religiously delusional and hospitalized involuntarily [59]. These findings suggest the potential benefit of spiritual supports in recovery-oriented therapy to facilitate the spiritual education, counseling, and practices of people with spiritual interests who have schizophrenia [56]. Based on findings from these studies, it is evident that sensitivity to spiritual and religious issues in psychotherapy may hold many benefits to the individual in recovery from schizophrenia.

\subsection{Outcomes of Spiritually-Oriented Psychotherapy with Schizophrenia}

Benefits. Incorporating clients' spirituality into psychotherapy can enhance treatment outcomes for individuals in general and holds applications for individuals with schizophrenia [7,60]. Spirituality contributes significantly to coping mechanisms and meaning-making systems when dealing with pain and suffering [61]. Clients frequently hold a variety of spiritual beliefs and coping resources that range from private personal practices (such as prayer or meditation) to involvement in supportive religious communities. Religious and spiritual practices, such as acceptance and forgiveness, prayer, meditation, and worship, are areas of coping which, developed in the context of psychotherapy, can enhance the ways in which people deal with adversity, and people with schizophrenia in particular.

A number of positive outcomes have been identified specifically for individuals with schizophrenia surrounding their religious and spiritual beliefs, yielding implications for therapy [37,62-64]. Fallot [37] indicated that positive outcomes are generally associated with positive religious coping - the affirmative religious beliefs and practices for coping with schizophrenia. Conversely, negative outcomes are generally related to negative religious coping - disparaging religious beliefs and intrusive practices for coping with schizophrenia. Positive religious coping has demonstrated improvement in mood and self-esteem. However, in cases of negative coping or religious strain, negative religious beliefs about the illness worsened self-esteem and anger at God for causing the 
illness. Therapists conducting spiritually oriented therapy with people with schizophrenia can bring an awareness of how positive or negative religious coping may be impacting the individual.

Several studies have delineated the benefits of positive religious coping for individuals with schizophrenia. In one study, individuals with schizophrenia who use positive religious coping had fewer hospitalizations and less symptom severity [65]. Other individuals with mental illnesses have reported higher levels of wellbeing and fewer symptoms [66]. Spiritual and religious practices were associated with lesser likelihood of smoking, potentially due to exposure to church doctrines and sense of fulfillment offered by spiritual practices with reinforcement for good behavior without substance use [67]. Religious involvement was negatively correlated with substance misuse, and may prevent development of alcoholism via religious doctrine, while offering a protective role for some [63]. In addition, reports of positive religious resources and commitments have been associated with lower rates of suicidality $[58,64]$. Faith may be helpful to a sense of self, sometimes arising during delusions by increasing a sense of relaxation, optimism, resilience, social supports, hope, positive identity, increased sense of insight, and medication adherence [54]. These outcomes suggest the potential benefits of integrating spiritual and religious content into therapy with people with schizophrenia.

Risks. For others, spiritual and religious beliefs and practices may be less helpful when they lead to negative religious coping. In several studies of individuals with schizophrenia, a small portion reported religious beliefs and values to contribute to medication non-adherence, increased suicide attempts, and increased substance abuse $[58,62,63]$. While generally in the minority, there are a number of individuals with schizophrenia who may engage in negative coping associated with religious beliefs, values, and practices. Therefore, it is essential that psychotherapists maintain an awareness of the potentially harmful outcomes for religiosity among individuals with schizophrenia.

Fallot [37] described the potential risks of integrating issues of religion and spirituality into therapy for individuals with schizophrenia. Fallot indicated that some spiritual leaders warn therapists of the segmented approach of mental health providers in addressing issues of religion and spirituality. These leaders have voiced concern that therapists frame religious practices in terms of mental health benefits as opposed to focusing on a connection to and alignment with a spiritual journey that may have positive byproducts.

Weighing risks and benefits. Fallot [38] provides a helpful guide to dealing with these potential risks and benefits for individuals with schizophrenia in therapy interventions. For one, there may be benefits associated with inclusion with some religious communities being inclusive and welcome of individuals with schizophrenia, leading to a sense of acceptance and support. However, other religious and spiritual communities may be rejecting of individuals with schizophrenia or have expectations to express a heterosexual identity, discourage psychiatric medication and traditional medical supports, or make financial contributions to the religious organization. Secondly, individuals with schizophrenia may feel empowered as someone who is valued by the divine within their religious involvement. Or, they may feel devalued within a religion if they are seen as someone who is being punished with schizophrenia for past sins. Third, religion may offer coping strategies for expression and relief including prayer, meditation, and other behavioral rituals that may add structure or self-expression to the day. In contrast, the expected religious rituals may contribute to a sense of rigidity and compulsivity that is overly constrictive. Fourth, religion may 
offer a sense of autonomy through liberation from a strict reliance on traditional psychiatric care. In contrast, some religious beliefs may place too much emphasis on external control without internal responsibility or capability in altering one's life circumstances. Lastly, religion may offer hope or despair as it can boost energy and calmness, hope, enthusiasm, joy, motivation, through meditative practices of prayer and connection. In contrast, it may also lead to increased feelings of despair by emphasizing sin, guilt, or encountering hopeless obstacles to reaching salvation. Practitioners can carefully consider the risks and benefits associated with religious involvement for individuals with schizophrenia as these issues arise in therapy [38].

\section{Clinical Implications of Spiritually-Oriented Psychotherapy for Schizophrenia}

\subsection{Religious Delusions and Schizophrenia}

Conducting psychotherapy with individuals with schizophrenia may necessitate awareness of the role of religious delusions in psychosis. The literature in mental illness and religiosity has often focused on the association of demonic, satanic delusions with violent behaviors [64]. While important to address, over-focusing on this topic often reinforces negative stereotypes of religious beliefs for individuals with schizophrenia. In addition, these types of delusions occur in a minority of individuals with schizophrenia who have religious beliefs, and are generally not acted on [54].

However, the topic of religious delusions is an important one. In fact, poorer treatment outcomes have been reported for individuals who report religious based delusions, potentially due to associated stigma [38]. A religious delusion is an unusual, fixed belief or preoccupation of a religious nature outside the cultural norm that impairs functioning [54]. Religious delusions may include supernatural, apocalyptical, or persecutory beliefs, in addition to beliefs of a special connection to, or identity as a God or another religious figure [54,64]. Therapists should differentiate mystical, spiritual, or transcendental experience from a delusion to avoid pathologizing spiritual experiences that are culturally congruent [64]. Therapists can differentiate between a transcendental spiritual experience from a psychotic delusion in that the former is typically followed by a return to reality, and is often considered acceptable within the individual's religion [64]. Psychotherapists are encouraged to avoid confronting religious delusions [54]. Instead, therapists can support the individual to recover from the acute distress of the delusion and draw from positive religious resources [38].

Rudalevicienel and colleagues [68] have indicated that religious based delusions may take on a cultural pattern within different groups. In their study of apocalyptic delusions, they found these types of delusions to be cross-cultural regardless of religious background. Religious delusions were particularly frequent in Catholic individuals with schizophrenia. In another study by the same authors, the sociocultural factors of gender, marital status, and education level revealed differences in religious based delusions [69]. In this study, it was found that men were more likely to describe themselves as Gods while women identified as Saints [69]. In this study, married individuals had fewer apocalyptic delusions, and lower levels of education were more predictive of religious based delusions [69]. It is important for clinicians to be mindful of sociocultural factors in presentation [69] and be able to adapt interventions around issues of religion and spirituality in a culturally sensitive manner [70]. 
Religious differences may also occur in the context of religious delusions among individuals with schizophrenia. Another study indicated that highly religious Christian participants were more likely to hold the belief that demons were responsible for mental illness [64]. However, for individuals without religious identification or faith, apocalyptic and religious-based delusions were less frequent. Persecutory or grandiose delusions are believed to be more common in Christian and Western faiths, although one does not have to be religious to develop a religious delusion [64]. In addition, terrorist activities within an individual's country of residence or origin may also influence religious delusions, with an increase being evidenced following the attacks on the World Trade Center towers of September 11, 2011 in NYC [71]. This phenomenon further reinforces the need for therapists to understand the unique sociocultural factors that impact beliefs of individuals with schizophrenia.

\subsection{Cultural Considerations for Spiritually-Oriented Psychotherapy with Schizophrenia}

Variations in spiritual and religious practices occur across ethnic and racial groups for individuals with schizophrenia. In fact, adapting mental health interventions to include the religious and spiritual practices and beliefs of a particular cultural group is considered a culturally competent approach to therapy $[38,70]$. Some general considerations for issues that may arise when conducting spiritually-oriented psychotherapy with schizophrenia will be presented here for several ethnic groups. These considerations are not meant to be a comprehensive list of all cultural groups or religious practices, but some general cultural considerations for several groups. In addition, a focus on groups predominant to North America is chosen here due to the scope of the paper. Moreover, given the large degree of variation within each ethnic group, it is important to understand that each member of these groups may not always fit these guidelines. However, it can be helpful for a culturally sensitive therapist to be mindful of the potential cultural differences among individuals with schizophrenia regarding religious and spiritual practices. It is also important to note that many of the following cultural traditions in spiritual and religious practices may be modified by the process of immigration and acculturation.

Religious practices of African descent. While individuals of African descent are a heterogeneous group with very diverse spiritual and religious practices, there are many shared cultural values among African Americans in particular due to the history of oppression. These common spiritual values include seeking liberation from injustice, and African perspectives of seeing spirituality within all parts of life [72]. Some spiritual and religious practices among African Americans in particular may include the use of prayer, the Bible, church attendance, religious singing, and the church community as coping strategies for dealing with mental health problems in schizophrenia [70]. The church has been not only a site of religious observance but also a place of education, sanctuary for escaping slavery, economic resources, and political activism, which allows the church to be a valuable resource with multiple community purposes [72]. In addition, therapists can consider the involvement of a spiritual healer or religious leader, which is often used in the treatment of schizophrenia in many African and Caribbean traditions $[72,73]$.

Asian religious practices. While the Asian continent is comprised of a diverse array of religions and religious practices, some of the most commonly practiced religions are outlined in this section. Hannah and Green [74] presented guidelines for clinicians working with Asian clients of diverse 
Hindu, Buddhist, and Islamic backgrounds that have implications for psychotherapy with individuals with schizophrenia. Hinduism and Buddhism involve meditation practices that can be incorporated into therapy to reduce anxiety and distress that often accompanies psychotic symptoms. For example, the Svetasvatara Upanishad meditation in Hindu practices or the walking meditation and mindfulness exercises in Buddhist meditation may be integrated into therapy to reduce the anxiety, impulsivity, and distress often associated with psychotic symptoms. These authors suggested that in the case of Islamic religions, spiritual values of benevolence, personal development, and forgiveness can promote positive religious coping in therapy for individuals with schizophrenia. In addition, Islamic mysticism, namely, Sufism, provides more detailed psychological perspectives on mental health which foster growth through the use of dance, music, meditation, and prayer, and may also hold utility in mental health treatment for individuals with schizophrenia (see Pryor, [75]).

Latin American religious practices. Cervantes [76] suggested guidelines for culturally sensitive clinicians to integrate issues of religion and spirituality into work with individuals of Latin American descent. These guidelines provide useful considerations for therapists working with Latino individuals with schizophrenia. Given the wide range of diversity in Spanish speaking groups, there may be significant variation in religious and spiritual practices. Cervantes recounted the history of indigenous Latin American groups whose religious and spiritual practices were eradicated by colonizers and replaced with European traditions that mixed indigenous practices with Christian and Catholic religions. Therefore, many Latino clients may observe Christianity, Catholicism, indigenous religions, or some combination. The indigenous contribution to religious practices of Latino individuals may be presented in worship of deities and shrines, devotional offerings, prayer, and pilgrimages. Mestizo spirituality among Mexican groups in particular may reflect religious values in diversity and connectedness to the social and physical environment. Cervantes emphasized that integration of Latino spirituality and religious practices is essential for effective psychotherapy. For therapists working with individuals with schizophrenia of Latin American descent, sensitivity to these religious and spiritual practices and beliefs can enhance a culturally congruent source of support.

Native American religious practices. Similarly, there is a large degree of diversity across tribal groups within Native American cultures [77]. Many Native American groups do not segment spirituality from the rest of daily life, but rather provide a spiritual infusion throughout daily life and culture. Some tribal groups initially viewed psychotic-like states as having a spiritual value to the culture. However, the influence of Western values has led many Native American groups to come to see mental illness as more stigmatizing [78]. In addition, European colonization also brought Christianity to many Native American groups [77]. Sensitivity to the different spiritual philosophy and potential Western influences on religion are important considerations for the therapist working with an individual with schizophrenia of Native American descent.

Culturally sensitive psychotherapy with individuals with schizophrenia may mean aligning oneself with the individual's religious or spiritual identity to work towards a desired goal, behavior, attitude, or emotional state $[38,70]$. Clinicians should also exercise caution and care about religious countertransference [70], including awareness of bias towards the client's religion due to their own religious or spiritual practices, or perhaps skepticism towards religion and spirituality altogether. 
These cultural considerations for the religious backgrounds of different ethnic groups can guide therapists working with a diverse population of individuals with schizophrenia to be mindful of the unique history and traditions of the individual's religious culture of origin.

\section{Implementation of Spiritually-Oriented Psychotherapy for Schizophrenia}

The process of spiritually sensitive psychotherapy with individuals with schizophrenia can be conceptualized as involving several phases. These steps include training, inquiry, assessment, and implementation. Therapists may not follow a strictly linear and progressive process through these steps. These steps of the intervention process can be used as a flexible framework for integrating issues of spirituality into psychotherapy for individuals with schizophrenia.

Training. The training phase for the spiritually thoughtful therapist may involve personal development of the psychotherapist around religion and spirituality in therapy. This preparation can occur in didactic training, education, and self-exploration of spiritual and religious issues. Therapists can develop self-awareness and familiarity with the religious and cultural beliefs of the cultures of the individuals they serve [38]. Didactic training may include in-service and continued education workshops in spirituality and religious issues for therapy with people with schizophrenia [37]. Therapists can develop understanding of the risks/benefits and positive/negative coping that can occur around religious and spiritual issues in psychotherapy for people with schizophrenia. Self-exploration may involve developing awareness of one's own beliefs and comfort level towards religious issues in therapy [79]. In addition, therapists should assess whether they have the ability to respect the spiritual and religious beliefs of clients with schizophrenia and refrain from proselytizing one's own religious beliefs [64]. Familiarizing oneself with the policy and attitudes towards religion and spirituality within the institution in which one is working [79] is equally important in this phase.

Inquiry. As previously stated, a large portion of individuals with schizophrenia feel spirituality is vital to their lives, but only a minority raise the issue with their providers [79]. Clinicians can actively inquire about the role of spirituality in their lives at a given time, and identify how spirituality might facilitate or interfere with recovery [38]. Therapists can use empathic questioning and listening, exploring the motives and meanings of spirituality and religion for the client with schizophrenia and communicate a "respectful openness" [37]. Therapists can engage individuals in a collaborative process to ask about when and how individuals would like religion and spirituality to be included in their life [37]. Therapists can work with the individual to identify the spiritual and religious goals and activities that would be supportive of recovery, relevant resources, and the structure for addressing spiritual and religious goals in therapy sessions [37]. Therapists can also ask about prayer or meditation in more depth given that there are large variations in what this practice means to people, with ranges in the content of the prayer, who they are praying to, the frequency, and expectations of the outcome of the prayer [38].

Clinicians should take care to avoid pathologizing religious beliefs as psychosis, given that intense religious beliefs are not necessarily a sign of pathology [38,55]. It is important to avoid misdiagnosis during the assessment process due to religious and spiritual practices. In fact, understanding and expressing a mental health problem like schizophrenia in spiritual terms can be 
powerful way of reframing mental illness, and many people may even use a spiritual framework for understanding their illness [36].

Assessment. Clinicians may choose from preexisting models of assessment [37] to assist with this process. For example, therapists can use the HOPE questionnaire, which examines dimensions of hope $(\mathrm{H})$, organized religion $(\mathrm{O})$, personal spiritual practices $(\mathrm{P})$, and the effects on medical care (E) [80]. Clinicians can take a spiritual history, examining changes in faith and levels of commitment, core religious and spiritual beliefs, religious activities and rituals, level of connection to religious/spiritual communities, and the relation of spiritual life to goals of wellbeing [38].

Russinova and Cash [17] have also created a checklist of descriptors of the dimensions of and attitudes towards religion and spirituality among individuals with schizophrenia that might be used as a checklist for providers in the assessment process. These descriptors encompass two dimensions in the lay person's conceptual understanding religion and spirituality: (a) a core characteristics dimension which includes descriptors of the nature of each of these two concepts; and (b) a functional characteristics dimension which includes descriptors of the impact of religion and spirituality on a given person. Often, these descriptors contrast the understanding of religion and spirituality based on conceptual continuums. For example, prominent continuums that distinguish between the core characteristics of religion and spirituality are the ones juxtaposing the organized, communal, extrinsic, prescriptive and ritualistic nature of religion to the informal, personal, intrinsic, exploratory, and continuous nature of spirituality, respectively [17]. Understanding the personal meaning attributed to religion and spirituality and the person's perceived level of religiosity and spirituality is important not only from the point of view of enhancing the therapeutic alliance and identifying most appropriate spiritual resources but also because there is emerging evidence about an association between the person's spiritual and religious beliefs and their perceptions of power in the therapeutic relationship. Both clinical observations and research findings suggest that religious persons with serious mental illness tend to attribute more power to their providers and expect treatment options to be prescribed to them, while non-religious individuals tend to seek partnerships with mental health providers who are open to their input as well as to the exploration of new treatment possibilities [17].

Implementation. The implementation of spiritual and religious perspectives in psychotherapy involves formulation and understanding of the individual's spiritual goals and making connections to appropriate resources in therapy. Implementation of religious or spiritual goals in therapy could occur in the context of individual therapy, group modalities, peer and professionally-led interventions, or in a religious setting [38]. A spiritually sensitive therapist may present a framework of recovery as a spiritual journey, and integrate some spiritual or religious practices into the session, with consideration for modeling one's own spirituality if appropriate [55]. These spiritual or religious practices may be psychoeducational or have a more traditional religious focus [37]. Depending on the specific religious doctrine at hand, activities may include prayer, meditation, scripture or devotional readings, religious services at church, radio, or $\mathrm{TV}$, singing in religious group, talking to religious leader, peers, or providers [81]. Spiritual and religious resource access may require providing concrete support in accessing or linking with the appropriate religious referral, or including religious leaders as part of the implementation. A therapist may consider making referrals to religious organizations or groups, clergy, religious leaders, or other facilitators 
of religious processes, exercising caution to insure that the referral is likely to be helpful and not harmful $[36,37]$.

\section{Conclusions}

The topics of spirituality, psychotherapy, and schizophrenia have often been controversial in the literature. Researchers and psychotherapists have historically raised doubts as to the appropriateness of the use of spiritual and religious resources in psychotherapy, and have even questioned the practice of psychotherapy for schizophrenia altogether. However, a significant body of literature reflected in this article suggests that psychotherapy, and therapy with a spiritual and religious focus, can hold many benefits for people with schizophrenia. Practicing therapy with sensitivity to aspects of religious, spiritual, and cultural diversity among individuals with schizophrenia can further enhance this process. Different strategies relevant to the phases of psychotherapy treatment, such as training, assessing, planning, and implementing can be considered for integrating issues of spirituality and religion into therapy in a flexible but thorough manner. Inclusion of spiritual and religious issues in psychotherapy for individuals with schizophrenia offers valuable opportunities to provide spiritual support in the individual's journey of recovery.

\section{Acknowledgments}

This work was supported by a grant (\#H133P070001) funded by the National Institute on Disability and Rehabilitation Research. The views expressed in this article do not necessarily represent the views of NIDRR, but are the sole responsibility of the authors.

\section{References}

1. Gottdiener, W.H. Individual psychodynamic psychotherapy for schizophrenia. Psychoanal. Psychol. 2006, 23, 583-89.

2. Klerman, G.L.; Vaillant, G.E.; Spitzer, R.L.; Michels, R. A debate on DSM-III. Am. J. Psychiatry 1984, 141, 539-46.

3. Dickerson, F.B.; Lehman, A.F. Evidence-based psychotherapy for schizophrenia. J. Nerv. Ment. Dis. 2006, 194, 3-9.

4. Lysaker, P.H.; Glynn, S.M.; Wilkniss, S.M.; Silverstein, S.M. Psychotherapy and recovery from schizophrenia: A review of potential applications and need for future study. Psychol. Serv. 2010, 7, 75-91.

5. Post, B.C.; Wade, N.G. Religion and spirituality in psychotherapy: A practice-friendly review of research. J. Clin. Psychol. 2009, 65, 131-46.

6. Plante, T.G. Integrating spirituality and psychotherapy: Ethical issues and principles to consider. J. Clin. Psychol. 2007, 63, 891-902.

7. Gorsuch, R.L.; Miller, W.R. Assessing spirituality. In Integrating Spirituality into Treatment: Resources for Practitioners; Miller, W.R., Ed.; American Psychological Association: Washington, DC, USA, 1999; pp. 47-64.

8. Ellis, A. The Case Against Religion: A Psychotherapist's View; Institute for Rational Living: New York, NY, USA, 1971. 
9. Freud, S. The Future of an Illusion; Norton: New York, NY, USA, 1961; original work published 1927 by Doubleday.

10. Watson, J.B. Psychology from the Standpoint of a Behaviorist; Frances Pinter: Dover, NH, USA, 1983; original work published 1924.

11. Jung, C.G. Psychology and Religion; Yale University Press: New Haven, CT, USA, 1938.

12. Allport, G.W. The Individual and His Religion; MacMillian: New York, NY, USA, 1950.

13. James, W. Principles of Psychology; Holt: New York, NY, USA, 1890.

14. James, W. The Varieties of Religious Experience; Harvard University Press: Cambridge, MA, USA, 1902.

15. Bartoli, E. Religious and spiritual issues in psychotherapy practice: Training the trainer. Psychotherapy. Theor. Res. Pract. Train. 2007, 44, 54-65.

16. Hill, P.C.; Pargament, K.I. Advances in the conceptualization and measurement of religion and spirituality: Implications for physical and mental health research. Am. Psychol. 2003, 58, 64-74.

17. Russinova, Z.; Cash, D. Personal perspectives about the meaning of religion and spirituality among persons with serious mental illnesses. Psychiatr. Rehabil. J. 2007, 30, 271-84.

18. Zinnbauer, B.J.; Pargament, K.I.; Cole, B.; Rye, M.S.; Butter, E.M.; Belavich, T.G.; Hipp, K.M.; Scott, A.B.; Kadar, J.L. Religion and spirituality: Unfuzzying the fuzzy. J. Sci. Stud. Relig. 1997, 36, 549-64.

19. Hill, P.C.; Pargament, K.I.; Wood, R.W., Jr.; McCullough, M.E.; Swyers, J.P.; Larson, D.B.; Zinnbauer, B.J. Conceptualizing religion and spirituality: Points of commonality, points of departure. J. Theor. Soc. Behav. 2000, 30, 51-77.

20. Zinnbauer, B.J.; Pargament, K.I.; Scott, A.B. The emerging meanings of religiousness and spirituality: Problems and prospects. J. Pers. 1999, 67, 889-919.

21. Koenig, H.G.; McCullough, M.E.; Larson, D.B. Handbook of Religion and Health; Oxford University Press: New York, NY, USA, 2001.

22. Stifoss-Hanssen, H. Religion and spirituality: What a European ear hears. Int. J. Psychol. Relig. 1999, 9, 25-33.

23. Miller, W.R.; Thoresen, C.E. Spirituality, religion and health: An emerging resource field. Am. Psychol. 2003, 58, 24-35.

24. Miller, W.R. Integrating Spirituality into Treatment: Resources for Practitioners; Oxford University Press: New York, NY, USA, 1999.

25. Richards, P.S.; Bergin, A.E. A Spiritual Strategy for Counseling and Psychotherapy; American Psychological Association: Washington, DC, USA, 1997.

26. Sperry, L.; Shafranske, E.P. Spiritually Oriented Psychotherapy; American Psychological Association: Washington, DC, USA, 2005.

27. Pargament, K.I.; Park, C.L. Merely a defense? The variety of religious means and ends. J. Soc. Issues 1995, 51, 13-32.

28. Paloutzian, R.F. An Invitation to the Psychology of Religion; 2nd ed.; Allyn and Bacon: Needham Heights, MA, USA, 1996.

29. American Religious Identification Survey. Summary Report; Trinity College: Hartford, CT, USA, 2009. 
30. Gallup Poll Inc. Religion. Available online: http:/www.gallup.com/poll/1690/Religion.aspx (accessed on 28 June 2011).

31. Day, J.M. Religion, spirituality, and positive psychology in adulthood: A developmental view. J. Adult Dev. 2010, 17, 215-29.

32. Doehring, C.; Clarke, A.; Pargament, K.; Hayes, A.; Hammer, D.; Nickolas, M.; Hughes, P. Perceiving sacredness in life: Correlates and predictors. Arch. Psychol. Relig. 2009, 31, 55-74.

33. Geyer, A.; Baumeister, R. Religion, morality, and self-control: Values, virtues, and vices. In Handbook of the Psychology of Religion and Spirituality; Paloutzian, R., Park, C., Ed.; Guilford: New York, NY, USA, 2005; pp. 412-34.

34. Klaasen, D.; Graham, M.; Young, R. Spiritual/religious coping as intentional activity: An action theoretical perspective. Arch. Psychol. Relig. 2009, 31, 3-34.

35. Silberman, I. Religion as a meaning system: Implications for the new millennium. J. Soc. Issues 2005, 6, 641-63.

36. Blanch, A. Integrating religion and spirituality in mental health: The promise and the challenge. Psychiatr. Rehabil. J. 2007, 30, 251-60.

37. Fallot, R.D. Spirituality and religion in recovery: Some current issues. Psychiatr. Rehabil. J. 2007, 30, 261-70.

38. Fallot, R.D. Spirituality and religion. In Clinical Handbook of Schizophrenia; Mueser, K.T., Jeste, D.V., Eds.; Guilford Press: New York, NY, USA, 2008; pp. 592-603.

39. Seligman, M.E. Positive psychology: Fundamental assumptions. Psychologist 2003, 16, 126-43.

40. Seligman, M.E.P.; Steen, T.A.; Park, N.; Peterson, C. Positive psychology progress: Empiricial validation of interventions. Am. Psychol. 2005, 60, 410-21.

41. Galanter, M. Spirituality and recovery in 12-step programs: An empirical model. J. Subst. Abuse Treat. 2007, 33, 265-72.

42. Galvez, J.F.; Thommi, S.; Ghaemi, S.N. Positive aspects of mental illness: A review of bipolar disorder. J. Affect. Disord. 2011, 128, 185-90.

43. Worthington, E.L. Integration of spirituality and religion in psychotherapy. In History of Psychotherapy: Continuity and Change, 2nd ed.; Norcross, J.C., VandenBos, G.R., Freedheim, D.K., Eds.; American Psychological Association: Washington, DC, USA, 2011; pp. 533-43.

44. Hage, S.; Hopson, A.; Siegel, M.; Payton, G.; DeFanti, E. Multicultural training in spirituality: An interdisciplinary review. Counsel. Val. 2006, 50, 217-34.

45. Puchalski, C.M.; Larson, D.B.; Lu, F.G. Spirituality in psychiatry residency training programs. Int. Rev. Psychiatr. 2001, 13, 131-38.

46. Chamberlin, J. The ex-patient's movement: Where we've been and where we're going. J. Mind Behav. 1990, 11, 323-36.

47. Deegan, P. Spiritual lessons in recovery. Available online: http://www/patdeegan.com/blog /archives/000011.php (accessed on 30 June 2011).

48. Gottdiener, W.H.; Haslam, N. The benefits of individual psychotherapy for people diagnosed with schizophrenia: A meta-analytic review. Ethical Hum. Sci. Serv. 2002, 4, 1-25.

49. Spaulding, W.; Nolting, J. Psychotherapy for schizophrenia in the year 2030: Prognosis and prognostication. Schizophr. Bull. 2006, 32, S94-S105. 
50. Bach, P.; Hayes, S.C. The use of acceptance and commitment therapy to prevent the rehospitalization of psychotic patients: A randomized control trial. J. Consult. Clin. Psychol. 2002, 70, 1129-39.

51. D'Souza, R.F.; Rodrigo, A. Spiritually augmented cognitive behavioral therapy. Australas. Psychiatry 2004, 12, 148-52.

52. Kehoe, N.C. A therapy group on spiritual issues for patients with chronic mental illness. Psychiatr. Serv. 1999, 50, 1081-83.

53. Revheim, N.; Greenburg, W.M. Spirituality matters: Creating a time and place for hope. Psychiatr. Rehabil. J. 2007, 30, 307-10.

54. Miller, R.; McCormack, J. Faith and religious delusions in first episode schizophrenia. Soc. Work Ment. Health 2006, 4, 37-50.

55. Lukoff, D. Spirituality in the recovery from persistent mental disorders. South. Med. Assoc. 2007, 100, 642-46.

56. Russinova, Z.; Blanch, A. Supported spirituality: A new frontier in the recovery-oriented mental health system. Psychiatr. Rehabil. J. 2007, 30, 247-49.

57. Davidson, L.; Drake, R.E.; Schmutte, T.; Dinzeo, T.; Andres-Hyman, R. Oil and water or oil and vinegar? Evidence-based medicine meets recovery. Community Ment. Health J. 2009, 45, 323-32.

58. Mohr, S.; Brandt, P.; Borras, L.; Gillieron, C.; Huguelet, P. Toward an integration of spirituality and religiousness into the psychosocial dimension of schizophrenia. Am. J. Psychiatry 2006, $163,1952-59$.

59. Hueguelet, P.; Mohr, S.; Borras, L.; Gillieron, C.; Brandt, P. Spirituality and religious practices among outpatients with schizophrenia and their clinicians. Psychiatr. Serv. 2006, 57, 366-72.

60. Propst, L.R.; Ostrom, R.; Watkins, P.; Dean, T.; Mashburn, D. Comparative efficacy of religious and nonreligious cognitive-behavioral therapy for the treatment of clinical depression in religious individuals. J. Consult. Clin. Psychol. 1992, 60, 94-103.

61. Walsh, F. Integrating sprituality in family therapy: Wellsprings for health, healing, and resilience. In Spiritual Resources in Family Therapy, 2nd ed.; Walsh, F., Ed.; Guilford Publications, Inc.: New York, NY, USA, 2008; pp. 31-64.

62. Borras, L.; Mohr, S.; Brandt, P.; Gillieron, C.; Eytan, A.; Huguelet, P. Religious beliefs in schizophrenia: Their relevance for adherence to treatment. Schizophr. Bull. 2007, 33, $1238-46$.

63. Huguelet, P.; Borras, L.; Gillieron, C.; Brandt, P.; Mohr, S. Influence of spirituality and religiousness on substance misuse in patients with schizophrenia or schizo-affective disorder. Subst. Use Misuse 2009, 44, 502-13.

64. Mohr, S.; Huguelet, P. The relationship between schizophrenia and religion and its implications for care. Swiss Med. Wkly. 2004, 134, 369-76.

65. Tepper, L.; Rogers, S.A.; Coleman, E.M.; Malony, H.N. The prevalence of religious coping among persons with persistent mental illness. Psychiatr. Serv. 2001, 52, 660-65.

66. Corrigan, P.; McCorkle, B.; Schell, B.; Kidder, K. Religion and spirituality in the lives of people with serious mental illness. Community Ment. Health J. 2003, 39, 487-99. 
67. Borras, L.; Mohr, S.; Brandt, P.; Gillieron, C.; Eytan, A.; Huguelet, P. Influence of spirituality and religiousness on smoking among patients with schizophrenia or schizo-affective disorder in Switzerland. Int. J. Soc. Psychiatry 2008, 54, 539-49.

68. Rudaleviciene, P.; Stompe, T.; Narbekovas, A.; Bunevicius, R. Influence of culture on world end (apocalyptic) delusions. World Cult. Psychiatr. Res. Rev. 2008a, 3, 96-105.

69. Rudaleviciene, P.; Stompe, T.; Narbekovas, A.; Bunevicius, R. Are religious delusions related to religiosity in schizophrenia? Medicina (Mex.) 2008b, 44, 529-35.

70. Abernethy, A.D.; Houston, T.R.; Mimms, T.; Boyd-Franklin, N. Using prayer in psychotherapy: Applying Sue's differential to enhance culturally competent care. Cultur. Divers. Ethnic Minor. Psychol. 2006, 12, 101-14.

71. Reeves, R.R.; Beddingfield, J.J. Persistent paranoid delusions following the September 11 terrorist attacks in a man with no pre-existing mental illness. South. Med. J. 2006, 99, 303-5.

72. Frame, M.W.; Williams, C.B. Counseling African Americans: Integrating spirituality in therapy. Counsel. Val. 1996, 4, 116-28.

73. Anders, S.L. Improving community-based care for the treatment of schizophrenia: Lessons from native Sfrica. Psychiatr. Rehabil. J. 2003, 27, 51-58.

74. Hanna, F.J.; Green, A. Asian shades of spirituality: Toward an integrated approach to psychotherapy. Prof. Sch. Counsel. 2004, 7, 326-33.

75. Pryor, A. Psychology in Sufism; International Association of Sufism: San Rafael, CA, USA, 2000.

76. Cervantes, J.M. Mestizo spirituality: Toward an integrated approach to psychotherapy for Latinas/os. Psychother. Theor. Rese. Pract. Train. 2010, 47, 527-39.

77. LaFramboise, T.D.; Trimble, J.E.; Monatt, G.V. Counseling intervention and Smerican Indian tradition: An integrative approach. Counsel. Psychol. 1990, 18, 628-54.

78. Dakota-Lakota-Nakota Human Rights Advocacy Coalition. Available online: http://www.dlncoalition.org/home.htm (accessed on 30 June 2011).

79. Huguelet, P.; Mohr, S.; Borras, L.; Gillieron, C.; Brandt, P. Spirituality and religious practices among outpatients with schizophrenia and their clinicians. Psychiatr. Serv. 2006, 57, 366-72.

80. Anandarajah G; Hight, E. Spirituality and medical practice: The hope questions as a practical tool for spiritual assessment. Am. Fam. Phys. 2001, 63, 81-89.

81. Fallot, R.D.; Flournoy, M.B. Trauma among women with co-occurring disorders. Presented at the Conference on State Mental Health Agency Services Research, Program Evaluation, and Policy, Washington, DC, USA, 2000. 


\title{
Meditation Based Therapies-A Systematic Review and Some Critical Observations
}

\section{Lone Overby Fjorback and Harald Walach}

\begin{abstract}
This article systematically reviews the evidence for Mindfulness-Based Stress Reduction (MBSR) and Mindfulness-Based Cognitive Therapy (MBCT) and analyses the conditions around their rising popularity. MBSR, MBCT and Mindfulness Meditation were used as key words. The inclusion criteria were randomized controlled trials using the standard MBSR/MBCT program with a minimum of 33 participants. Twenty four studies were included. MBSR improved mental health in ten studies compared to waitlist control or treatment as usual. Moreover, MBSR was as efficacious as active control group in four studies, and showed a tendency over active control in one study. MBCT reduced the risk of depressive relapse in all five included studies. Evidence supports that MBSR improves mental health and MBCT prevents depressive relapse. It is interesting to observe that meditation based therapy programs are rapidly enjoying popularity. We discuss the cultural and theoretical implications.
\end{abstract}

Reprinted from Religions. Cite as: Fjorback, L.O.; Walach, H. Meditation Based Therapies-A Systematic Review and Some Critical Observations. Religions 2012, 3, 1-18.

\begin{abstract}
Abbreviations
MBSR: Mindfulness-Based Stress Reduction; MBCT: Mindfulness-Based Cognitive Therapy; RCT: randomized controlled trials; TAU: treatment as usual; TM: transcendental meditation; CBGT: Cognitive Behavioral Group Therapy.
\end{abstract}

\section{Introduction}

In recent years, literature on meditation based therapy programs has been rapidly growing. During the 1970s and 1980s, there was the first spike of interest with the transcendental meditation (TM) program being studied widely and showing promising effects compared to other relaxation or therapeutic techniques in anxiety [1], psychological health [2], and various other issues such as drug addiction and behavioral problems [3], blood pressure and cardiovascular risk factors [4,5] The TM program is a mantra-based concentration technique derived from the Vedic tradition and is heavily dependent on the whole TM-system with especially installed and approved teachers and a strong in-group with close relationships that have sometimes been likened to those of religious sects. Interest in this specific type of meditation program seems to have decreased following the death of its founder Maharishi Mahesh Yogi several years ago.

Meanwhile a new wave of interest in meditation based programs has swept across academic and medical culture. This time it is based on the concept of mindfulness. It was popularized by Jon 
Kabat-Zinn who, starting in the eighties, developed a secularized meditation program founded on the old Theravada-Buddhist practice of mindfulness meditation [6-8].

Mindfulness holds a special place within Buddhist teaching [9-11]. According to this teaching, the suffering humans experience in this world exists from the beginning. It happens due to our own shortcomings, mainly greed and other mental toxins or destructive emotions [12]. It can, however, and this is the good news, be overcome [13]. The path towards this liberation is known as the eightfold path. This can be separated into three main domains: some concern ethical conduct (right speech, right action, right livelihood), some refer to the culture of the mind (right intention, right concentration, right mindfulness), and from these, finally, grow wisdom and insight (vipassana) [12]. From this goal of the whole path, insight, vipassana, the whole meditation tradition takes its name, Vipassana-Meditation. This is the old Buddhist tradition that is reputed to go back to Gautama Buddha himself. It is mainly taught in South-East Asia in countries such as Sri Lanka, Myanmar, Thailand, Laos and Vietnam, while other countries have adopted different teachings or have developed their own traditions and see themselves as the "larger vessel-Mahayana". Within the older or Theravada Buddhist tradition, insight - into the non-substantiality of the ego and the fact that we create our suffering through clinging and greed-is the prime goal of all actions and meditation, since it means the end of all suffering. To reach it, ethical conduct is a prerequisite, and cultivation of the mind through good intention, practice of concentration and mindfulness is the prime method. Hence the importance placed on meditation as a spiritual practice $[12,13]$. In the Vipassana tradition, concentration types of meditation are practiced to strengthen the mind. This happens through mindfulness of breathing, where the diligent observation of the breath predominates, or mindfulness of the body, where attention is directed towards physical sensations in the body. Only after the mind has become used to steadying attention on objects are further techniques employed, such as observation and mindfulness of mental objects or mental activity. It is only after lengthy practice in Buddhist teaching often over many reincarnations, that wisdom and insight is reached, which finally leads to enlightenment and complete freedom. In this concept, concentration and mindfulness are interconnected: Concentration enables mindfulness, and the practice of mindfulness even outside meditation enhances concentrative power and thus makes mindfulness possible. Observe, further, that this whole edifice rests on ethical conduct as a prerequisite [13].

Out of this tradition, the new interest in meditation based techniques arose with Kabat-Zinn's training, which he called a "Mindfulness Based Stress Reduction" Program (MBSR). Kabat-Zinn was a long-term meditator and a student of Jack Kornfield, one of the first Vipassana teachers in the West [14]. His professed goal was to make this tradition available to Westerners without any religious context, to secularize it. From this, MBSR emerged as an eight week group program [15-18]. Participants have to be committed to practice meditation for at least half an hour a day, preferably 45-60 min, for at least the eight weeks of the program. Afterwards they may decide for themselves whether they want to continue or not. Once a week they meet for $2.5 \mathrm{~h}$ in groups of 12 to 20 , sometimes up to 40 people. They have the support of the group and their leader; they learn formal types of meditation such as sitting in mindful presence attending to the breath, or the body scan - a particular type of mindfulness of the body. They also learn mindful hatha yoga. They hear lectures about the connection between mind and body, how stress impacts physical systems and our 
immunity, and how mindfulness and meditation may combat these. This is in strict analogy to so called "Dharma Talks" in the Vipassana tradition or "Teishos" in the Zen tradition. These talks are intended to give a theoretical background, but even more importantly motivate the disciple to increase his efforts and keep on meditating. The lectures within MBSR programs are, of course, secular and also of a motivating nature, using obvious and well established knowledge about the importance of attention, the mind-body connection, and the psycho-neuro-immunological consequences of mental habits $[15,17,18]$.

Kabat-Zinn developed the program from his own rich meditation experience [19] and offered it first to patients of pain clinics and other outpatients who had no treatment success within the conventional system. These patients were desperate and presumably happy to commit themselves to anything that could potentially help. This may also explain the success of the early studies. German language teachers first started offering courses in the nineties, and our group was among the first to start evaluating these programs in Germany [20] and to develop a measurement instrument $[21,22]$. Interest grew rapidly, publications were produced in an exponential growth curve and a general enthusiasm seemed to grip the community. We did a first meta-analysis in 2004 and found quite good, medium sized effect sizes, both in controlled and in uncontrolled studies, for MBSR in clinical populations [23]. Meanwhile, the body of literature is growing; mindfulness is becoming a concept used by many people in many different contexts and presumably with meanings different from the original ones. The discussion whether "mindfulness" is perhaps simply a psychological function that can be used outside religion [24-26] has already been raised. This is at least implied by the current classic definition that defines mindfulness as moment-to-moment awareness in a non-judgmental stance [27].

Thus, mindfulness has received interest from clinicians and researchers, perhaps because it seems to improve acceptance of symptoms that are difficult or impossible to change, installs a cognitive meta-reflective capacity [28] that enhances the degree of freedom of patients, and can help patients change their focus by emphasizing experience of the present moment. Most therapeutic concepts see symptoms as defects that have to be changed, either pharmacologically or psychologically. Thus, pharmacological concepts try to counteract symptoms, and behavioral approaches try to change mental habits towards what is considered to be healthier. In contrast, mindfulness approaches teach one to simply observe, pass no judgment and accept things as they are. The paradoxical experience of patients seems to be that it is exactly this non-judgmental, even curious mental stance of observation that sometimes changes the symptoms, and sometimes just instills peace of mind in relation to them. The MBSR program starts by focusing on the body and reconnecting the mind to the body. In a second step the mind is itself the object of attention and awareness. This may finally lead to a stance of acceptance which also helps to experience compassion for oneself and for others. A state of connectedness and an experience of being, belonging and caring are strong pillars of this program.

Mindfulness-Based Cognitive Therapy (MBCT) [29] is an adaptation of the MBSR program. It incorporates elements of cognitive therapy facilitating a detached or decentered view of one's thoughts and is designed to prevent depressive relapse [30]. It is based on the clinical observation that decentering one's view and looking at one's own symptoms and mental activities with some detachment can help both alleviate symptoms and discover triggers for potential downward spirals 
of affect or mood. Long-term vulnerability to depression may be related to the presence of perceived discrepancies between the actual self and ideal self-guides, and MBCT might both protect against increases in self-discrepancy and facilitate a shift in the goals of self-regulation [31].

These maladaptive self-guides, rumination, avoidance and perfectionism are four characteristics that can be seen as different aspects of the same "mode of mind" and mindfulness training might allow people to recognize when this mode of mind is operating [32].

As a prevention program for those depressed patients who are at great risk of lifelong suffering from depressive relapses, MBCT is certainly an important potential addition to the therapeutic arsenal.

Due to the different approach to illness-acceptance rather than change-adopted by both MBSR and MBCT and due to the different potential mechanism-observing and non-reacting rather than acting and fighting-MBSR and MBCT pose a conceptual challenge to Western medical concepts.

It is therefore of special interest to see whether these treatments actually work, and if so, whether they work better than or similar to established treatments. We therefore decided to conduct a systematic review focusing only on randomized controlled studies, as only these offer a reasonable protection against bias. We have reported this systematic review in detail elsewhere [33]. Here we will summarize the main results with an update of new studies, and draw special attention to some conceptual, theoretical, practical and methodological consequences.

\section{Methods}

\subsection{Identification and Selection}

This review focuses on MBSR and MBCT because both treatments are well-defined and mindfulness training is their key element.

Studies were identified by systematic searches of Medline, PsychInfo and Embase from 1980 to October 2010, using "mindfulness-based stress reduction", "mindfulness-based cognitive therapy" and "mindfulness meditation" and appropriate abbreviations as keywords. Titles, abstracts and full-texts of the identified papers were screened for eligibility by one reviewer. All abstracts were read, and when an indication of mindfulness and RCT was found, the entire article was retrieved. The reference lists of selected papers were checked for additional eligible papers. We included only randomized controlled studies on adults, published in English, on either MBSR or MBCT interventions, either in their original form or in appropriate adaptations for certain patient populations.

\subsection{Analysis}

To examine the effects on physical and mental health, studies were grouped according to study population in non-clinical populations and clinical populations with physical illness or psychiatric disorders. The update of new studies is presented in a Table 1.

\section{Results}


Twenty four out of 72 studies fulfilled the criteria and were included. The main reasons for exclusion were too few participants and the intervention not being the standard MBSR or MBCT program.

\subsection{Non-clinical Populations}

Nyklicek et al. [34] compared the effects of MBSR to a wait-list control condition while examining potentially mediating effects of mindfulness. They found that well-being, quality of life, vital exhaustion and positive affect improved in the mindfulness but not in the wait-list control condition, whereas negative affect remained unchanged. Mindfulness might mediate this effect. Davidson et al. [35] found that a mindfulness training offered to employees changed not only their anxiety level, but also their immunological functioning measured by higher antititers to vaccines when compared to a wait-list control group. Moreover, the change of anxiety was correlated to stronger frontal left-asymmetry in their EEG, which was correlated to improved immunity. Davidson interpreted this as an improved plasticity in dealing with emotional stress, an interpretation which is, however, contested [36].

Daily hassles, psychological distress and medical symptoms improved in self-selected community residents compared to a control group receiving educational materials [37]. The MBSR training improved medical students' depression and anxiety, and improved their empathy and their spirituality scores compared with wait-list controls [38].

Thus, in the four studies on non-clinical populations MBSR was demonstrated to improve mental and physical health without exception. Effect sizes were medium to large. None of the studies, however, used a strong, active control.

\subsection{Clinical Populations with Physical Illness}

In a large study of 150 patients suffering from multiple sclerosis, Grossman and colleagues [39] showed moderate to strong effects in all measures, especially in quality of life, when compared to treatment as usual (TAU).

Foley et al. [40] adapted the MBCT manual to the situation of cancer survivors in a wait-list trial and showed, in a mixed group of cancer patients, of which more than $50 \%$ were in late stages 3 and 4, significant improvements in depression and anxiety, as well as in distress and quality of life. Mindfulness improved, and effects sizes were medium to large.

Mularski et al. [41] were unable to see any improvement in a group of patients with chronic obstructive pulmonary disease who were taught mindful breathing, or an active control. A high drop-out rate of $40 \%$ suggests that the program was either not suited to the patients or that the patients recruited were not committed to really participating in the program.

A study with a similarly negative result was published by Wong who studied 100 patients with chronic pain [42]. MBSR was compared to a strong active control group and both groups improved about the same.

Monti et al. [43] tested the efficacy of Mindfulness Based Art Therapy in women with cancer, and observed reduction in symptoms of distress and improved health related quality of life when compared to a wait-list control group. 
Creswell et al. [44] provided initial evidence that MBSR can buffer CD4+T lymphocyte declines in an ethnically diverse sample of HIV-1 infected adults. Additional analyses suggested that the MBSR treatment effects on CD4-T lymphocytes are independent of antiretroviral medication use. The control group received 1 day of MBSR intervention.

Morone et al. [45] conducted a pilot wait-list study to assess the feasibility of recruitment and adherence to an MBSR program for older adults with chronic low back pain, and to develop initial estimates of treatment effects. The completion rate for the intervention group was $68 \%$ and $78 \%$ for the control group after they crossed over to the MBSR program. Because it was a pilot study, they explored participant outcome on a variety of outcome measures. As a result, no final conclusion can be drawn.

Pradhan et al. [46] suggested after a wait-list controlled pilot study that MBSR may complement medical disease management by reducing psychological distress and strengthening well-being in patients with rheumatoid arthritis.

Sephton et al. [47] showed that MBSR alleviated depressive symptoms in patients with fibromyalgia when compared to a wait-list control group. All findings persisted when pain, sleep and antidepressant medication use were controlled for. Functional impairment, pain and sleep quality were measured prior to randomization. The results of these outcomes were not reported.

Astin et al. [48] was unable to show a difference between a treatment combining MBSR and Qi Gong, and an educational program. High drop-out rates of up to $49 \%$ make it difficult to draw final conclusions. While both groups improved, they showed no difference between them.

A similar finding was observed in our own recent study [49]. Being the largest and one of the few active controlled studies, it shows a small difference between MBSR and active control in fibromyalgia patients, which, however, is not significant, due to power problems. The wait-list group also improved significantly.

Speca et al. [50,51] concluded after a wait-list study that the modified MBSR program was effective in decreasing mood disturbance and stress symptoms in both male and female patients with a wide variety of cancer diagnoses, stages of illness and ages. These improvements were maintained at six-month follow-up.

Hebert et al. [52] compared the effectiveness of an intensive dietary intervention on diet and body mass in women with breast cancer to an MBSR program or usual supportive care. Results indicated that MBSR did not make women with breast cancer consume less fat.

Among the thirteen MBSR studies in clinical populations with physical illnesses included, eleven reported changes in mental health, six out of seven showed significant improvements compared to wait-list or TAU, three improved similar to active control conditions, and one did not improve either in the mindfulness or the active control condition. Three fibromyalgia studies were conducted and none of them showed convincing results, but gave some indications as to improvements. Disease activity was assessed in three studies and no effect was found in rheumatoid arthritis and COPD patients, whereas a positive effect was found in HIV patients.

\subsection{Clinical Populations with Psychiatric Disorders}


Cognitive Behavioral Group Therapy (CBGT) was superior to MBSR in the improvement of generalized anxiety disorder, although MBSR patients also improved and had similar results in depression and general symptoms [53].

Moritz et al. [54] suggested that a home study-based spirituality educational programme can affect mental health by improving mood and quality of life within the same range as reported by other mood intervention programs such as cognitive behavioral therapy and MBSR. The mindfulness intervention followed the modified program developed for cancer patients. Only 57\% of the participants in the MBSR group completed the treatment, which is $20 \%-40 \%$ lower than the figures reported by the other included MBSR/MBCT studies.

In their first study on MBCT, Teasdale et al. [55] suggested that MBCT offers a promising costefficient psychological approach to preventing relapse in recovered, recurrently depressed patients. This was replicated by Ma [56] and more recently by Kuyken and colleagues [57], who also added a cost-benefit analysis and could show that MBCT was the more cost-effective option long term. This was again replicated in principle by Segal and colleagues [58], who also showed superiority over placebo. It was concluded that MBCT offers protection against relapse on a par with that of maintenance antidepressant pharmacotherapy.

Although slightly better, Bondolfi and colleagues [59] did not see superiority of MBCT over psychiatric treatment in their Swiss sample of 60 patients. This might be mainly due to the fact that the conventionally treated patients had much better results than in the other studies. Teasdale et al. [55], Ma [56], and Bondolfi [59] compared MBCT to TAU, while Kuyken [57] and Segal [58] compared MBCT to maintanance antidepressant medication.

Thus, seven MBSR/MBCT studies in clinical populations with psychiatric disorders are included. All five MBCT studies reduced depressive relapse. The two MBSR studies were compared to active control conditions, the improvements were significantly higher in active control conditions at the end of treatment, but when four-week follow-up was assessed, mindfulness and active control conditions were equal.

\subsection{Quality of the Included Randomised Controlled Trials}

Waiting-list control group is the weakest possible control, and is the design used in most of the MBSR studies included. MBCT/MBSR was compared to TAU in four studies. It is difficult to know whether TAU as used in these studies was a strong active control or a minimum treatment.

A treatment method that in previous research has been found effective for a specific disorder is the most stringent comparison condition to use, but this design was only used in three studies [52,56,57].

In order to avoid confounding therapist and treatment condition, treatment should be delivered by more than one therapist; five studies included reported the use of two or more therapists. To conclusively determine if authors actually apply the treatment they describe, independent assessors should rate recorded sessions for adherence to the treatment manual and competence of the therapists. This is reported only in the MBCT studies. Only about half of the studies included reported power calculation, primary outcome and effect sizes. Thus, the field clearly is still in the initial stage, and conclusions as to its efficacy cannot be considered final. What is also puzzling is that only half of all studies with reported homework practice show a positive correlation between 
homework and improvement [60]. This could indicate that mindfulness is only one, and perhaps not even the most important, component in this complex program. This would, however, certainly need further clarification.

Overall, studies provided evidence supporting that:

- MBSR is superior to waiting-list in improving mental health in self-selected clinical and non-clinical populations and

- MBCT can reduce the risk of depressive relapse among referred and self-selected recovered, recurrently depressed patients with three or more previous episodes.

\subsubsection{Compliance}

The review showed that most patients randomized to the mindfulness interventions $(75 \%-97 \%)$ did complete treatment, which was defined as attending at least four or five sessions.

\subsubsection{Limitations}

Most studies did not include active control groups. Among the MBSR studies, nine only assessed end of treatment results, and seven reported one- to six-month post-treatment results. The lack of active control groups and long-term follow-up periods constitutes a limitation of many of the assessed studies. Publication bias cannot be ruled out because most studies have shown positive results. 


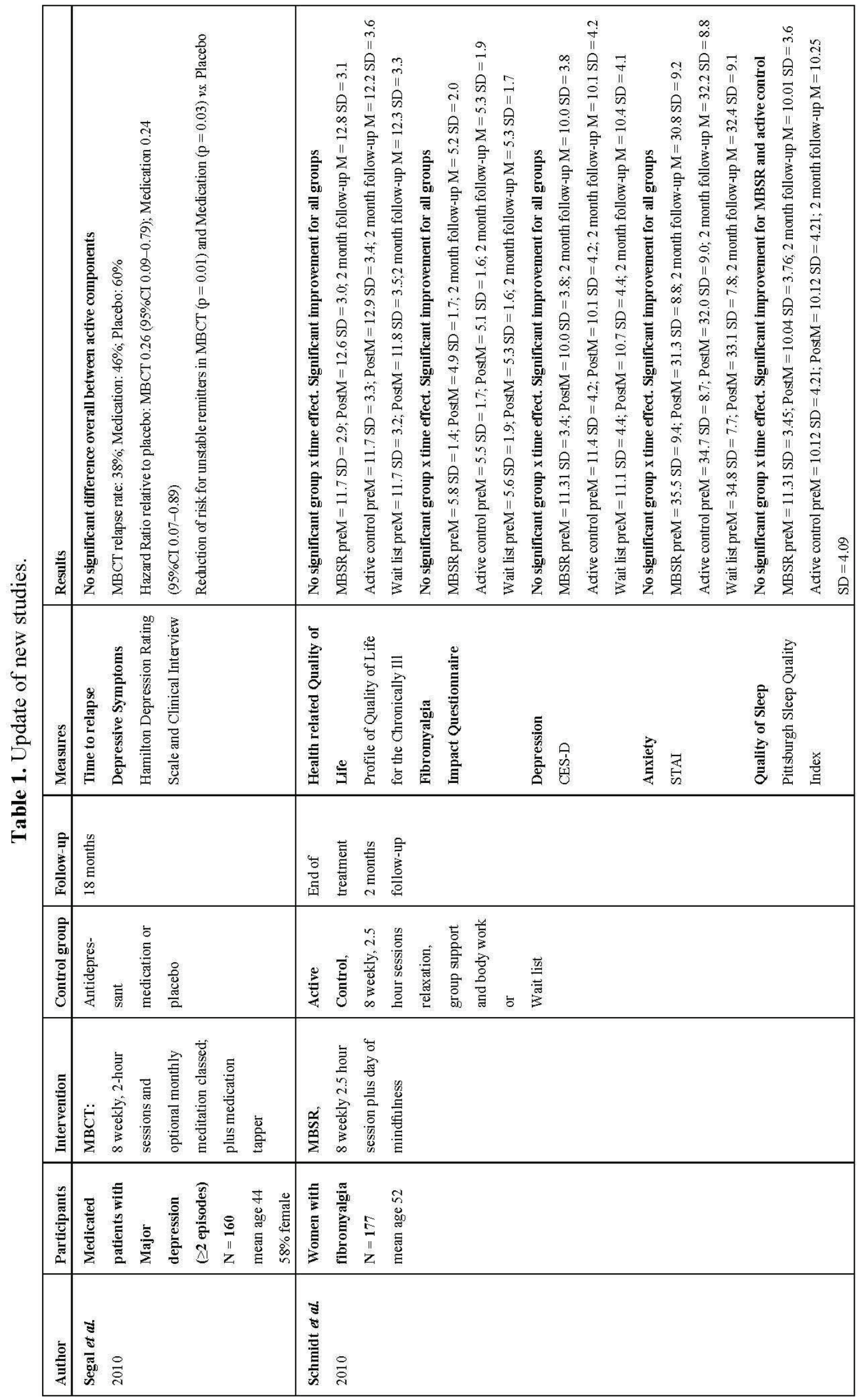




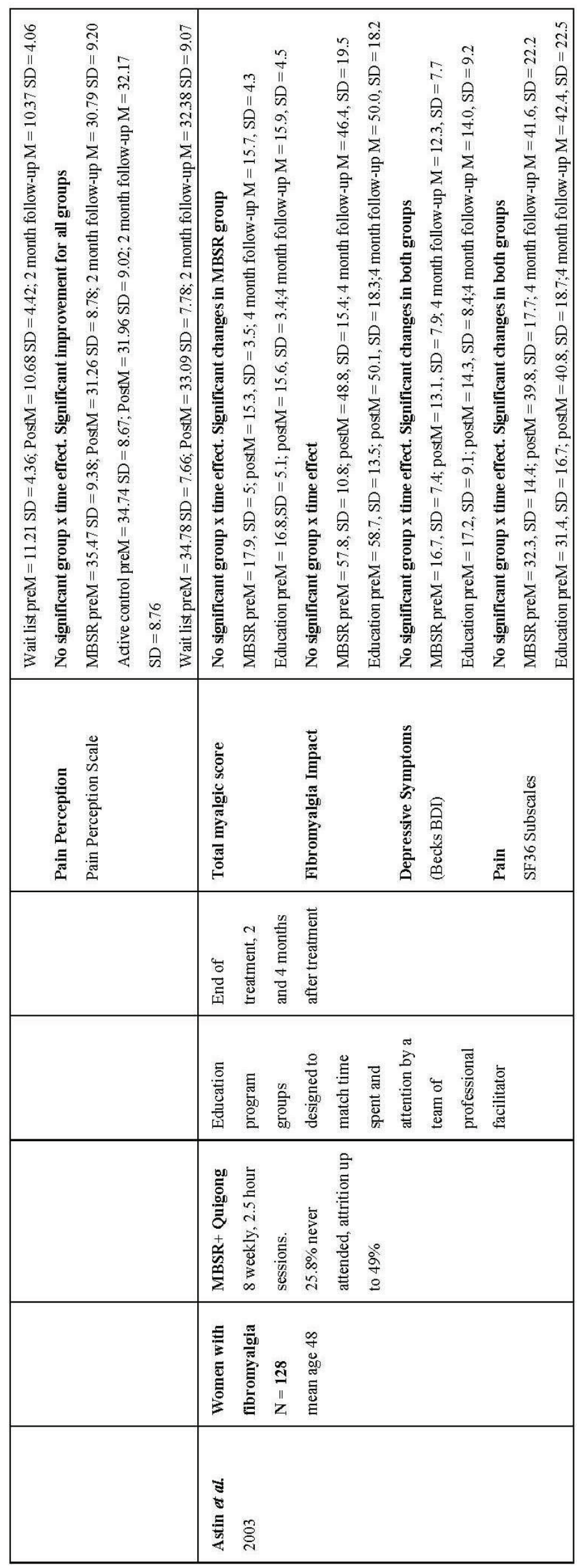




\section{Discussion}

We tried to answer the question: Are meditation based interventions, especially those using mindfulness as a potential mechanism, effective? We conducted a systematic review of RCTs on MBSR/MBCT. Evidence supports that MBSR improves mental health in non-clinical and clinical populations. It remains unclear; however, whether it can also improve physical health. In clinical populations with physical illness, MBSR complements medical disease management by relieving psychological distress and strengthening well-being. In clinical populations with psychiatric disorders, MBSR has some benefit as it reduces symptoms of distress, anxiety and depression, or teaches patients coping skills to handle these symptoms. MBCT is an effective and efficient way to prevent relapse in recovered, depressed patients with three or more previous episodes. It deserves further study and potentially even inclusion into public mental health schemes as a more sustainable alternative to pharmacotherapy, especially for those who do not reliably improve after medication. Overall, studies showed medium to large effect sizes, and improvement fell within the range reported in other psychosocial interventions.

The APA Division 12 Task Force has developed criteria that therapies must fulfill in order to be considered well-established and empirically supported [61]. MBSR meets these criteria. 17 of the MBSR studies included reported mental health outcomes and 14 found MBSR to be more effective than a waiting-list or equivalent to active control conditions. Experiments were conducted using treatment manuals and effects have been demonstrated by different investigators in large and clearly specified samples. MBSR thus meets the criteria for the "well-established" designation.

MBCT also approached the "well-established" designation regarding prevention of depressive relapse. Methodologically, the reviewed studies are strong, and they show MBCT to be superior to TAU and equivalent to continuing antidepressant medication when compared to MBCT plus support in discontinuing antidepressants in preventing relapse. Treatment manuals and large and clearly specified samples of formerly depressed patients were used, and the studies were conducted by independent investigators. MBCT did not prevent depressive relapse in patients with only two previous episodes, and the number of past episodes of depression is a determined characteristic that might predict differential benefit from MBCT.

Thus, we now know that implementation of the manuals of both MBSR and MBCT are effective for some people. But what is the mechanism? There are weak indications only that mindfulness itself is the "active ingredient" in the therapeutic programs. The fact that the intensity of the homework is weakly correlated only in half of the studies, that the increase of mindfulness is not always correlated to the improvement of symptoms, and that actively controlled studies show only small effect sizes, if at all, of mindfulness over active control, indicate that mindfulness is only partially involved. Hence it is likely that all the other components-group support, the novelty of the program, commitment and compliance, the cognitive restructuring-might play equally important roles. Research into mechanisms is only starting to emerge. Initial results point to the fact that mindfulness decreases automatic reactions [62], reduces the propensity for negative reinforcements [25], increases acceptance [63], fosters patients with a meta-cognitive viewpoint that allows for some freedom from established and potentially painful ways of reacting [28], and enhances self-compassion [64]. 
One culturally very interesting fact that has gone unnoticed so far is the following: Western medicine and psychotherapy has mainly focused on combating symptoms and has defined therapeutic success by absence of symptoms. Mindfulness based interventions however do not focus on symptoms, but on the conscious attitude towards them. By letting symptoms be and teaching patients a different mental stance, namely accepting what is and being attentive to the present moment instead of running away from their illness and trying to change it, these approaches provide patients in particular and the medical culture at large with a completely new viewpoint. Thus patients might not experience less symptoms, but experience decreased suffering from their symptoms and more freedom in relation to them, manifesting as improved mental health and quality of life. One of the patients in our mindfulness study on fibromyalgia [48] expressed this beautifully by saying: "For 20 years I have been bullied by my illness, never took a week holiday because I felt I have to be close to a doctor. Now I don't care. I simply go on holidays and have a good time." Another patient who was in one of our mixed patient groups, who had suffered from severe agoraphobia and had not left the house for quite some year, suddenly started going out again, visiting her aunt hundreds of miles away. She was unable to say how it had happened, but all of a sudden, her anxiety was gone. By attending to the present moment, dysfunctional loops which keep patients either fixed to the past, such as in depression, or anxiously anticipating the future, as in anxiety, can be broken. What religions over the ages, not only Buddhism, have taught can then become experience for patients: The richness of present-moment experience is the richness of life itself [6]. With mindfulness this rather simple but very important truth comes back into our culture, clad in psychological and Buddhist clothes but, in fact, being quite universal. It is arguably not an easy task to catch this altered stance scientifically. So far it has escaped researchers it seems, except in anecdotes and vignettes.

Future research should primarily tackle the question of whether mindfulness itself is a decisive ingredient by controlling against other active control conditions or true treatments. Mindfulness is a systematic training of attention, awareness, compassion and wisdom. It may be useful because the Dharma is universal [65]. This universal quality may also, however, be present in other programs; in fact it may be this quality that is present when a psychosocial intervention is working. Further, this quality may be pointed to as common humanity, which makes it difficult to capture and investigate.

So far we have not discussed MBSR and MBCT separately. The following three books represent the MBSR manual: Full Catastrophe Living: Using the Wisdom of Your Body and Mind to Face Stress, Pain, and Illness [6], Wherever You Go, There You Are: Mindfulness Meditation in Everyday Life [66] and Heal Thy Self: Lessons on Mindfulness in Medicine [65]. What is very special about the MBSR program is that mindfulness has to be integrated in the teacher and that it includes periods of silence. Using the wisdom of the body and mind to face stress, pain and illness is very different from a traditional CBT perspective which focuses on fixing and problem solving. MBCT focus more on thoughts compared to MBSR, and MBSR teachers more often have a meditation background than MBCT teachers, who often have a psychotherapeutic background. The MBCT manual may look simpler describing mindfulness as attention control training, [29]but the authors behind the MBCT manual describe the mindful presence of the therapist as playing a crucial role in the efficacy of treatment. They themselves observed a shift from being problem solving therapists to roles as instructors empowering patients to relate mindfully to their experience [29]. 
It is clear that mindfulness is not a pill that can be prescribed. Patients must be ready to practice, be willing to engage and to take daily time out to keep practicing. Naturally, results apply only to this type of patient, and for them it seems to work.

We saw relatively few studies with negative outcomes. Since most clinical research in this field is either publicly or self-supported it is likely that the file-drawer problem of unpublished negative studies is small, but it cannot be excluded.

There is certainly a danger involved in the "hype" around mindfulness: If we take it out of its original context and see it only as a tool, similar to others, it might lose its impact. As explained in the Introduction, mindfulness has to be seen within a certain context. It is a habit and a way of being rather than merely a psychological skill. It might well be the case that it only lives up to its original strength and power if it is incorporated as a habit into daily life and not just seen as a tool switched on and off according to symptom load. If that danger is heeded, however, then mindfulness based approaches might be able to reintroduce a much needed skill to people, which seems previously to have been within the remit of classical religions: that of focusing on the present moment and imbuing it with meaning. Perhaps the modern interest in mindfulness is part of the larger cultural shift which seems to be bringing back religious concepts in secular clothes. Spirituality is, after all, a human condition, and even very "secularly" trained people such as psychotherapists report on spontaneous spiritual experiences [66] and the importance of spirituality in psychotherapy. Thus we might be currently witnessing a transition of religious concepts into secular and scientific culture. Whether this is a beneficial process or not is difficult to say. It seems, at least from a scientific point of view, that the inclusion of concepts of mindfulness into therapeutic approaches is helpful for people.

\section{Recommendations for Further Research}

Future RCTs of MBSR and MBCT should use optimal design including the use of an active treatment as comparison, properly trained instructors, follow-up of at least one year and should describe attrition. In clinical populations, it is recommended to test the combination of mindfulness treatment and specialized treatment for the specific medical disorder in question. It is also recommended to explore the effect of longer treatment times, as several of the strong studies reviewed included 3-4 reinforcement classes.

\section{Standardized Training}

MBSR teachers from America and Europe have developed principles for training teachers. This non-exclusive list of essential elements of training programs to develop MBSR teachers would include [67]:

1. The MBSR teacher trainer needs to have a personal longstanding grounding in meditative practices and be a committed student of the dharma, as it is expressed both within the Buddhist meditation traditions and in more mainstream and universal contexts exemplified by MBSR. This has nothing to do with being or not being a Buddhist.

2. MBSR is a vehicle for embodying and transmitting the dharma in a wholly secular and universal idiom. It is a recontextualizing of dharma, not a decontextualizing of it. 
3. MBSR instructors need to have their own personal meditation practice and attend retreats in the spirit of "continuing education" and the ongoing deepening of their practice and understanding.

4. MBSR instructors follow the principle that they never ask more of program participants than they do of themselves on a daily basis in terms of both formal and informal mindfulness practices. This also needs to be the case for MBSR teacher trainers.

5. The teaching of mindfulness is never a matter of merely teaching or operationalizing techniques. Mindfulness is a way of being in a wiser relationship to one's experience, not one particular mental state to be pursued and attained. Thus, the non-instrumental dimensionality of the work and of the practice of mindfulness is the foundation of effective practice and teaching.

6. Teaching MBSR is an opportunity for right livelihood. Thus, it is important to develop a fair and non-exploitative pricing structure for both MBSR implementation and teacher training.

Similar guidelines were established by the UK Network of Mindfulness-Based Teacher Trainers, along with a professional mental health training that includes the use of evidenced based therapeutic approaches (if delivering MBCT) [68].

\section{Conclusions}

Mindfulness based interventions work. They can be seen to be clinically validated. Further research is needed to clarify what the exact role of the mindfulness and meditation components in these interventions are. For patients who choose these interventions they seem to be beneficial because they foster within them a sense of control and self-efficacy, allowing them to take an active role in their condition without having to rely on external help.

\section{Acknowledgments}

The study was funded by The Danish Agency for Science Technology and Innovation, Aase og Ejnar Danielsens Fond (Aase and Ejnar Danielsen's Fund) and TrygFonden.

The funding sources have not been involved in the study or in the writing of this manuscript.

\section{References}

1. Eppley, K.; Abrams, A.I.; Shear, J. The differential effects of relaxation techniques on trait anxiety: A meta-analysis. J. Clin. Psychol. 1989, 45, 957-974.

2. Alexander, C.N.; Rainforth, M.V.; Gelderloos, P. Transcendental meditation, self-actualization, and psychological health: A conceptual overview and statistical meta-analysis. J. Soc. Behav. Pers. 1991, 6, 189-247.

3. Alexander, C.N.; Robinson, P.; Orme-Johnson, D.W.; Schneider, R.H. The effects of transcendental meditation compared to other methods of relaxation and meditation in reducing risk factors, morbidity, and mortality. Homeostasis 1994, 34, 243-263. 
4. Rainforth, M.V.; Schneider, R.H.; Nidich, S.I.; Gaylor-King, C.; Salerno, J.W.; Anderson, J.W. Stress reduction programs in patients with elevated blood pressure: A systematic review and meta-analysis. Curr. Hypertens Rep. 2007, 9, 520-528.

5. Anderson, J.W.; Liu, C.; Kryscio, J. Blood pressure response to transcendental meditation: A meta-analysis. Am. J. Hypertens. 2008, 21, 310-316.

6. Kabat-Zinn, J. Full Catastrophe Living: Using the Wisdom of Your Body and Mind to Face Stress, Pain, and Illness; Delacorte: New York, NY, USA, 1990.

7. Kabat-Zinn, J. An outpatient program in behavioural medicine for chronic pain patients based on the practice of mindfulness meditation: theoretical considerations and preliminary results. Gen. Hosp. Psychiat. 1982, 4, 33-47.

8. Kabat-Zinn, J. Wherever You Go, There You Are: Mindfulness Meditation in Everyday Life; Hyperion: New York, NY, USA, 1994.

9. Chah, A. A Taste of Freedom. Selected Dhamma Talks; The Sangha, Bun Wai Forest Monastry, Sukhi Hotu Dhamma Publications: Penang, Malaysia, 2010.

10. Docket, K.H.; Dudley-Grant, G.R.; Bankart, C.P., Eds. Psychology and Buddhism: From Individual to Global Community; Kluwer Academic/Plenum Publishers: New York, NY, USA, 2003.

11. Monneyya, B. Teaching and Training: Pa-Auk Forest Monastery, 4th ed.; Wave Publications: Kuala Lumpur, Malaysia, 2009.

12. McCown, D.; Reibel, D.; Micozzi, M.S. Teaching Mindfulness; Springer Science: New York, NY, USA, 2010.

13. Goleman D. Destructive Emotions. How can we overcome them? A scientific Dialogue with the Dalai Lama; Bantam Dell, A division of Random House, Inc.: New York, NY, USA, 2003

14. Kornfield, J. Intensive insight meditation: A phenomenological study. J. Transpersonal. Psychol. 1979, 11, 41-58.

15. Kabat-Zinn, J. Meditation. In Jimmie Holland Textbook of Psycho-Oncology; Oxford University Press: Oxford, UK, 1998; pp. 767-779.

16. Kabat-Zinn, J. Indra's Net at Work: The mainstreaming of Dharma Practice in Society. In The Psychology of Awaking: Buddhism, Science and Our Day to Day Lives; Watson, G., Batchelor, S., Claxton, G., Eds.; Rider: London, UK, 1999; pp. 226-249.

17. Kabat-Zinn, J. Foreword in Fabrizio Didonna. Clinical Handbook of Mindfulness; Springer: New York, NY, USA, 2009.

18. Kabat-Zinn, J. Some reflections on the origins of MBSR, skillful means, and the trouble with maps. Contemp. Buddhism 2011, 12, 281-306.

19. Kabat-Zinn, J. An outpatient program in behavioral medicine for chronic pain patients based on the practice of mindfulness meditation: theoretical considerations and preliminary results. Gen. Hosp. Psychiat. 1982, 4, 33-47.

20. Majumdar, M.; Grossman, P.; Dietz-Waschkowski, B.; Kersig, S.; Walach, H. Does mindfulness meditation contribute to health? Outcome evaluation of a German sample. J. Altern. Complement. Med. 2002, 8, 719-730. 
21. Buchheld, N.; Grossman, P.; Walach, H. Measuring mindfulness in insight meditation (vipassana) and meditation-based psychotherapy: The development of the Freiburg Mindfulness Inventory (FMI). J. Meditation Meditation Res. 2001, 1, 11-34.

22. Buchheld, N.; Walach, H. Achtsamkeit in Vipassana-Meditation und Psychotherapie. Die Entwicklung des "Freiburger Fragebogens zur Achtsamkeit". Zeitschrift für Klinische Psychologie Psychiatrie und Psychotherapie 2002, 50, 153-172.

23. Grossman, P.; Niemann, L.; Schmidt, S.; Walach, H. Mindfulness based stress reduction and health: A meta-analysis. J. Psychosom. Res. 2004, 37, 35-43.

24. Sauer, S.; Lynch, S.; Walach, H; Kohls, N. Dialectics of mindfulness: Implications for western medicine Philos. Ethics Humanit. Med. 2011, 6.

25. Sauer, S.; Walach, H.; Kohls, N. Gray's Behavioural Inhibition System as a mediator of mindfulness towards well-being. Pers. Individ. Dif. 2011, 50, 506-511.

26. Wallace, B.A.; Shapiro, S.L. Mental Balance and Well-Being: Building Bridges Between Buddhism and Western Psychology. Am. Psychol. 2006, 61, 690-701.

27. Brown, K.W.; Ryan, R.M. The benefits of being present: Mindfulness and its role in psychological well-being. J. Pers. Soc. Psychol. 2003, 84, 822-848.

28. Teasdale, J.D.; Segal, Z.; Williams, M.G. How does cognitive therapy prevent depressive relapse and why should attentional control (mindfulness) training help? Behav. Res. Ther. 1995, 33, 25-39.

29. Segal, Z.V.; Williams, J.M.G.; Teasdale, J.D. Mindfulness-Based Cognitive Therapy for Depression: A New Approach to Preventive Relapse; Guilford Press: New York, NY, USA, 2002.

30. Baer, R. Mindfulness training as a clinical Intervention: a conceptual and empirical review. Clin. Psychol. Sci. Pract. 2003, 10, 125-143.

31. Crane, C.; Barnhofer, T.; Duggan, D.S.; Hepburn, S.; Fennel, M; Williams, J.M.G. Mindfulness-Based Cognitive Therapy and Self-Discrepancy in Recovered Depressed Patients with a History of Depression and Suicidality. Cogn. Ther. Res. 2008, 32, 775-787.

32. Williams, J.M.G. Mindfulness, Depression and Modes of Mind. Cogn. Ther. Res. 2008, 32, $721-733$.

33. Fjorback, L.O.; Arendt, M.; Ornbøl, E.; Fink, P.; Walach, H. Mindfulness-based stress reduction and mindfulness based cognitive therapy-A systematic review of randomized controlled trials. Acta Psychiatr. Scand. 2011, 124, 102-119.

34. Nyklicek, I.; Kuijpers, K.F. Effects of mindfulness-based stress reduction intervention on psychological well-being and quality of life: Is increased mindfulness indeed the mechanism? Ann. Behav. Med. 2008, 35, 331-340.

35. Davidson, R.J.; Kabat-Zinn, J.; Schumacher, J; Rosenkranz, M; Muller, D.; Santorelli, S.F.; Urbanowski, F; Harrington, A.; Bonus, K; Sheridan, J.F. Alterations in brain and immune function produced by mindfulness meditation. Psychosom. Med. 2003, 65, 564-570.

36. Hagemann, D.; Neumann, E.; Becker, G.; Maier, S.; Bartussek, D. Resting brain asymmetry and affective reactivity: Aggregated data support the right-hemisphere hypothesis. Pers. Individ. Dif. 2005, 26, 139-154. 
37. Williams, K.A.; Kolar, M.M.; Regar, B.E.; Pearson, J.C. Evaluation of a wellness-based mindfulness stress reduction intervention: a controlled trial. Am. J. Health Promot. 2001, 15, 422-432.

38. Shapiro, S.L.; Schwartz, G.E.; Bonner, G. Effects of mindfulness based stress reduction on medical or paramedical students. J. Behav. Med. 1998, 21, 581-599.

39. Grossman, P.; Kappos, L.; Gensicke, H.; DSouza, M.; Mohr, D.C.; Penner, I.K.; Steiner, C. MS quality of life, depression, and fatigue improve after mindfulness training: A randomized trial. Neurology 2010, 75, 1141-1149.

40. Foley, E.; Baillie, A.; Huxter, M.; Price, M.; Sinclair, E. Mindfulness-based cognitive therapy for individuals whose lives have been affected by cancer: A randomized controlled trial. J. Consult. Clin. Psychol. 2010, 78, 72-79.

41. Mularski, R.A.; Munjas, B.A.; Lorenz, K.A.; Sun, S.; Robertson, S.J.; Schmeizer, W.; Kim, A.S.; Shekelle, P.G. Randomized controlled trial of mindfulness-based therapy for dyspnea in chronic obstructive lung disease. J. Altern. Complement. 2009, 15, 1083-1090.

42. Wong, S.Y. Effect of mindfulness-based stress reduction programme on pain and quality of life in chronic pain patients: A randomised controlled clinical trial. Hong Kong Med. J. 2009, 15 (Suppl. S6), 13-14.

43. Monti, D.A.; Peterson, C.; Kunkel, E.J.; Hauck, W.W.; Pequignot, E; Rhodes, L.; Brainard, G.C. A randomized, controlled trial of mindfulness-based art therapy (MBAT) for women with cancer. Psychooncology 2006, 15, 363-373.

44. Creswell, J.D.; Myers, H.F.; Cole, S.W.; Irwin, M.R. Mindfulness meditation training effects on CD4+ T lymphocytes in HIV-1 infected adults: A small randomized controlled trial. Brain. Behav. Immun. 2009, 23, 184-188.

45. Morone, N.E.; Greco, C.M.; Weiner, D.K. Mindfulness meditation for the treatment of chronic low back pain in older adults: A randomized controlled pilot study. Pain 2008, 134, 310-319.

46. Pradhan, E.K.; Baumgarten, M.; Lagenberg, P. Effect of Mindfulness-Based Stress Reduction in rheumatoid arthritis patients. Arthritis Rheum. 2007, 57, 1134-1142.

47. Sephton, S.E.; Salmon, P.; Weissbecker, I.; Ulmer, C.; Floyd, A.; Hoover, K.; Studts, J.L. Mindfulness meditation alleviates depressive symptoms in women with fibromyalgia: results of a randomized clinical trial. Arthritis Rheum. 2007, 57, 77-85.

48. Astin, J.A.; Berman, B.M.; Bausell, B.; Lee, W.L.; Hochberg, M.; Forys, K.L. The efficacy of mindfulness meditation plus Qigong movement therapy in the treatment of fibromyalgia: A randomized controlled trial. J. Rheumatol. 2003, 30, 2257-2262.

49. Schmidt, S.; Grossman, P; Schwarzer, B; Jena, S.; Naumann, J.; Walach, H. Treating fibromyalgia with mindfulness-based stress reduction: Results from a 3-armed randomized controlled trial. Pain 2011, 152, 361-369.

50. Speca, M.; Carlson, L.E.; Goodey, E.; Angel, M.A. randomized, wait-list controlled clinical trial: The effect of a mindfulness meditation-based stress reduction program on mood and symptoms of stress in cancer outpatients. Psychosom. Med. 2000, 62, 613-622.

51. Carlson, L.E.; Ursuliak, Z.; Goodey, E; Angel, M.; Speca, M. The effects of a mindfulness meditation-based stress reduction program on mood and symptoms of stress in cancer outpatients: 6 Month follow-up. Support Care Cancer 2001, 9, 112-123. 
52. Hebert, J.R.; Ebbeling, C.B.; Olendzki, B.C. Change in women's diet and body mass following intensive intervention for early-stage breast cancer. J. Am. Diet Assoc. 2001, 101, 421-428.

53. Koszycki, D.; Benger, M.; Shlik, J.; Bradwejn, J. Randomized trial of a meditation-based stress reduction program and cognitive behavior therapy in generalized social anxiety disorder. Behav. Res. Ther. 2007, 45, 2518-2526.

54. Moritz, S.; Ouan, H.; Rickhi, B. A home study-based spirituality education program decreases emotional distress and increases quality of life-A randomized, controlled trial. Altern. Ther. Health 2006, 12, 26-35.

55. Teasdale, J.D.; Segal, Z.V.; Williams, J.M.; Ridgeway, V.A.; Soulsby, J.M.; Lau, M.A. Prevention of relapse/recurrence in major depression by mindfulness-based cognitive therapy. J. Consult. Clin. Psychol. 2000, 68, 615-623.

56. Ma, S.; Teasdale, J.D. Mindfulness-based cognitive therapy for depression: Replication and exploration of differential relapse prevention effects. J. Consult. Clin. Psychol. 2004, 72, 31-40.

57. Kuyken, W.; Byford, S.; Taylor, R.S. Mindfulness-based cognitive therapy to prevent relapse in recurrent depression. J. Consult. Clin. Psychol. 2008, 76, 966-978.

58. Segal, Z.V.; Bieling, P; Young, T; Macqueen, G; Cooke, R; Martin, L.; Bloch, R.; Levitan, R.D. Antidepressant monotherapy vs. sequential pharmacotherapy and minfulness-based cognitive therapy, or placebo, for relapse prophylaxis in recurrent depression. Arch. Gen. Psychiat. 2010, 67, 1256-1264.

59. Bondolfi, G.; Jermann, F.; Der Linden Jermann, F.; Der Linden, M.V.; Gex-Fabry, M; Bizzini, L.; Rouget, B.W.; Myers-Arrazola, L.; Gonzalez, C.; Segal, Z.; Aubry, J.M.; Bertschy, G. Depression relapse prophylaxis with Mindfulness-Based Cognitive Therapy: Replication and extension in the Swiss health care system. J. Affect. Disord. 2010, 122, 224-231.

60. Vettese, L.C.; Toneatto, T.; Stea, J.N.; Nguyen, L.; Wang, J.J. Do mindfulness meditation participants do their homework? And does it make a difference? A review of the empirical evidence. J. Cognit. Psychother. 2009, 23, 198-225.

61. Chambless, D.L.; Ollendick, T.H. Empirically supported psychological interventions: controversies and evidence. Ann. Rev. Psychol. 2001, 52, 685-716.

62. Sauer, S.; Walach, H.; Schmidt, S.; Hinterberger, T; Horan, M.; Kohls, N. Implicit and explicit emotional behavior and mindfulness. Conscious. Cogn. 2011, doi:10.1016/j.concog.2011.08.002.

63. Kohls, N.; Sauer, S.; Walach, H. Facets of mindfulness. An online study investigating the Freiburg Mindfulness Inventory. Pers. Individ. Dif. 2009, 46, 224-230.

64. Kuyken, W.; Watkins, E.; Holden, E.; White, K.; Taylor, R.S.; Byford, S.; Evans, A.; Radford, S.; Teasdale, J.D.; Dalgeish, T. How does mindfulness-based cognitive therapy work? Behav. Res. Ther. 2010, 48, 1105-1112.

65. Santorelli, S. Heal Thy Self: Lessons on Mindfulness in Medicine; Crown, Random House: New York, NY, USA, 1999.

66. Hofmann, L.; Walach, H. Spirituality and religiosity in psychotherapy-A representative survey among German psychotherapists. Psychother. Res. 2011, 21, 179-192. 
67. Kabat-Zinn, J.; Santorelli, S.F. Training Teachers to Deliver Mindfulness-Based Stress Reduction. Available online: http://www.umassmed.edu/cfm/trainingteachers/index.aspx (accessed on 1 November 2011).

68. Centre for Mindfulness Research and Practice, Bangor University. Our Mission Statement. Available online: http://www.bangor.ac.uk/mindfulness (accessed on 1 November 2011). 


\title{
Section of Original Papers
}

\section{"Religion in Psychiatry and Psychotherapy?" A Pilot Study: The Meaning of Religiosity/Spirituality from Staff's Perspective in Psychiatry and Psychotherapy}

\section{Eunmi Lee, Anne Zahn and Klaus Baumann}

\begin{abstract}
This study examined: (1) the spirituality of staff; (2) its relationship with staff's attitudes towards religiosity/spirituality of patients; and (3) with staff's integration of religious and spiritual contents in the patient's therapy. Method: An anonymous survey distributed to the staff in the department of psychiatry and psychotherapy at the Freiburg University Hospital. The main predictor variable was the spirituality of staff using DRI (Duke Religion Index). The main criterion variables were the relevance of religiosity/spirituality of patients and staff's attitude towards religious/spiritual contents during their therapy using the questionnaire of Curlin et al. Results: The spirituality of staff was 6.91 on a scale of 12.0. There was no significant relationship between variables. Staff regarded the influence of religious/spiritual contents generally positive to patients. However, the staff did not use religious/spiritual elements in their therapy methods. Frequent reasons were insufficient time/occasion and insufficient knowledge. Conclusions: Religious/spiritual contents have not been integrated yet in therapy methods, although they are regarded as important for patients. Further studies and discussion about religious/spiritual matters are essential for their integration into psychiatric therapies in order to overcome these inconsistencies.
\end{abstract}

Reprinted from Religions. Cite as: Lee, E.; Zahn, A.; Baumann, K. "Religion in Psychiatry and Psychotherapy?" A Pilot Study: The Meaning of Religiosity/Spirituality from Staff's Perspective in Psychiatry and Psychotherapy. Religions 2011, 2, 525-535.

\section{Introduction}

Anger, sadness, pressure, anxiety or depressive mood changes are typical factors determining the daily exposition to psychological stress. In such encumbered situations, religious persons turn to religion including prayers and worship in the hope to cope with their difficult situation. Positive correlation of religiosity/spirituality does find acceptance as support or potential resource with not directly affected groups. In the context of psychiatry and psychotherapy, however, this correlation is traditionally met with skepticism, as a variety of psychological disorders is connected with peculiar or exaggerated religious experiences such as hallucination or depressive sense of guilt. 
According to D. Wyss, it is doubtable, if there is any "Neurosis" or "Psychosis", in which no religious content can be observed in a distorted form [1,2].

Since the late 1980s, there has been a noteworthy increase in empirical studies dedicated to "religiosity/spirituality and health". Since then, the number of related empirical studies has continued to grow significantly. In English speaking countries, the field of research for the topic "religiosity/spirituality and health" has already become an important topic [3-5]. Numerous studies, most of them undertaken in English-speaking countries, show a significant, though weak, positive correlation between religious/spiritual contents and both physical and mental health [6-10]. However, it is not strongly surveyed yet, how staff regards the religious/spiritual contents, although their attitude has an important impact on the integration of these contents [4,11-14].

\section{Objectives}

In the context of a growing body of international research, though not in German-speaking countries, this study is placed in a department of psychiatry and psychotherapy of a German University Hospital. The study aims to examine the staff's self-assessment regarding their own spirituality (the main predictor variable), staff's attitudes towards religiosity/spirituality of patients according to their experiences (a main criterion variable), and staff's point of view regarding the integration of religious/spiritual contents in psychiatric therapeutic methods (a main criterion variable). Moreover, this study examines the correlation between these variables.

Taking into account the relevance given to religious/spiritual aspects for health and life quality by the WHO $[2,15,16]$, integration of religious/spiritual resources in the therapeutic process should be discussed. Based on aforementioned objectives, three main questions guided the pilot study.

(1) How does staff in psychiatry and psychotherapy assess their own spirituality?

(1) What is the attitude of staff in psychiatry and psychotherapy towards patients' religiosity/spirituality, and what is the relationship to staff's own spirituality?

(3) How does staff in psychiatry and psychotherapy regard the integration of religious/spiritual contents in therapeutic methods, and what is the relationship to staff's own spirituality?

\section{Design and Methods of the Study}

To answer the aforementioned main questions, this study was composed of three parts:

(1) The spirituality of staff. The concept of spirituality has been increasingly used and is usually understood as the inner attitude towards life related to the transcendent. There is a host of different attempts to operationalize spirituality and religiosity [3,17], without arriving at satisfactory solutions yet. In this study, for pragmatic reasons, spirituality, as an increasingly popular term, is assumed to be intrinsic religiosity according to Allport and Ross [17]. According to them, extrinsic religiosity is a tool to fulfill a wish like security, sociability, or self-justification. In this sense, people "use" their religions, whereas intrinsic religiosity is inner motivated and internalized, so that people "live" their religions and try to live according to the beliefs and prescriptions of their religions. Accordingly, spirituality in this study is measured with DRI (Duke Religion Index) [18], which is a strongly accepted 
instrument to measure religiosity (both extrinsic and intrinsic religiosity) [18-20], especially for high reliability and validity though we would concede and state a lack of sophisticated differentiations. The DRI consists of five items; three of them measure the intrinsic religiosity through an ordinal scale (5-Likert Scale). In this pilot study, the reliability (internal consistence) of the three questions about spirituality was Cronbach's $\alpha=0.819$.

(2) Staff's attitudes towards religiosity/spirituality of patients; and

(3) The integration of religious and spiritual contents into the therapies; both (2) and (3) were measured using the questionnaire of Curlin et al. He and his research team constructed these questionnaires based on several pilot studies; they were tested via multiple iterations of expert panel review [11]. The questions regarding attitudes towards religiosity/spirituality of patients were categorized into positive and negative influence, and the questions regarding staff's point of view in relation to the integration into therapy were divided into attitudes and behaviors.

These main instruments were translated into German and improved through comments by a team of professionals. Additionally several master students answered the translated version prior to this pilot study. An anonymous survey was distributed to the staff in the department of psychiatry and psychotherapy of the Freiburg University Hospital from December 2008 to January 2009. Staff in this study was medical, psychotherapeutic, and nursing staff working directly with patients.

The study was analyzed using SPSS 15.0 for Windows. UNIANOVA was used for the differentiation of various groups according to the spirituality (gender, occupation and religion). The correlation between variables was analyzed through the (one tailed) Spearman-Rho-correlation test.

\section{Results ${ }^{1}$}

The response rate was $44.16 \%$ (87 of 197), of which 86 questionnaires could be analyzed. One questionnaire was returned almost empty and therefore not included in the analysis.

The average age of the staff was 41.5 years (range $24-58$ years). Among the staff $56.8 \%$ were women and $43.2 \%$ men. Nursing staff was $44.7 \%, 21.2 \%$ doctors, $12.9 \%$ psychotherapists, and $21.2 \%$ from other professional groups, for example music therapists, social workers or physiotherapists. The average work experience was 16.4 years for staff of the psychiatric and psychotherapeutic field. Protestant were $34.9 \%$ of staff and $32.5 \%$ were Catholic. $26.5 \%$ said that they have no confession.

\subsection{How Does Staff in Psychiatry and Psychotherapy Assess Their Own Spirituality?}

The spirituality of staff is $6.91(\mathrm{SD}=3.02)$ on a scale of 12.0 (the highest possible score $\left.^{2}\right)$. The answers of each question are described in the following Table 1.

Table 1. Staff's intrinsic religiosity ${ }^{3}(N=86)$.

\footnotetext{
The discrepancy $N<86$ is possible, as missing values are not listed in the table.

2 In the analysis of spirituality (intrinsic religiosity in DRI), the translated answer ,,unsure “ was removed, to ensure that ordinal scale could remain after a German translation. Therefore the highest possible score in the German version is 12,0 , not 15,0 as in the original version DRI.
} 


\begin{tabular}{cccccc}
\hline $\begin{array}{c}\text { Category } \\
\text { Intrinsic religiosity }\end{array}$ & $\begin{array}{c}\text { Definitely } \\
\text { true of me }\end{array}$ & $\begin{array}{c}\text { Tends to } \\
\text { be true }\end{array}$ & Unsure & $\begin{array}{c}\text { Tends not } \\
\text { to be true }\end{array}$ & $\begin{array}{c}\text { Definitely } \\
\text { not true }\end{array}$ \\
\hline Experience & $16(18.6)$ & $24(27.9)$ & $11(12.8)$ & $20(23.3)$ & $15(17.4)$ \\
Philosophy & $15(17.4)$ & $30(34.9)$ & $2(2.3)$ & $20(23.3)$ & $19(22.1)$ \\
Practice & $12(14.0)$ & $30(34.9)$ & $3(3.5)$ & $19(22.1)$ & $20(25.6)$ \\
\hline
\end{tabular}

Table 2. The extent of intrinsic religiosity.

\begin{tabular}{cccccc}
\hline \multirow{4}{*}{ Total } & Category & $\boldsymbol{N}$ & Mean & SD & $\boldsymbol{p}$ \\
& Total & 86 & 6.91 & 3.02 & - \\
Occupation & Doctors & 18 & 6.50 & 2.43 & \\
& Psychotherapists & 11 & 6.36 & 3.26 & \multirow{6}{*}{ Ge.372 } \\
& Nursing staff & 38 & 6.71 & 3.06 & \\
& Other professional groups & 18 & 8.00 & 3.34 & \\
& Women & 46 & 7.56 & 3.00 & \multirow{2}{*}{$\mathbf{0 . 0 2 2}^{5}$} \\
& Men & 35 & 6.00 & 2.93 & \\
& No confession & 22 & 5.77 & 2.84 & \\
& Catholic & 27 & 7.44 & 3.16 & \multirow{2}{*}{$0.212^{6}$} \\
& Protestant & 29 & 7.06 & 2.92 & \\
\hline
\end{tabular}

There was no significant difference of spirituality between occupations or between religions by UNIANOVA (Table 2). However, a significant difference between men and women was shown $(p=0.022)$. The spirituality was on average 7.56 by women and 6.00 by men.

3 For better readability, the questions are categorized in the table. Questions: 1) Experience: In my life, I experience the presence of the divine (i.e., God). 2) Philosophy: My religious beliefs are what really lie behind my whole approach to life. 3) Practice: I try hard to carry my religion over into all other dealings in life.

$4 \quad N=85, \mathrm{~F}=1,058, \mathrm{df}=3, p=0.372, \eta^{2}=0.038$

$5 \quad N=81, \mathrm{~F}=5,501, \mathrm{df}=1, p=0.022, \eta^{2}=0.065$

${ }^{6} \quad N=83, \mathrm{~F}=1,533, \mathrm{df}=3, p=0.212, \eta^{2}=0.055$ 


\subsection{What is the Attitude of the Staff in Psychiatry and Psychotherapy towards Patients'}

religiosity/spirituality?

For the psychiatric staff religious/spiritual issues are generally prevalent. $76.5 \%$ answered that their patients mention religious/spiritual issues such as God, meditation or prayer (Table 3). Only $6.3 \%$ responded that religiosity/spirituality has negative influence on health, and $5.1 \%$ concluded that religiosity/spirituality has no influence. The majority of staff stated that religiosity/spirituality helps patients to cope with illness and suffering (90.3\%) or gives a positive state of mind $(89.1 \%)$. Following comments were taken from the free text input section; "It [religiosity/spirituality] is important for certain patients", "Initiative from patients would be supported" or "I am sure, that it could be good for religious patients, if one prayed with them, when it is their wish."

Table 3. Staff's attitude towards patients' religiosity/spirituality $(N=86)$.

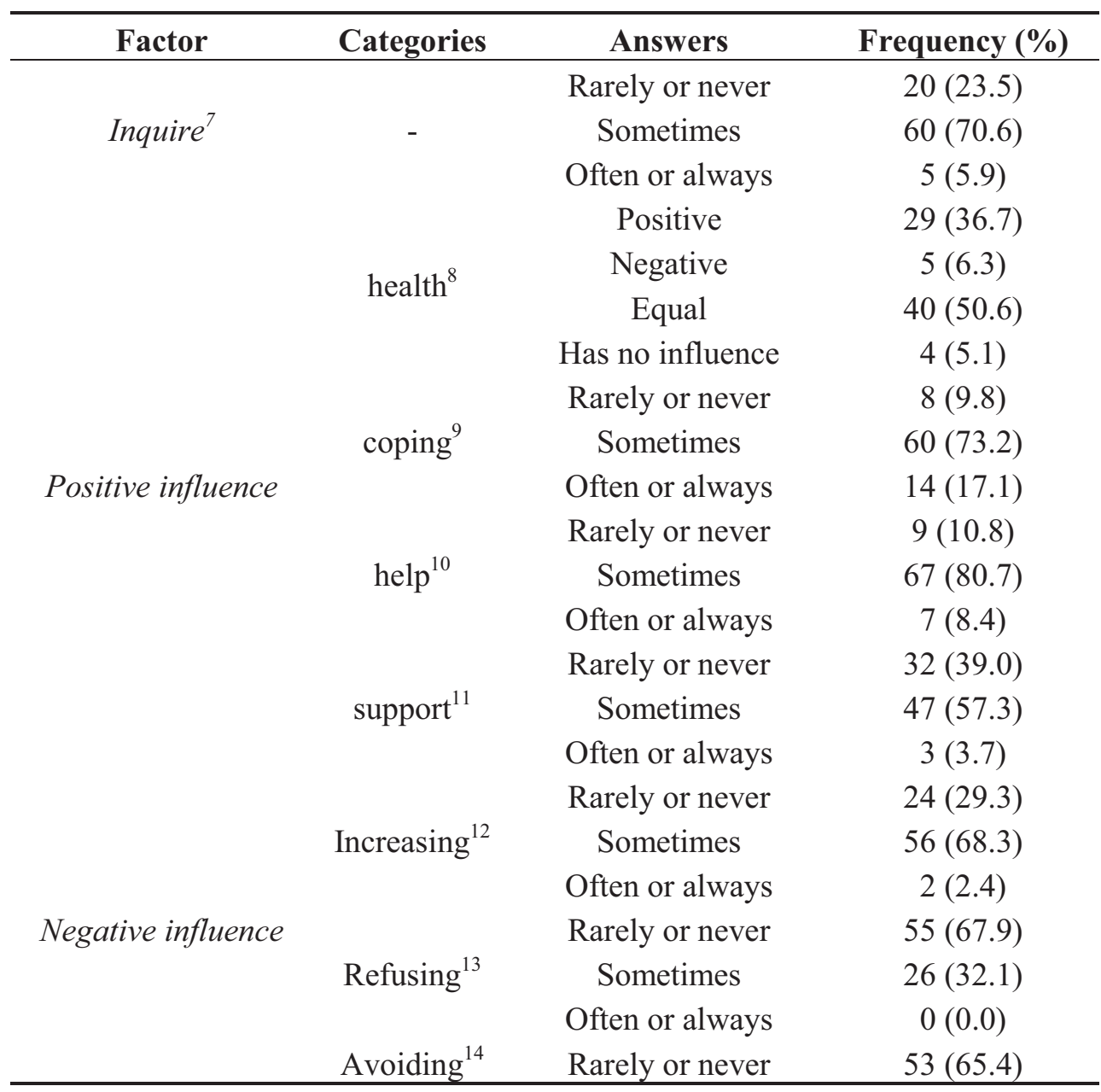

7 Question: How often have your patients mentioned religion/spirituality issues such as God, Prayer, meditation, the bible, etc.?

8 Question: Is the influence of religion/spirituality on health generally positive or negative?

9 Question: Religion/spirituality helps patients to cope with and endure illness and suffering.

10 Question: Religion/spirituality gives patients a positive and hopeful state of mind.

11 Question: How often have your patients received emotional or practical support from their religious community?

12 Question: Religion/spirituality causes guilt, anxiety or other negative emotions that lead to increased patient suffering.

13 Question: Religion/spirituality leads patients to refuse, delay or stop medically indicated therapy. 


$\begin{array}{cc}\text { Sometimes } & 28(34.6) \\ \text { Often or always } & 0(0.0)\end{array}$

The correlation between the extent of staff's spirituality and each item of inquire, positive influence (except "health") and negative influence was analyzed, but there was no significant correlation.

\subsection{How Does Staff in Psychiatry and Psychotherapy Regard the Integration of Religious/Spiritual Contents in Therapeutic Methods?}

Staff's attitudes toward religious/spiritual contents and during the therapeutic process showed certain diversity (Table 4). 80\% of staff found it, in general, appropriate to inquire about a patient's religiosity/spirituality, and $76.5 \%$ already did so. When patients bring up religious/spiritual issues, $91.7 \%$ consider it generally appropriate to discuss them with their patients. However, 54.2\% refused to talk about their own religious/spiritual ideas and experiences, and $96.4 \%$ of staff denied encouraging patients to engage in concrete religious activities, especially praying. Nearly $90 \%$ found it, in general, inappropriate to pray together with patients and only $3.6 \%$ have prayed with their patients.

The foremost mentioned barriers in integrating religious/spiritual practices with patients were insufficient time (22.4\%) and insufficient knowledge (21.1\%). Among "other reasons" (30.6\%) privacy was the most frequent answer. Moreover, therapeutic neutrality is stated by doctors and psychotherapists, and assumed reservations by supervisors are stated by nursing staff as other frequently mentioned barriers. Some open comments were; "An expert training would be good", "I think, it is good, but I don't practice it", "My work as doctor should be ideologically neutral" or "I have already often noticed [it] and it is a pity, that there are so few possibilities for religious patients in the clinic."

The correlation between the staff's spirituality and each item of behaviors was analyzed (Table 5). Since items of attitude were based on a nominal scale, their correlation could not be analyzed. Besides the correlation with the sum of items could not be analyzed, as items have different possible answers. A significant correlation was found with the item sharing $\left(\mathrm{r}_{\mathrm{s}}=0.236, p=\mathbf{0 . 0 1 5}\right)$. That is, the more spiritual the psychiatric staff, the more they tend to share their own religious ideas and experiences with patients.

\section{Discussion}

Contrary to the widespread assumption that staff of psychiatric clinics has low to no spirituality, empirical studies published in English speaking countries showed that staff is more spiritual or religious, as could generally be expected [11-14]. According to Baetz et al. the intrinsic religiosity of the Canadian psychiatrists had a mean of 13.9 of $15.0(\mathrm{SD}=1.9)$ using DRI in its original version. Curlin et al. surveyed the American psychiatrists among whom only $22 \%$ indicated their

14 Question: How often have your patients used religion/spirituality as a reason to avoid taking responsibility for their own health? 
spirituality to be low [11]. This pilot study conducted in Freiburg leaned in the same direction, indicating the psychiatric staff's opinion about their own spirituality to be not low.

According to our pilot study, the psychiatric staff believes that religiosity/spirituality plays an important role for patients. However, there is evidence that religious/spiritual contents are seen to be taken with care and precaution, as religious/spiritual contents could also cause psychiatric problems or aggravate already existing ones. About $70 \%$ of the surveyed people commented, that religiosity/spirituality can cause anxiety, guilt, or another negative emotion. The survey of Curlin et al. showed a similar tendency (63\%). Differently from the answer of psychiatrists, only $40 \%$ of the non-psychiatrist physicians agreed with this statement $(p<0.0001)$ [11].

Table 4. Staff's point of view regarding the integration of religious/spiritual contents $(N=86)$.

\begin{tabular}{|c|c|c|c|}
\hline Factor & Categories & Answers & Frequency $(\%)$ \\
\hline \multirow{9}{*}{ Attitude } & \multirow{2}{*}{ Inquiry $^{15}$} & Usually or always appropriate & $68(80.0)$ \\
\hline & & Usually or always inappropriate & $17(20.0)$ \\
\hline & \multirow{2}{*}{ Discussion $^{16}$} & Usually or always appropriate & $77(91.7)$ \\
\hline & & Usually or always inappropriate & $7(8.3)$ \\
\hline & \multirow{3}{*}{ Dialogue $^{17}$} & Never & $20(23.5)$ \\
\hline & & Only when the patient asks & $31(36.5)$ \\
\hline & & Whenever the staff senses... & $34(40.0)$ \\
\hline & \multirow{3}{*}{ Pray } & Usually or always appropriate & $10(12.7)$ \\
\hline & & Usually or always inappropriate & $69(87.3)$ \\
\hline \multirow{10}{*}{ Behaviors } & & Rarely or never & $19(22.4)$ \\
\hline & \multirow[t]{2}{*}{ Frequency $^{18}$} & Sometimes & $43(50.6)$ \\
\hline & & Often or always & $23(27.1)$ \\
\hline & \multirow{3}{*}{$\underset{19}{\text { Encouraging }}$} & Rarely or never & $20(23.8)$ \\
\hline & & Sometimes & $44(52.4)$ \\
\hline & & Often or always & $20(23.8)$ \\
\hline & \multirow{3}{*}{ Sharing $^{20}$} & Rarely or never & $45(54.2)$ \\
\hline & & Sometimes & $34(41.0)$ \\
\hline & & Often or always & $4(4.8)$ \\
\hline & Issues $^{21}$ & Rarely or never & $57(68.7)$ \\
\hline
\end{tabular}

15 Question: In general, is it appropriate or inappropriate for a physician to inquire about a patient's religion/spirituality?

16 Question: In general, is it appropriate or inappropriate for a physician to discuss religious/spiritual issues, when a patient brings them up?

17 Question: When, if ever, is it appropriate to talk about his or her own religious beliefs or experiences with a patient?

18 Question: How often do you inquire about a patient's religion/spirituality, when a patient suffers from anxiety or depression?

19 Question: I encourage patients in their own religious / spiritual beliefs and practices, when religious / spiritual issues come up in discussions with patients.

20 Question: I respectfully share my own religious ideas and experiences, when religious/spiritual issues come up in discussions with patients.

21 Question: I try to change the subject in a tactful way, when religious/spiritual issues come up in discussions with patients. 


\begin{tabular}{ccc}
\hline & Sometimes & $24(28.9)$ \\
& Often or always & $2(2.4)$ \\
\multirow{3}{*}{ Pray together } & Rarely or never & $81(96.4)$ \\
& Sometimes & $3(3.6)$ \\
& Often or always & $0(0.0)$ \\
Barriers $^{22}$ & Insufficient time & $19(22.4)$ \\
& Concern about offending patients & $9(10.6)$ \\
& Insufficient knowledge & $18(21.1)$ \\
& Concern that my colleagues will disapprove & $3(3.5)$ \\
& Others & $12(14.1)$ \\
Nothing & $26(30.6)$ \\
\hline
\end{tabular}

Table 5. Correlation between staff's behaviors and spirituality.

\begin{tabular}{lccc}
\hline \multirow{2}{*}{ Categories } & \multicolumn{2}{c}{ Spirituality } \\
& $r_{s}$ & $p$ \\
\hline \multirow{4}{*}{ Behaviors } & Frequency & 0.057 & 0.302 \\
& Encouraging & 0.053 & 0.313 \\
& Sharing & 0.236 & $\mathbf{0 . 0 1 5}$ \\
& Issues & -0.095 & 0.194 \\
& Pray together & 0.058 & 0.300 \\
\hline
\end{tabular}

The integration of religious and spiritual contents into psychiatric therapeutic methods seems difficult, especially incorporating "prayer", which is the most frequently mentioned religious/spiritual practice by patients [21,22]. It rarely plays a role in therapeutic action, as this pilot study and other empirical studies have shown [11,14]. Inquiring about patients' confession or religious background, like "spiritual history", can encourage the usage of such a resource $[23,24]$. Elements of "Vipassana-meditation" in dialectical behavior therapy are used without greater attention to its Buddhist roots [25].

In therapeutic settings one of the important aspects seems to be professional neutrality, which could be opposed to the salutogenesis use of religious/spiritual contents in the therapeutic process. In this pilot study a notable number of the respondents mentioned that religious/spiritual contents should not be integrated in the therapeutic process because of the importance of the aforementioned professional neutrality and the protection of patient's privacy. Other private domains such as job, friends, sexuality, or hobbies, which are not normatively neutral either, are, however, incorporated "neutrally". What is the reason for this difference?

As a major reason we assume that staff shows some behavior insecurity when it comes to dealing with religious/spiritual issues though there is a certain awareness in regarding related activities and resources. Improved curricula of psychiatry and psychotherapy trainings can reduce the staff's uncertainty and insecurity and help to integrate religious/spiritual aspects in psychiatric therapeutic processes $[4,13,26]$, including an adequate understanding of professional neutrality. Promoting interdisciplinary teamwork between professionals of clinical pastoral care and

22 The subjects had multiple possibilities for their response. 
psychiatric staffs could help to improve the integration of patients' religious/spiritual needs, as can be seen in palliative care medicine $[21,26,27]$.

In spite of the aforementioned results and discussions, this study has certain limits. First of all, the staff's spirituality was measured by DRI according to the intrinsic religiosity concept of Allport and Ross, even though spirituality and intrinsic religiosity, strictly speaking, are not the same. Thus, three items of the DRI are not completely sufficient for precisely measuring spirituality. Secondly, it is possible that the German questionnaire has minor content differences, as it is a translation of the English original. In general, one must also consider that the results of this pilot study only cover a limited geographical area, as it was undertaken only at the Freiburg University Hospital. In future studies, these limitations should be improved in order to achieve more exact results, which can be generalized to a larger public.

\section{Conclusions}

According to empirical studies published in English (speaking countries), therapists do not incorporate patients' religious/spiritual backgrounds into therapeutic processes [28]. This seems to be valid for German speaking countries as well [29].

It is needless to say that, in medical settings, understanding all dimensions of a person is important. It seems only natural, however, to include religious/spiritual issues, because a person as a whole can only be understood by looking at the physical, mental, social and also spiritual dimensions $[2,6,15,16]$.

After having been successfully sensitized for multifactoral, bio-psycho-social ways of thinking in psychiatry and psychotherapy, it is now a task to achieve an equal acceptance for religious/spiritual needs. More and more empirical studies have shown a weak but positive correlation between religiosity/spirituality and mental health [6-10,21]. However, an exact explanation about such correlations and more accurate observations of religious/spiritual needs and resources are needed.

This pilot study has shown, that staff in psychiatry and psychotherapy neither regard religious/spiritual contents as a potential risk factor (any more) nor pathologically. However, religious/spiritual contents are still not proactively incorporated into therapy. Properly trained staff can acknowledge, respect, and even appreciate patients' religious/spiritual needs. The positive consideration of staff in psychiatry and psychotherapy about religious/spiritual contents, which has been shown in this pilot study, matches the viewpoint of the WHO regarding the meaning of religiosity/spirituality for therapy, coping and patients' life quality.

\section{Acknowledgments}

We thank all participants and collaborators, particularly M. Berger and U. Voderholzer for assisting and cooperating with the pilot study. 


\section{References}

1. Pajonk, F.-G.B. Religiosität und psychische Gesundheit. In Wenn Geist und Seele streiken. Handbuch psychische Gesundheit; Hohagen, F., Nesseler, T., Eds.; Südwest Verlag: München, Germany, 2006; pp. 93-104.

2. Wyss, D. Psychologie und Religion; Königshausen \& Neumann: Würzburg, Germany, 1991.

3. Klein, C.; Utsch, M. Religion, Religiosität, Spiritualität. Bestimmungsversuche für komplexe Begriffe. In Gesundheit-Religion-Spiritualität. Konzepte, Befunde und Erklärungsansätze; Klein, C., Berth, H., Balck, F., Eds.; Juventa Verlag: Weinheim; München, Germany, 2011; pp. 25-45.

4. Hofmann, L. Spiritualität und Religiosität in der psychotherapeutischen Praxis. Eine bundesweite Befragung von psychologischen Psychotherapeuten. Ph.D. Dissertation, University of Oldenburg, Oldenburg, Germany, 2009.

5. Koenig, H.G. Medicine, Religion and Health: Where Science and Spirituality Meet; Templeton Foundation Press: West Conshohocken, PA, USA, 2008; pp. 21-36.

6. Baumann, K. Macht Glaube gesund?: Zum Effekt religiösen Glaubens in Prävention und Krankheitsbewältigung. Prävention 2008, 2, 61-64.

7. Büssing, A. "Spiritualität"-Worüber reden wir? In Spiritualität, Krankheit und Heilung-Bedeutung und Ausdrucksformen der Spiritualität in der Medizin; Büssing, A., Ostermann, T., Glöckler, M., Matthiessen, P.F., Eds.; VAG: Frankfurt am Main, Germany, 2006; pp. 11-25.

8. Fontana, A.; Rosenheck, R. Trauma, change in strength of religious faith and mental health service use among veterans treated for PTSD. J. Nerv. Ment. Dis. 2004, 192, 579-584.

9. Galanter, M. Spirituality, evidence-based medicine and alcoholics anonymous. Am. J. Psychiatr. 2008, 165, 1514-1517.

10. Seybold, K.S. Physiological mechanisms involved in religiosity / spirituality and health. J. Behav. Med.2007, 30, 303-309.

11. Curlin, F.A.; Lawerence, R.E.; Odell, S.; Chin, M.H.; Lantos, J.D.; Koenig, H.G.; Meador, K.G. Religion, spirituality, and medicine: Psychiatrists' and other physicians' differing observations, interpretations, and clinical approaches. Am. J. Psychiatr. 2007, 164, 1825-1831.

12. Baetz, M.; Larson, D.B.; Marcoux, G.; Jokie, R.; Bowen, R. Religious psychiatry: The Canadian experience. J. Nerv. Ment. Dis. 2002, 190, 557-559.

13. Delaney, H.D.; Miller, W.R.; Bisono, A.M. Religiosity and Spirituality among psychologists: A survey of clinician members of the American psychological association. Prof. Psychol. Res. Pract. 2007, 38, 538-546.

14. Shafranske, E.P.; Malony, H.N. Clinical Psychologists' religious and spiritual orientations and their practice of psychotherapy. Psychotherapy 1990, 27, 72-78.

15. Chuengsatiansup, K. Overview: Spirituality and Health; an initial proposal to incorporate spiritual health in health impact assessment. Available online: www.who.int/hia/examples/ overview/whohia203/en/ (accessed on 26 September 2011). 
16. Mental Health: Evidence \& Research, Department of Mental Health \& Substance Dependence World Health Organization Geneva, Switzerland. WHOQOL-SRPB Field-Test Instrument. Available online: www.who.int/mental_health/media/en/622.pdf (accessed on 26 September 2011).

17. Allport, G.W.; Ross, J.M. Personal religious orientation and prejudice. J. Personal. Soc. Psychol. 1967, 5, 432-443.

18. Hill, P.; Hood, R. Measures for Religiosity; Religious Education Press: Birmingham; AL, USA, 1999; pp. 130-132.

19. Koenig, H.G.; Büssing, A. The duke university religion index (DUREL): A five-item measure for use in epidemological studies. Religions 2010, 1, 78-85.

20. Sherman, A.C.; Plante, T.G.; Adams, D.C.; Harbison, C.; Burris, S.K. A multidimensional measure of religious involvement for cancer patients: the Duke religious index. Support. Care Canc. 2000, 8, 102-109.

21. Larson, D.B.; Larson, S.S. Spirituality's potential relevance to physical and emotional health: A brief review of quantitative research. J. Psychol. Theolog. 2003, 31, 37-51.

22. Tepper, L.; Rogers, S.A.; Coleman, E.M.; Malony, H.N. The prevalence of religious coping among persons with persistent mental illness. Psychiatr. Serv. 2001, 52, 660-665.

23. Baumann, K. Krankheit - Heilung - Heil. Medizin und Pflegewissenschaft im Gespräch mit der Theologie. Stimmen der Zeit 2010, 135, 633-637.

24. Frick, E., Roser, T., Eds. Spiritualität und Medizin: Gemeinsame Sorge für den kranken Menschen; Kohlhammer: Stuttgart, Germany, 2009.

25. Germer, C.K., Siegel, R.D., Fulton P.R., Eds. Mindfulness and Psychotherapy; The Guilford Press: New York, NY, USA, 2005.

26. Aten, J.D.; Worthington, E.L. Next steps for clinicians in religious and spiritual therapy: An endpiece. J. Clin. Psychol. 2009, 65, 224-229.

27. Roser, T. Spiritual Care. Ethische, organisationale und spirituelle Askpekte der Krankenhausseelsorge. Ein praktisch-theologischer Zugang; Kohlhammer GmbH: Stuttgart, Germany, 2007.

28. Jensen, J.P.; Bergin, A.E. Mental health values of professional therapists: A national interdisciplinary survey. Prof. Psychol. Res. Pract. 1998, 19, 290-297.

29. Kaiser, P. Religion in der Psychiatrie. Eine (un)bewusste Verdrängung? V\&R Unipress: Göttingen, Germany, 2007. 


\title{
Psychotherapy with African American Women with Depression: Is it okay to Talk about Their Religious/Spiritual Beliefs?
}

\author{
Maigenete Mengesha and Earlise C. Ward
}

\begin{abstract}
A growing body of research focusing on African Americans' mental health is showing that this group relies heavily on their religious/spiritual beliefs and practices to cope with mental health issues including depression. Unfortunately, the psychotherapy literature provides little guidance on how to incorporate religion/spirituality into psychotherapy with African American women. With the growing cultural diversity of the U.S. population, there has been more emphasis on providing patient-centered culturally sensitive care, which involves providing care that is respectful of, and responsive to, individual patient preferences, needs, and values. This paper provides a synthesis of literature that psychotherapists could use to become more culturally sensitive and patient-centered in their clinical practices; that is, to recognize and integrate religion/spirituality into their work with African American women experiencing depression, and possibly other groups with similar needs.
\end{abstract}

Reprinted from Religions. Cite as: Mengesha, M.; Ward, E.C. Psychotherapy with African American Women with Depression: Is it okay to Talk about Their Religious/Spiritual Beliefs?. Religions 2012, 3, 19-36.

\section{Introduction}

African American women's use of mental health services is lower than other groups, and when they do seek professional treatment many of them terminate treatment prematurely in part because their racial and or cultural needs have not been addressed [1-3]. Results of a study examining acceptability of depression treatment, suggested that compared to Whites, African Americans were less likely to find either antidepressant medication or counseling acceptable [4]. These research results then raise the question, how are African American women actually coping with depression?

There is a growing body of literature indicating that African American women rely on religious beliefs and practices to cope with health problems including depression. Chatters, Taylor, Jackson, and Lincoln [5] examined religious coping among African Americans, Caribbean Blacks, and nonHispanic Whites when dealing with stressful situations, they found that African Americans (90.4\%) and Caribbean Blacks (86.2\%) reported higher use of religious coping compared to non-Hispanic Whites (66.7\%). In another study, Dessio et al. [6] found that $43 \%$ of African American female participants used religion to cope with serious health problems including depression, cancer, and heart disease "in the past year".

African American women's low use of mental health services, high rates of premature termination from counseling, and high reliance on religious/spiritual coping to manage depression, 
raises two questions: (1) are African American women's low use of professional mental health services related to receiving conventional mental health services rather than psychotherapy incorporating religion/spirituality? and (2) do psychotherapists know when and how to incorporate religion/spirituality into psychotherapy in working with African American women with major depressive disorders (MDD)? Currently, these two questions are unanswered due to: (1) limited use of religion/spirituality in psychotherapy; (2) little or no training provided to psychologists and clinical social workers regarding use of religious/spiritual psychotherapy [7,8]; and (3) little published literature to help psychotherapists incorporate religion/spirituality into psychotherapy when working with African American clients [7].

Use of the Patient-Centered Culturally Sensitive Health Care Model (PC-CSHC) has the potential to address some of the issues discussed above. The PC-CSHC Model postulates: (a) training provided to both the patient/client and health care provider can promote provision of patient-centered culturally sensitive health care; (b) when patient-centered culturally sensitive health care is provided to patients/clients it influences patients/clients perceived levels of provider cultural sensitivity and interpersonal control (psychological empowerment), which in turn impact patient/client level of engagement in healthier behaviors, and satisfaction with health care; (c) patient/client satisfaction with health care in turn influences treatment adherence; (d) level of treatment adherence and level of engagement in healthier behaviors which directly influence patients health outcomes [9,10]. See Figure 1 for depiction of the PC-CSHC Model. The PC-CSHC Model was developed to help guide researchers and providers in promoting culturally sensitive health care practices and research, with the goal of providing high quality of care and reducing health disparities [10]. 


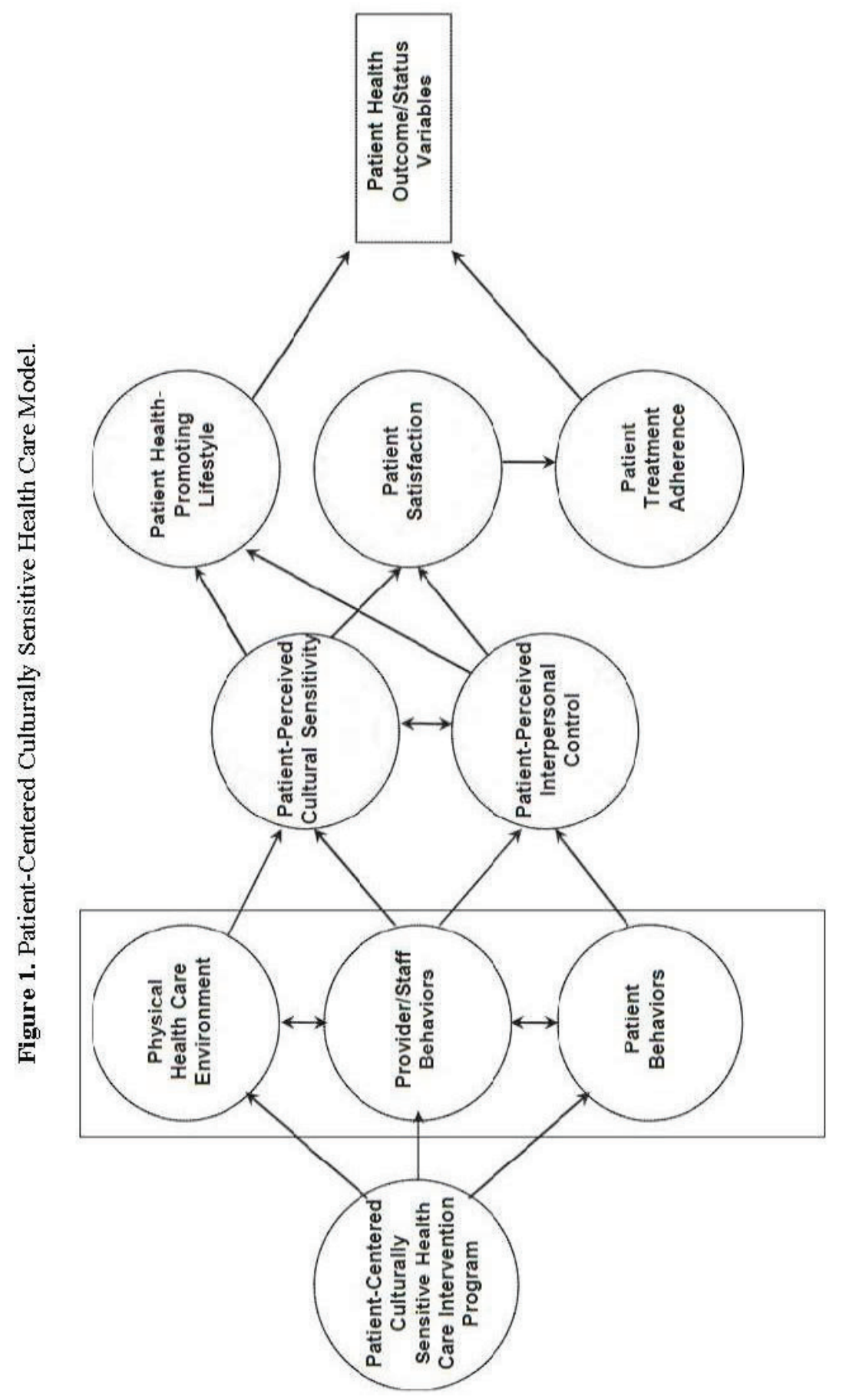

Given the importance of religion/spirituality for African American women with life stressors and mental health challenges; use of the PC-CSHC can potentially aid in providing patient-centered culturally sensitive care in a manner that recognizes these women's religious/spiritual beliefs and incorporates those beliefs into psychotherapy.

Using the tenets of PC-CSHC, the purpose of this paper is to provide a synthesis of literature that can be used to inform training of psychotherapists to become more patient-centered and culturally sensitive in their clinical practices. Such training can potentially help psychotherapists to recognize and integrate religion/spirituality into their work with African American women experiencing depression. A further aim is to use the synthesis of the literature to inform future research. To this end, we: (1) Examined current mental health literature with a focus African American 
women, depression, mental health service use and quality of care, use of religious/spiritual coping, and the role of Black churches. (2) Discussed implications for future research, training, and clinical practice with a focus on religion/spirituality among African American women.

For the purpose of this paper we will use the terms religious/spiritual, and religion/spirituality. Koenig, McCullough \& Larson, [11] defines religion as an organized system of beliefs, practices, and rituals designed to facilitate closeness to God, and spirituality is defined as a personal quest for understanding answers to ultimate questions about life, meaning, and relationships to the sacred. A person can be religious and spiritual, religious but not spiritual, spiritual but not religious, or neither religious nor spiritual [12]. Although the terms religious and spiritual are distinct, they have overlapping meaning [13] and are often used interchangeably among African Americans. There is, however, debate among researchers about the definition of these constructs [7,14]. See Zinnbauer, Pragament, \& Scott, 1999 [15] for more details about these debates.

To remain consistent with the PC-CSHC model we decided to focus our definitions of these constructs on the self-definitions common among African Americans. When examining self-definitions of religiosity and spirituality, Chatters found that Americans irrespective of race/ethnicity generally characterize themselves as both spiritual and religious $[5,16]$. Yet, similar research findings indicated African Americans were even more likely to identify as both spiritual and religious [16-18].

Since African Americans tend to identify as both religious and spiritual, and use these terms interchangeably in their identification, for the purpose of this paper, we chose to use the terms religious/spiritual, and religion/spirituality as defined by Koenig, McCullough \& Larson, [11].

\section{Synthesis of Relevant Literature}

\section{African American Women and Major Depressive Disorder}

According to the Diagnostic and Statistical Manual of Mental Disorders, Fourth Edition (DSMIV-TR), the guidelines used by mental health providers to diagnose mental illness, MDD symptoms cluster on five dimensions: emotional; behavioral; physiological; motivational; and cognitive [19]. Some of the specific symptoms associated with MDD include: depressed mood; feelings of sadness; hopelessness; worthlessness; helplessness; changes in sleep habits (increase or decrease); lack of motivation and energy; difficulty concentrating; recurrent thoughts of death; and in cases of severe MDD present and past suicide attempt(s).

MDD is increasingly becoming a national health crisis. According to the National Institute of Mental Health (NIMH), in any one-year period, MDD affects more than 12 million women (12\%) and more than 6 million men (7\%) in America. MDD is also the most common mental illness among all women, especially women of childbearing and childrearing ages [20]. Women affected with severe MDD are at increased risk of attempting suicide [21]. Equally concerning, by 2020 depression will be the second most common disorder afflicting the elderly [22]. MDD is also becoming a global concern. By the year 2030 depression will be one of the top three leading causes of death in the world [23].

Although the 12-month prevalence of MDD among African Americans and Caucasians are similar, 5.9\% and 6.9\% respectively, African Americans (56.5\%) report more severe symptoms and associated disability than Caucasians (38.6\%) [24]. Specific to women, the prevalence of 
depression is twice the rate for men [25]. Poverty has been identified a risk factor for the development of MDD [26], particularly among women. Poverty is such a powerful risk factor among women that McGrath et al., [27] postulates that a woman experiencing poverty is on a "pathway to depression." Given that African American women are heavily burdened by poverty, child rearing responsibilities, and an increased likelihood of racial and gender discrimination, they are at high risk for MDD [28,29]. More specifically, due to the intersection of gender and poverty, low-income African American women are at particularly high risk for experiencing depression at some point in their lifetime [30]. Such that a national study conducted by the California Black Women's Health Project showed 60\% of African-American women have symptoms of depression [31].

\section{Mental Health Service Use and Quality of Care}

The high prevalence of MDD among African American women does not translate to increased use of mental health services. Historically and currently, African American women tend to underutilize mental health services, relative to other groups [32,33]. A recent study with a sample of 3570 (56\% of the sample were female) showed that only $26.1 \%$ of African Americans with MDD used specialty mental health care within a 12 -month period. Furthermore, only $28 \%$ of African Americans with severe MDD sought treatment within a 12-month period [24]. Health disparities research has shown that African Americans, including African American women's low use of mental health services is in part due low access to mental health services due to poverty resulting in lack of health insurance [34]. Low use of treatment services is also due in part to the quality of mental health care they receive [34]. For instance, although psychotherapy care is preferred among African Americans [4] research has shown they receive culturally insensitive psychotherapy care, resulting in high rates of premature termination from mental health services [35].

The issue of quality of care specifically culturally insensitive care or care that does not meet the cultural needs of clients is a concern among African American clients/patients [34]. In a study of 201 African Americans (134 women and 66 men), which examined participants perceptions of psychotherapy and psychotherapists, findings showed concerns about quality of care. For instance, a participant who had used mental health services in the past stated, “it doesn't seem like they're truly concerned about you, what you could possibly be going through. You know, it's just like "I'm about to get paid.... your hour is up" [35].

Poor quality of care is also evident in disparities in rates of diagnoses. Cheung and Snowden [36] reported that schizophrenia diagnosis rates among African Americans were sometimes twice as high as those for Whites, but that Whites were diagnosed with affective disorders (i.e., depression) at nearly twice the rate of African Americans. This finding suggests that African Americans are more likely to be diagnosed with schizophrenia and less likely to be diagnosed with an affective disorder compared to Whites. It is possible these racial differences in psychiatric diagnoses may be due to diagnosticians' misunderstanding of ethnic/ racial differences in psychopathology [37,38].

There have also been reports of problems with communication. An analysis of patient-physician encounters indicates that physicians may be more likely to minimize emotional symptoms of African American than of Whites [39]. Also, relative to Whites, African Americans were more likely to rate their visits with White physicians as less participatory [37]. 
Missing from the quality of care research is use of religion/spirituality practices in psychotherapy. Is it possible that incorporating religion/spirituality in psychotherapy with African American will improve quality of care? Furthermore, is it possible that because African American women rely on religion/spirituality, incorporating religion/spirituality into psychotherapy might actually increase use of mental health services by this group? The section below will help to answer some of these questions.

\section{African American Women and Use of Religious/Spiritual Coping with MDD}

Research suggests religiosity and spirituality are integral to African American culture, identity, and coping [40-44]. "Many African Americans are raised with an internalized sense of connectedness to religious values, which provide a sense of purpose, power and self-identity" [42]. Prayer and religion have been cited as primary coping skills used by African Americans in dealing with personal problems: cancer; recovery from substance abuse; pregnancy or infant loss [41]; agoraphobia; bipolar disorder; and depression [44-48]. In comparison with Caucasians, African Americans regularly endorse more use of prayer and spiritual coping strategies [5,41,46,49].

Despite African American's heavy reliance on religious/spiritual coping, research examining religious/spiritual coping in association with MDD outcomes is limited. In addition most of the studies available have used small sample sizes, which were often not representative of African Americans, and were conducted in the 1990s. However, more recently, there has been an increase in research in this area. For the purpose of this paper, we chose to focus on studies using larger samples, and some of the more recently published literature examining religious/spiritual coping in association with MDD and other mental health outcomes.

Brown \& Gary [50] examined whether degree of religiosity was related to levels of depression. The sample comprised of non-institutionalized African American adult men $(\mathrm{N}=142)$ from a large northeastern U.S. city. The Center for Epidemiological Studies Depression Scale (CES-D) scale was used to measure levels of depression. The CES-D is a 20-item self-report inventory developed by National Institute of Mental Health to assess the frequency and severity of depression symptoms, with a possible range $0-60$. A standard cutoff score of 16 indicates depressive symptoms. Differences in mean scores in the CES-D were examined across a measure of participation in personal, group, or institutional religious activities, ranked into three groups of high, medium, and low religiosity. A protective trend was apparent in the findings, such that low, medium and high religiosity was associated with decreasing CES-D scores (12.78, 12.08, and 11.30, respectively). However, the sample was non-clinical, meaning they did not have clinical depression (CES-D score of 16 or higher), and results did not achieve statistical significance.

Brown and colleagues used data from a community survey of African American adults from a northeastern city $(\mathrm{N}=451)$ to examine the relationship between several measures of religiosity and scores on the CES-D [50]. In this study, a 10-item summary index of religiosity was constructed from several items assessing institutional and non-group religious activities, as well as attitudes about religion. Analyses revealed a significant inverse association between religiosity and depressive symptoms. CES-D scores were lower in successively higher categories of religiosity for both men and women. 
Another study of religion and depression by the same investigators was based on a sample of 537 African American adult men from an eastern U.S. city [51]. The researchers used the CES-D scores to assess depressive symptoms. Regression analysis results revealed significant protective effects for both religiosity and presence of denominational affiliation. After controlling for a variety of socio-demographic variables, denominational affiliation maintained a significant protective effect against depression.

A subsequent investigation by Brown and colleagues included a more explicitly clinical and epidemiological focus using data from a sample of African American men $(\mathrm{N}=865)$ [52]. The past-year prevalence of depressive symptoms was assessed and found that the one-year prevalence rate of major depression among participants without a religious affiliation was $6.4 \%$, the highest for any category of any exposure variable in the study except for poor health status (6.9\%). However, after adjusting for the effects of various measures of socio-demographic and household characteristics, such as health, stress, and family history of mental illness, the odds ratio associated with lack of a religious affiliation was no longer statistically significant [52].

In a more recent study, in which data from the National Survey of American Life (NSAL) and the National Comorbidity Survey-Replication (MCS-R) were used to examine racial and ethnic differences in the use of complementary and alternative medicine (CAM) for the treatment of mental disorder and substance use disorders among African Americans, Black Caribbean and Whites. CAM "is a group of diverse medical and health care systems, practices, and products (i.e., chiropractic, massage, acupuncture and megavitamins), that are not presently considered part of conventional medicine" (CAM Basics). Results indicated a higher proportion of Whites (39\%) used CAM for mental disorders or substance use disorder compared to African Americans (24\%) and Black Caribbeans (12\%) [53]. Yet, consistent with current research, a higher proportion of African Americans (18\%) reported using spiritual healing by consulting with their spiritual and religious leaders than either Black Caribbeans (13\%) or Whites (9\%) [53]. This finding builds on other recent research using the NSAL which found that compared with Whites, African Americans are more religious and more likely to rely on religious coping for their mental health needs [5,54].

Although the research by Brown and colleagues make a significant contribution to the sparse literature in this area, most of the study samples were primarily African American men, thus limiting generalizability of study results to African American women. Similarly, although more recent literature documents African Americans tendency to rely on spirituality and religious coping to address mental health needs, none of the studies examined effectiveness of psychotherapy incorporating religion/spirituality in reducing symptoms of MDD. Given that within the African American community, women, the elderly and those facing health problems are more likely to tap into religion/spirituality as a coping mechanism [33,55], efficacy research examining health outcomes associated with use of psychotherapy integrated with religion/spirituality are critically needed. Such research has the potential to increase delivery of culturally sensitive patient-centered care to African American women.

\section{Cultural Competence and Psychotherapy}

With the increasing focus on cultural competence in an effort to meet the needs of culturally diverse individuals, psychologists and researchers are challenged to integrate multicultural 
strategies into psychotherapy [56]. Psychologists are becoming more culturally competent in addressing the needs of culturally diverse clients, but incorporating the religious and spiritual worldviews of clients including African American clients is still lagging [57].

The slow pace in which religion and spirituality is emphasized in the psychotherapy literature is not surprising given the limited courses and training in religious/spirituality. For instance, Young et al. [58] found that only 23 of 94 counseling programs accredited by Council for Accreditation of Counseling and Related Educational Programs (CACREP) offer only one specific course on spirituality and religion in counseling. Furthermore, content analysis of syllabi for spirituality courses showed inclusion of religion/spirituality in the curriculum was addressed in limited detail [59].

In a similar helping professional field, social work, the limited training in religion/spirituality is also a concern for clinical social workers who provide psychotherapy [60]. More recently, Asher [61] postulated "Over the past two decades there has been expanding exploration of spirituality and religion in social work, although they remain largely on the periphery of the profession's educational enterprise and mainstream practice." Asher further stated "My social work education and training ignored the spiritual and religious dimensions of practice."

It is evident that while a growing body of research suggests use of religious/spiritual coping to deal with mental health issues including depression is quite common among African American women $[6,33,57,62]$, psychotherapists are not receiving adequate training to recognize and integrate religion/spirituality into psychotherapy [59-61].

\section{Role of the Black Church in Addressing Mental Health Issues}

African Americans have reported significant levels of religious involvement in their churches [63]. Furthermore, throughout history, African American clergy and the African American church have been integral in providing social services and battling oppression of African Americans [64]. Given the role of African American clergy and the African American churches, researchers are beginning to recognize the African American church as a potential preventive resource for addressing health disparities by assisting in the dissemination of health information, and education within their communities [48].

Black Churches have been the longest standing and most influential institution in African American history [65-67]. From the early 1900s, there has been continuing research interest in the patterns, and functions of religion/spirituality in the lives of African Americans $[65,66]$. The definition for the terms Black church or African American church is to refer to churches that collectively are predominantly African American Christian churches of any and all denominations that minister to African American communities in the United States [68,69]. Although some groups of African American churches, such as the African Methodist Episcopal churches belong to predominantly African American denominations [69], many African American churches may also be a part of predominantly White denominations (i.e., Lutherans, older established Episcopalians, Protestants, etc.). The combined term, The Black church, likely came into reality sometime after emancipation because at that time African Americans were free to establish separate churches, to create their own communities, and to worship in their own culturally distinct ways $[68,70]$. Within 
the Black churches, African Americans were finally able to build strong community organizations and to hold positions of leadership that were previously denied to them in America [70].

Lincoln and Mamiya [69] argued that the role of the Black Church in the African American community are more socially active in their communities and tend to participate in a greater number of community programs than are Caucasian churches. This distinctiveness may be due to the fact that African American churches are more central organizations in their communities compared with Caucasian churches. It may also be that African American church members, as well as other ethnic groups confront higher levels of poverty and other socioeconomic and social issues, and are therefore more pressured to advocate and address these issues within their congregations [69]. For example, in a national study of African American clergy, Lincoln and Mamiya [71] found 92\% of Black clergy endorsed involvement of Black churches in social and political issues, and indicated it was appropriate for them to express their views in support of these issues.

In contrast to African Americans relatively low use of the formal health system, research indicates that they report a relatively high use of clergy and Black church as a resource to solve or discuss many health problems, including mental illness $[47,48]$ and psychical illnesses such as AIDS, heart disease, and cancer [6,72]. The tendency of African Americans to use clergy for health care services that might otherwise be provided by primary care or mental health care system may be related to receiving poor quality care [34]. They may also use the Black churches because historically Black churches have functioned as social service agencies in the Black communities.

\section{Implications for Future Research and Clinical Practice}

\section{Research}

Outcome studies examining the effectiveness of religious/spiritual psychotherapy interventions are still in their infancy [73]. In fact, few empirical studies of religious/spiritual interventions in psychotherapy have been conducted [74]. And to date, no research study could be located that has examined effectiveness or health outcomes associated with use of religious/spiritual psychotherapy among African American women with MDD. These gaps in the literature underscore the need for: (1) more effectiveness research, (2) research focusing on specific racial/ethnic and cultural groups, and (3) developing and testing of psychotherapy interventions incorporating religious/spiritual for specific groups. Such research can potentially inform treatment provided to these groups. Prior to conducting this line of research, there is however, a need for more valid and reliable measures of religion/spirituality in general [75], and especially for African Americans.

Recognizing the prominent role of Black churches in the African American community, mental health researchers could explore opportunities for collaboration to develop and test effectiveness of religious/spiritual psychotherapy interventions. Giving voice to religious/spiritual African Americans in development of such interventions is critical in providing patient-centered culturally sensitive care. More specifically, studies examining African American women's needs for religious/spiritual integrated psychotherapy, and what such psychotherapy should entail is needed. Thus, studies using qualitative approaches and community based participatory design would be useful. There is also a need for studies using longitudinal design examining changes and 
fluctuations in religious/spiritual coping over time and implication for adjustment and mental health treatment [74]. Use of longitudinal designed studies can also provide insight about long term effects of religious/spiritual intervention over time.

Researchers and academicians might also explore working with Black churches to develop training programs for psychology and social work students interested in receiving training to work with religious/spiritual clients, as well as continuing education training for licensed psychologists and clinical social workers. Also needed are clear practice guidelines regarding incorporation and use of religious/spiritual interventions in psychotherapy. Researchers can collaborate with clergy from various faiths and denominations to inform development training programs and practice guidelines.

\section{Clinical Practice}

According to the competencies developed by Burke [76] and colleagues at the 1995 Summit on Spirituality, to be competent in integrating and using religion/spirituality in psychotherapy, psychotherapists could be able to incorporate the following in their patient practice:

1. "Explain the relationship between religion and spirituality, including similarities and differences;",

2. "Describe religious and spiritual beliefs and practices in a cultural context;"

3. "Engage in self-exploration of his/her religious and spiritual beliefs in order to increase sensitivity, understanding and acceptance of his/her belief system;"

4. "Describe one's religious and/or spiritual belief system and explain various models of religious/spiritual development across the lifespan;"

5. "Demonstrate sensitivity to and acceptance of a variety of religious and/or spiritual expressions in the client's communication;"

6. "Identify the limits of one's understanding of a client's religious/spiritual expression, and demonstrate appropriate referral skills and general possible referral sources;"

7. "Assess the relevance of the spiritual domains in the client's therapeutic issues;"

8. "Be sensitive to and respectful of the spiritual themes in the counseling process as befits each client's expressed preference;" and

9. "Use a client's spiritual beliefs in the pursuit of the client's therapeutic goals as befits the clients expressed preference" $[59,76]$.

Below is a more detailed description and discussion of some of the above-mentioned competencies, and some additional approaches generated from our review of current literature and the Patient-Centered Culturally Sensitive Health Care Model.

\section{Understanding Conceptualizations of Religion and Spirituality}

According to Burke's [76] first competency, he describes the importance of "Explaining the relationship between religion and spirituality, including similarities and differences;" While Burke's competency is important, results noted in this review triggered another essential aspect to add to Burke's competency. Given that this review describes the ways in which religious, spiritual or both religious and spiritual may be an important aspect of how individuals self-define their 
worldview within particular groups - mainly African American women, it is critical to reiterate the need for psychotherapists to allow clients to self-define. It then becomes the role of the psychotherapist to understand the client's self-definition (perhaps a client may say, I am both religious and spiritual) to discover the role of religion/spirituality in the lives of their clients.

\section{Self-awareness}

Prior to working with religious/spiritual clients, psychotherapists should become more self-aware of their own religious/spiritual beliefs and practices as well as their concerns and skepticism about religion and spirituality. According to Post [7], "awareness of one's own beliefs and biases regarding religion/spirituality will help therapists avoid imposing their own values on their clients." Use of a spiritual autobiography is one method to explore and examine one's own religious and spiritual views and values, as well as experiences, situations, and education that have led to their religious and spiritual beliefs and practices or doubts, skepticism and biases [77]. During this selfawareness process and in the process of providing psychotherapy, psychotherapists need to recognize and own their limitations. When limitations are identified, clients can be informed and referrals provided, or the psychotherapist can seek consultation from relevant clergy and religious/spiritual leaders.

Although it is helpful for psychotherapists to be somewhat knowledgeable about basic doctrines of their clients' religion/spirituality, they do not have to be experts. However, they could be open [7] to differing doctrines. Recent research indicates that when clients felt their therapist were open to discussing and respectful of their religious/spiritual beliefs it helped to strengthen the therapeutic alliance [78]. In sum, clinicians should be mindful of their own beliefs, and biases regarding religion and spirituality. When necessary seek consultation, supervision and facilitate referrals.

\section{Client Assessment}

During the initial clinical intake assessment, a scale/questionnaire capturing clients' religious/spiritual beliefs and practices could be included in the clinical assessment. Although few of the measures of religion and spiritual have been evaluated for validity and reliability [74], the RCOPE and Brief RCOPE are valid and reliable measures of religious coping $[73,79]$. The RCOPE is a comprehensive assessment of religious coping that can be used by researchers and practitioners to measure religious coping with major life stressors [73]. The Brief RCOPE is a shorter version of the RCOPE, with 14 items assessing religious coping with major life stressors. The Brief RCOPE is the most commonly used measure of religious coping [79].

In cases where clients' self-identify in the intake that they are religious/spiritual, as early as possible psychotherapists need to let clients know that they are open to discussing religion/spirituality. In particular, they should explicitly state, possibly in the first session, that they are open to and welcome a discussion of religion/spirituality if clients are interested. In addition, psychotherapists can further assess/inquire about clients' religious/spiritual beliefs, and preferences and expectations for treatment. 
Some clients may come to therapy with religious/spiritual concerns/struggles; in such cases therapists should assess clients concerns by first conducting a religious/spiritual history and present religious/spiritual status in a manner similar to conducting a psychosocial history [80]. With such data the psychotherapist and client can collaboratively work on establishing an appropriate plan of care [7]. It is strongly suggested to have clients provide informed consent to receive religious/spiritual interventions, so that clients are informed and receive their preferred choice of care.

\section{Do Not Make Assumptions}

Engaging clients in developing an appropriate treatment plan of care is important because not all religious/spiritual clients may want their psychotherapy to focus on their religious/spiritual needs. In some cases, religious/spiritual clients may prefer to have religious/spirituality issues addressed by their religious/spiritual leader [7].

\section{Types of Religious/Spiritual Interventions}

Religious/spiritual interventions involve the use of techniques from formal religious traditions, which are used as adjuncts to counseling or traditional theories of counseling and are adapted to the needs and preference of religious/spiritual clients [12]. Although there are varying views regarding defining religious/spiritual interventions, there are at least three common views [7,81]. For instance, one view defines religious/spiritual interventions as any secular techniques or approaches used to strengthen the faith of a religious/spiritual client. The second view involves use of secular techniques modified to include religious content in an explicit manner (e.g., Christian cognitive therapy). The third view focuses on use of actions or behaviors derived from religious practices such as blessings, reference to sacred text including the Bible, scripture reading, and audible prayer [7,81].

Religious and spiritual interventions that can be incorporated into psychotherapy when working with clients include: therapist prayer or client and therapist prayer, teaching scriptural concepts, reference to Scriptures, religious or spiritual self-disclosure, spiritual confrontation, spiritual assessment, religious relaxation or imagery, blessing by the therapist, encouraging forgiveness, use of religious or faith community, client prayer, encouragement of confession, referral for blessing, religious journaling, spiritual meditation or relaxation, religious bibliotherapy, scripture memorization and dream interpretation [14].

It is important to note that outcomes studies on the effectiveness of these interventions are still in an infancy stage [14-73], and few empirical studies of religious/spiritual interventions in psychotherapy have been conducted [74]. However, based on clients' needs and preferences, psychotherapists with appropriate training, supervision, and consultation can use these interventions.

\section{Partnership with Clergy}

Psychotherapists could also establish partnerships with clergy and religious/spiritual leaders in an effort to seek consultation when necessary [82]. Such partnerships are critical in ensuring that psychotherapists are not inadvertently counseling outside their scope of practice or crossing "turf." 
Psychotherapists can also work with religious/spiritual leaders to educate them and the larger African American community about mental health, mental illness and treatment options. Such collaborations have the potential to reduce stigma associated with mental illness in the African American community and increase treatment-seeking behaviors.

\section{Conclusions}

In this paper, we provided a synthesis of literature and discussed implications for research and clinical practice that can aid psychotherapists in developing the skills necessary in providing patient-centered culturally sensitive care to African American women. Based on our review of the literature, we found a growing body of research suggests African American women rely heavily on religious/spiritual beliefs and practices to cope with mental health issues including depression. However, outcome studies examining the effectiveness of religious/spiritual psychotherapy interventions are still in an infancy stage [73]. In fact, few empirical studies of religious/spiritual interventions in psychotherapy have been conducted [59,74]. And to date, no research study could be located that has examined effectiveness or health outcomes associated with use of religious/spiritual psychotherapy among African American women with major depressive disorder. In addition, there are no clear practice guidelines regarding incorporation and use of religious/spiritual interventions in psychotherapy [59,74]. Furthermore, there is virtually no training for psychotherapists who are interested in learning procedures to incorporate religion/spirituality in psychotherapy when working with African American women. Given that current research indicated African American women are using religious/spiritual beliefs and practices to cope with depression, it is imperative that psychotherapists are able to work effectively with this group. In sum, research focusing on developing interventions examining health outcomes associated with incorporating religion/spirituality in psychotherapy is critically needed. Also needed are treatment guidelines focusing on incorporating religion/spirituality in psychotherapy, and establishing competencies for effective clinical practice. And, most importantly, training must be provided to psychotherapists interested in incorporating religion/spirituality into their clinical practice. 


\section{References}

1. Cannon, L.W.; Higginbotham, E.; Guy, R.F. Depression among Women: Exploring the Effects of Race, Class, and Gender; Center for Research on Women, Memphis State University: Memphis, TN, USA, 1989.

2. Ward, E.C. Keeping it Real: A grounded theory study of African American clients engaging in counseling at a community mental health agency. J. Couns. Psych. 2005, 52, 10.

3. Warren, B. Depression in African-American women. J. Psychosoc. Nurs. 1994, 32, 29-33.

4. Cooper, L.; Gonzales, J.; Gallo, J.; Rost, K.; Meredith, L.; Rubenstein, L.; Wang, N.; Ford, D. The acceptability of treatment for depression among African- American, Hispanic, and White primary care patients. Med. Care 2003, 41, 479-489.

5. Chatters, L.; Taylor, R.; Jackson, J.; Lincoln, K. Religious coping among African Americans, Caribbean Blacks and Non-Hispanic Whites. J. Community Psychol. 2008, 36, 371-386.

6. Dessio, W.; Wade, C.; Chao, M.; Kronenberg, F.; Cushman, L.E.; Kalmuss, D. Religion, spirituality, and healthcare choices of African-American women: Results of a national survey. Ethn. Dis. 2004, 14, 189-197.

7. Post, B.C.; Wade, N.G. Religion and spirituality in psychotherapy: A practice-friendly review of research. J. Clin. Psychol. 2009, 65, 131-146.

8. Ringel, S.; Park, J. Intimate partner violence: Faith-based interventions and implications for practice. J. Relig. Spiritual Soc. Work 2008, 27, 341-360.

9. Institue of Medicine. Crossing the Quality Chasm: A New Health System for the 21st Century; National Academy Press: Washington, DC, USA, 2001.

10. Tucker, C.M.; Herman, K.C.; Ferdinand, L.A.; Bailey, T.R.; Lopex, M.T.; Cooper, L.L. Providing Patient-Centered Culturally Sensitive Health Care: A Formative Model. Couns. Psychol. 2007, 345, 679-705.

11. Koenig, H.; McCullough, M.; Larson, D. Handbook of Religion and Health; Oxford University Press: New York, NY, USA, 2001.

12. Worthington, E.L.; Kurusu, T.A.; McCollough, M.E.; Sandage, S.J. Empirical research on religion and psychotherapeutic processes and outcomes: A 10-year review and research prospectus. Psychol. Bull. 1996, 119, 448-487.

13. Hage, S. A closer look at the role of spirituality in psychology training programs. Prof. Psych. Resrc. Pract. 2006, 37, 303-310.

14. Richards, I.S., Bergin, A.E. A Spiritual Strategy for Counseling and Psychotherapy; American Psychological Association: Washington, DC, USA, 2005.

15. Zinnbauer, B.; Pargament, K.; Scott, A.B. The Emerging Meanings of Religiousness and Spirituality: Problems and Prospects. J. Pers. 1999, 67, 889-919.

16. Taylor, R.J.; Chatters, L.M.; Levin, J. Religion in the Lives of African Americans: Social, Psychological and Health Perspectives; Sage Press: Thousand Oaks, CA, USA, 2004.

17. Krause, N.; Chatters, L.M. Exploring race differences in a multidimenstional battery of prayer measures among older adults. Soc. Rel. 2005, 66, 23-43.

18. Taylor, R.J.; Chatters, L.M.; Jayakody, R.; Levin, J.S. Black and white differences in religious participation: A multi-sample comparison. J. Sci. Stud. Relg. 1996, 35, 403-410. 
19. American Psychological Association. Diagnostic and sTatistical Manual of Mental Disorders: DSM-IV-TR; American Psychiatric Publishing Inc: Arlington, VA, USA, 2000.

20. Weissman, M.M.; Olfson, M. Depression in women: Implications for health care research. Science 1995, 269, 799-801.

21. National Institue of Mental Health. Transforming the understanding and treament of mental illness through research. Available online: http:/www.nimh.nih.gov/health/publications/ women-and-depression-discovering-hope/complete-index.shtml (accessed on 12 December 2011).

22. Chapman, D.; Perry, G. Depression is a major component of public health for older adults. Prev. Chronic Dis. 2008, 5, 1-6.

23. Mathers, C.; Loncar, D. Projections of global mortality and burden of disease from 2002 to 2030. PLoS Med. 2006, 3, 2011-2030.

24. Williams, D.R.; Gonzalez, H.; Neighbors, H.; Nesse, R.; Abelson, J.M.; Sweetman, J.; Jackson, J.S. Prevalence and distribution of major depressive disorder in African Americans, Caribbean Blacks, and Non-Hispanic Whites: Results for the national survey of American life. Arch. Gen. Psychiatry 2007, 64, 305-315.

25. Kessler, R.C.; McGonagle, K.A.; Zhao, S.; Nelson, C.B.; Hughes, M.; Eshleman, S.; Wittchen, H.; Kendler, K.S. Lifetime and 12-month prevalence of DSM-III-R psychiatric disorders in the United States. Arch. Psychiatr. Nurs. 1994, 51, 8-19.

26. Culbertson, F.M. Depression and gender: An international review Am. Psychol. 1997, 52, $25-31$.

27. McGrath, E.; Keita, G.; Gwendolyn, P.; Strickland, B.; Russo, N. Women and Depression: Risk Factors and Treatment Issues: Final Report of the American Psychological Association's National Task Force on Women and Depression; American Psychological Association: Washington, DC, USA, 1990.

28. Murray, C.J.L. Global Burden of Disease 2000: Version 2 Methods and Results; World Health Organization: Geneva, Switzerland, Available online: http://www.who.int/evidence/bod (accessed on 30 June 2011), Global Program on Evidence for Health Policy Discussion Paper No. 50.

29. McGrath, E.; Keita, G.; Strickland, B.; Russo, N. National Depression Summit; American Psychological Association: Washington, DC, USA, 2001.

30. Kohn, L.P.; Hudson, K.M. Gender, ethnicity, and depression: Intersectionality and context in mental health research with African American women. Afr. Am. Resrch. Perspect. 2002, 8, 174-184.

31. Project, C.B.W.H. Healing for the mind, body, and soul: new notes from California Black women's health project. Available online: http://www.cabwhp.org./pdf/Surveyreport.pdf (accessed on 30 May 2011).

32. Barbee, E.L. African American women and depression: A review and critique of the literature. Arch. Psychiatr. Nurs. 1992, 6, 257-265.

33. Ward, E.C.; Clark, L.O.; Heidrich, S. African American Women's Beliefs, coping behaviors, and barriers to seeking mental health services. Qual. Health Res. 2009, 19, 1589-1601. 
34. U. S. Department of Health and Human Services. Mental Health: Culture, Race, and Ethnicity. A Supplemental of Mental Health: A Report of the Surgeon General; Author: Rockville, MD, USA, 2001.

35. Sanders,B.; Akbar, M. African Americans' Perceptions of Psychotherapy and Psychotherapists. Prof. Psych. Resrc. Pract. 2004, 35, 19-26.

36. Cheung, F.K.; Snowden, L.R. Community mental health and ethnic minority populations. Community Ment. Health J. 1990, 26, 277-291.

37. Gallo, J.; Marino, S.; Ford, D.; Anthony, J. Filters on the pathway to mental health care, II: Sociodemographic factors. Psychol. Med. 1995, 25, 1149-1160.

38. Whaley, A.L.; Geller, P.A. Toward a cognitive process model of ethnic/racial biases in clinical judgement. Rev. Gen. Psych.1997, 11, 75-96.

39. LaVeist, T.; Carroll, T. Race of physician and satisfaction with care among African-American patients. J. Am. Med. Assoc. 2002, 94, 937-943.

40. Bell, C.; Mattis, J. The importance of cultural competence in ministering to African American victims of domestic violence. Viol. Against Wom. 2000, 6, 515-532.

41. Bourjolly, J. Differences in religiousness among black and white women with breast cancer. Soc. Work Health Care 1998, 28, 21-39.

42. Constantine, M.; Lewis, E.; Conner, L.; Sanchez, D. Addressing spiritual and religious issues in counseling African Americans: Implications for counselor traning and practice. Couns. Values 2000, 45, 10.

43. Tully, M. Lifting Our Voices: African American Cultural Responses to Trauma and Loss. Honoring Differences: Cultural Issues in the Treatment of Trauma and Loss; Brunner/Mazel: Philadelphia, PA, USA, 1999.

44. Van, P. Breaking the silence of African-American women: Healing after pregnancy loss. Health Care Women Int. 2001, 22, 229-243.

45. Brome, D.; Owens, M.; Allen, K.; Vevaina, T. An examination of spirituality among African American women in recovery from substance abuse. J. Black Psychol. 2000, 26, 470-486.

46. Smith, L.C.; Friedman, S.; Nevid, J. Clinical and sociocultural differences in African Ameican and European American patients with panic disorder and agoraphobia. JNMD 1999, 187, 549-560.

47. Neighbors, H.; Musick, M.; Williams, D. The African American minister as a source of help for serious personal crises: bridge or barrier to mental health care? Health Educ. Behav. 1998, 25, 759-777.

48. Queener, J.; Martin, J. Providing culturally relevent mental health services: Collaboration between psychology an the African American church. J. Black Psychol. 2001, 27, 112-122.

49. Pollack, L.; Harvin, S.; Cramer, R. Coping resources of African American and White patients hospitilized for bipolar disorder. Psychiatr. Serv. 2000, 51, 1310-1312.

50. Brown, D.R.; Gary, L.E. Social support network differentials among married and nonmarried Black females. Psych. Women Quart. 1985, 9, 229-241.

51. Brown, D.R.; Gary, L.E. Religous involvement and health status among African-American males. J. Natl. Med. Assoc. 1994, 86, 825-831. 
52. Brown, D.; Ahmed, F.; Gary, L.E.; Milburn, N.G. Major depresion in a community sample of African Americans. Am. J. Psychiatr. 1995, 152, 373-378.

53. Woodward, A.T.; Bullard, K.M.; Taylor, R.J.; Chatters, L.M.; Baser, R.E.; Perron, B. Use of Complementary and Alerternative Medicine for Mental Disorders Among African Americans, Black Caribbeans, and Whites. Psychiatr. Serv. 2009, 60, 1342-1349.

54. Chatters, L.; Mattis, J.; Woodward, A.T.; Taylor, R.J.; Neighbors, H.W.; Grayman, N.A. Use of Ministers for a Serious Personal Problem Among African Americans: Findings from the National Survey of American Life. Am. J. Orthopsychiatry 2011, 81, 118-127.

55. Brown, D.R.; Ndubuisi, S.C.; Gary, L. Religiousity and psychological distress among blacks. J. Rel. Health 1990, 29, 55-68.

56. Boyd-Franklin, N.; Lockwood, T. Spirituality and Religion: Implications for Psychotherapy with African American Clients and Families; Guilford Press: New York: NY, USA, 1999; p. 13.

57. Myers, W.Integrating spirituality into counselor preparation: A developmental, wellness approach. Couns. Values 2003, 47, 142-155.

58. Young, J.; Cashwell, C.; Wiggins-Frame, M.; Belaire, C. Spiritual and religious competencies: A national survey of CACREP-accrediated programs. Couns. Values 2002, 47, 22-33.

59. Cashwell, C.; Young, J. Spirituality in counselor trainning: A content analysis of syllabi from introductory spirituality courses. Couns. Values 2004, 48, 96-109.

60. Canada, E.R.; Furman, L.D. Spiritual Diversity in Social Work Practice; Free Press: New York, NY, USA, 1999.

61. Asher, M. Spirituality and religion in social work practice. Available online: www.gatherthepeople.org/Downloads/SPIRIT_IN_SW.pdf (accessed on 12 July 2011).

62. Zinnbauer, B.; Pargament, K. Working with the sacred: Four approaches to religious and spiritual issues in counseling. J. Couns. Dev. 2000, 78, 162-171.

63. Gallup, G.; Lindsay, D. Surveying the Religious Landscape: Trends in U.S. Beliefs; Morehouse Publisher: Harrisburg, PA, USA, 1999.

64. Blank, M.; Fox, J.C. Guterbock Alternative Mental Health Services: The role of the Black Church in the South. Am. J. Public Health 2002, 92, 1668-1672.

65. Meyer, R.E. Black History and the Historical Profession, 1915-1980; University of Illinois Press: Urbana, IL, USA, 1986.

66. Foner, N. Race and color: Jamaican migrants in London and New York City. Forced Migr. Rev. 1985, 19, 708-727.

67. Du Bois, W.E.B. The Negro Church in America; Atlanta University Press: Atlanta, GA, USA, 1903.

68. Foluke, G. The Old-time Religion: A Holistic Challenge to the Black Church; Winston-Derek: New York, NY, USA, 1999.

69. Sutton, C. Pass it on: Outreach to Minority Communities; Big Brothers/Big Sisters of America: Philadelphia, PA, USA, 1992.

70. Abdul, A. Religion and the Black Church: Introduction to Afro-American Studies; TwentyFirst Century Books: Chicago, IL, USA, 1991. 
71. Lincoln, C.E.; Mamiya, L.H. The Black Church in the African American Experience; Duke University Press: Durham, NC, USA, 1990.

72. Cunningham, W.E.; Davidson, P.; Nakazono, T.; Anderson, R. Do Black and White adults use the same sources of information about Aids prevention. Health Educ. Behav. 1999, 26, 703-710.

73. Pargament, K.I.; Koenig, H.G.; Perez, L. The many methods of religious coping: Development and initial validation of the RCOPE. J. Clin. Psychol. 2000, 56, 519-543.

74. Paloutzian, R.; Park, C.L. Integrative Themes in the Current Science of the Psychology of Religion. In Handbook of the Psychology or Religion and Spirituality; Guilford Press: New York, NY, USA, 2005.

75. Pargament, K.I.; Hill, P.C. The Psychology of Religion and Coping; The Guilford Press: New York, NY, USA, 2003.

76. Burke, M.T. From the chair. The Council for Accreditation of Counseling and Related Educational Programs (CACREP) Connection Winter 1998.

77. Wiggins, M.I. Therapist self-awareness of spirituality. In Spirituality and the Theraputic Process; Leach, J.D.A.M.M., Ed.; American Psychological Association: Washington, DA, USA, 2008; pp. 53-74.

78. Post, B.C.; Wade, N.G. Religion and Spirituality in Psychotherapy: A Practice-Friendly Review of Research. J. Clinical Psych. 2007, 65, 131-146.

79. Pargament, K.I.; Feuille, M.; Burdzy, D. The brief RCOPE: Current psychometric status of a short measure of religious coping. Religions 2011, 2, 51-76.

80. Johnson, C.V.; Hayes, J.A.; Wade, N.G. Psychotherapy with troubles spirits: A qualitative investigation. Psych. Resrch. 2007, 17, 1450-1460.

81. Worthington, E.L. Religious counseling: A review of published empirical research. J. Couns. Dev. 1986, 64, 421-431.

82. Ward, E.C.; Collins, J. Depression in African American males. Perspectives (Montclair) 2010, 6-21. 


\title{
Transforming Losses-A Major Task of Spiritually Integrated Psychotherapy
}

\section{Eckhard Frick}

\begin{abstract}
Since Freud's "Mourning and Melancholia", bereavement encompasses the dilemma between continuing versus relinquishing bonds to deceased persons. Mourning is the process of symbolizing the loss, of making sense by facing the conflict between the absence of the lost object and the continuing presence of an emotional relationship to that which is lost. Furthermore, mourning is not limited to bereaved persons but also concerns dying persons and, in a broader sense, our whole symbolic life which is playful coping with a rhythm of absence and presence. True consolation connects the individual and the archetypical mourning. Spiritually integrated psychotherapy may accompany this process by amplification. Christian mysticism takes its starting point from the experience of Jesus Christ's lost body, and this may be understood as a model of spiritual transformation.
\end{abstract}

Reprinted from Religions. Cite as: Frick, E. Transforming Losses-A Major Task of Spiritually Integrated Psychotherapy. Religions 2011, 2, 659-675.

\section{Introduction}

The work of mourning does not only cope with situations of bereavement but also with any loss "of some abstraction which has taken place of one, such as fatherland, liberty, an ideal, and so on" [1]. Taking Freud's seminal text as a starting point, this paper argues that our whole life encompasses a work of mourning and that spiritually integrated psychotherapy accompanies the patient's life long coping process and his or her searching for meaning, especially by means of living and grief transforming symbols.

Spirituality may be understood as a search for the sacred, especially in times of stress when spiritual coping helps conserve the sacred. In the practice of psychotherapy, spirituality may be a part of the problem or a part of the solution or even both.

"Spirituality is a therapeutic fact of life. The reality is we cannot divorce spirituality from the therapeutic process. The choices are to be explicit about it, to tiptoe around it, or to reduce it to something else. [...] Like it or not, spirituality is fully interwoven into human experience, including what takes place in the therapy room. The question, then, isn't whether to address spirituality in psychotherapy. Therapeutic neutrality toward spirituality is impossible. As with every other dimension of behavior, spirituality will be shaped one way or another by the therapy process. The real question is how we choose to address spirituality in psychotherapy" [2].

Or, with the words Carl Gustav Jung carved above the door of his house, VOCATUS ATQUE NON VOCATUS, DEUS ADERIT (Whether called or not, God will be there). We shall now 
examine how psychotherapy addresses situations of mourning and, more fundamentally, how the work of mourning is a crucial aspect of spiritual life and of spiritually integrated psychotherapy.

The focus of this paper is individual psychotherapy in the context of collective mourning processes. That is why, psychoanalytic reflection is supplemented by the mystical approach to the void and by authors who bring together psychoanalysis and mysticism in the context of mourning.

\section{Our Whole Life Is a "Work of Mourning"}

Everything starts with Freud's seminal text "Mourning and melancholia" [1] where we find in statu nascendi not only his (second) theory of mental structure [3] but also later developments of post-Freudian thinking such as attachment theory, psycho-analysis of narcissism / self-psychology, and object-relations theory. "Mourning and Melancholia" was originally part of a metapsychology. Some other chapters seem to be destroyed by Freud himself [4]. It is true that many contemporary readers shrink back from his drive-psychology's physicalist language. Freud himself admits that his energetic and economic terminology is not entirely satisfying. We must, consequently, reconstruct Freud's thought using more recent authors who more or less refer to him. Freud describes the work of mourning as follows:

"The testing of reality, having shown that the loved object no longer exists, requires forthwith that all the libido shall be withdrawn from its attachments to this object. [...] The task is now carried through bit by bit, under great expense of time and cathectic energy, while all the time the existence of the lost object is continued in the mind. Each single one of the memories and hopes which bound the libido to the object is brought up (eingestellt) and hyper-cathected, and the detachment of the libido from it is accomplished. Why this process of carrying out the behest of reality bit by bit, which is in the nature of a compromise, should be so extraordinarily painful is not at all easy to explain in terms of mental economics. It is worth noting that this pain [Schmerzunlust] seems natural to us. The fact is, however, that when the work of mourning is completed the ego becomes free and uninhibited again."

The testing of reality "shows" that the loved object no longer exists: This "showing" is not absolute, it is, on the contrary, impeded by all forms of defenses. Freud, in his physicalist language, speaks about the libido "bound to the object": Reality-testing requires "that all the libido shall be withdrawn from its attachments to this object" although we "never willingly abandon a libido-position".

What about the libido and what about its binding to the object?

Let us read the short text "On transience" [5], a remarkable "summer-walk through a smiling countryside", published in war-times one year before "Mourning and Melancholia" (but actually written some months after it). Freud is "in the company of a taciturn friend and of a young but already famous poet". The young poet, probably R.M. Rilke, was "disturbed by the thought that all this beauty was fated to extinction". Freud anticipates what he will write about mourning and tells us:

"But why it is that this detachment of libido from its objects should be such a painful process is a mystery to us and we have not hitherto been able to frame any hypothesis to account for it. We only see that libido clings to its objects and will not renounce those that are lost even when a substitute lies ready to hand. Such is mourning."

Note that mourning in this text is not severance of attachment but continuity of bonds. How can we distinguish the mere defense against the reality of loss and this desire of continuity? 
In this text, Freud defines libido as "Liebesfähigkeit" (capacity to love). He presumes that we come to this life with a certain amount of narcissistic libido, i.e., libido turned towards the ego. When we withdraw libido from the ego and invest it in the objects those objects are somehow integrated in our ego. Conversely, after destruction or loss of objects, libido becomes free and returns to the ego.

Consequently, we have now reconstructed a first and simple meta-psychological model: Investment of libido in objects means that the ego loosens the narcissistic libido and that those objects become somehow part of the ego. Conversely, after destruction or loss of the objects and loss of the libido's point of contact, narcissistic libido will be tightened up or re-invested in other objects.

Freud uses a special concept for the libido's investing or "clinging": "Besetzung" (occupation). The Standard Edition translates by "cathexis". This nice Greek term is composed by "hexis" (having) and "kata" (under/according to). It is true that we hold tight whom or what we love and that we grasp even with more energy when we are about to lose it.

Freud does not yet postulate a "death drive". He considers a sexual drive in a broad sense, libido, which can "cathect", or invest, in an "object" (the site of satisfaction). The ego is a kind of reservoir of all libido, origin of cathexes to objects in the outside world as well as to representations of objects in the internal world. It is true that Freud's early mourning theory understands "the loss of a love object as a temporary disruption of the mourner's narcissism" [6]. What he calls "ego" in his theory of narcissism will be renamed "self" by post-Freudian authors.

Now we may have a second look on the Mourning \& Melancholia quotation.

"The testing of reality, having shown that the loved object no longer exists, requires forthwith that all the libido shall be withdrawn from its attachments to this object".

The object has been destroyed by death or another loss. Reality testing reminds the bereaved person of this fact and commands the withdrawal of attachment against a resistance demanding a particular effort.

"[...] The task is now carried through bit by bit, under great expense of time and cathectic energy, while all the time the existence of the lost object is continued in the mind".

Despite the knowledge of facts, libido is still clinging to the object (cathexis) and this ongoing cathexis is continued by the object's mental presence. There is an inner conflict between reality testing and emotional ties. Its resolution requires time and energy.

"Each single one of the memories and hopes which bound the libido to the object is brought up (eingestellt) and hyper-cathected, and the detachment of the libido from it is accomplished".

Notice that in this sentence every philosopher will discover a category mistake: cathexis (binding of libido), hyper-cathexis, and detachment are physical terms. Memory and hope, on the contrary, are mental terms. Slipping from one category to the other is philosophically unsound.

The work of mourning consists in singularizing, bringing-up and intensifying (hyper-cathexis) of memories and hopes as a prerequisite of detachment. Paradoxically, the work of mourning is not a process of piecemeal fading away.

This paradoxical intensification is accompanied and expressed by the experience of pain:

"Why this process of carrying out the behest of reality bit by bit, which is in the nature of a compromise, should be so extraordinarily painful is not at all easy to explain in terms 
of mental economics. It is worth noting that this pain [Schmerzunlust] seems natural to us. The fact is, however, that when the work of mourning is completed the ego becomes free and uninhibited again."

After this last crescendo of suffering, the work of mourning seems to be "completed". But this is only one part of the story.

Let us see how contemporary psychoanalysis and attachment theory deal with Freud's theory.

Volkan differentiates two aspects of the German term "Trauer" used by Freud: The painful grief reaction and the more silent mourning process. "Trauerarbeit" (grief work) in the first meaning of emotional disclosure and detachment requires that the bereaved "confront and express their feelings and reactions" [7]. Some authors think that the therapist should compel bereaved persons to express sadness, "in the belief that the abreaction of suppressed affect is at the core of successful treatment" [8]. In empirical studies, there is little evidence that induced disclosure of emotions is effective in coping with bereavement [7].

"Uncomplicated grieving may be seen as nature's exercise in loss and restitution" [9]. However, the "burial" of mental images (of the lost person or thing) does not parallel the physical loss. It is, on the contrary, a long process which will be completed when the bereaved person makes the mental representation of the lost person or thing "futureless" [10], when the images of the lost item are no longer utilised to respond to the mourner's wishes.

How can we understand the mental images, the object representations? Volkan and Zintl [11] coined the term "psychic double" for every person who populates or once populated our world. This is a very understandable expression of what Melanie Klein calls "inner objects". Every "new" upcoming or happening bereavement challenges our experiences with good objects and may entail a regression toward more archaic, paranoid forms of relationship.

When someone important to us dies, the psychic double "remains hot" or even intensifies due to the separation (Freud's "hyper-cathexis"). "The work of mourning involves taking the heat out of the loss and cooling down, but not eliminating the psychic double", says Volkan.

Freud distinguishes normal mourning from melancholia. In melancholia, the lost object's shadow remains upon the ego, provoking troubles of self-esteem not observed in normal mourning. Melancholic identification means that the ego treats itself as if it was the object, with all the characteristics of hate and love. According to Volkan, we may distinguish normal mourning, melancholia, and perennial mourning: "Normal" mourning, depression (melancholia), and perennial mourning.

Using the term depression, Volkan follows Freud's vision of melancholic identification: "The mourner wants, unconsciously, to destroy (hate) the lost object's representation and feels guilty, whilst feeling obliged to hold on to (love) it because he/she still feels dependent on the representation of the lost object, as if it still has a "future". Conversely, the "normal" mourner examines the images of the disease and gets rid of the "futureless" images. His or her unconscious identification with the beloved person is selective, concerns certain enriching functions of the lost object.

New and important is Volkan's concept of perennial mourners: They conserve the deceased person's mental representation in an "envelope" (introject) and have an illusion "that the deceased's images in this envelope can be brought back to life". This introject may remain unassimilated, it "relates to and stimulates the mourner's self-image" [12]. 
This new vision of perennial mourners' introjects is very important for understanding and treatment of traumatic losses: Losses without normal grief, e.g., without touching the dead body or losing it by extraordinary events such as a Tsunami, block the normal mourning process and may require psychotherapeutic help [13].

\section{Linking Objects May "Freeze" or Deblock the Mourning Process}

Volkan found that perennial mourners often used symbolic items, 'linking objects' which stop the process of mourning at a certain point. This freezing and postponing may hinder the individual from accomplishing the process or, on the contrary, permit completing the work of mourning. Linking objects may be (table 1):

Table 1. Linking objects according to Volkan.

\begin{tabular}{c}
\hline 1. Personal possession of the deceased \\
2. Gift or symbolic farewell note \\
3. Something the deceased used to extend his/her senses or body functions \\
4. Realistic or symbolic representation of the deceased \\
5. 'Last-minute object' \\
6. Created linking objects
\end{tabular}

The personal possession of the deceased, e.g., a watch, usually needs repair. The mourner becomes preoccupied about this repair. The object remains, however, unrepaired. The gift or symbolic farewell note is the last object given before a fatal accident, or before being killed as a soldier. Something the deceased used to extend his/her senses or body functions: May be a camera or another optical instrument or a mobile phone. Again, it may be broken, waiting for repair. Realistic or symbolic representation of the deceased: a photograph, a video, a tape recording, a painting or a text. 'Last-minute object': "something at hand when the mourner learned of the death or saw the deceased's body". Finally, the mourner may create linking objects by painting or other representations [12].

Linking objects are a frozen form of symbols, proto-symbols which may develop in the sense of symbolization. They have an "eerie" character, and there may be a "spiritual merging" with the dead person, including the fear to be influenced by the dead person who may actually come back into the mourner's life. Volkan distinguishes the highly symbolised linking object from Winnicott's "transitional object" which creates the intermediate space in the infant's development and from the fetish which is a rigid placeholder. Conversely, linking objects can initiate future mourning. In his "regrief therapy" Volkan used linking objects for beginning the mourning process as if the loss had just happened. Consequently, possessing linking objects, is a double-edged sword as far as personal growth is concerned.

Furthermore, enlarging individual psychology, he described mourning and frozen mourning processes in societies such as ex-Yugoslavia, South-Africa, and in the US [14].

A collective linking object may be a "chosen trauma" such as Serbian Prince Lazar's death during the Battle of Kosovo (June 28, 1389). In the approaches to the Serbs' war with Bosnian Muslims in 1990-1991 and again before the conflict with Kosovar Albanians in 1998, Slobodan 
Miloševič and his entourage "reactivated" the Serbs' chosen trauma in order to distinguish Serb and non-Serb identities and in order 'legitimate' Serb violence against non-Serbs.

"As the six-hundredth anniversary of the Battle of Kosovo approached, the remains of leader captured and killed at the Battle of Kosovo, were exhumed. For a whole year before the atrocities began, the coffin traveled from one Serbian village to another, and at each stop a kind of funeral ceremony took place. This "tour" created a time collapse. Serbs were primed to react as if Lazar had been killed just the day before, rather than six hundred years earlier. Feelings, perceptions, and anxieties about the past event were condensed into feelings, perceptions, and anxieties surrounding current events, especially economic and political uncertainty in the wake of Soviet communism's decline and collapse. Since Lazar had been killed by Ottoman Muslims, present-day Bosnian Muslims - and later present-day Kosovar Albanians (also Muslims) - came to be seen as an extension of the Ottomans, giving the Serbian people, as a group, the "opportunity" to exact revenge from the group that had humiliated their large group so many centuries before. In this context, many Serbs felt "entitled" to rape and murder Bosnian Muslims and Kosovar Albanians" [15].

Trauma in wartime and ethnic conflicts are painful examples of the interdependency between collective and the individual suffering: The traumatized person is not alone with her/his pain, there are hundreds and thousands sharing the same experience. However, the traumatized person is terribly alone given that social comparison does not provide any consolation. Mal de muchos, consuelo de tontos (it is a fool's consolation the think everyone is in the same boat).

Linking objects occur at the individual as well as on the collective level. They are half-way between a non-symbolized and absurd beta-element and an alpha-element which is growing in a loving, understanding, containing relationship and which eventually entails reconciliation with the past. Bion told us that such a helpful relationship metabolizes and detoxifies beta-elements. We may call this process a symbolic transformation of trauma into "normal" mourning:

"The capacity to symbolize allows an individual to represent an experience mentally rather than concretely. In the aftermath of a trauma, painful and disturbing images, thoughts and feelings are often unable to be held in the mind in a way that distinguishes them from the actual reality of the event. They cannot be contained as memories. Instead these thoughts and images become concrete, live flashbacks that typically intrude into consciousness as a literal re-experiencing of the event. If the mental capacity is flawed or impaired in this way, there is also often an intrusion of the flashback experience into the body. This intrusion can take the form of psychosomatic illness" [16].

Accordingly, a collective linking object such as the Serb "chosen trauma" or an individual one, encompasses an ambivalent potential: it may provoke narcissistic identification, further trauma and violence, or, on the contrary, trigger the continuation of a "frozen" mourning process.

Returning to the individual dimension: When patients arrive in psychotherapy, they present us a symptom they want to get rid of or a problem they want to resolve. It is a great therapeutic chance to consider the symptom/problem as a kind of linking object, as an unfinished business, as a frozen mourning, requiring therapeutically accompanied re-grieving or, as the psychodramatist Jacob Moreno says, the therapeutic true second time which delivers the first time. Writing these lines, I am thinking about two men who brought their sexual symbol/problem to the therapy room: The 
first suffered from premature ejaculation. He had lost his father by a sudden cerebral stroke. His mother - he says - hindered him from touching his father's dead body and from emotional grieving. His lacking capacity to enjoy pleasure and increasing excitation in a woman's presence may be understood as a linking object encompassing emotions such as sadness and grief but also anger, rebellion and self-assertiveness. The second analysand, conversely, was "delayed" at ejaculation. He was so orientated towards his partner's pleasure that he almost "forgot" his ejaculation. This young man had not lost his father by death but felt abandoned by him after his parents' divorce, he felt less loved and perceived by him than his (half-) brothers coming from his father's second marriage. But more than about all this, my analysand had to mourn the loss of one testicle which had to be extirpated after the diagnosis of cancer. The question of "balls" in professional and relational life was for a long time condensed in the lost testicle he missed after the operation. This loss, as the loss of other extirpated organs in cancer diseases, had to be mentalised during the analytic process.

\section{Mourning's Spiritual Dimension}

Kernberg resumes Freud's vision of the accomplished mourning by the term "identification" (with the lost object) while Freud reserves this term to the melancholic process and insists on the decathexis in normal mourning. Melanie Klein adds that normal mourning reawakens and resolves the depressive position in a process of reparation. Finally, Kernberg highlights the spiritual aspect of mourning. He proposes "a permanent relationship between the representation of self and the representation of the lost object, the combination of an intrapsychic presence of that object, and the awareness of its objective permanent absence" [17]. On the one hand, there is now no more forgiveness nor repair with the lost person. On the other hand, aspirations and values of the dead person may be experienced by the person in mourning as a mandate, a command: They become part of the mourner's superego as "highly personalized relations with the lost object". Libidinal investments are "not a zero sum capacity". On the contrary, "mourning interminably may become part of the increased capability for love and appreciation of life".

"[...] the expansion of moral values and ethical commitments related to the mandates that reflect the desires and aspirations of the person who died, whose life project was interrupted, are frequently a powerful stimulus to reparative action of the survivor providing a sense of purpose. They become, as mentioned before, ethical commands and aspired for ideals. Reparative processes, in short, expand into spiritual demands" [17].

The danger of the unaccomplished, frozen mourning process is, as Volkan says, a defensive "spiritual merging" between the mourning and the mourned person. However, when the reality of object loss is recognized, the power of the emotional and spiritual reality reflected in a permanent internalized relation with the lost object becomes an 'absent presence' as Kernberg quotes Sara Zac de Filc.

"The irresistible urge for reunion, the fantasy and concern over life after death, the expanding moral universe related to the mandate all combine in the expression of powerful religious impulses, whether they take the form of adherence to an established religious belief system, or are constructed individually as a painful yet indispensable aspect of spiritual existence and survival" [17]. 
Using the theoretical framework of attachment theory, Kernberg's spiritual bond and its structural consequences have been described as transformative process observed in securely attached mourners [18]. The lost person is "resurrected" in terms of "mentally represented legacy components (e.g., what would he have said, how would he have responded)", enriching "those mental representations of the lost person's legacy that carry substitute value" [19].

The analyst's role, his or her containing function during the mourning process, encompasses "the transference function of reinstating and maintaining that internalized relationship" with the lost object, while "bringing it to life in the relation with the analyst". According to Kernberg, this transference aspect reflects the double function of the mourning process - superego restructuring and maintaining the relationship [17]. Using Pargament's words, we can say that the analyst helps conserving the sacred in a situation of loss.

\section{Is Consolation Possible?}

In his criticism of religion, Freud often opposes scientific enlightenment and the soothing function of religion who feeds with empty promises, poor consolations, with hopes of a better world. This criticism basically concerns the illusion of narcissistic perfection and fulfilling of wishes [20]. Is a true consolation conceivable, a consolation which encompasses the work of mourning, i.e., the acknowledgement of a given object-loss? The answer will depend on the general theory of mourning: Does it consist in severance of attachment and redemptive replacement or is a continuity of bonds conceivable as Freud suggests in his dialogue with the silent as well as in a 1929 letter to Binswanger:

"Although we know that after such a loss the acute state of mourning will subside, we also know we shall remain inconsolable and will never find a substitute. No matter what may fill the gap, even if it be filled completely, it nevertheless remains something else. And actually, this is how it should be. It is the only way of perpetuating that love which we do not want to relinquish."

The Dual Process Model [18] endorses an "oscillation" between loss orientated and restoration orientated coping. This orientation entails emotional and cognitive commitments during the mourning process which is never entirely accomplished but encompasses, as the Dual Process Model shows, a relocated presence of the absent, a transformation of mental representations. This is true for bereaved persons but also for other losses, especially for the dying person's mourning called "travail du trépas" (transition work) [21].

De M'Uzan insists that we decipher the hastened death desire:

"In fact, the dying person engages, under the terms of what I imagine like a kind of knowing of the species, in an ultimate relational experience. Whereas the bonds which attach him to the others are about to be finally severed, he is paradoxically raised by a powerful and somehow passionate movement".

The ultimate relational experience engaged by the dying person is paradoxical: "Although the dying person' s links to others are about to be untied, he/she over-invests objects, as a last attempt to assimilate unresolved issues" [22]. Des Rosiers considers life as "between two deaths": During the "first death" [23,24], during analysis or finally during the travail du trépas, the "wonderful baby" is mourned. The dying process "can be seen as an attempt at an ultimate completion of the shift from narcissistic investment to object investment" [22]. 
True consolation cannot be provided by dead things but by living objects. Symbolically charged things may, however, convey this relational bond and restauration:

"The function of grave-stones, memorial monuments, pictures and photographs and works of art symbolically representing the lost person derive their consoling function from the assurance that the dead person is still out there, somewhere, in the external world" [17].

True and trustful consolation connects the individual and the archetypical mourning, deuil originaire (Racamier 1992). This archetypical layer is originally represented to us by the mother as first incarnation of world and Self [25] and transcends the narrow borders of our individual ego. This archetypical process of deuil originaire may be completed during an analytical process, entailing 'true' consolation. Helpful may be the Jungian "amplification" technique, i.e., confronting the individual experience with collective models such as myths, fairy tales, biblical texts.

The intensity of mourning corresponds, as a matter of fact, to the intensity of loving attachment bonds. Paradoxically, a secure "inner working model" does not entail a "clinging" continuity of bonds but an adaptive mentalizing capacity, corresponding to early experiences of coping with separation. What is true on the individual level also applies to the level of collective memory: Not the compulsive repetition of grief-signs but the work of memory transforms and heals bereaving experiences [26].

When we revive the infantile depressive position we do not only revive an individual experience but also a collective, as C.G. Jung puts it, an archetypical one:

"The manic-depressive and the person who fails in the work of mourning, [...] have this in common, that they have been unable in early childhood to establish their internal "good" objects and to feel secure in their inner world. They have never really overcome the infantile depressive position. In normal mourning, however, the early depressive position, which has become revived through the loss of the loved object, becomes modified again, and is overcome by methods similar to those used by the ego in childhood. The individual is reinstating his actually lost loved object; but he is also at the same time re-establishing inside himself his first loved objects-ultimately the "good" parents-whom, when the actual loss occurred, he felt in danger of losing as well. It is by reinstating inside himself the "good" parents as well as the recently lost person, and by rebuilding his inner world, which was disintegrated and in danger, that he overcomes his grief, regains security, and achieves true harmony and peace" [27].

Volkan's studies show that freezing of mourning processes may occur not only at an individual but also at collective or a national level. Collective "linking objects" are as much obstacle to accomplished mourning as a starting point for re-grieving and new libido, new capacity of love.

As in the classical Greek tragedy, true consolation does not consist in a narcissistic identification with my personal ego-ideal. True cathartic consolation is depersonalized, links my destiny to the hero's destiny who incarnates the human condition. This "desire-cathexis", according to Freud part of the mourning process, connects personal and archetypical mourning.

\section{Living Symbols Require a Work of Mourning}

Sym-ballein in Greek means to put or to throw together. When friends separated, they broke a bowl or a coin of money. When they met again (or their children), the joined pieces not only "signified" unity, they made unity. 
According to Jung, a symbol is more than a sign which may be explained, verbalized, decoded. Deciphering "kills" a symbol which is "the best expression of a relatively unknown cause", better than our explanations or verbalizations. The symbol is the joint of two (separated, opposed) realities, and it generates a third which is beyond the original opposition ("transcendent" function of the symbol). "Perhaps the central task of mourning is to make sense of the conflict between the absence of the lost object and the continuing presence of an emotional relationship to that which is lost" [28].

My thesis is that every living, transformational symbol requires an absence and, in a certain sense, a work of mourning, of sense and meaning making. Our whole symbolic life which is playful coping with a rhythm of absence and presence. Freud's grandson Ernst [29] repeated this rhythm of absence and presence with a reel of thread: "Fort - da" (away - here):

"Occasionally, however, this well-behaved child evinced the troublesome habit of flinging into the corner of the room or under the bed all the little things he could lay his hands on, so that to gather up his toys was often no light task. He accompanied this by an expression of interest and gratification, emitting a loud longdrawn-out "o-o-o-oh" which, in the judgment of the mother (one that coincided with my own), was not an interjection but meant "go away" (fort). I saw at last that this was a game, and that the child used all his toys only to play "being gone" (fortsein) with them. One day, I made an observation that confirmed my view. The child had a wooden reel with a piece of string wound round it. It never occurred to him, for example, to drag this after him on the floor and so play horse and cart with it, but he kept throwing it with considerable skill, held by the string, over the side of his little draped it, so that the reel disappeared into it, then said his significant "o-o-o-oh" and drew the reel by the string out of the cot again, greeting its reappearance with a joyful " $D a$ " (there). This was, therefore, the complete game, disappearance and return, the first act being the only one generally observed by the onlookers, and the one untiringly repeated by the child as a game for its own sake, although the greater pleasure unquestionably attached to the second act".

By repeating the turning-point of this rhythm in both senses (absence $\leftarrow \bullet$ presence), Ernst acquires a symbolic self-empowerment, a playful trial of the unavoidable absence-and-presence-rhythms linked with his young life's forthcoming losses. According to Freud, his grandson's game is for coping with powerlessness and passivity: passive in the first place, "Overtaken by the experience", he now "brings himself in as playing an active part, by repeating the experience as a game in spite of its unpleasing nature. This effort might be ascribed to the impulse to obtain the mastery of a situation (the power instinct)". Freud adds another interpretation: The "gratification of an impulse of revenge suppressed in real life but directed against the mother for going away": "Yes, you can go, I don't want you. I am sending you away myself." Some years later, Ernst throw on the floor a toy and to say "Go to the war!". It seems evident, that he is coping with his father's absence as a soldier of World War I.

Freud's grandson's symbolic game may be interpreted as a tried mastery when facing the rhythm of presence and absence. Living symbols which produce libido, energy, as Jung says, are quite different from signs and proto-symbols in the sense of Volkan's linking objects.

They come forth of a liberating ritual, a mourning which is at the same time accepting the loss and opening a space for transformation, for the ongoing game. 
Jung's distinction between a "killed" or "dead" symbol and a living one has an equivalent in Hanna Segal's distinction between "symbolic equation" and "symbolic representation". When asking patient "A" why he stopped playing violin, this young man suffering from schizophrenia "replied with some violence, 'Why, do you expect me to masturbate in public?'. Mr A had identified violin and penis in a concretistic manner. Conversely, "another patient, B, dreamed one night that he and a young girl were playing a violin duet. He had associations to fiddling, masturbating, etc." [30]. In distinction from A, B is able to distinguish violin and penis (symbolic representation).

Symbolic representations help us to cope with the loss of an (external) object. We learn that we do not possess it, that the mastery of the "o-o-o-oh"/ " $D a$ " is limited. This acceptance of the uncontrollable external objects entail the possibility of an internal (symbolic) presence. "No breast-therefore a thought" [31]. Only when the infant can recognize the absence of the object she or he can either symbolize or think [28,32]. There is a strong difference between lost objects (which can be symbolized, e.g., in a therapeutic relationship) and objects which are gone (nameless dread according to Bion):

"Since the restoration of lost objects is preeminently a symbolic process, this cannot be achieved if absence remains in the unthinkable state of being 'gone' where the absence of the object is coexistent with the absence of a mind in which it can be known. In Bion's terms, there are only beta elements without a thinker to process them. This can only occur through the internalization of a container/contained apparatus which enables the development of alpha function and the formulation of mental contents into thoughts" [28].

If mourning expresses the conflict between the absence of the lost object and the continuing presence of an emotional relationship a symbol is born-in the mourner's mind, between analyst and patient, between conscious and unconscious:

"Projective identifications are gradually withdrawn and the separateness of the subject from the object becomes more firmly maintained. With that comes a greater awareness of one's own psychic reality and the difference between internal and external. In such a situation the function of symbolism gradually acquires another meaning. Symbols are needed to overcome the loss of the object which has been experienced and accepted and to protect the object from one's aggressiveness. A symbol is like a precipitate of the mourning for the object" [32].

From a spiritual point of view, a loss or a traumatic experience such as the terrorist attack on 9/11, entails a violation, threat, or even loss of the sacred [2]. Paradoxically, such an experience may foster spiritual support and spiritual support seeking in order to conserve the sacred. However, critical life experience may trigger important spiritual struggles. Whether those struggles lead to growth or decline depends on the subject's ability to engage in spiritual transformation. By this term, Pargament refers to changes (1) “in the place of the sacred in the person's life" and (2) in the pathways the individual takes to the sacred" [2]. A first form of transformation consists in spiritual transitions / rites of passage permitting new roles by a re-working of linking objects, e.g., leaving the frozen and post-traumatic warrior-like identity. Additionally, revisioning the sacred encompasses a working-through of God-images. Finally, centring the sacred is a cognitive and emotional process entailing fundamental changes. The current crises may help to recognise the limitations of current strivings and to the letting go of old values. This mourning of old values 
"creates a value and meaning vacuum. To fill that void, the individual looks to other sources of significance. When a spiritual transformation takes place, the shift is profound and may represent a change form 'playing God' to 'seeking God'" [2]. The process of spiritual transformation, as Pargament presents it, is not a synonym of goodness. It may entail losing or forgetting of yearnings for the sacred which will perhaps "smolder for a while beneath the ashes of disappointment and pain" [2]. Notwithstanding, this experience of 'negativity' may reconnect itself with deep mystical pathways.

\section{Towards a Mystical Mourning of the Archetypical Loss}

We have seen that mourning deals with an "absent presence" which may be expressed in religious symbols. Christianity is, according to Michel de Certeau, "a lost-body discourse": "Christianity founded a discourse (the evangelical Logos) which offers ,consolation" for the loss of the body" [33]. In the context of his study about Jean-Joseph Surin, a XVIIth century Jesuit mystic, Certeau affirms that the name (Jesus Christ) is a substitute for his lost body, for the empty tomb. The name is the origin of another body, the church, and of the biblical text [34]. The experience of Pentecost requires the (lost) body's absence, the original spiritual experience of the void. The Eucharist (a sacramental "real presence" of Christ) is impossible without his real absence. The early Christian texts, especially St John and St Paul, call the Holy Spirit paráklētos: helper, advocate, consoler, comforter (facing an absence). Michel de Certeau calls mysticism-not only Christian mysticism-"utopical" because it does not "measure", pin down the spiritual neither scientifically nor psychologically. Although we want to locate God in what may be called a spiritual paradise, those attempts are missing their goal, leading to illusions or to non-places, outopoi such as the resurrected Christ's empty tomb. Certeau stresses a double attitude in mystical experience: One the one hand, it accepts this "spiritual utopia", on the other hand it opens a search for the sacred, a spiritual journey encompassing three moments: 
1. The event, the kairós, the dotting and use of commas in the spiritual process: We identify such events later, post-hoc as sacred moments. We have seen God's back, says Certeau with allusion to Exodus 33:23: "Then I will take away my hand, and you shall see my back; but my face shall not be seen."

2. The epiphany, God's coming to history. He is the "always greater" as Christian and Islamic mysticism teach accordingly.

3. The apparition of the infinite which we need, which we cannot miss but which remains, nevertheless, unfathomable, incomprehensible, and unobjectivizable [35].

The infinite is an important name given to the sacred. As C.G. Jung puts it in his autobiography: "The decisive question for man is: Is he related to something infinite or not? That is the telling question of his life" [36]. Kierkegaard finds at the very beginning of The sickness unto death (chapter 1) the following definition of the human being as an ongoing, unaccomplished self-finding process:

"Man is a synthesis of the infinite and the finite, of the temporal and the eternal, of freedom and necessity, in short it is a synthesis. A synthesis is a relation between two factors. So regarded, man is not yet a self'.

Michel de Certeau is not the only contemporary thinker who takes up Meister Eckhart's teaching about the void. There is a post-secular and post-Christian rediscovery of the hymn in Philippians 2:5-11:

"Let the same mind be in you that was in Christ Jesus,

who, though he was in the form of God, did not regard equality with God as something to be exploited,

but emptied himself, taking the form of a slave, being born in human likeness. And being found in human form,

he humbled himself and became obedient to the point of death-- even death on a cross.

Therefore God also highly exalted him and gave him the name that is above every name,

so that at the name of Jesus every knee should bend, in heaven and on earth and under the earth,

and every tongue should confess that Jesus Christ is Lord, to the glory of God the Father".

The words in verse 7, "emptied himself" (heautòn ekénōsen), gave rise to a veritable "kenotic" philosophy. Gianni Vattimo, e.g., argues that secularization brings kenosis to its accomplishment: "Incarnation is an archetypical occurrence of secularization" [37]. The weakness assumed by Jesus Christ in his incarnation is not a secondary phenomenon, a kind of concession made by the godhead to humankind's redemption. It is - granted the differences during the centuries of theological and philosophical thinking [38] - an aspect of the Christian god-image itself, a kind of God's individuation process as Jung accounts for in "Answer to Job" [39]. Consequently, the "split" between God and the world, between the sacred and the secular, has to be reworked. If incarnation is an archetypical occurrence of secularization secularization is an aspect of God himself, and still further: if creation of this worldly world is an archetypical occurrence of secularization, the process of demythologizing of this world begins in the Creator him/herself. As Vattimo notes, secularization is not a term in contrast with the essence of the Christian message, 
but rather is constitutive of it. The Logos', Jesus Christ's incarnation (the kenosis, the selfemptying of God), as an event both salvific and hermeneutical.

Jobin stresses the hermeneutics of this kenotic process as a major post-metaphysical understanding of the secularization, beyond the classical ontology of the Logos' nature and beyond the of s messianic consciousness inspired by the German idealism [38]. He reminds the "play" between mechanical structures which may provide an allowed clearance or, conversely, entail a dangerous void ("there is too much play in the steering"). The traditional vision of divine grace considers the human condition as empty, sinful, negative, in need of being "filled" with the redemptive gift of divine positivity. However, the kenosis presents another modality of divine grace, the self-emptying grace, kenotic redemption, the gift by void [40].

It is true that the classical kenotic discourse considers God's self-emptying as reverse of his glory and pleroma (fullness). However, if pleroma is not instrumentalized as a form of denial or of social institutions' self-glorification, kenosis provides an important and permanent critical potential regarding "full" forms of religious life, such as institutions, rituals, and social discourses, including post-modern highly individualized 'non-religious' discourses. This critical kenotic potential is particularly helpful when old or new spiritual discourses appear in social realities, e.g., in health care and psychotherapy.

Facing post-modern sensibilities and discourses, the kenotic criticism helps "discern the spirits" as St Ignatius of Loyola formulates in according with the church's spiritual tradition. Ignatius differentiates the "good Angel" and the "evil" one, using the oscillation between consolation and desolation and between false consolation and sustainable consolation. Nowadays we have to discern a plurality of spiritualities, "various spirits", as Ignatius puts it (e.g., in Spiritual Exercises \#176). The challenge to find true and sustainable consolation remains the same.

Considering science fiction, fantasy, and fantastic horror, the post-modern sacred has been qualified as popular culture spirituality, as wholly profane, as a kind of profaning the traditional holy. "It is texts that are consumed [...] for their spiritual content, for an experience of the transcendent outside of the bounds of formal religious and spiritual traditions" [41]. Furthermore, mourning seems rather characteristic of post-modern longing for authenticity, manifesting itself as "sadness without object". Post-modern nostalgia is "the repetition that mourns the inauthenticity of repetition" [42].

Spiritually integrated psychotherapy supports the (post-)modern subject searching for the sacred, very often lost in spiritual transformation processes. It helps discern the nostalgic mourning without object and the true archetypical mourning, the mystical acknowledge of the void, the spiritual journey towards true and sustainable consolation.

One of the major theological objections against a broad understanding of spirituality in the public discourse, in research, and in psychotherapy is the following: When the sacred is completely undetermined and undefined, religion is up in the air, dissolved in individualism and without social and ethical commitment. It is true that spiritually caring psychotherapy deals with the undetermined (be it in the patient's or in the therapist's perspective). Authentically dealing with the undetermined does not refer to traditional answers, assignable contents, and collective forms of belief but to the authentic resources of the speaker [43]. Consequently, we need a discernment 
between different manners to address the undetermined. The psychoanalytic way has been explored

by Wilfred R. Bion. He calls the unknown beyond our knowledge and beyond death "O":

"["O"]... stands for the absolute truth in and of any object; it is assumed that this cannot be known by any human being... its presence can be recognized and felt, but it cannot be known. It is [however] possible to be at one with it.

That it exists is an essential postulate of science, but it cannot be scientifically discovered. No psycho-analytic discovery is possible without recognition of its existence, at-one-ment with it and evolution.

The religious mystics have probably approximated most closely to expression of experience of it... Its existence is as essential to science as to religion. Conversely, the scientific approach is as essential to religion as it is to science..." [31].

What Bion calls "Faith-in-O" is a non-religious "scientific state of mind", inspite of his religious allusions, especially to Christian and Jewish mystics. At-one-ment is Bion's expression of a symbol which produces reconciliation between presence and absence.

\section{Conclusions}

Traditionally, we consider the work of mourning as an individual challenge to cope with negative life changing events such as bereavement, major disease, or harmful deceptions. However, collective reconciliation processes show that mourning and its incomplete, "frozen", forms are the prerequisite for successful social and psychological development and ongoing life. Furthermore, the mystical experience of the void, of lost physical "guaranties", and of detachment, offers a model for spiritual and psychotherapeutic processes. In light of these investigations on the personal level, perhaps we may better understand the difficult peace-making process in past and current political, social, and ethnic conflicts. Trauma is a particular poignant example for this analogy between individual and collective suffering and healing.

Mourning is greater than coping with bereavement. It is deeply rooted in the mystical acknowledgement of self-emptying, of a "kenotic" void. Consequently, the experiences of Christian mystics and of other mystical traditions can shed light on the spiritual quest of modern men and women, on the ambivalent potentials of spirituality, and on the risks of a spiritual quest.

Psychotherapy can accompany this quest. However, it does not fill up the patient's spiritual void. It supports his or her reappraisals, transformations, struggles which may be linked to unconscious conflicts. Even if therapists do not speak about their spirituality it will not be possible to remain in a third-person-perspective. In other words: patients help us discover our own spirituality.

\section{References}

1. Freud, S. Trauer und melancholie. In Gesammelte Werke; Freud, A., Bibring, E., Hoffer, W., Kris, E., Isakower, O., Eds.; Imago: London, UK, 1917e; Volume 10, pp. 427-446.

2. Pargament, K.I. Spiritually Integrated Psychotherapy. Understanding and Addressing the Sacred; Guilford: New York, NY, USA; London, UK, 2011. 
3. Freud, S. Das ich und das es. In Gesammelte Werke; Freud, A., Bibring, E., Hoffer, W., Kris, E., Isakower, O., Eds.; Imago: London, UK, 1923b; Volume 13, pp. 235-290.

4. Bradbury, M. Classics revisited: Freud's mourning and melancholia. Mortality 2001, 6, 212-219.

5. Freud, S. On transience [vergänglichkeit]. In The Standard Edition of the Complete Psychological Works; Freud, A., Ed.; Hogarth Press Institute of Psychoanalysis: London, UK, 1916a; Volume 14, pp. 303-307.

6. Clewell, T. Mourning beyond melancholia: Freud's psychoanalysis of loss. J. Am. Psychoanal. Assoc. 2004, 52, 43-67.

7. Stroebe, W.; Schut, H.; Stroebe, M.S. Grief work, disclosure and counseling: Do they help the bereaved? Clin. Psychol. Rev. 2005, 25, 395-414.

8. Hagman, G. Beyond decathexis: Toward a new psychoanalytic understanding and treatment of mourning. In Meaning Reconstruction \& the Experience of Loss; Neimeyer, R.A., Ed.; American Psychological Association: Washington, DC, USA, 2001; pp. 13-31.

9. Volkan, V. A study of a patient's 're-grief work' through dreams, psychological tests and psychoanalysis. Psychiatr. Q. 1971, 45, 244-273.

10. Tähkä, V. Dealing with object loss. Scand. Psychoanal. Rev. 1984, 7, 13-33.

11. Volkan, V.D.; Zintl, E. Life after Loss. The Lessons of Grief; C. Scribner's Sons: New York, NY, USA, 1993.

12. Volkan, V.D. The re-libidinalization of the internal world of a refugee family. Group Anal. 2003, 36, 555-570.

13. Bacqué, M.-F. Psychothérapie analytique des deuils post-traumatiques. Rev. Francoph. Stress Trauma. 2005, 5, 153-160.

14. Volkan, V.D. Not letting go: From individual perennial mourners to societies with entitlement ideologies. In On Freud's "Mourning and Melancholia"; Fioroni, L.G., Lewkowicz, S., Bokanowski, T., Eds.; International Psychoanalytic Association: London, UK, 2007; pp. 90-109.

15. Volkan, V. The Next Chapter: Consequences of Societal Trauma; University of Cape Town: Cape Town, South Africa, 2006.

16. Lemma, A.; Levy, S. The impact of trauma on the psyche: Internal and external processes. In The Perversion of Loss. Psychoanalytic Perspectives on Trauma; Whurr Publishers: London, UK, 2004; pp. 1-20.

17. Kernberg, O. Some observations on the process of mourning. Int. J. Psycho-Anal. 2010, 91, 601-619.

18. Stroebe, M.; Schut, H.; Boerner, K. Continuing bonds in adaptation to bereavement: Toward theoretical integration. Clin. Psychol. Rev. 2010, 30, 259-268.

19. Boerner, K.; Heckhausen, J. To have and have not: Adaptive bereavement by transforming mental ties to the deceased. Death Stud. 2003, 27, 199-226.

20. Westerink, H. Verwehte trauer. Ansätze zu einer freudschen theorie des trostes. Wege zum Menschen 2010, 62, 61-75.

21. de M' Uzan, M. Le travail du trépas. In De l'art à la mort; de M' Uzan, M., Ed.; Gallimard: Paris, France, 1976/1977; pp. 182-199. 
22. Des Rosiers, P. Repetition of the mother-infant dyad and the process of dying in the psychotherapy of an hiv-positive man. J. Am. Acad. Psychoanal. 1999, 27, 191-204.

23. Leclaire, S. On tue un Enfant: Un essai sur le Narcissisme Primaire et la Pulsion de Mort; Seuil: Paris, France, 1975.

24. Racamier, P.C. Le génie des Origines. Psychanalyse et Psychoses; Payot: Paris, France, 1992.

25. Neumann, E. The Great Mother: An Analysis of the Archetype; Pantheon Books: New York, NY, USA, 1955.

26. Ricoeur, P. La mémoire, l'histoire, l'oubli; Seuil: Paris, France, 2000.

27. Klein, M. Mourning and its relation to manic-depressive states. In Essential Papers on Object Loss; Frankiel, R.V., Ed.; New York University Press: London, UK; New York, NY, USA, 1940/1994; pp. 95-122.

28. Colman, W. Mourning and the symbolic process. J. Anal. Psychol. 2010, 55, 275-297.

29. Freud, S. Jenseits des lustprinzips. In Gesammelte Werke; Freud, A., Bibring, E., Hoffer, W., Kris, E., Isakower, O., Eds.; Imago: London, UK, 1920g; Volume 13, pp. 3-69.

30. Segal, H. Notes on symbol formation. In The Work of Hanna Segal; Jason Aronson: London, UK, 1957/1981.

31. Bion, W.R. Attention and Interpretation. A Scientific Approach to Insight in Psycho-Analysis and Groups; Tavistock Publications: London, UK, 1970/1975.

32. Segal, H. Dream, Phantasy and Art; Brunner-Routledge: New York, NY, USA, 1991.

33. Certeau, M.D. Heterologies. Discourse on the other; University of Minnesota Press: London, UK, 1986.

34. Certeau, M.D. Folie du nom et mystique du sujet: Surin. In Folle vérité. Vérité et vraisemblance de texte psychotique; Kristeva, J., Ed.; Seuil: Paris, France, 1979; pp. 274-304.

35. Certeau, M.d. L'expérience spirituelle. Christus 1970, 17, 488-489.

36. Jaffé, A. Memories, Dreams, Reflections by c.G. Jung; Vintage: New York, NY, USA, $1961 / 1989$.

37. Vattimo, G. After Christianity; Columbia University Press: New York, NY, USA, 2002.

38. Jobin, G. Instituer l'évidement? Heuristique kénotique et positivité éthique. Laval Théol. Phil. 2011, 67, 69-86.

39. Jung, C.G. Antwort auf hiob. In Zur Psychologie Westlicher und Östlicher Religion (gw xi); Niehus-Jung, M., Hurwitz-Eisner, L., Riklin, F., Eds.; Rascher: Zürich, Switzerland, 1952/1963; Volume 11, pp. 385-506.

40. Jobin, G. Quand la faiblesse est donnée...Kénose et participation au temps du nihilisme. Et. Théol. Rel. 2010, 85, 323-346.

41. McAvan, E. The Postmodern Sacred: Popular Culture Spirituality in the Genres of Science Fiction, Fantasy and Fantastic Horror. Ph.D. Thesis, University of Murdoch, Perth, Australia, 2007.

42. Stewart, S. On Longing; Duke University Press: Durham, UK, 1993.

43. Nassehi, A. Spiritualität. Ein soziologischer versuch. In Spiritualität und Medizin. Gemeinsame Sorge für den Kranken Menschen; Frick, E., Roser, T., Eds.; Kohlhammer: Stuttgart, Germany, 2011; pp. 35-44. 


\title{
The Spiritual Approach to Group Psychotherapy Treatment of Psychotraumatized Persons in Post-War Bosnia and Herzegovina
}

\section{Mevludin Hasanović, Osman Sinanović, Izet Pajević and Mark Agius}

\begin{abstract}
Psychological trauma and post-traumatic stress disorder (PTSD) may have an intensive negative impact on a patient's spiritual beliefs or his/her belief in God; this effect may diminish the social and professional skills of many survivors. In the same time researches showed that religion plays a coping role among patients with medical and mental health illnesses. During the war in Bosnia-Herzegovina (1992-1995) the whole population, regardless of age, gender, nationality or profession, suffered severely. During the pre-war period in communistic Yugoslavia religious believes altered with atheistic public life styles. Additionally, war traumatization had a negative impact on spirituality and religious beliefs. In the series of case reports we intended to describe and assess the impact of a session of group psychotherapy, with spiritual topics and content, which was offered to patients who needed to reestablish religious beliefs. The patients who come to the Psychiatry Clinic because of trauma-induced mental health problems and who we are interested in strengthening their spirituality met each other in the group regardless of their religious or spiritual conviction. We described the conceptualization and development of such a group and present some self-reported views of clients who took part in these groups. The supportive and empathetic presence of such group in the community helps to prevent withdrawal and isolation, alienation and deviation of traumatized persons. The presence of such group facilitates the rehabilitation process of the victims, allowing them to understand that people are available to them in certain critical moments, to help, to offer protection or to console. Groups like this one, offer long term social and spiritual support to extremely severely traumatized victims.
\end{abstract}

Reprinted from Religions. Cite as: Hasanović, M.; Sinanović, O.; Pajević, I.; Agius, M. The Spiritual Approach to Group Psychotherapy Treatment of Psychotraumatized Persons in Post-War Bosnia and Herzegovina. Religions 2011, 2, 330-344.

\section{Introduction}

The terms religion and spirituality must be defined because of their ambiguous meanings that may impact on the understanding of this article. According to Koening (2009), religion is generally agreed on and involves beliefs, practices, and rituals that are sacred. Additionally, he defined sacred as that which relates to the numinous or God, and in Eastern religious traditions, to Ultimate truth to Reality. Religion may also involve beliefs about spirits, angels, or demons and usually religions have specific beliefs about life after death and rules to guide life within a social group. Religion is often organized and practiced within a community, but can also be practiced alone and privately [1]. On the other hand, spirituality is considered more personal, something people define for themselves that is largely free of the rules, regulations, and responsibilities associated with 


\section{8}

religion. There are more and more individuals categorized as spiritual-but-not-religious. They deny any connection at all with religion and understand spirituality entirely in individualistic, secular terms. Koening emphasized that a spiritual person was considered earlier as someone with whom the spirit of God dwelt, often referring to the clergy. In the Second Vatican Council, spirituality replaced terms of ascetical and mystical theology. While in the Greek's definition of spirituality, the word spiritual was used to distinguish humanity from non-rational creation, throughout Western history spiritual and/or spirituality has been distinctly religious. Eastern religions adopted this term much later, and then spiritual people were a subset of religious people whose lives and lifestyles reflected the teachings of their faith tradition [1].

Due to the difficulties in finding appropriate measuring instruments to assess spirituality Koenig proposed that spirituality be defined in terms of religion [2], where religion is a multidimensional construct not limited to institutional forms of religion. Thus he either referred to religion or used the terms religion and spirituality synonymously [1].

From time immemorial, religion has had an educational role and an outstanding influence on the population [3]. From the beginning, many people tried to overcome illness by the use of religious rituals and mystical experiences to attempt to reestablish the body and spiritual equilibrium and harmony in search of the most valuable treasure: health [4]. However, religion is frequently ignored within the clinical domain. Systematic research published in the mental health literature to date does not support the argument that religious involvement usually has adverse effects on mental health. On the contrary, religion is recognized as a common important coping mechanism among patients with medical and mental illness [1]. Interest in the relationship between spirituality and health is growing and there is extensive research in the medical and psychiatric literature on the physical and psychological benefits of religious and spiritual practice and beliefs [1,5]. Religious beliefs and practices have long been linked to hysteria, neurosis, and psychotic delusions. However, recent studies have identified another side of religion that may serve as a psychological and social resource for coping with stress. Religious beliefs provide a sense of meaning and purpose during difficult life circumstances that assist with psychological integration. Unlike many other coping resources, religion is available to anyone at any time, regardless of financial, social, physical, or mental circumstances [1]. Prayer is an integral component of the spiritual life of mankind. Prayer allows people to express themselves during crisis and emotional turmoil. It can serve as an important source of personal strength and as a foundation for self-resilience during times of adversity. Holistic nurses may use prayer with patients to positively influence their ability to cope with anxiety related to their illness [6]. Using MEDLINE, limited to the English language and the reference lists of randomized controlled trials, Townsend et al. (2002) assessed the impact of religion on health outcomes via systematic, critical review of the medical literature published from 1966 to 1999. They used the Canadian Medical Association Journal's guidelines for systematic review of medical literature to evaluate each manuscript. Randomized controlled trials showed that Islamic-based psychotherapy speeds recovery from anxiety and depression in Muslims [7].

However, intensive physical or psychological traumas can devastate the human psyche and leave the traumatized personality in ruin [8]. The events which represent an integral part of wars, natural catastrophes and similar situations may cause much pain and suffering to the survivors 
which overwhelms their psychophysical capacities. This can lead to a collapse of internal defense mechanisms and the appearance of psychical complains which leads to disorder in a previously normal life [9]. Extreme trauma, after the devastation of the human psyche leaving the human personality in ruins, can bring complete disorder into religious beliefs and spirituality, which are integral parts of human existence [8]. Mental health professionals are increasingly aware of the need to incorporate the patient's religious and spiritual beliefs into mental health assessments and treatment plans [10]. On the other side, Koenig (2009) reviewed studies examining the relationship between religion and mental health in five areas and emphasized that religious involvement is related to better coping with stress and less depression, suicide, anxiety, and substance abuse, while among patients who suffer from psychotic disorders religion played more of a positive than a negative role in the lives and treatment of these patients [1]. Therefore, faced with the reality of the entire tragedy and insecurity of human existence on Earth today, all mental health professionals and clergy need to understand the influence of psycho-trauma and post-traumatic stress disorder (PTSD) on human spirituality and personality [11,12]. The written resources bear witness that the first organized institution for complex mental healthcare on the territory of Bosnia and Herzegovina has been Hajjy Sinan's tekke in Sarajevo. In regard to its stirring history, which is not primary goal of the investigation in this paper, there is no material existing today about how it was organized in terms of admissions, accommodation, and treatment and dismissing of mentally ill persons during that time. From the existing written resources it is clear that there existed an organized institutional approach to the mental health problem, even much wider and deeper than is expected within a hospital framework. Besides complex skilled works, sheikhs (spiritual guides) of Sinan's tekke occupied themselves with other works too, such as curing and similar activities [13]. In regard to tekke as an institution for definite mental healthcare for mentally ill individuals, Cerić and others mentioned its existence at The First Physician Congress in Bosnia and Herzegovina in 1977, in Sarajevo, giving reflection about mentally ill persons, not about the mental healthcare system. "The status of mentally ill persons was especially difficult, because for their treatment there were not any institutions almost until 1640, when in so-called Sinan's tekke in Sarajevo there was organized some sort of shelter for mentally ill persons, and only for Islamic believers“" [14].

In this paper we present our positive experiences acquired by the introduction of spiritual and religious parameters into everyday practice and particularly into group psychotherapy, in the treatment of psycho-traumatized clients in the Psychiatry Clinic in Tuzla, after the war in Bosnia and Herzegovina (1992-1995).

Between April 1992 and December 1995 a war occurred in Bosnia and Herzegovina (BH) which caused tremendous destruction and poverty and affected the whole population [15]. Out of the 4.3 million population of prewar BH, $40 \%$ were Muslims, 30\% were Serbs who belonged to the Orthodox Church, and 18\% were Croat Catholics. The figures after the war show that in Bosnia and Herzegovina 242000 people were killed, 175000 were wounded and 1.3 million made into refugees [16]. After the war, which caused so many cases of trauma, stress and sufferings to the whole population, common people and professionals have had to deal with many issues which can only be understood in terms of the state of the public mental health [17-19], as well as the ongoing reform and development of mental health care [18]. The mental health of the average citizen 
of Bosnia and Herzegovina, regardless of age, gender, nationality or profession, is seriously damaged [14,15,20-22].

Everyday prayers establish and revive the belief from which courage, sincerity, resoluteness, purity of heart and soul, moral standing, and all other positive characteristics of a person originate, so such prayer is the best way to help an individual to adapt his/her behavior to his own ideals [23] In his research, carried out as part of his Master thesis, Pajević (1999) was interested in the influence of Islamic daily routine (five daily prayers) on psychological stability in adults. He studied a sample of 100 soldiers of the BH Army who had experienced different traumas during the recent war in Bosnia and Herzegovina (1992-1995). In the experimental group there were 50 Muslim soldiers who had kept their prayers every day continually during the war, and in the control group there were 50 Muslim soldiers who did not pray at all. It was found that regular practicing of five daily prayers made the will and the ability of self-control stronger, that it induced the tendency for self-perfection and for modeling one's own personality, for acquiring new knowledge and its practical application. Those individuals, who regularly practiced five daily prayers, distinguished themselves by a more correct and more explicit life orientation, with better and stronger character, with more constructive identity, stability and pragmatism. He found that a religious lifestyle has a positive influence on mental health and human individual stability, so it represents one very efficient way of achieving higher resistance to different stressful factors in everyday life and particularly in extraordinary, catastrophic situations like war [9,24]. Religiosity strengthens psychological stability in humans [25], and provides more successful strategies to cope with the various stress factors that war veterans face. It also increases the readiness of soldiers for battle, making them more willing to confront all the hardships brought about by war activities and destruction [26].

Many scientists admit that the specific forms of religious engagement are associated with better functioning, which is then ascertained by various measurements of mental health [27]. The role of spiritually oriented group psychotherapy, led by the principles of psychotherapy guidelines of the group leader, with equal participation of all members, helps in the discovery of the healing role of religion. The elements of Spiritual care in group psychotherapy include:

1. Sitting in a circle as a purposeful approach to creative and structured work and enjoyment in the essence of our very existence;

2. Feeling safe and secure; being treated with respect and preserve dignity and be allowed to develop the feeling of belonging, of being valued and trusted;

3. Having time to express feelings to other members in the group with a sympathetic, open ear; Opportunities and encouragement for emotions to grow and develop, and helping patients to draw their own conclusions from their experience and from the disease;

4. Receiving permission and encouragement to develop a relationship with God or with the Absolute (however the person conceives what is sacred), the time, place, and space for prayer and privacy, education in spiritual matters and encouragement in deepening faith, the feeling of universal connection and perhaps also forgiveness [28].

Stable groups like this can represent the first line in a protective response for trauma victims. The supportive and emphatic presence of these groups can help by preventing the traumatized 
person from withdrawing into isolation, alienation or deviation. Such a structured existence can facilitate rehabilitation from traumatic events, allowing victims to realize that people are available in critical moments, to help, to take care or to console. Groups like these offer ongoing social and spiritual support for severe trauma victims [24]. This can help in the discovery of the healing role of religion [29]. This illustrates the effect of patience and the role of endorphins in pain relief and stabilization [30].

We aimed to describe and assess the impact of group psychotherapy sessions, with spiritual topics and content, whichwere offered to psychotraumatized patients who-on an assessment of needs-were found to have a spiritual inclination. Due to negative impacts of war traumatization on spirituality and religious beliefs, this treatment was targeted to reestablish religious beliefs of the involved patients and to improve overall outcomes of the clinical treatments.

\section{Clinical Environment as Room for Spiritual Recovery}

We first here discuss the rationale which led us to the development of a specific psychotherapeutic group in which spiritual values were discussed. We later discuss the environment, or therapeutic milieu, in which the group takes place and the structure of the group, including how clients were recruited and how the group was organized as compared to an ordinary psychotherapeutic group. It is worthy of note that the request for the development of the group came from the patients themselves.

Regarding our clinical experiences, the incidence of PTSD and trauma related disorders are seriously increasing. The majority of our clients, who we treated during the war and in the post-war period, were soldiers of the Bosnia-Herzegovina Army (AR BH) and Croat's Defense Council (HVO), their family members, as well as civil war victims, and among them particularly refugees, displaced persons, adolescents and children. These included Bosnians with the Muslim cultural-spiritual and historical background, and the Croats of Catholic faith, the Serbs of Orthodox faith and the members of all three ethnicities who considered themselves atheists. All Bosnia and Herzegovina citizens belonged to some culturally-historical background based on religious traditions before the communist regime in the former Yugoslavia (1945-1991). Parents of the actual population were raised in the spirit of religious manner and tradition. After religion behaviors were condemned and expelled from public life and school programs, the postwar generation had double standards in regards to religious and spiritual values. On one hand, a the secret home environment, which remained as religious because of keeping religious customs and obligations, and on the other hand the public life where interpersonal relationships were displayed in an atheistic manner in public communications. Before the war, after Yugoslav president Tito passed away, communism and atheism weakened, and all national groups began to seek their particular values in the return to own religious believes, behavior and gathering. After the war a new religious group emerged within Bosnia and Herzegovina, known as Jehovah's Witnesses, who were recruited from the members of all three ethnicities, but mainly from the atheists. All of them show a certain level of spirituality, regardless of whether they practice it in daily or weekly routines, or just as passive consumers of the contents offered in different media programs or in the community. During different clinical procedures which we developed in our clinic after the war, a significant number of our clients showed an open desire for conversation about the spiritual perspectives of life; the meaning of death and the symbolism of life sacrifice of their close family members, as well as of the spiritual 
meaning of the sacrifice of those who had lost their own body parts, properties, social status and social relations. Very often during the individual, family or group psychotherapy sessions there appeared tendencies toward spiritual and more often religious explanations of life, and the hereafter. Our clients, particularly those from Bosniac ethnicity, expressed a need to keep a daily rhythm of obligatory prayers. In the Islamic religion every believer is required to perform five daily prayers at defined times. Before these prayers the ritual washing of certain body parts is also required (ablution). In our clinical experiences with traumatized clients and those who are suffering from PTSD, we have noted that a daily program of religious activities was clinically helpful. Religious clients participate voluntarily by making a free choice of how to spend their $24 \mathrm{~h}$ in clinic. To support this choice, we arranged that there should be, within the clinical environment, one room dedicated to spiritual psychotherapy, which was also the same room which was set aside for performing prayer. The inpatients experienced this facility with pleasure, because it completed their $24 \mathrm{~h}$ stay in the clinic, and particularly facilitated the healing of their mental disorders and disturbances.

Since the day hospital patients often demanded clarifications based upon the domain of spiritual dimensions regarding their experiences and the conditions and situations they survived and were obliged to remain, it became clear that these domains needed to be incorporated into the group psychotherapy which was being offered. Initially, the group leader resisted such an introduction, trying to maintain the classical structure of a group with a cognitive psychotherapy approach. Furthermore, a certain number of patients who declared themselves as atheists expressed the opinion that: "...religions were guilty for the breakout of war in BH", so they rejected any possibility of opening any discussion about the suggested spiritual issues.

Since we observed the need of the patients who showed a spiritual inclination, to discuss these issues, it was decided to offer them for a term an extra session of group psychotherapy which had primarily spiritual topics and contents. The session was held only once a week with open access and the clients did not need a specialist's referrals. The sessions lasted $60 \mathrm{~min}$., from 13:15 to 14:15 every Thursday, and took place in this manner for over two years. The patients sat in a circle as in every other session. The number of clients varied from 20 to 30 . There were 20 permanent clients and the rest changed throughout the running of the program. All who happened to be in the day clinic or those who were inpatients in the Psychiatry Clinic met regardless of their religious or spiritual orientation. Those who completed their course of treatment and were discharged but continued to receive outpatient treatment, along with citizens (who heard about the group from their friends or relatives) also came to the Psychiatry Clinic for these sessions. We observed that after such sessions the clients are less anxious, less depressed, have better communication skills, while symptoms of avoidance and hyper-arousal symptoms become decreased in intensity. After finishing their prayer, the clients continued with the work in the group therapy of spiritual sessions where all the team members collaborated. In such open sessions, the therapeutic team, which was well trained in using religious faith as a part of the whole therapy, gave answers about religious obligations and its value in achieving mental wellbeing. Sessions of such groups provide for an increase of the participants' interest in their daily spiritual program, and can teach them how to use their time in a constructive way and choose some recreational activities which bring satisfaction, as a foundation for the reconstruction of their behavior for a therapeutic purpose [31]. 


\section{Case Presentations}

Here we present some data regarding patients' trauma experiences, mental health sufferings, recovery outcomes and satisfaction with the group. Data were collected using individual interviews and standardized psychological tests performed by clinical psychologist employed in our clinic. Data about reflections on spiritual group experiences were collected by action research methods, whereby we asked our clients to write down their own impressions of the group and how introduction of religious issues in the group affected their lives. We believe that this data demonstrates the positive effect that the group has had on patients' mental state and ability to cope with difficulties.

Mrs. S. J. Worker, 47 years old, married, mother of two grown-up sons: She was born out of wedlock from a father and mother who are Serbs-orthodox. Her father did not admit her, her mother had left her in an orphanage where she had grown up, and met her husband who was an orphan too but he was a Muslim. During the war her husband and older son were engaged in the Bosnia-Herzegovina Army. Son was wounded. Both sons witnessed the massacre that happened in Tuzla downtown "Kapija-Gate" on 25 May 1995 where only one shell hit the crowd of adolescents gathered to celebrate the traditional "Day of Youth" the birthday of President Tito, which was celebrated in the whole Yugoslavia before this war. At the certain moment of 8:55 p.m., 71 girls, boys and children aged from three to 26 years were brutally killed and about one hundred were wounded [32]. When she heard the shell detonation, she thought that her sons could be victims, after that she watched TV and was horrified with the massacre that could be seen. She was shocked until her sons returned in bloody shirts, because they helped in collecting parts of dead bodies. From that period she suffered chronic PTSD, Persisting Depressive disorder, high blood hypertension. She visited her family physician regularly on a monthly basis and use antidepressants, anxiolitics, antihypertensive drugs, but without significant improvement of symptoms. Finally she was referred to the Department of Psychiatry where she was treated in Day hospital and included in the spiritual group. After two months she recovered significantly and she continued with spiritual groups as an outpatient. During a year of spiritual group psychotherapy she became stabilized with no PTSD symptoms, without depression, with controlled blood pressure with low doses of antihypertensive drugs. Asked to reflect on her impressions of the spiritual group psychotherapy she stated: "For the first time I speak openly among these people without the feeling that my problems will cause a nuisance to everyone. I don't feel weak here, but rather think that everyone carries his own burden and that we all require some kind of help. Some time ago I used to think that religion was something that rather belonged to elderly people, but now I know that we're all able to find it within ourselves and that we're all capable of living it in our own ways."

Miss. A.M. Administrator, 31 years old, single, has no child: Originally Croat-Catholic, has older sister, older brother and both parents died. During war as an employee in the Clinical hospital Tuzla she helped many times to nurse wounded civilians and soldiers when there were needs for additional staff. She saw numerous crippled, injured and dying young individuals. She witnessed the gradual death of her mother; she still has difficulties missing her mother as a friend. Father was alcoholic, who died in orthopedic clinic after he fractured his hip in the bathroom in a drinking state. It is difficult for to come to terms with not having had an easy life with her father, she 
suffered with her mother, sister and brother as kids and later until her father's death. Her sister misused marijuana, and her brother often behaved crudely toward her. In his behavior she recognized her father's behavior. Whenever she witnessed violence, to street kids without parental care with bad behavior, to alcoholics and old helpless persons, she suffered PTSD symptoms, became depressed and could not be functional in her job. She was referred to Day hospital, and she was included in the spiritual group. She was active in group settings; she spoke about her series of traumatic experiences in childhood, adolescence and during the war. She successfully understood the psychological side of her problems, she was oriented positively to peaceful settlement of her suffering. She successfully understood her behavior was learned from her helpless mother in the marriage with violent father. She recovered significantly. Asked to give impressions about her experiences in the spiritual group settings, she stated: "I used this kind of therapy only on two occasions, and I already feel its positive effects. I communicate much more easily with people around me and I am much clearer in the expression of my attitudes. I don't have much opportunity to join in conversations of this kind (my house mates don't practice their faith and moreover, talk about these matters does not occur). After these therapy sessions, I feel that deep inside me, I experience the suppressed feeling of belonging to a large group of people ('believers')."

Mrs. N.S. Worker, 45 years old, divorced, has no child: She survived loss of her father because of war, she is a displaced person with two brothers and mother. She was married to a taxi driver who was violent and they divorced after four years of his violent behavior. She is suffering from chronic back pain, as a 15 years girl she was raped by her neighbor ten years older than her. She never told her parents. About her impressions of psychotherapy in spiritual groups she stated: "I am a chronic patient with a neurological disorder and even with the therapy I use, my condition did not get any better, so I committed myself to the faith, and in the performance of my daily prayers I found peace. Nevertheless, I still have episodes of nervousness, discontent, insomnia, and bursts of tears (depression). My biggest problem is that I don't really know how to find out for myself the right solution at the right time. My coming to the sessions of 'spirituality and humanism' enables me to discard negative energy and wrong thinking and bad decision making. In the presence of the group leader, I am able to discard that negative energy and to absorb a positive one. I feel relaxed, I am in a good mood, and I feel that I am not under pressure. My desire to talk about these things in this company of people frees me from problems that put pressure on my body too."

Mrs. Sh. P. Shopkeeper, 46 years old, she has two grown up daughters; one daughter is married and has a child: "Contact with the group has sparked a warm presence of light, as at the end of a long and dark tunnel; it is very pleasant to be there. I met people with similar difficulties and my medical status changed for the better. My dark tunnel is now enlightened and I don't use any sedatives anymore, instead I cure my soul with firm belief in The Most High, the God. I am aware, that it is only He who can help me now and I pray for His guidance and help. I am certain that He will never abandon me or betray me. His are not ways of corruption and I believe in Destiny and in the Bounty of The Most High, the Lord. The state of my soul is much better now as well as my physical state. I will continue with this spiritual therapy, although I'm being retired with God's help, I think that this is my spiritual filling up, my inspiration, my stimulation and I am happy now, my Life is not a 'dark tunnel' anymore, but rather a 'lit crystal hall'." 
Mrs. R.B. Shopkeeper, 53 years old widow, remarried, has no children: Operated on after an extra uterine pregnancy; she looks after two young children of her second husband. During the war she lost her father, one brother, another brother was injured; she was forcedly expelled from her home. She had chronic PTSD, headache, and back pain; she was overweight and suffered from blood hypertension. She was referred to Day hospital, where she was included in spiritual group psychotherapy. After two months she recovered significantly and continued with group psychotherapy for an additional year as an outpatient. Her recovery became stable. About her impressions in these groups she stated: "This group has given me back my lost confidence, self-respect, and the strength I need to cope with entirely different and new experiences in my life. This group is a school for my future. With this I feel stronger for my present and future life. It gives me strength and fills me with positive energy. I use what I have learned within my capacities and every session adds strength and gives me back my peace."

Mr. M. S. an active Army officer, 43 years old, married, father of three young children: During the war he witnessed massacre of young people in the Tuzla downtown [32], and a massacre that happened in the military camp, when only one shell killed almost a hundred soldiers who were lined up in the morning on the runway in front of military barracks. M.S. collected remains of bodies in both tragedies. He was wounded in his head and his left knee with shrapnel. He was hospitalized because of vertigo, nausea, back pain, nightmares, and severe intrusive thoughts that prevented him from being functional in his duties. He was included in the spiritual psychotherapy groups and contributed well during sessions. After one month of inpatient care he continued to be active in spiritual groups the next year as an outpatient. He recovered significantly, he organized an association of war veterans who were treated for PTSD, and became its president, and did a lot on destigmatization of war veterans who suffered from PTSD. He stated: "By visiting these sessions, I have gradually recovered my strength and desire to fight for my life and have become aware of how much my wife and kids need me. Every hour spent with the group has left a deep imprint, and with God's help has given me a great strength to cope with my difficulties, war nightmares that have haunted me by night, to feel my body parts as they were really mine, since they were heavily injured in the conflict, with a desire to recover, as much as it is possible in my case. The leader of the group has helped me to make one great decision, to give up smoking, a vice difficult to get rid of, but now I feel like I've never smoked before."

Mrs. R.S. Shopkeeper, 51 year old, married, mother of two grown up daughters: Her elder daughter is married and has two sons, she emigrated to the USA with her family four years ago. She survived the first attack on 15 May 1992 in Tuzla, when war broke out-in front of the building where she has an apartment. Her husband is violent; jealous and he often blames and tortures her. Her father died after stroke at our clinic, consequently she is afraid of injections, because her father died after intramuscular injection of analgesic. While she was talking her face, neck and across her chest became red and itchy, with intense erythematous swelling, which indicates neurovegetative reaction to trauma. After Day hospital treatment she continued with spiritual group settings for an additional year. She recovered, retired and divorced. About spiritual group impressions she stated: "A large number of people of all faiths take part in these sessions. This is practically the only place where I feel comfortable and well. In these sessions I have learned so much about things that I have not known until now, and which help me to cope with my problems." 


\section{Discussion}

Religion has been found to be a significant protective factor against many types of maladaptive adjustment outcomes among adolescent samples [29] and war veterans [33]. By identifying the ways in which religion may exert a positive impact on individuals, mental health professionals can design interventions which have the potential to help improve the quality of life for these persons [34].

Clinical studies maintain the statement emphasized in DSM III and DSM IV, that extreme trauma influences the "important fields of functioning" of many survivors [35,36]. Psychological trauma and PTSD can have a severe negative impact on spiritual faith or faith in God by decreasing social and professional skills. Because of the effects of psycho trauma and PTSD effects, the faith of the traumatized person collapses. Therefore, the spiritual sense of binding, confidence and order of that person become "scattered" as well as defeated, because the trauma experience of an individual deranges his psychological dimensions. The same experience influences the individual's systems of faith and spirituality, which are fundamental for the meaning of life for this individual. When an individual's faith is overthrown, a believer falls into an exhausted state of existential crisis. In our clinical work with the survivors of (an) some early childhood trauma or different traumas in the adult period, we are very often faced with males and females who are suspicious and dubious regarding belief in God. They question aloud, expressing guilt, and asking why they are "punished so cruelly". They usually consider themselves innocent and the victims of "God's injustice", which they are not ready to accept [24], or they ask themselves: "God, why did this happen to me?" [37]. The traumatized experience the feeling of being cast away from both human and God's care and protection,thus losing these fundamental supports for normal human existence. As a result, they feel spiritually abandoned and completely alone. This leads to a situation where all relationships, whether the most intimate family bonds or the most abstract communication in the community and religion become colored with the feeling of alienation and disconnection [8]. Psychotherapists are more likely to be relevant when they appreciate the fact that many clients have religious values and commitments. Greater awareness of religion and religious values in the lives of their clients may aid clinicians' efforts to provide more accurate assessments and effective treatment plans. The "Ethical Principles of Psychologists and Code of Conduct" of the American Psychological Association's (1992) are used as a framework to examine many of the ethical issues relevant for the psychologists' work with religious clients. These guidelines also provide suggestions for clinicians as to how to obtain the skills needed to offer competent assessments and interventions with religiously committed clients [38]. During the process of treating their clients, psychotherapists should “discover patients' religion", even if they say that they are not religious. In this way they could help them to alter their life views, which is necessary for good treatment outcomes [39]. Recent changes in the assessment and treatment guidelines in the USA have resulted in corresponding curricular changes, with at least 16 USA psychiatric residency programs now offering formal training in religious and spiritual issues. Currently, most Canadian programs offer minimal instruction on issues pertaining to the interface of religion, spirituality, and psychiatry. Grabovac and Ganesan (2003) proposed that a lecture series focusing on religious and spiritual issues is needed to address this apparent gap in the curricula across the country. Therefore, 
they propose a 10 -session lecture series and outline its content. They believe that including this lecture series in core curricula will introduce residents in psychiatric wards to religious and spiritual issues, as they pertain to clinical practice [10]. This, therefore, means that psychotherapists and priests, in the Muslim faith imams, work together with other community mental health workers [40]. It would also be necessary to establish and maintain environmental conditions in which traumatized persons are enabled to reflect again, to revalue and to change their presumptions about spirituality and beliefs. In addition, it may be necessary to revive certain religious values, ritual practices, belief systems and traditions [31], along with common efforts and constructive and open collaboration. Such developments may provide chances for trauma victims and survivors to experience an added dimension to their treatment, and to develop a new perspective in life [24].

In his research, Levin (2002) suggests that a relationship with a God filled with Love can make a positive impact on psychological distress. So a person's relationship with the God can present a significant personal resource of consolation regarding the emotional consequences of poor health and other distressing living circumstances, as well as religious guidance in tackling difficult circumstances [41]. A true religious affiliation surely represents a positive factor for the protection of mental health and some experts in mental health have had no doubt about this for a very long time $[42,43]$.

The believers who practice their daily religious rituals, dedicated to achieve, as much as possible, the inner peaceful state of mind, can be expected to achieve the following:

The creation of conviction that personal fate is determined by personal actions, this then ensures the feeling of safety against tragedy;

The creation and strengthening of conviction that a person is being protected by the true and eternal Power which then offers a chance to a person to establish a relationship with God;

Some convictions regarding their contemplation about death; they are likely to feel more secure with a promise of eternal life;

A healthy religious perspective offers a person the possibility to cope with guilt by offering the mechanisms for repentance;

It offers a transcendental shelter from the crude realities of daily life [44].

Evidence supports the idea that a framework utilizing a religious perspective in assessment and treatments is indeed helpful. The relationship between religious variables and mental health can depend on cognitive-behavioral mechanisms. Understanding in this area can encourage clinicians to further consider the ways in which religious variables can be utilized in therapy. It is clear that there is need for further efforts incorporating religious and spiritual factors into the clinical arena [4].

There is good evidence in the existing literature, that surviving intensive traumas can devastate the human psyche and have traumatic effects on personality. Wars, natural catastrophes and similar situations cause much pain and suffering to the survivors and can lead to a collapse of internal defense mechanisms and the appearance of psychological complains which disorder normal life. Nowadays it is very important that professional helpers of trauma victims are ready to develop an integral and holistic model based on a multidisciplinary approach, including all relevant resources in the assessment and healing of psycho trauma and PTSD consequences; indeed an eclectic approach, utilizing all positive experiences in human practice are valuable. Following the needs of 
our psycho-traumatized clients in clinical treatment in postwar Bosnia and Herzegovina we have found that it is very helpful to involve spiritual issues in the process of healing.

It is known that Islamic behavior principals are multilaterally beneficial when applied in the everyday life of believers; therefore, the use of daily Muslim routine incorporated in therapy facilitates the process of healing of mental dysfunction. The five obligatory daily prayers play a focal role, if they are practiced constantly either individually or in a group. To realize a holistic approach in the community based mental healthcare it is very important to educate religious professionals in a psychotherapeutic approach, so that they can be included as professional helpers in a therapeutic team and get ready to meet the sophisticated spiritual needs of traumatized believers. This can strongly help in the process of spiritual healing of PTSD and other different mental disorders related to psycho trauma. Professional and personal development in terms of spiritual attitudes, values and skills can be nurtured by encouraging the language and practice of spirituality and religiosity in mental healthcare.

Practically also, an adequate room, which provides a quiet space encouraging contemplative spiritual and religious activities, is useful. Spiritual skills can be taught by directly educating mental healthcare workers through official curricula, and directly in the doctor-patient relationship.

\section{Conclusions}

Group psychotherapy is very useful for achieving higher spiritual and religious awareness as a therapeutic tool for clients, and in building up better personal, trustworthy relationships between professionals and patients, which is a very important aspect of good mental healthcare practice. We believe that our group psychotherapy described above has had a positive effect on the mental health and lives of the patients who have participated in it. Further research about effects of spirituality and religiosity and its' influence on mental health improvement of traumatized individuals in individual and group psychotherapy settings is needed.

\section{Acknowledgment}

The authors are grateful to all individuals and institutions that helped in the development of a better and more modern mental healthcare and on the promotion of mental health in the post-war Bosnia-Herzegovina. Special thanks to Azur Salihović for the help and support that he provided in finalizing this paper, we are thankful to Gordana Rajter who improved the language of this paper. Particular thanks go to our patients who were willing to give their impressions about their experiences in such an approach to their mental health problems.

\section{References}

1. Koenig, H.G. Research on religion, spirituality, and mental health: A review. Can. J. Psychiatry 2009, 54, 283-291.

2. Koenig, H.G. Concerns about measuring "spirituality" in research. J. Nerv. Ment. Dis. 2008, 196, 349-355.

3. Moro, L. Mentalno zdravlje i religija. In Duhovnost i mentalno zdravlje; Sinanović, O., Hafizović, R., Pajević, I. Eds.; Svjetlost: Sarajevo, Bosnia and Herzegovina, 2002; pp. 51-55. 
4. Jakovljević, M.; Nikić, M. Vjera i duševno zdravlje. In Duhovnost $i$ mentalno zdravlje; Sinanović, O., Hafizović, R., Pajević, I. Eds.;.Svjetlost: Sarajevo, Bosnia and Herzegovina, 2002; pp. 31-46.

5. Simmonds, G.J. Heart and spirit: Research with psychoanalysts and psychoanalytic psychotherapists about spirituality. Int. J. Psychoanal. 2004, 85, 951-971.

6. Lo, R. The use of prayer in spiritual care. Aust. J. Holist. Nurs. 2003, 10, 22-29.

7. Townsend, M.; Kladder, V.; Ayele, H.; Mulligan, T. Systematic review of clinical trials examining the effects of religion on health. South Med. J. 2002, 95, 1429-1434.

8. Wilson, J.; Moran, T. Understanding and Assessing PTSD in Religion and Spiritual Context. In Assessing Psychological Trauma and PTSD: A Handbook for Clinical, and Legal Practitioners; Wilson, J., Keane, T., Eds.; Guilford Press: New York, NY, USA, 1997; Chapter 22.

9. Pajević, I. Islamski način života kao faktor psihičke stabilnosti. Magistarski rad; Univerzitet u Tuzli, Medicinski fakultet, Tuzla, Bosnia and Herzegovina, 1999.

10. Grabovac, A.D.; Ganesan, S. Spirituality and religion in Canadian psychiatric residency training. Can. J. Psychiatry 2003, 48, 171-175.

11. Hasanović, M. Islamic Approach to Treatment of Alcoholism, Depression, Suicide and Trauma. Abstracts of 6th International Congress of the World Islamic Association for Mental Health, Tuzla, Bosnia and Herzegovina, 13-15 August 1999; pp. 50-51.

12. Hasanović, M.; Pajević, I.; Sinanović, O. TheRole of Spiritual Dimension in Mental Health. Acta Med. Sal. 1998, 1-2, 25-34.

13. Hasanović, M.; Sinanović, O. Islamic Roots of Mental Health Care in Bosnia and Herzegovina. Ment. Peace 1999, 5, 9-14.

14. Cerić, I. Stanje neuropsihijatrijske službe u Bosni i Hercegovini- Zbornik radova I Kongresa Ljekara Bosne i Hercegovine; Medicinski Arhiv: Sarajevo, Bosnia and Hercegovina, 1977.

15. Cerić, I.; Loga, S.; Sinanović, O.; Oruč, L.; Čerkez, G. Reconstruction of mental health services in the Federation of Bosnia-Herzegovina. Med. Arh. 1999, 53, 27-30.

16. Husain, S.A. Resiliency in Children: Lessons from Bosnia. Mental Peace 1999, 5, 4-8.

17. Hasanović, M.; Avdibegović, E.; Sinanović, O. Mental Health Promotion as a Way of Mental Disorders Destigmatisation. Neurol. Croat. 2000, 49, 71.

18. Hasanović, M.; Sinanović, O.; Pajević, I-; Avdibegović, E.; Sutović, A. Post-war mental health promotion in Bosnia-Herzegovina. Psychiatr. Danub. 2006, 18, 74-78.

19. Sinanović, O.; Avdibegović, E.; Hasanović, M.; Pajević, I.; Sutović, A.; Loga, S.; Cerić, I. The organisation of mental health services in post-war Bosnia and Herzegovina. Int. Psychiat. 2009, 6, 10-12.

20. Goldstein, R.D.; Wampler, N.S.; Wise, P.H. War experiences and distress symptoms of Bosnian Children. Pediatrics 1997, 100, 873-878.

21. Husain, S.A.; Nair J.; Holcomb, W.; Reid, J.C.; Vargas, V.; Nair. S.S. Stress Reaction of Children and Adolescents in War and Siege Conditions. Am. J. Psychiatr. 1997, 155, 1718-1719.

22. Hasanović, M.; Sinanović, O.; Pavlovic, S. Acculturation and Psychological Problems of Adolescents from Bosnia and Herzegovina during Exile and Repatriation. Croat. Med. J. 2005, 46, 105-115. 
23. El-Mevdudi, E.A. Ka razumijevanju islama; Ilmija BiH: Sarajevo, Bosnia and Herzegovina, 1997.

24. Hasanović, M.; Pajević, I.; Sinanović, O. Islamic Perspective of Spiritual Healing of PTSD. J. Bosn. Islam. Med. Asson. 2002, 3, 110-123.

25. Pajević, I.; Sinanović, O.; Hasanović, M. Religiosity and mental health. Psychiatr. Danub. 2005, 17, 61-66.

26. Pajević, I.; Sinanović, O.; Hasanović, M. The role of religiosity in the prevention of pathological response to stress in war veterans. Eur. Psychiatry 2004, 19 (Suppl. S1), 123.

27. McCullough, E.M. Research on Religion-Accommodative Counseling: Review and MetaAnalysis. J. Couns. Psychol. 1997, 46, 92-98.

28. Culliford, L. Spiritual care and psychiatric treatment: an introduction. Adv. Psychiat. Treat. 2002, 8, 249-261.

29. Pajević, I.; Hasanović, M.; Delić, A. The influence of religious moral beliefs on adolescents' mental stability. Psychiatr. Danub. 2007, 19, 173-83.

30. Pajević, I.; Hasanović, M. Uloga džamije u očuvanju mentalnog zdravlja zajednice. Psihijatrija u zajednici; Psihosocijalne posljedice rata u Bosni i Hercegovini. Zbornik radova Sedmih (Prvih poslijeratnih) Psihijatrijskih dana Bosne i Hercegovine, Tuzla, Bosnia and Herzegovina, 1999; pp. 64-68.

31. Al Radi, O.M. An Islamic Approach to Psychotherapy. Mental Peace 1995, 4, $23-26$.

32. Hasanović, M.; Haračić, E.; Ahmetspahić, Š.; Kurtović, S.; Haračić, H. Poverty and Psychological Disturbances of War-Traumatized Adolescents from Rural and Urban Areas in Bosnia and Herzegovina. In Child Development and child Poverty, Fiedler, A., Kuester, I. Eds.; Nova Publishers: New York, NY, USA, 2010; pp. 229-255.

33. Hasanović, M.; Pajević, I. Religious moral beliefs as mental health protective factor of war veterans suffering from PTSD, depressiveness, anxiety, tobacco and alcohol abuse in comorbidity. Psychiatr. Danub. 2010, 22, 203-210.

34. Ball, J.; Armistead, L.; Austin, B.J. The relationship between religiosity and adjustment among African-American, female, urban adolescents. J. Adolesc. 2003, 26, 431-446.

35. American Psychiatry Association: Diagnostic and Statistic Manual of Mental Disorder, 3rd ed.; American Psychiatry Association: Washington, DC, USA, 1980; pp. 247-251.

36. American Psychiatry Association: Diagnostic and Statistic Manual of Mental Disorder, 4th ed.; American Psychiatry Association: Washington, DC, USA, 1994; pp. 424-429.

37. Bradshaw, A.; Fitchett, G. "God, why did this happen to me?": Three perspectives on theodicy. J. Pastoral Care Counsel 2003, 57, 179-189.

38. Yarhouse, M.A.; VanOrman, B.T. When psychologists work with religious clients: Applications of the general principles of ethical conduct. Prof. Psychol Res. Pr. 1999, 30, 557-562.

39. Peck, M.S. Put kojim se rjeđe ide. Narodna knjiga Alfa: Belgrade, Serbia, 1998.

40. Abou El Azayem, G.M. Role of the Mosque in Confronting the Epidemic of Substance Abuse. Ment. Peace 1995, 4, 27-31.

41. Levin, J. Is depressed affect a function of one's relationship with God?: Findings from a study of primary care patients. Int. J. Psychiatry Med. 2002, 32, 379-393. 
42. Husain, S.A.; Sinanović, O. Uloga religije uočuvanju mentalnog zdravlja. In Duhovnost imentalno zdravlje; Sinanović, O., Hafizović, R., Pajević, I. Eds.; Svjetlost: Sarajevo, Bosnia and Herzegovina, 2002; pp. 13-21.

43. Ljubičić, Đ.; Vučić Peitl, M.; Vitezić, D.; Peitl, V-; Grbac, J. Psychopharmacotherapy and spirituality. Psychiatr. Danub. 2007, 19, 216-221.

44. Hasanović, M. Islamski pristup u tretmanu alkoholizma, depresije, suicidalnosti i psihotraume. In Duhovnost i mentalno zdravlje. Sinanović, O., Hafizović, R., Pajević, I., Eds.; Svjetlost: Sarajevo, Bosnia and Herzegovina, 2002; pp. 107-124. 


\title{
Suicide in Judaism with a Special Emphasis on Modern Israel
}

\section{Eliezer Witztum and Daniel Stein}

\begin{abstract}
Judaism considers the duty of preserving life as a paramount injunction. Specific injunctions against suicide appear in the Bible, Talmud, and thereafter. Nevertheless, Jewish tradition emphasizes that one should let himself be killed rather than violate cardinal rules of Jewish law. Mitigating circumstances are found for the six deaths by suicide mentioned in the Bible, for example to account for one's sins, or avoid shameful death. Heroic suicide is praised throughout the Jewish history, from the suicide of Samson and the collective suicide in Masada, to the collective readiness of Jews in Medieval times and during the Holocaust to kill themselves rather than succumb to their enemies. Suicide rates for Jews are lower than those of Protestants and Catholics. Similarly, suicide rates in Israel are lower in comparison to Europe and North America, although being higher than those in most Moslem Asian and North African countries. This low rate of suicide is found in Jewish Israelis of all ages, including in adolescents. Elevated suicidal risk may be found in specific sub-populations, including male Israeli soldiers, immigrants from the former USSR and Ethiopia, in particular adolescent immigrants from the former USSR, elderly Holocaust survivors, and young Israel-Arab women. The meaning of these findings is discussed according to different socio-cultural perspectives.
\end{abstract}

Reprinted from Religions. Cite as: Witztum, E.; Stein, D. Suicide in Judaism with a Special Emphasis on Modern Israel. Religions 2012, 3, 725-738.

"Of all religions, Judaism counts the fewest suicides, yet in none other is education so general. But if the Jew manages to be both well instructed and very disinclined to suicide, it is because of the special origin of his desire for knowledge. It is a general law that religious minorities, in order to protect themselves better against the hate to which they are exposed, or merely through a sort of emulation, try to surpass in knowledge the population surrounding them. Primitive in certain respects, in others [the Jew] is an intellectual and man of culture. He thus combines the advantages of the severe discipline characteristic of small and ancient groups, with the benefits of the intense culture enjoyed by our great society. He has all the intelligence of modern man without sharing his despair" [1].

\section{Introduction}

It was the French-Jewish sociologist Emile Durkheim who made these optimistic remarks at the turn of the century, in 1897, in his famous work Le suicide, which marked the beginning of the scientific study of suicide [1]. Inspired by positivism and a faith in progress, Durkheim set out to probe the relationship between society and the individual, and the social phenomenon of suicide appeared to him the ideal subject, demonstrating the need for establishing sociology as an independent academic discipline. 
The universality of suicide as a form of human behavior across all societies and cultures is well documented [2]. Attitudes toward suicide have varied over time and place, reflecting the ideologies of each society to the value of life and the concept of death. Thus, the attitudes toward suicide in some societies of the ancient world, for example the Ancient Egyptians or the Greeks of the Homeric period, could be described as "justifiable in specific situations" and "non-condemning" [3]. In contrast, current Western negative attitudes toward suicide are likely a consequence of JudeoChristian traditions. St. Augustine's 4th century writings against suicide and the 6th century council of Braga both illustrate Christianity's consistent regard of suicide as the most grievous crime of all [2].

\section{Suicide in Judaism}

\subsection{Introduction}

In Judaism, the duty of preserving life, including one's own, is considered a paramount injunction [4]. Nevertheless Jewish tradition has constantly emphasized that one should let himself be killed rather than violate three cardinal rules of Jewish law: Commands against idol worship, murder, and incest [4]. In the Bible, although no explicit command forbidding suicide is given, the sovereignty of God and not of man over life and death is repeatedly emphasized: "It is I who put to death and give life" (Deuteronomy 32:39). "The Lord kills and makes alive" (Samuel I 2:6). Job rhetorically asks, "In whose hand is the life of every living thing, and the breath of all mankind?" (Job 12:10). The context supplies the unequivocal answer: God. Although God is equally sovereign over the deaths of all men, those of his people touch him deeply: "Precious in the sight of the Lord is the death of His godly ones" (Psalms 116:15).

Theologically, suicide interferes with human purpose on earth that is to be co-partner with God in recreating another Garden of Eden on this planet. Suicide also supersedes God's role as the judge who decrees who is to be rewarded and who is to be punished. The taking of one's life places man in that supreme role. Further, the suicide is denied reincarnation, a part of traditional Jewish theology. Finally, a phrase that is said when a person dies, epitomizing Judaism's theological posture, is "God gives and God Takes". By killing oneself, one is presuming to be powerful enough to take over a right that belongs to God alone [5].

\subsection{Historical Background}

Six deaths by suicide are recorded in the Bible: Samson, King Saul and his arm bearer, Ahitophel, Avimelech and Zimri. In every instance mitigating circumstances for the suicidal act can be found, for example to account for one's sins or mistakes, or to avoid captivity, unbearable torture, or shameful death. In the case of Avimelech, the Old Testament account of his death, after capturing the city of Thebez and assaulting a fortified tower in the center of the city, reads: "So Avimelech came to the tower and fought against it, and approached the entrance of the tower to burn it with fire. But a certain woman threw an upper millstone on Avimelech's head, crushing his skull. Then he called quickly to the young man, his armor bearer, and said to him, 'Draw your sword and kill me, lest it be said of me, "A woman slew him."' So the young man pierced him through, and he died" (Judges 9:52-54). 
The account of king's Saul's is almost identical to that of Avimelech. It reads: "And the battle went heavily against Saul, and the archers hit him; and he was badly wounded by the archers. Then Saul said to his armor bearer, 'Draw your sword and pierce me through with it, lest these uncircumcised come and pierce me through and make sport of me.' But his armor bearer would not, for he was greatly afraid. So Saul took his sword and fell on it. And when his armor bearer saw that Saul was dead, he also fell on his sword and died with him (Samuel I 31:1-6 and Chronicles I 10:1-6). It seems that these two accounts are virtually identical.

In the case of Ahitophel who was King David's counselor and then betrayed him, David prayed that Ahitophel's advice would be regarded as wrong and foolish, which indeed was the case (Samuel II 15:31). The bible reads: "Now when Ahitophel saw that his counsel was not followed, he saddled his donkey and arose and went to his home, to his city, and set his house in order, and strangled himself; thus he died and was buried in the grave of his father" (Samuel II 17:23). Lastly, the king Zimri gained the throne of Israel by assassination. He lacked popular support and was soon attacked by a rival. "And it came about, when Zimri saw that the city was taken, that he went into the citadel of the king's house, and burned the king's house over him with fire, and died, because of his sins which he sinned, doing evil in the sight of the Lord, walking in the way of Jeroboam, and in his sin which he did, making Israel sin (Kings I 16:18-19).

\subsection{Suicide and Heroism}

Another relevant typology in Judaism relates to heroic suicide, demonstrated, for example, in the story of Samson. Samson's death is thus recorded: "It so happened when [the Philistines] were in high spirits, that they said, 'Call for Samson, that he may amuse us.' So they called for Samson from the prison, and he entertained them. And they made him stand between the pillars. Then Samson called to the Lord and said, 'O Lord God, please remember me and please strengthen me just this time, O God, that I may at once be avenged of the Philistines for my two eyes.' And Samson grasped the two middle pillars on which the house rested, and braced himself against them... and he bent with all his might so that the house fell on the lords and all the people who were in it. So the dead whom he killed at his death were more than those whom he killed in his life" (Judges 16:25-30).

Heroic suicide is particularly materialized in the narrative of Masada, the most famous case of collective suicide in Jewish history [6]. Masada - a fortress built on top of a mountain overlooking the Dead Sea in the Judean desert, was the last stronghold against the Roman Empire at the end of the Jewish revolt of 66-73 A.D. After a long and enduring siege, the Romans succeeded to demolish the walls and it was evident that the invasion of the fortress was inevitable. The leader of the rebels, Elazar Ben-Yair, convinced his people to die. It was a profound religious conviction and an equally strong sense of freedom that led the 960 surviving defenders of Masada to kill their wives and children and then each other rather than surrender to the Romans.

Still, it is of interest to note that although the suicide of Ben Yair and his warriors in Masada has become a symbol of bravery in modern Israel and all over the world, it has never been mentioned in Judaic rabbinic literature. Moreover, for years, it has been known only through the account of Josephus, a Jewish historian of the Roman times. Any mention of suicide is conspicuously absent in Yosippon [7], a later Hebrew account of the Jewish revolt; here the defenders fought against the 
Romans to the death Some argue that Josephus's story of Masada sheds some insight into his own views on suicide [8]. Thus, while regarding suicide as completely alien to Jewish intellect, spirit, and law, Josephus, has nevertheless, seen it as justifiable, even admirable, as part of the heroic legacy of Judaism in times of persecution and captivity.

Indeed, from the chapter of Masada, voluntary death as an ultimate refuge of persecution [9] can be followed in Jewish history through the High and Late Middle Ages into the modern era. It can be shown that suicides on a mass scale have occurred during the persecutions occasioned by the Crusades, the Black Death, the expulsions from Spain and Portugal, and the pogroms of the Chmelnicki uprisings in Eastern Europe. There is no saying if, and to what extent, memories of those acts of despair and religious fervor have been still alive in Jewish communities of the twentieth century, particularly during the Holocaust [9]. Still, suicide of Jews under Nazi rule is a phenomenon with a historical dimension, that is to say, there are precedents going far back into Jewish history, always connected with particular moments of crisis, persecution and despair [6].

Some authors argue that suicides of Jews during the Holocaust should be regarded as acts of heroism and resistance, for example the readiness of the Jewish warriors in Second World War Polish ghettos to die rather than to be captured by the Germans [6]. This point of view has encountered considerable opposition and has not been widely accepted. Kwiet [9] suggests that during the Holocaust period, Jews, both individually and collectively, have developed a variety of strategies of defense and survival determined by tradition as well as by the prevailing social and personal circumstances. The strategies have varied in form and intensity, ranging from emigration, accommodation and collaboration to protest, escape attempts, politically organized resistance and suicide.

Suicide was the ultimate and most radical attempt to resist Nazi terror. Not surprisingly, the Nazis sought to prevent Jewish suicides. Wherever Jews tried to kill themselves - in their homes, in hospitals, on the deportation trains, and in the concentration camps - the Nazi authorities would invariably intervene in order to save the Jews' lives, wait for them to recover, and then send them to their prescribed deaths [9].

\subsection{Judaic Injunctions against Suicide}

The Biblical basis for the injunction against suicide has been derived from the Noahide laws: "For your lifeblood too, I will require a reckoning" (Genesis 9:5). This statement has been seen as a prohibition not only against suicide but also against any form of self-mutilation. The Hebrew Bible contains several additional prohibitions with regard to self-mutilation. For example, "Yeare the children of the Lord your God: Ye shall not cut yourselves, nor make any baldness between your eyes for the dead" (Deuteronomy 14:1) [8].

Injunctions against suicide continue to appear in the Talmud (5), and in later post-Talmudic writings [4]. The prohibition against suicide is clear in Jewish Rabbinic law. It is written that a suicide victim is not given full burial honors. Rending one's garments, delivering memorial addresses, and other rites to honor the dead are not performed for a suicide victim, whose burial is done in a separate place, outside of the cemetery [4]. Only rites respecting mourners are permitted [4]. Still, there are exceptions to the prohibition against suicide even in the Talmud. Thus, according to the Talmud (Sanhedrin, 74a) one is obliged to accept death when the alternative is to be forced to 
commit adultery, murder, or idolatry. It should be nevertheless stressed that this means allowing oneself to be killed under certain prescribed circumstances, not to actively killing oneself.

Some mitigation in the overall restriction of suicide continues to appear in later Jewish codes of law. Thus, the codes of Maimonides from the 12th Century, and the Shulhan Arukh from the 16th Century, distinguish between suicide while of sound mind - to which these restrictions apply, and suicide while of unsound mind (including suicide by minors and people with mental illness), which is forgiven. Still, injunctions against suicide still apply in Modern Judaism, in that official orthodox burial ceremonies are not performed in the case of suicide [10].

Altogether, there seems to be an inherent duality of Judaism in ancient and modern times with respect to suicide. On the one hand, to regard it as a sinful and forbidden act that should be opposed as a paramount Jewish injunction; yet to allow, if not worship, the readiness of the individual to take his/her life when it comes to protect the existence of the Jewish religion, morality, or nation $[6,11]$.

\section{Suicide in Modern Israel}

\subsection{Introduction}

Israel presents ample opportunities for the study of the association of Judaism with suicide. Nevertheless, other socio-cultural influences are likely of considerable relevance. More than many other countries, Israel is a society in transition, undergoing major socio-economic and socio-cultural changes both before, and since its independence in 1948. This is of particular relevance, as social instability may increase the risk of suicide [12]. Other important socio-cultural factors likely influencing suicide relate to the considerable ethnic diversity in Jewish Israeli society, the influence of the massive immigration to Israel in the past 60 years from many countries around the globe, and the repeated switches between war and peace conditions within a relatively brief period of time $[10,13]$.

A recent study by Oron [14] analyzes the relations existing between war conditions and suicide rates in Israel from its independence to the recent 2nd Lebanon War. In keeping with studies of other existential wars (World Wars 1 and 2), Oron [14] has shown a reduction in suicide rate during the three existential wars Israel has faced (the Independence War in 1948, the Six Days War in 1967, and the Yom Kippur War in 1973), with an increase in the rate of suicide in the year after, and either a stabilization or a decrease in its rate in the next years. Similar to other researchers, Oron [14] associates the reduction in suicide rates during war conditions with an increase in the national sense of cohesion, commitment and solidarity that decrease once again when the crisis is over. Wars that are not existential (e.g., the Suez War in 1956) have usually a lesser effect on the suicide rate of the population. Still, a decrease in suicide rate has been noted during the 2 nd Lebanon War in 2006 in comparison to 2005, the sole conflict-free year since the 2nd Palestinian uprising in 2000. In keeping with this trend, Lester [15] has shown a significant inverse correlation between the number of suicide terrorist attacks/number of people killed in these attacks and suicide rates in Israel from 1983-1999. Lastly, an increase in suicide rate has been found during the 1st Lebanon War, the first controversial war Israel has faced in 1982, in comparison to the years preceding this war [14]. 


\subsection{Suicide in the General Jewish Israeli Population}

From the early documentation of suicide in Europe by Durkheim in the second part of the 19th century and in North America in the 1920s, the suicide rates for Jews have been consistently lower than those of Protestants and in most, although not all studies, also lower in comparison to Catholics $[10,16]$. In keeping with these trends, the suicide rates in Israel are also relatively low [17,18]. Thus, of all European countries investigated in the late 1980s, only England and Greece have had lower suicide rates than Israel [19]. In a report of the World Health Organization of suicide rates in 110 countries in the 1990s [20], Israel ranks in the 73rd place for males $(10.5 / 100,000)$ and the 76 th place for females $(2.6 / 100,000)$. Lastly, in a further report of suicide rates in 25 European countries in recent years, Israel ranks in the 23rd place for males, and the 24th place for females [21]. Accordingly, suicide rates in Israel are consistently lower than those found in most countries in Europe and North America, in the range of many South and Central American countries, and higher in comparison to Muslim countries in Asia and North-Africa. In keeping with these findings, the suicide rates of Israeli Jews are mostly considerably higher than those of Israeli Arabs [10,21-23]. These findings likely reflect the inclination of Judaism to negate suicide to a greater extent than Christianity, but to a lesser extant than the Islam [2,10,22].

Several factors may account for the relatively low suicide rate in Israel, in addition to the influence of Judaism [10,22]. Thus, the tendency towards secularization, likely increasing the risk of suicide, is more pronounced in Western industrialized countries than in Middle-Eastern or North African countries [24,25]. Israel is in this respect less secular than most European and North American countries. Currently, more than a half of Israeli Jewish citizens are of Middle-Eastern or North-African descent. Israelis of this descent likely tend to keep their traditional religious adherence, an inclination potentially associated with reduced suicidal risk [25]. From a different perspective, suicide rates are usually higher in industrialized compared to non-industrialized non-urban societies, reflecting greater psychosocial distress and social alienation in the former [12]. Again, Israel is in this respect in a middle-ranked position between Europe and North America on the one hand and Asia (with the exception of Japan and South Korea) and North-Africa on the other.

Suicide is recorded in Israel since its independence in 1948. The highest rates have been found in the early 1950s (around 18/100,000) decreasing to 11-14/100,000 in the 1960s and 1970s, and to rates between $8.1-8.5 / 100,000$ in the early 1980 s. It rose to values of $10.8-11.2 / 100,000$ from the mid 1980s to the mid 1990s. From 1995-2009, the annual Israeli suicide rate has fluctuated between 6.3-9.4/100,000 [17,18,21,23,26,27]. Although the temporal changes in suicide rates in Israel may be influenced by methodological inconsistencies (e.g., the lack of systemized reliable multi-informant medical and forensic recordings before 1974 [10]), they may be nevertheless associated with several important socio-demographic processes: Firstly, the high suicide rates in the early years of Israel might be related to the highly unstable socio-political condition at that time, when the young nation was at a constant threat to its existence, likely presenting a continuous state of alert, coupled with a highly unfavorable economic condition $[10,13,17]$. Secondly, the increase in suicide rates in the mid 1980s to the mid 1990s may reflect the influence of the massive immigration from the former USSR and Ethiopia to Israel, as will be dealt with later in this chapter. 
Thirdly, the majority of the Jewish population in the early years of Israel was of Jewish Ashkenazi, (i.e., Eastern European) descent. By contrast, the immigration in the 1950-1960s brought to Israel mostly Non Ashkenazi Jews from North Africa and Middle Eastern countries, which currently comprise the majority of the Jewish Israeli population [10]. It has been repeatedly shown that Jews born in Europe may have brought to Israel the potential proneness to suicide in many of their native countries, in contrast to the low rate of suicide in many Muslim NorthAfrican/Middle Eastern countries, whereas the heterogeneously constituted group of Israeli-born Jews stands in-between [10]. This indeed has been the condition until the mid-1980s [18]. However, since the mid-1990s, the suicide rates among Jews born in North-African/Middle Eastern countries have reached values close to those of European and American-born Jews [27]. Moreover, since 2000, the highest suicide rate is found in those Israeli-born of Non-Ashkenazi descent [27].

Israeli Jews of non-Ashkenazi descent tend to attempt suicide to a greater extent, particularly with respect to repeated attempts, in comparison to Ashkenazi Jews [10,22,28]. The higher rate of repeated suicide attempts among individuals of Asian/North African descent may reflect their tendency to express emotions and frustrations more openly, including the use of behavioral channels. Accordingly, this pattern may suggest an expression of emotional distress rather than a wish to die [29]. By contrast, guilt feelings, which are positively associated with suicide and death-related wishes, are more common in European than in Middle Eastern cultures [10].

A low suicide rate is also found in Jewish Israeli adolescents [22,27]. The average rate of suicide between 1975-1989 for 15-19 years old Israeli Jewish males $(5.3 / 100,000)$ and females $(1.9 / 100,000)$ has been among the lowest in the world [22]. The suicide rate for 15-17 years old for the years 1990-2008, fluctuating between 2.7-5.7/100,000 for males and 1.8-3.0/100,000 for females, is still considered low in comparison to most European countries [21]. Among other likely protective factors in addition to the influence of Judaism, a striking finding is the low rate of suicides in Israeli youth performed under the influence of alcohol and drugs [30,31]. This likely reflects the relatively low rate of substance use in Israeli adolescents in comparison to European and North American countries [32].

\subsection{Suicide in Specific Jewish Sub-populations}

\subsubsection{Suicide in Male Israeli Soldiers}

One striking exception to the low rate of suicide in Israeli youth, as shown in data gathered from 1975 to 1994, is the high rate of completed suicides in 18-21 years old males vs. both 15-17 and 21-29 years old males [22,23]. As most 18-21 year old males likely serve in the Israeli army, the high suicide rate in this age group likely reflects the considerable psychosocial stress and loss of previous social support networks associated with recruitment and service, combined with the availability of firearms [22,23]. During peace time, suicide is the leading cause of death in the Israeli Army [18]. Moreover, the suicide rate in male Israelis aged 18-21 is higher than in any other age group [27].

In addition, a significant increase in suicide rate has occurred in 18-21 years old males (but not in 15-17 and 21-29 years old males) from 1984-1985 to 1992-1994 (3.9/100,000 vs. $18.2 / 100,000$, respectively). This change may reflect an increase in the overall stress associated 
with serving in the army following the first Palestinian uprising in 1987, as well as a greater availability of weapons during that period due to military requirements [10,23]. Indeed, a dramatic rise in the use of firearms in suicides of 18-21 year old males has been found during this time period (11\% vs. $77 \%$ of all suicides, respectively) [22]. In the same token, a recent analysis in the US army has shown an increase in the suicide rate among 18-24 years old male soldiers from 2004-2008, surpassing comparable civilian rates in 2008 [33]. Among the factors likely associated with higher suicide risk, the authors note the trend toward greater exposure to combat events in Iraq and Afghanistan in soldiers who have later committed suicide.

A well-designed study in Israeli combat soldiers who have killed themselves during service [34] has found a highly distinctive profile of this group. Most have appeared above average in intelligence, physical fitness, and in personality measures predictive of successful adaptation to military service, with no evidence of pre-existing mental health problems, and their motivation and performance during service have been generally more than satisfactory. Their suicide has been unexpected, conceived in psychological autopsies to represent a sense of failure to live up to their expectations, appearing for the first time in their life, and leading to the development of narcissistic insult and concomitant depression [34]. These "good soldiers" have avoided the seeking of professional help, and have usually not communicated their distress and suicidal ideation to significant others $[34,35]$. These findings stand in sharp contrast to findings in the US army, showing significantly greater prevalence of mental health problems treated on an outpatient basis in soldiers committing suicide [33].

\subsubsection{Suicide in Immigrants from the Former USSR and Ethiopia}

Whereas high suicide rates have been shown for 18-21 years old Israeli males of all ethnic backgrounds, these rates have been specifically elevated in young male immigrants from the former USSR [23]. Immigration is known to be associated with an increase in suicide risk, particularly among younger immigrants [36]. Accordingly, between 2000 and 2009, a third of all suicides in Israel have occurred in immigrants, a percentage far exceeding their proportion in the Israeli population [21]. The highest suicide rate has been found in former USSR youths aged 15-24 [27]. The elevated suicide risk in young Russian-born immigrants to Israel may be related to identity crises, loss of familial and social support, severe intergenerational conflicts, social isolation, immigration-based difficulties with the Hebrew language, and a sense of estrangement in the new country [37]. Similar differences between immigrants and Israeli-born individuals have also been shown for attempted suicide [21].

Additional support for the association of immigration with increased suicide risk comes from two Israeli studies assessing temporal trends in completed [17] and attempted [28] suicides during the 1980s and 1990s. Nachman et al. [17] have found an overall increase in the rate of suicide from 1987 to 1992, stabilizing thereafter to 1997. Stein et al. [28], examining attempted suicide in two cities in Israel (Holon and Bat Yam) have shown high rates from 1990-1992, with a steady decrease from 1993 to 1998 . Both studies relate these temporal changes to the massive immigration of around 400,000 Jews from the former USSR to Israel during the late 1980s and the early 1990s. Indeed, Russian-born individuals have been found to be over-represented among suicide attempters 
in Holon and Bat Yam in comparison to their overall representation in these two cities [28]. Additionally, the suicide rate among Russian immigrants to Israel has been shown to be significantly higher in comparison to that of both Russian-born and Israeli-born individuals [37,38]. This is of special note, as the suicide rate in Russia is among the highest in Europe [21].

Israel has faced a massive immigration also from Ethiopia, occurring in two waves, in the early 1980s and the early 1990s. Elevated suicide and attempted suicide rates have been shown also for Ethiopian immigrants to Israel in comparison to native-born Israelis, especially in 15-24 years old Ethiopian males $[21,23,27,39,40]$, although the findings for Ethiopian immigrants have been usually less striking in comparison to immigrants from the former USSR. Still for the years 2000-2004, young Ethiopian males have had 7.4 times higher suicide rates compared to non-immigrant Israeli Jews, and 2.8 times higher rates compared to former USSR immigrants [27]. This trend, although to a lesser extent, continues in 2007-2009 [21]. Additionally, in Ethiopian males, the average annual percentage of suicides from all suicidal acts (attempted and completed suicides) has been found considerably higher (43\%) in comparison to both former USSR immigrants (21\%) and native-born Israelis (17\%) [27].

Lastly, in a psychological autopsy of 44 of the 49 reported suicides of immigrants from Ethiopia for the years 1983-1992, Arieli et al. [41] have found that the male/female suicide ratio among Ethiopian immigrants is twice higher in comparison to the general Israeli population. In addition, only two suicide methods have been used by both Ethiopian males and females-hanging and jumping from high places. The frequent use of violent methods has been replicated also in more recent suicides of Ethiopian immigrants [42]. Interestingly, violent methods are prevalent in both genders also in suicides and attempted suicides occurring in Ethiopia itself [42].

Some suggest that the high suicide risk among Ethiopian immigrants likely reflects their difficulties in adjusting to a completely new culture that does not always accept them as equals [42]. Thus, the high suicide rate of Ethiopian male immigrants may reflect the distress and sense of humiliation associated with the loss of their traditional dominant role at home following immigration in comparison to their homeland [41]. Similarly, suicide in Ethiopian women immigrating to Israel may be associated with the loss of protection from community leaders that have kept them previously safe from domestic violence [41]. Others relate the high suicide risk of Ethiopian immigrants to the difficulties in the diagnosis and management of severe psychopathology by Israeli-born professionals who are often not familiar with the Ethiopian culture [43], as well as to the reluctance of immigrants from Ethiopia to use the Israeli mental health systems [42]. Lastly, suicidal behavior in first-generation immigrants may be related to their exposure to severe traumatic experiences and loss of many family members during the immigration from Ethiopia to Israel [42].

\subsubsection{Other Populations of Interest}

Three additional points of interest deserve attention. The first relates to the relatively high proportion of suicidal behavior in Holocaust survivors in comparison to the elderly population in Israel [44]. Aging in Holocaust survivors may be associated with reactivation of past traumatic syndromes. This reactivation, coupled with the presence of physical disturbances, some of them unique 
to the survivors of the concentration camps, and with an increase in psychosocial distress that may occur in any elderly population, may increase the risk of suicide in this population $[10,44]$.

Secondly, the lowest annual suicide rate in Israel as assessed for 2007-2009 has been found among the inhabitants of the Jewish settlements in the Western Bank (3.7/100,000 vs. 7.4/100,000 for the general Israeli population, see [21]). A similar trend exists also for attempted suicide [21]. These findings likely reflect the sizable proportion of observant religious Jews living in the settlements, as well as the cohesion and sense of mission and entitlement found in this population, despite, or perhaps even because, of the constant threat it is exposed to [15].

Thirdly, greater religious belief and commitment, and to a lesser extent, greater religious attendance, may be associated with lower suicide rates and less tolerance toward suicide in both Christianity and Judaism [25,45-47]. To the best of our knowledge, this issue has not been investigated in Israel. Still, a study assessing attitudes to suicide and suicidal ideation in Jewish Israeli adolescents has shown that lesser religious affiliation is significantly associated with both greater tolerance of suicide and greater suicidal ideation $[11,48]$.

\subsection{Suicide in Israeli Arabs}

Lastly we address the issue of suicidal behavior among Israeli Arabs, of whom the majority are Muslims, and the rest Arab-Christians and Druze [10]. In general, Islam forbids suicidal behavior [49,50] and its attitude to suicide is more condemning than both Christianity and Judaism [51]. Indeed, suicide is considered illegal in Muslim countries [49]. Although since 1985 no Middle Eastern country has provided data on suicide to the World Health Organization [52], current suicide rates still appear lower in Muslim countries [49,52].

The finding of low suicide rates in many Muslim countries has been replicated also in Israeli Arabs [50]. Similar findings exist also with respect to attempted suicide. Whereas differences may exist between Israeli Jews and Arabs in the disclosure of information about suicide [10,50], the suicide rates of Israeli-Arabs of both genders are consistently lower for all age groups in comparison to Israeli Jews [10,21-23,50]. Socio-demographic factors likely reducing the suicide risk in Israeli Arabs in comparison to the Jewish majority include lower rates of urbanization, greater social and religious cohesion, a greater inclination to live in groups (extended families, tribes), and less use of alcohol $[10,23,50]$.

It is of note that the difference in the rate of attempted suicide in Israeli Jews $v s$. Israeli Arabs has considerably decreased in recent years [21,29,50]. The highest rates of attempted suicide among Israeli-Arabs are currently found among 15-29 years old women [21,29,50], who tend to live in a highly patriarchal society where women's rights are relatively few [53]. Attempted suicide in the Arab population may represent a means to convey emotional distress, rather than a wish to die [29]. Thus, the rise in deliberate self-harm behaviors in young, likely married, Arab women in recent years may constitute one of a few means they have to convey, albeit indirectly, their distress, as well as their wish not to have to accept anymore their problematic life conditions $[29,53]$.

Another interesting finding relates to the relatively high suicide rate among 15-24 years old Israeli-Arabs, being higher in this cohort than in any other age group [21,52]. More than a third of all suicides among Israeli Arabs in recent years occur in 15-24 years old individuals in comparison to less than $20 \%$ in the case of Israeli Jews [21,52]. This finding may reflect the ever growing 
stress in which young Israeli Arabs may find themselves particularly in recent years, torn between their relations with the Jewish Israeli majority that does not always accept them as equals, and their ambivalence towards their Palestinian neighbors.

A third exception to the low suicide rate among Israeli Arabs is the high rate of suicide found in young Druze males. This finding may reflect the greater exposure of Druze youngsters to the influence of the mainstream Jewish Israeli lifestyle, particularly as male Druze do serve in the Israeli army [22]. Still, the absolute numbers of completed suicides in the Druze population are too small to draw definite conclusions [10].

\section{Concluding Remarks}

Historically, Judaism presents firm negative attitudes towards suicide [4]. The impact of this religious socio-cultural construction is expressed in the low rate of suicide found in Modern Israel Jews in comparison to Christian Protestants and Catholics. An interesting support for the assumption about the importance of religious attitude in suicide comes from the authors' own study assessing attitudes to suicide and suicidal ideation in Jewish Israeli adolescents $[11,48]$. This study shows that lesser religious affiliation is associated with both greater tolerance of suicide and greater suicidal ideation.

Exceptions to the overall low suicide rate in Israeli Jews are the high rates of suicide found in male Israeli soldiers, new immigrants to Israel, and Holocaust survivors. Other at risk populations include young Israeli Arab women. These specific populations, necessitate early identification of distress associated with lack of adjustment to their specific circumstances, and tailoring of specialized adequate culture-sensitive interventions.

\section{References}

1. Émile Durkheim. Suicide, a Study in Sociology. London: Free Press, 1966, 167.

2. E. Stengel. Suicide and Attempted Suicide. Harmondsworth: Penguin Books, 1975.

3. J. Choron. Suicide. New York: Charles Scribner's Sons, 1972.

4. H.C. Cohn. "Suicide.” In Encyclopedia Judaica. Jerusalem: Keter, 1972, Vol. 15.

5. S.J. Kaplan, and L.A. "Schoenberg. Defining suicide: Importance and implications for Judaism." Journal of Religion and Health 27 (1988): 154-56.

6. Y. Zerubavel. "The death of memory and the memory of death: Masada and the Holocaust ashistorical metaphors." Representations 45 (1994): 72-100.

7. D. Flusser. Book of Yosippon. Jerusalem: Bialik Institute, 1978, Vol. 1, 429.

8. K.J. Kaplan, and M. Schwartz. "Suicide in Jewish and Christian thought." Journal of Psychology and Judaism 24 (2000): 43-64.

9. K. Kwiet. "The ultimate refuge suicide in the Jewish community under the Nazis." Leo BaeckInstitute Year Book 29 (1984): 135-68.

I. Levav, and E. Aisenberg. Suicide in Israel: Crossnational comparisons. Acta Psychiatrica Scandinavica 79 (1989): 468-73.

10. D. Stein, E. Witztum, and A. Kaplan De-Nour. "Attitudes of adolescents to suicide." Israel Journal of Psychiatry and Related Sciences 26 (1989): 58-68. 
11. A.H. Schmidtke, and C. Lohr. "Sociodemographic variables of suicide attempters." In Suicidal Behaviors: Theory and Research Findings, edited by D. de Leo, U. Bille-Brahe, A. Kerkhof, and A.H. Schmidtke: Hogrefer \& Huber, 2004, 81-91.

12. A.H. Schmidtke, U. Bille-Brahe, D. DeLeo, A. Kerkhof, T. Bjerke, P. Crepet, C. Haring, K. Hawton, J. Lonnqvist, K. Michel, X. Pommereau, I. Querejeta, I. Phillipe, E. Salander-Renberg, B. Temesvary, D. Wasserman, S. Fricke, B. Weinacker, and J.G. Sampaio-Faria. "Attempted suicide in Europe: Rates, trends and sociodemographic characteristics of suicide attempters during the period 1989-1992. Results of the WHO/EURO Multicentre Study on Parasuicide.” Acta Psychiatrica Scandinavica 93 (1996): 327-38.

I. Oron. "War and suicide in Israel, 1948-2006." International Journal of Environmental Research and Public Health 9 (2012): 1927-38.

13. D. Lester. "Suicide attacks in Israel and suicide rates." Perceptual and Motor Skills 102 (2006): 104.

14. B.L. Danto, and J.M. Danto. "Jewish and non-Jewish suicide in Oakland County, Michigan." Crisis 4 (1983): 33-60.

15. R. Nachman, O. Yanai, L. Goldin, M. Swartz, Y. Barak, and J. Hiss. "Suicide in Israel: 1985-1997."Journal of Psychiatry and Neuroscience 27 (2002): 423-28.

16. C. Bursztein, and A. Apter. "The epidemiology of suicidal behavior in the Israeli population." In Psychiatric and Behavioral Disorders in Israel: From Epidemiology to Mental Health Action, edited by I. Levav. Jerusalem: Gefen Publishing House Ltd., 2009, 267-84.

17. C. La Vecchia, F. Lucchini, and F. Levi. "Worldwide trends in suicide mortality, 1955-1989." Acta Psychiatrica Scandinavica 90 (1994): 53-64.

18. "Mental Health Resources: SuicideRates.” World Health Organization, 2003.

19. Z. Haklai. Suicidality in Israel (in Hebrew). Jerusalem, Israel: Information and Computer Services. Health Information Department, Ministry of Health, State of Israel, 2011.

20. R. Kohn, I. Levav, B. Chang, B. Halperin, and P. Zadka. "Epidemiology of youth suicide in Israel." Journal of the American Academy of Child and Adolescent Psychiatry 36 (1997): $1537-42$.

21. G. Lubin, S. Glasser, V. Boyko, and V. Barell. "Epidemiology of suicide in Israel: A nationwide population study." Social Psychiatry and Psychiatric Epidemiology 36 (2001): $123-27$.

22. B. Beit-Hallahmi. "Religion and suicidal behavior." Psychological Reports 37 (1975): 1303-6.

23. G. Domino, and K. Miller. "Religiosity and attitudes toward suicide." Omega 25 (1992): 271-82.

24. "Statistical Abstracts of Israel." Central Bureau of Statistics, Jerusalem, Israel, 1970-2004.

25. Z. Haklai, M. Aburrdeh, and N. Stein. Suicidality in Israel (in Hebrew). Jerusalem, Israel: Information and Computer Services. Health Information Department, Ministry of Health, State of Israel, 2008.

26. D. Stein, J. Asherov, E. Lublinsky, D. Sobol-Havia, L. Lazarevitch, A. Weizman, and A. Apter. "Sociodemographic factors in attempted suicide in two cities in Israel, between 1990-1998." Journal of Nervous and Mental Disease 190 (2002): 115-18. 
27. K. Ashkar, C. Giloni, A. Grinshpoon, N. Geraisy, E. Gruner, R. Cohen, O. Paryente, F. Nassar, and A.M. Ponizovsky. "Suicidal attempts admitted to a general hospital in the Western Galilee: An inter-ethnic comparison study." Israel Journal of Psychiatry and Related Sciences 43 (2006): 137-45.

28. D. Kandel. "Substance abuse by adolescents in Israel and France: A cross-cultural perspective." Public Health Reports 99 (1984): 277-83.

29. D. Stein, A. Apter, G. Ratzoni, D. Har-Even, and G. Avidan. "The association between recurrent suicidal behavior and negative affective conditions among adolescents." Journal of the American Academy of Child and Adolescent Psychiatry 37 (1998): 488-94.

30. L. Degenhardt, W.T. Chiu, N. Sampson, R.C. Kessler, J.C. Anthony, M. Angermeyer, R. Bruffaerts, G. de Girolamo, O. Gureje, Y. Huang, A. Karam, S. Kostyuchenko, J.P. Lepine, M.E. Mora, Y. Neumark, J.H. Ormel, A. Pinto-Meza, J. Posada-Villa, D.J. Stein, T. Takeshima, and J.E. Wells. "Toward a global view of alcohol, tobacco, cannabis, and cocaine use: Findings from the WHO World Mental Health Surveys." PLoS Medicine 5 (2008): e141.

31. K.E. Bachynski, M. Canham-Chervak, S.A. Black, E.O. Dada, A.M. Millikan, and B.H. Jones. "Mental health risk factors for suicides in the US Army, 2007-8." Injury Prevention (7 March 2012). doi:10.1136/injuryprev-2011-040112.

A. Apter, A. Bleich, R.A. King, S. Kron, A. Fluch, M. Kotler, and D.J. Cohen. "Death without warning? A clinical postmortem study of suicide in 43 Israeli adolescent males." American Journal of Psychiatry 50 (1993): 138-42.

32. E. Bodner, E. Ben-Artzi, and Z. Kaplan. "Soldiers who kill themselves: Contribution of constitutional and situational factors." Archives of Suicide Research 10 (2006): 29-43.

A. Kosic. "Acculturation strategies, coping process and acculturation stress." Scandinavian Journal of Psychology 45 (2004): 269-78.

33. A.M. Ponizovsky, S. Safro, Y. Ginath, and M.S. Ritsner. "Suicide ideation among recent immigrants: An epidemiological study." Israel Journal of Psychiatry and Related Sciences 34 (1997): 139-48.

A. M. Ponizovsky, and M.S. Ritsner. "Suicide ideation among recent immigrants to Israel from the former Soviet Union: An epidemiological survey of prevalence and risk factors." Suicide and Life Threatening Behavior 29 (1999): 376-92.

A. Arieli, I. Gilat, and S. Aycheh. "Suicide by Ethiopian immigrants to Israel. (in Hebrew)" Harefuah 127 (1994): 65-70.

34. G. Ratzoni, A. Apter, R. Blumensohn, and S. Tyano. "Psychopathology and management of hospitalized Ethiopian adolescent immigrants in Israel." Journal of Adolescence 11 (1988): 231-36.

A. Arieli, I. Gilat, and S. Aycheh. "Suicide among Ethiopian Jews: A survey conducted by means of a psychological autopsy." Journal of Nervous and Mental Disease 184 (1996): 317-19.

35. N. Grisaru, L. Carmel, and E. Witztum. "Suicide in Ethiopian immigrants to Israel." In Social, Cultural and Clinical Aspects of the Ethiopian Immigrants in Israel (in Hebrew), edited by N. Grisaru, and E. Witztum. Beer Sheva: The Ben-Gurion University of the Negev Press, 2012, 295-321. 
36. G. Shoval, G. Schoen, N. Vardi, and G. Zalsman. "Suicide in Ethiopian immigrants in Israel: A case for the genetic-environmental relationship in suicide." Archives of Suicide Research 11 (2007): 1-7.

37. Y. Barak, D. Aizenberg, H. Szor, M. Swartz, R. Maor, and H.Y. Knobler. "Increased suicidal risk amongst aging Holocaust survivors. "American Journal of Geriatric Psychiatry 13 (2005): 701-4.

38. J. Neeleman, D. Halpern, D. Leon, and G. Lewis. "Tolerance of suicide, religion and suicide rates: An ecological and individual study in 19 Western countries." Psychological Medicine 27 (1997): 1165-71.

39. K. Dervic, M.A. Oquendo, M. F. Grunebaum, S. Ellis, A.K. Burke, and J.J. Mann. "Religious affiliation and suicide attempt." American Journal of Psychiatry 161 (2004): 2303-8.

40. S. Stack, and A.J. Kposowa. "Religion and suicide acceptability: A cross-national analysis." Journal for the Scientific Study of Religion 50 (2011): 289-306.

41. D. Stein, D. Brom, A. Elizur, and E. Witztum._"The association between attitudes toward suicide and suicidal ideation in adolescents." Acta Psychiatrica Scandinavica 97 (1998): 195-201.

42. K. S. Chaleby. "Issues in forensic psychiatry in Islamic jurisprudence." Bull Am Acad Psychiatry Law 24 (1996): 117-24.

43. G. Gal, N. Goldberger, A. Kabaha, Z. Haklai, N. Geraisy, R. Gross, and I. Levav. "Suicidal behavior among Muslim in Israel." Social Psychiatry and Psychiatric Epidemiology 47 (2012): 11-7.

44. L. I. Dublin. Suicide: A Sociological and Statistical Study. New York: Ronald Press, 1963.

45. D. Lester. "Islam and suicide." Archives of Suicide Research 10 (2006): 77-97.

46. E. Elnekave, and R. Gross. "The healthcare experiences of Arab Israeli women in a reformed healthcare system." Health Policy 69 (2004): 101-16. 


\title{
Mind-Body Practices in Integrative Medicine
}

\section{Harald Walach, Marie-Louise Gander Ferrari, Sebastian Sauer and Niko Kohls}

\begin{abstract}
Mind-Body practices have become increasingly popular as components of psychotherapeutic and behavior medicine interventions. They comprise an array of different methods and techniques that use some sort of mental-behavioral training and involve the modulation of states of consciousness in order to influence bodily processes towards greater health, well-being and better functioning. Mind-body practices may thus be interpreted as the salutogenetic mirror image of psychosomatic medicine, where psychophysiological and health consequences of specific psychological states are studied, such as stress arousal, psychological trauma or depression. This contribution examines the empirical evidence of the most common mind-body techniques with regard to their salutogenetic potential. We concisely discuss some aspects of the mind-body problem, before we consider some historical aspects and achievements of psychosomatic medicine. We then turn to some prominent mind-body practices and their application, as well as the empirical database for them.
\end{abstract}

Reprinted from Religions. Cite as: Walach, H.; Ferrari, M.-L. G.; Sauer, S.; Kohls, N. Mind-Body Practices in Integrative Medicine. Religions 2012, 3, 50-81.

\section{Abbreviations}

ALS: Amyotrophic lateral sclerosis; IL 1: interleukin 1, IM: Integrative Medicine, ACTH: adrenocorticotropic hormone, HPA: hypothalamic-pituitary-adrenal axis, CNS: Central Nervous System, NO: nitric oxide, RR: relaxation response, MBSR: mindfulness based stress reduction, TM: Transcendental Meditation, AT: Alexander Technique, OCD: obsessive-compulsive disorder, EEG: Electroencephalography. MBCT: Mindfulness Based Cognitive Therapy.

\section{Introduction}

Mind-Body practices, such as Yoga or mindfulness training, have become increasingly popular among the public and researchers. They are a hallmark of Integrative Medicine (IM), since here the integration of psychological and medical, mental and physical approaches is most clearly visible. Mind-Body-Practices are also frequently utilized as components of psychotherapeutic and behavior medicine interventions [1-3]. Mind-body practices comprise an array of different methods that have one thing in common: they all use some sort of mental-behavioral training and involve modulating states of consciousness in order to influence bodily processes towards greater health and well-being and better functioning. In a sense, mind-body practices are thereby the salutogenetic mirror image of psychosomatic medicine, where psychophysiological and health consequences of specific psychological states, such as stress arousal, psychological trauma or depression, are studied. In this article, we aim to describe, elaborate and evaluate the philosophical background, 
rationale and value of Mind-Body-interventions. To place mind-body practices philosophically, it seems mandatory to us to discuss some issues around the mind-body problem. Some basic philosophical stances held by researchers and practitioners regarding this question might have a direct practical impact determining which mind-body practices are deemed useful and how they are being employed. Let us therefore start with a brief treatment of the mind-body problem before we consider some of the history and achievements of psychosomatic medicine. We then turn to some mind-body practices and their application, as well as the empirical database for them.

\section{The Mind Body Problem}

The mind-body problem raises the questions of whether mental events and our corresponding first person experience of consciousness are derived from, or secondary to, our physical make-up, our biology, and whether they are produced by the brain and its concomitant neurological processes, or is there such a thing as a soul- or spirit-like entity that is different from material events in the body. One can actually distinguish two levels of the problem [4]. The first concerns the question of how consciousness and brain events are related. Is consciousness a consequence and therefore causally dependent on the brain and its functioning? Alternatively, can a case be made that consciousness and material brain processes are different in kind, as was believed by the founding father of experimental psychology, Wilhelm Wundt (1832-1920)? In other words, is there a satisfying physical explanation for human consciousness? This is the classical mind-body problem. The second level we would like to term the "spiritual part" of the mind-body problem. This deals with questions such as: is there some immaterial or even transcendental essence to human consciousness that could potentially even survive personal death? How can we understand certain spiritual experiences such as enlightenment experiences within the framework of a physicalist program? Our opinion is that it is useful to distinguish between these two levels of the problem, because frequently some personal spiritual or religious motives lie hidden behind seemingly simple philosophical questions [5].

Since the beginning of the modern scientific era in the 18th century the questions of whether there is such a thing as a spirit-like soul, and if so, whether is it amenable to scientific scrutiny. These were central questions of modern physiology and psychology [5,6]. It was a hallmark of the surge of the scientific enterprise that physiologists replaced philosophers in tackling the question of how mental events come about by adopting a reductionist program, which was mainly inspired by Newtonian physics and mechanics, thereby reducing mental events to physical events in the brain. One historically important document is a famous letter written by Emil du Bois-Reymond (1818-1896), destined to become one of the most famous and influential physiologists of his time. This letter that he wrote at the age of 26 to some friends notes a meeting in 1848 of some young researchers, who would all become highly influential thinkers. Among them was du Bois-Reymond and Ernst Brücke (1819-1892), the physiologist who later became the teacher and mentor of Sigmund Freud (1856-1939) in Vienna. "Brücke and myself," the letter notes, "have conspired to bring forth the truth that there are no other forces active in the human organism than the common chemical-physical ones. And where this is not sufficient as an explanation as yet, the mathematical method of physics needs to be applied in order to search for the way they are active in a concrete case, or else new forces have to be assumed which, however, have to be of the same dignity than 
the physical-chemical ones, also inherent in matter, and always to be reduced to attractive and repulsive forces. ${ }^{, 23}$ [7] This text delineates the program of physicalism: all explanations of mental events are to be reductions of physical laws, and hence mental events will eventually be explained by reference to physical events; much as physics was able to explain seemingly different events, such as lightning and magnetism as instances of electro-magnetism. Briefly, the brain was conceived as a complex but rather clockwork-like neuronal machine for producing thoughts and mental sensations. The eighteenth-century French physician Pierre Jean Georges Cabanis (1757-1808) expressed in a famous phrase "the brain secretes thought as the liver secretes bile". Mind then, in such a view, is simply a consequence of the complex neural assembly that forms our brain. Just how far such a physicalist program will be able to progress is still a matter of heavy debate. Some have said, and still keep saying, that we will not need a mentalist-psychological language any longer, as we will explain everything in terms of neuroscience [8]. Similar to our saying "a bolt of lightning has struck" instead of using the more precise terminology "a strong current of electricity has balanced the large potential difference between clouds and the earth" we will still be talking about "pain", but will then have a precise definition and description of what it is to have pain in neuroscientific terms. There is a plethora of philosophical positions that differ in just how much of causal efficacy they attribute to our mental events [9]. Some appear to be saying that our subjective impression of agency and will is just an illusion and that there is no such thing as real causal agency driving our mental life [10]. Others would say that, although those mental events of will and causal activity are caused by our material substrate, i.e., the brain, these mental events, once produced, may have some causal repercussions on the physical system [11].

On the whole, physicalist approaches agree on the basic stipulation that mental events are consequences of our brain architecture and are caused by it. When the brain and its sustaining organism cease to live, our individual consciousness will also collapse.

Clearly, this physicalist view has much to recommend itself as a parsimonious and yet adequate theory for explaining consciousness. A host of neuropsychological studies have shown how the brain sustains mental functions [12], and that, where certain brain functions have been damaged, very particular and specific mental functions have also been compromised. The study of coma and anesthesia, for instance, has shown which brain structures are necessary to sustain conscious awareness, and we know pretty well that if such essential structures as the brainstem are severely damaged then consciousness cannot be maintained or regained [13]. We also know that long projection fibers ranging from the brain stem via the thalamus to the cortex seem to form circular structures that are necessary for the sustenance of conscious experience [14]. If these thalamocortical loops are deranged, severe chronic pathologies, such as pain syndromes, may result [15]. These pain syndromes can sometimes be influenced by diligent microsurgery in some areas of the

23 Translation ours. Original: "Brücke und ich, wir haben uns verschworen, die Wahrheit geltend zu machen, dass im Organismus keine anderen Kräfte wirksam sind, als die gemeinen physikalisch-chemischen; dass, wo diese bislang nicht zur Erklärung ausreichen, mittels der physikalisch-mathematischen Methode entweder nach ihrer Art und Weise der Wirksamkeit im konkreten Falle gesucht werden muss, oder dass neue Kräfte angenommen werden müssen, welche, von gleicher Dignität mit den physikalisch-chemischen, der Materie inhärent, stets auf nur abstossende oder anziehende Componenten zurückzuführen sind" S. 108. 
thalamus [16]. These and similar experiences have shown without any reasonable doubt that the brain certainly is necessary for consciousness to arise.

However, can a rational conclusion be drawn that the brain is also sufficient for consciousness? At issue is the philosophical problem of sufficient and necessary cause. A functioning engine, for instance, is a necessary condition for a car to drive. Nevertheless it is not sufficient. Gasoline, oil and a battery are also necessary to start the engine. Moreover, in order to get the car in motion, tires, a gearbox and a clutch are also essential. At another level, a driver is also needed to operate the car. Taken together, these components establish necessary and sufficient boundary conditions that allow the car to be driven. In the same sense, it does not seem to make sense to doubt that the brain is a necessary condition for consciousness. However, is it sufficient?

What about, for instance, the gut? Amyotrophic lateral sclerosis (ALS) is a disease that destroys the muscular endplates of motor neurons, leading to complete paralysis. Because this condition also brings about a more-or-less complete destruction of visceral feedback to the brain, patients with this disease can experience a state of consciousness that can sometimes be quite serene $[17,18]$.

This seems to be due to the fact that some feedback from the gut and from other parts of the periphery is missing. The gut has its own system of innervation, for instance, with many millions of neurons and some orders of magnitude more of synaptic connections. These use serotonin as its major transmitter, and in addition acetylcholine [19]. To date, not all of its function is clearly understood. Most has to do with the registering of nutrients and antigens in the bowel, being taken up by the blood, and with the regulation of peristaltic movement. It may well be the case that this complex neuronal system of gut regulation contributes to the tone and color to our consciousness, without us ever knowing [20].

The neuronal system regulating the gut is part of a larger neuronal system, the autonomic nervous system. It has long been thought to be completely separate from the central nervous system, operating autonomously, hence its name. However, we know nowadays that there are multiple ways how the two systems interact and that IM interventions may change their reciprocal action [21]. Imbalances of the autonomic nervous system can severely affect our conscious experience [22]. Chronic pain syndromes such as fibromyalgia and chronic fatigue syndromes are two examples of how an imbalance in autonomic regulation, i.e., in a part of the nervous system that is largely outside the brain and does not contribute to consciousness as such, have a clear and perceptible impact on the sufferers' conscious experience [23,24].

Another system, seemingly autonomous but with a multitude of interactions both with the autonomic and the central nervous system is the immune system. We now know that nearly every molecule used by the central nervous system as a messenger or transmitter molecule can have immunological functions as well. Most molecules used by the immune system for communication between components of itself may also have some function within the central nervous system, or at least will have some receptors in certain brain areas such as the hypothalamus, where the brain seems to scan the immunological situation of the body [25].

Thus, the status of another, highly interlinked and complex system that operates mainly as a system of cells distally linked through very specific messenger molecules, also potentially contributes to the state of our consciousness. To give an example: Whenever we suffer from an infection, the level of the messenger molecule interleukin 1 (IL 1), a protein used by the immune system to 
activate lymphocytes and commandeer them to a place of infection and stimulate the growth and division of B-lymphocytes, will rise. IL 1 is also now known to exert very specific effects in the brain. It produces a feeling of tiredness, a behavioral withdrawal syndrome with a lack of motivation, a profound sense of fatigue and the feeling of not being able to cope with the world. Under normal circumstances, this is a signal for the organism to withdraw and save energy in order to fight the infection. It appears that in some forms of depression, IL1 also seems to play a role by producing a facsimile of clinical depression. This raises intriguing questions about how our immunological situation plays a role in the way our consciousness is toned [26-29].

These two examples show that defining the brain as a necessary condition for consciousness is by no means equivalent to explaining consciousness sufficiently. They also illustrate that opponents of a physicalist solution of the mind-body problem may have a point which is difficult to counter: saying that something is necessary for consciousness - the brain - is not identical to having a sufficient explanation.

A series of arguments can and have been leveled against a physicalist view. Some of them are of a principal philosophical nature. Some use phenomenological and empirical facts. Several philosophical arguments use the principal difference of our first-person subjective experience and brain events [30,31]. While brain events are always similar-neuron discharges and patterned firing of neurons, as well as chemical transmission of molecules, personal subjective experience is quite varied. One might want to use the differences in transmitter molecules to explain the differences in subjective phenomenology. However it may be argued that there are probably many more subjective feelings and tastes than can be accounted for by types of molecules or any mixture thereof. It is very difficult to jump from the hardwiring of neurochemistry and neurophysiology to the subjective feel of what it is like to be myself, or yourself, in any particular situation. Although we all know what pain is, it is quite something to think about pain, remember it, even empathize with someone who experiences pain, and having pain oneself. Moreover, pain defies the Cartesian taxonomy, as this phenomenon is actually something in between objective and subjective categories [32,33]. As a matter of fact, no knowledge about our pain-brain circuitry is able to help us understand what someone who suffers from severe chronic pain of a phantom limb actually feels. Although we may be able to describe this in a somewhat objectified manner, for example as abnormally strong patterns of theta-activity reverberations between some thalamo-cortical loops, and also see the result of a therapeutic intervention in the normalization of these patterns, these patterns themselves do not carry any of the subjective flavor of being in pain $[16,34,35]$. It could also have been the correlate of a strong emotional reaction to one's grandmother. It only happened to be the correlate of strong pain, and nothing in itself tells us so, except the context of the research, and the private experience of the person who suffered from the pain in the first place.

Such arguments have been leveled to bring home the point that an objective, physical description, even an explanation of a subjective content of mind, such as a feeling, an emotion or a particular subjective phenomenological experience, is not identical to that experience itself. As Thomas Nagel has pointed out, such an explanation, no matter how complete, will, in principle, never be able to give us the feeling of "what it is like to be in this state" [36]. This first-person singular, or subjective, view is categorically different from the third person view of scientific description and explanation. In the philosophical literature such phenomenological states have 
been termed "qualia", from the Latin "how it is", and it has been argued that as yet no way leads from a closed external description of the functioning of our brain to the subjective experience itself [37,38].

Some have gone as far as to say that because of this categorical difference between mental and physical events, subjective experience and objective description, the mind must be altogether a different entity $[4,39,40]$. Such a dualist position was of course first voiced by René Descartes (1596-1650), although Descartes was of course much more sophisticated than to merely postulate two substances. He was aware of the problem: If two completely different substances are unified within the human person, then they need a place of interaction [41]. Descartes saw the pineal gland as this organ of interaction, whereas Wundt, relying on Gottfried Wilhelm Leibniz' (1646-1716) metaphysical ideas of a pre-established harmony, developed the idea of psychophysical parallelism assuming that brain and mind states are two independent yet synchronized layers of description that are both necessary in order to understand and describe consciousness [5,6]. Modern proponents of dualist ontologies or solutions of the mind-body question also face the same problem [4-6]. They have to say how such an interaction can happen in the first place. Some have made the point that the physiology of our brain, more precisely the synaptic vesicles, are of a size that might sustain quantum fluctuations such that our consciousness could actually use these physical events for the purpose of steering the physical make-up of our brain $[42,43]$. Others have pointed out that the micro-skeleton of the neurons, the so-called neurotubules, are of a size and geometry such as to sustain long-range coherence of electromagnetic vibrations - similar to a laser — which then collapse into a definite state in the act of consciousness [44,45].

Such models derived from quantum theory are implicitly dualistic because the application of quantum theory itself presupposes the fact of a conscious observer in the first place. This is a precondition of quantum mechanics, and hence of all physicalist approaches. Still, this fact is rarely appreciated by proponents of monist-materialist physicalist solutions of the mind-body problem. Moreover, it is precisely through the thorough analysis of the preconditions of a physicalist position that quantum mechanical models bring up the problem of consciousness as a second entity, different from the physical-material make-up of the world $[30,46]$.

Some empirical arguments stem from the systematic study of near-death experiences $[47,48]$. Some documented experiences have apparently been reported by persons who have been clinically dead for more than $30 \mathrm{~min}$ [49]. This is a period which would not allow the heart to keep the brain sufficiently provided with blood, oxygen and nutrients, and which would hence have resulted in a physiologically dead brain that, in theory, should not have been capable of consciousness. Hence, conscious experience of a person with such a physiologically dead brain would be a weighty counter-argument against a physicalist theory of consciousness.

Some have used the formal structure of quantum mechanics, which presupposes a conscious observer to work formally, to make consciousness primary altogether [43,45,50-54]. On this basis, they reinforce what, in the history of philosophy, has been termed idealism. This is the position that ultimately, mind or consciousness is the only "real" thing in the world, and matter is a consequence of, or derived from, consciousness. The German idealists Fichte, Schelling and Hegel were the last influential philosophers to hold such a view. In modern days some mathematicians and physicists sympathized with this view, and some esoteric and transpersonal ontologies that are influenced by 
Eastern philosophies adopt such an idealist mind-over-matter stance. In fact, most of Yoga or Hindu psychology can be seen as an attempt to work out such a world view. Needless to say, our modern scientific-physicalist program is not easily reconcilable with such an idealist position. On the contrary, it arose despite heavy philosophical criticism from idealist quarters.

A pragmatic solution to the conundrum might be provided by a complementarist solution, a particular form of dual aspect theory $[38,55]$. Dual aspect theories have a long tradition, going back at least to Spinoza in the 17th century. They suggest that mind and matter are just two expressions of the same basic stuff in the universe that happens to have a physical side and a mental side. Some, such as Plotinos in the 2 nd century AD, have suggested a transcendental origin for this basic stuff. Others, such as the modern philosopher Feigl, have chosen not to address this question [56,57]. The Swiss psychiatrist Carl Gustav Jung (1875-1961) held a similar position by saying that mental and physical events are unified by a common source he termed "unus mundus", using a notion from medieval alchemy [58]. One potential model is to refer back to the basic structure of quantum mechanics, which uncovered complementarity as a basic structuring principle of the quantum realm. Nils Bohr, one of the fathers of quantum mechanics, pointed out that in order to describe matter properly we need to adopt notions that are at the same time maximally incompatible with each other, yet have to be applied to the same thing [59]. This structure he called complementarity, borrowing a term from the psychology of his days [60]. Bohr speculated that this structuring principle may be more general than just applicable to the description of processes in the quantum realm. Following Bohr, one could apply this notion to the relationship of mind and matter [61], and, it should also be noted, also within consciousness itself, as one finds both emotional and cognitive aspects therein that are both necessary in order to explain the human condition. That is, that two maximally incompatible concepts that nevertheless have to be applied at the same time to describe one and the same thing: a conscious human being (or another animal, for that matter). Similarly to quantum mechanics, we do not have another way at talking about the underlying nature of the world than by using such complementary concepts as a heuristic template in order to grasp the complexity of the phenomenon in question. Neither would it make sense to forfeit one of the sides. There may still be an underlying unifying nature on an ontological level, but we ordinarily do not have epistemological access to it. Hence the world appears to us in these dual aspects of material and mental events which, however, are intimately related with each other. Various ways have been pointed out how this could be conceptualized properly, one being the assumption that mind and matter represent a breaking of an underlying symmetry [62], another one being the idea that the basic structure of quantum mechanics might be applicable to other systems, as well [30,31]. Hence complementarity between mental and physical events could be orchestrated by non-local correlations, similar to quantum correlations proper.

We think that no matter which one of these views will emerge as being "true", it is important to reflect on the preconditions, consequences and the scope of these philosophical options. For, if one holds on to a narrow materialist-physicalist solution of the mind-body problem, then some forms of mind-body medicine or psychosomatic practices might not sound very reasonable. For instance, in order to sustain a certain type of, say, refinement of altered states of consciousness and spirituality [63-65], it is actually implicitly understood that a materialist ontology would not be compatible. Interestingly, by acknowledging the complementarist functions of cognitions and 
emotions, the principle of complementarity has been successfully employed to extend the scope of the traditional cognitive theories of mind and it has been suggested as a "generative principle" for explaining visual perception [66]. Thus, it appears to us that a complementarist notion is a promising minimal meeting ground. It ascertains the reality and causal efficacy of mental events, yet does not buy into a dualist or idealist ontology and guarantees the unity of the human person at the same time, thus being true to the thrust of the scientific enterprise of finding unitary explanations and causes. Hence, for pragmatic reasons, we will adopt such a position for the remainder of this chapter.

\section{Psychosomatic Medicine, Psycho-Neuro-Endocrinology and Psycho-Neuro-Immunology}

Psychosomatic approaches were at the cradle of modern medicine and psychology. By rejecting the old spiritist possession 'animal magnetism' model created by Franz Anton Mesmer (1734-1815). He thought that some sort of energy flows through the body that produces health and disease, physical as well as mental [67-69]. Hence, balancing this animal magnetism through his magnetic strokes would create or at least restore health. It later emerged, when his followers and other neurologists took these discoveries further-Charcot, Bernheim and Janet-that despite all their conceptual differences what Mesmer had probably done was use psychological methods, such as suggestion and hypnosis, to affect the physiology of the body [6,70-72].

Treating hysterical women with hypnosis was also the starting point for the young Freud. He not only studied physiology with Ernst Brücke in Vienna, from where he got his physiological ideas, but he also visited Jean-Martin Charcot (1825-1893) at the Salpetriere in Paris and Hippolyte Bernheim (1840-1919) in Nancy where he became accustomed to the two important French schools of hypnotism [71,72]. Moreover, he translated the most important book of Bernheim into German and not only named his oldest son Jean-Martin, but also wrote a favorable obituary of Charcot, although he was not very favorable towards another French psychologist, Pierre Janet (1859-1947). However, on closer scrutiny it turns out that a substantial amount of Freud's seemingly original ideas are actually unaccredited developments of discoveries of these French giants $[6,73]$. Thus it is not a big surprise to find Freud theorizing and speculating about the possibility that mental problems and psychological trauma could express themselves in the body, or even use a secret code to express psychological problems physically. Although Freud developed only a rough outline, psychosomatic ideas are genuinely at the base of the psychoanalytic enterprise. If the psyche and the subconscious are to have any power at all, this power cannot stop where psychological phenomenology stops. It must reach into the realm of the body. This idea was developed further by Freud's followers and also those who effectively became psychoanalytical renegades. Alfred Adler (1870-1937), who initially considered himself a student and follower of Freud but then broke away, developed the concept of organ inferiority [70]. This is the idea that the inferiority complex, which in Adler's view is one of the driving forces of positive striving as well as of neurosis, manifests also physically [74]. From there it is only a small step to what Freud himself called "organ language", together with early psychoanalytically-inspired psychosomatic theorists, such as Sandor Ferenczi (1873-1933), Wilhelm Reich (1897-1957) and Georg Groddeck (1866-1934) [75]. In the same way that neurosis uses symbols in dreams and thereby develops a certain language to manifest conscious experience, it may also use body function to express itself. 
Thus, anger that is "swallowed" may express itself as stomach ulcers, or implicit wishes to avoid sexual intercourse may express themselves as skin disease that discourages physical contact, and so on.

Modern empirical psychosomatic research has largely disproved the crude psychosomatic equations fashionable with the early analysts [70]. However, it has also uncovered multiple links between the psyche and the body and thereby potentially expanded the scope of a psychosomatic view. If anything, the psychosomatic view has been solidified and grown in importance by liaising with another important movement: systems theory. Systems theory is a theoretical movement that originated in Austria and Hungary around the 1930s. It was driven mainly by biologists, such as Albert Szent-György (1893-1986) and Ludwig von Bertalanffy (1901-1972), who were dissatisfied with the reductionist view in biology [76-78]. They argued that a living system is different from and more than just its constituent parts. From there it was only a small step to argue that such an abstract systemic view can be applied to a variety of systems. Thus, not only cells, plants and animals can be considered such systems, but also human beings. They not only comprise a physical system, but are also embedded in a social context that creates the meaning that is transported in their psychological world, both of which are intimately related to humans. Hence, systemically, there is not only an intimate connection between the mental and the physical, but also between those two dimensions and the social aspect. Thus a bio-psycho-social view was increasingly applied to medical problems $[79,80]$. Such a view postulated that one had to consider not only the physical plane but also how this reflected the psychological situation and the social plane as well as their complex interdependencies. Such a systemic view was akin to what German psychosomatic medicine had been teaching since the early 20th century, developed out of the Heidelberg school, centering on Victor von Weizsäcker (1886-1957) [81].

Modern psychosomatic research became less dogmatic and more and increasingly pragmatic, trying to uncover the concrete links between the psychological plane and the physical reality of the body [75]. While the crude links of early psychosomatic approaches turned out to be barren, the generic idea seemed to be fruitful and is still inspiring new research programs. Two important developments were instrumental. They are known as psycho-neuro-immunology and psycho-neuro-endocrinology. These terms denote the programs that try to uncover the links between the psychological system, the brain and the endocrine or the immunological systems respectively. Often, they are now considered one program, and it is mainly for disciplinary reasons that they are distinguished.

The immunological system was long considered fairly self-contained and self-sufficient, operating independently from the central or autonomic nervous system. While some earlier ideas were already around, the idea of a psycho-neuro-immunological connection was boosted by Robert Ader's work i.e., the central nervous system interacting with the immune system, and the immune system with the central nervous system [82-84]. This showed that a supposedly independent immunological reaction, the immunosuppression produced by a pharmacological stimulus, could be classically conditioned. This meant that an immunologically irrelevant but psychologically relevant stimulus could be imbued with immunological meaning. If that was principally possible, then it was conceivable that a host of immunologically mediated responses, and hence diseases also, might be susceptible to conditioning. If rats could be conditioned to show an 
immunosuppressive reaction in a taste-aversion paradigm, then it was also conceivable that humans could show enhanced or suppressed immune reactions to aversive psychological stimuli [85]. This opened, at least in principal, a route to understanding psychological concomitants of immunologically mediated diseases, such as asthma, atopic dermatitis, colitis or Crohn's disease, to name but a few of the more important diseases.

At the same time, immunologists and endocrinologists discovered that the distinction between hormones, cytokines and transmitters was fairly artificial. Ever more receptors for ever more molecules were discovered on immunocompetent immune cells. Cells, such as lymphocytes or macrophages, not only respond to cytokines proper, i.e., to signaling molecules used by the immune system to communicate and regulate the immune response, but also express receptors for most of the transmitter molecules used by the central or autonomic nervous system, as well as to some hormones. Cortisol, for instance, a hormone that is introduced into the blood stream by the adrenal cortex in response to a perceived stress, not only has a host of reactions in the periphery, such as an increased metabolism, but also via further sympathic activation leads to a quicker heart rate and a change in temperature, as well as a redirection of blood distribution from the intestines to the periphery. Cortisol receptors are also expressed by some immune cells which then decrease activity. Cortisol receptors have also been discovered in the cortex, for instance in hippocampal areas, amygdala and in the hypothalamus [86]. Hence, what classically used to be seen as a hormone, is now considered to have multiple actions: , as a hormone, as an immunologically active molecule and as a molecule with central nervous system activity. In the same vein, it has been discovered that most of the distinctions previously considered instrumental are rather artificial, due to our ignorance or our failing theoretical models. While we have neither the competence nor the space to give a complete overview, it is sufficient for our purposes to simply note this thrilling fact that research has uncovered a multitude of links between the immune system, the brain and the endocrine system in both directions. This allows for an understanding, at least in principle, of the fact that the brain, and thereby the mental system, can have a direct influence on the body $[87,88]$.

Take stress as an example. The stress response can be distinguished into two phases. The immediate stress response is via autonomic innervation of the adrenal medulla and autonomic reactions [89]. On a threat stimulus, the threat is perceived through sensory input, which then via parts of the thalamus activates the locus coeruleus in the brain stem to stimulate the sympathetic adrenal medullary (SAM) axis [90]. Adrenalin is injected into the blood stream within several hundreds of milliseconds by the adrenal gland [91].

At the same time, direct connections from perceptual centers in the lower brain areas activate neurons in the amygdala where the emotional valence of stimulus is analyzed even before clear conscious perception is formed by higher centers [92,93]. If a threat stimulus is detected, direct innervations of hypothalamic centers by amygdala neurons activate corticotropin-releasing hormone $(\mathrm{CRH})$. This in turn stimulates the emission of adrenocorticotropic hormone (ACTH) from the pituitary [94]. This then travels via the bloodstream to the adrenal gland, where, in the cortex of the adrenal, cortisol is released, starting the second phase of the stress response as briefly outlined above. Blood cortisol peak is reached roughly within 10-15 min after the perceived stress [95]. 
The sympathetic system will have reacted to the perception of the fear stimulus within a matter of several hundred milliseconds. It will have not only triggered the release of adrenalin and nor-adrenalin, also known as epinephrine, and norepinephrine from the medulla of the adrenal gland, several minutes before the hormonal regulation of the excretion of cortisol will have started. It will also have increased the heart rate almost instantaneously and rushed the emission of glucose from depots in the liver into the bloodstream to make immediate muscular action possible. If the perceived threat that has triggered this autonomic reaction is shortly afterwards discovered to be a false alarm by more intricate analysis-a stick of wood, say, instead of a dreaded snake-the second phase will be halted immediately and we calm down again. This will be the case at least under normal circumstances. Negative feedback loops will stop the arousal. This is because epinephrine is not only a hormone, but also a neuro-transmitter. The epinephrine level in the bloodstream is monitored by receptors in the hypothalamus and possibly elsewhere in the brain. It will block the respective centers responsible for activating the sympathetic arm of the autonomic nervous system. The cortisol system which starts out a little more slowly will take over the necessary regulation activities if the threat or the challenge persists [96].

Stress response normally subsides once the organism has successfully dealt with it. Then a down-regulation of the system takes place and a rebalancing can be effected. The ability of the body to increase or decrease vital functions to a new steady state on challenge during stress is called allostasis. However, there are four types of reactions describing how a system can mal-adapt to a stressor, which in the long term can increase the probability of disease [97]. The four maladaptive responses to a stressor are: (1) frequent exposure to stress; (2) inability to habituate to repeated challenges; (3) inability to terminate a stress response, (4) an inadequate response. In these four reaction types to challenge, the system accumulates high allostatic load as the cost of chronic exposure to elevated or fluctuating endocrine and neural responses. A high allostatic load is predictive of mortality and morbidity $[89,98]$.

If, however, for some reason, the stress persists and the organism is not effective in coping, the negative feedback winding-down processes will not work. Alternatively, if the stress response is activated too frequently or in too short a period of time, the pituitary-adrenocortical axis will be taxed and worn out. Challenges may not be met with the right level of reaction, exposing the organism to inefficient capabilities to cope with the situation, prolonging the stress situation and hence the potential threat.

Both chronically elevated levels of cortisol and a lack of reaction to cortisol emission are problematic [99]. Chronically elevated cortisol levels may have a host of immunological reactions. Cortisol in the short term stimulates the immune activity of some cells, but over a longer period has suppressive effects. Elevated stress levels might actually make the organism prone to either infections or deregulated immune responses and auto-immunological reactions, such as elevated inflammatory response. It is a well-known clinical fact that immunologically-mediated diseases such as atopic dermatitis, asthma, rheumatoid arthritis or multiple sclerosis can be triggered or aggravated by stress or emotional upheavals [100,101]. Chronic immune suppression brought about by elevated cortisol levels might also contribute to some forms of cancer, where the immune system fails to attack some cells that have not destroyed themselves as they should have [102,103]. 
It may even be possible that chronically elevated cortisol levels may inhibit the formation of synaptic diversity in the hippocampus, an area of the brain necessary for the transition of content from short term to long-term memory, and an important comparator of perceived information with expected information [104]. The hippocampus also plays important roles in emotional regulation, and thus elevated cortisol levels may have powerful repercussions in affective tone. For instance, some forms of depression have been associated with chronically elevated cortisol levels [99]. If cortisol levels are chronically elevated, or traumatic challenges of the stress-response system have been experienced in childhood, the responsivity of the hypothalamic-pituitary-adrenal axis (HPAaxis) can be down-regulated and hypocortisolism results [105]. This is an inability of the system to respond adequately to stressors, either because of a fatiguing of the system or because of a protective mechanism against flooding with cortisol. Hypocortisolism is associated with chronic disease, such as atypical depression, fibromyalgia, chronic fatigue syndrome or post traumatic stress disorder [106,107].

Thus, in principle and probably depending on individual vulnerabilities and learning histories, some quite non-specific and ubiquitous stress reactions could be responsible for a wide range of dysregulations and potentially even for chronic disease. This is possible, because immunological reactions, hormone reactions, autonomic nervous system effects and central nervous activity are all intimately linked and all communicate with each other.

In conclusion: While the old psychosomatic theories were certainly much too crude, the general intuition was correct. Psychological content, experiences and traumata, such as anxiety, fear, grief, depression and hopelessness may have profound reactions on the body. What we have discovered through exploring immunological and endocrinological connections within the brain and thus within the sphere of psychological experience is a highly intricate and complicated network of potentially mutual influence. We have also seen that simple equations such as anger leading to stomach ulcers, anxiety to asthma, repressed hostility to myocardial infarction, are nearly always wrong in their linear simplicity. However, the generic possibilities of such connections have been unraveled, based on the discovery that the whole body and not only the Central-Nervous-System (CNS) is a complex network communication system and continues to be researched [108]. It can be expected that in the near future, this research program will generate a more specific and detailed understanding of how some somatic diseases are linked to psychological states. In the next section, we consider the aspiration and the rationale of such interventions.

\section{The Hope of Mind-Body Interventions}

By now it should be clear that if mental states and psychological experiences can influence the body towards disease, the same connections should also be pathways for therapeutic interventions. If chronic stress, to name but one condition, can produce a host of negative consequences or exacerbate many diseases, then a chronically relaxed state, or the capacity to counteract stress and relax quickly and effectively, could potentially exhibit beneficial health effects. If negative affect and depression can produce profound dysfunctional immunological changes, then the induction of positive and serene affects should be protective, if not therapeutic. This is the basic assumption of Mind-Body Interventions. 
One of the first systematic explorations and exploitations of that idea was Benson's Relaxation Response [109,110]. Following this line of reasoning, Benson suggested that similar to the universal stress response that allows the organism to combat a wide variety of challenges and cope with all sorts of difficult situations through a circumscribed set of physiological reactions, there should also be an innate relaxation response that does the opposite: leading the organism back into a state of regeneration. Associated with the parasympathetic arm of the autonomic nervous system, Benson and his associates studied a variety of techniques, mainly derived from meditation techniques, that would trigger such a relaxation reaction. The hallmark of this reaction is an activation of the parasympathetic arm of the autonomic nervous system, which is antagonistic to the sympathetic arm mediating the stress response [111]. The main pathway to accessing and stimulating this is through the regulation of breathing. By regulating one's breathing the sympathetic activation can be modified and eventually countered [112]. A slowing down in breathing slows down the heart rate. It also effects a dilation of blood vessels, mainly in the periphery, but also in the bowels. Glucose is moved back into depots, cortisol emission is downregulated, endorphins are released, and as a consequence constitutive nitric oxide synthase is stimulated and nitric oxide (NO) is produced. NO is an immune, vascular and neural signaling molecule, and is itself bactericidal and antiviral. It scavenges free radicals and down-regulates endothelial and immunocyte activation and adherence, thus performing vital physiological activities, including vasodilation [113]. Thus, a comprehensive state of regeneration is triggered by this relaxation response [114]. Most, if not all, beneficial effects of mind-body techniques are supposed to work through this generic mechanism of the relaxation response, according to this claim. They all influence breathing and heart rate, and thus exert a stimulating influence on the parasympathetic system.

The question whether the relaxation response is sufficient as an explanation of beneficial effects of mind-body techniques is certainly open at this time, although there is some evidence that it cannot be seen as the sole pathway driving the health connection $[21,115,116]$. While it is a reasonable assumption that some form of relaxation is germane to most, if not all, mind-body techniques, it might well be the case that more subtle changes that are difficult to measure or are exerted only centrally in the brain with very poor proxy measures in the periphery have so far evaded researchers. Pain often being a subjective phenomenon of immediate experiential directness might nevertheless be highly elusive locally, if the pain is not one secondary to a local inflammatory process but one that has generalized and is now due to a centrally mediated dysregulation of pain perception [117,118]. Effects of mind-body techniques on the experience of pain, for instance, will require more elaborate models of explanation than just the generic activity of the relaxation response.

But it is precisely the fact that some chronic diseases are complex functional diseases with only few local and peripheral abnormalities, where mainly central regulation either of pain perception, or of the immune network or of endocrine-immune-functions are deranged, that attracts people to mind-body techniques. After all, nearly all diseases that are medically difficult to treat or are only treated symptomatically, seem to have a strong component of central functional dysregulation. This is true for all chronic pain syndromes which are not due to injuries or mechanical disruptions, such as for fibromyalgia, chronic idiopathic pain, or some neuropathic syndromes such as 
sciatica $[119,120]$. This is also true for chronic fatigue syndrome, for all chronic diseases with an involvement of dysfunctional immune-regulation, such as atopic diseases, and perhaps even for coronary heart disease and atherosclerotic diseases [121-123]. It is certainly also valid for psychological disorders, such as anxiety and depressive disorders, and perhaps even for some compulsive disorders and potentially also for substance abuse disorders [88,124-126].

That is not to say that mind-body techniques are effective in all these cases. Nevertheless, it means that it makes sense to study mind-body techniques in connection with diseases where a component of central regulation: pain, psychological experience or endocrine and immune regulation is involved. In addition, this is true nowadays for nearly all relevant chronic diseases that pose a challenge.

\section{A Typology of Mind-Body Techniques, Brief Descriptions and a Summary of the Evidence Base}

Mind-Body techniques can be ordered according to several components:

1. Self-directed vs. other-directed

2. Narrow $v s$. wide focus of attention

3. Direct $v s$. indirect action and intervention

4. Body oriented vs. mind-oriented

5. Amount of practice (high vs. low)

First, a technique can be more or less completely dependent on the instructions of a trained therapist. This is the case with classical or modern hypnotherapeutic approaches, where the mental states of a patient are modified and modulated by a therapist in order to influence some bodily function. On the other hand, it can be comparatively self-contained after an initial training period. This is the case for most therapeutic meditation programs that are instructed by a teacher such as the relaxation response (RR) program, the Mindfulness Based Stress Reduction (MBSR) program, Qi Gong, Tai Chi, or the Transcendental Meditation (TM) program. Some of the more complex Yoga, Qi Gong or Tai Chi techniques are in-between as they often presuppose the presence of a skilled teacher and a long training period for correct postures and movements. At the extreme end of the self-directed techniques range are simple relaxation programs that are conveyed by self-help books and accompanying tapes and discs and self-hypnosis programs.

Second, most techniques explicitly direct attention towards a clear focus, at least initially. This is certainly true for all meditation techniques that either use the focus of breathing on the body and its function, or on mantras and phrases as a vehicle to redirect attention. After that initial focusing some techniques are quicker than others in broadening out the focus towards observing all mental activities and content, such as mindfulness based techniques, while others encourage practitioners more strongly to keep this focus and intensify it, such as techniques derived from Yoga traditions, such as TM or Yoga itself, Qi Gong or Tai Chi. However, it should be said here that this distinction seems rather technical and artificial to us. Every technique that targets the capacity to redirect and focus attention will eventually increase mindfulness also outside the context of meditation. Moreover, every technique that intends to increase mindfulness and thus initially favor an open focus has to teach people how to shift and direct their attention in the first place and is achieves this 
by focusing on breathing. Nonetheless, seemingly orthogonal constructs, mindfulness and focused attention seem to be complementary in the sense that they are both necessary and fostered by mindbody techniques.

Third, some techniques are quite direct in regulating bodily function and prescribe patterns of breathing and moving, such as Tai Chi, Qi Gong or Yoga meditations. Others, such as mindfulness techniques and even TM are more indirect in just having people observe the breath or bodily functions and thus use the simple fact that observation itself changes the function.

Fourth, some techniques use the body directly and influence bodily states through movement, posture or bodily manipulation with the expectation that either psychological or bodily changes will ensue. This is true for techniques such as Tai Chi, Qi Gong, Yoga or the Alexander Technique. Other techniques are in an intermediate position in that they use some body awareness but only in a supportive fashion. That would be true for most meditation techniques that recommend a certain posture, such as upright sitting position, or a certain type of slow movement. Examples for mind-body techniques with little direct emphasis on the body would be hypnosis or self-hypnosis. Table 1 presents a summary classification for some of the more widely known Mind-Body Interventions.

Fifth, the degree of practice that is estimated as necessary varies considerably between different Mind-Body-interventions. For example, some mindfulness trainings expect their students to practice for approximately one hour daily, whereas the Alexander Techniques is organized around one or more classes each week.

In the following paragraphs we present brief descriptions of the techniques. The order does not imply any inherent quality rating or judgment of usefulness. 
Table 1. Summary Classification of Some Better Known Mind-Body Interventions.

\begin{tabular}{|c|c|c|c|c|c|}
\hline & Direction & Focus & Action & Body & Practice \\
\hline $\begin{array}{l}\text { Transcendental } \\
\text { Meditation }\end{array}$ & $\begin{array}{l}\text { Self-directed with } \\
\text { some emphasis on } \\
\text { teacher }\end{array}$ & Focused & Indirect & $\begin{array}{c}\text { Little } \\
\text { emphasis }\end{array}$ & $\begin{array}{l}\text { Daily } 1 \text { to } 2 \text { times } \\
20-30 \mathrm{~min}\end{array}$ \\
\hline $\begin{array}{l}\text { Relaxation } \\
\text { Response }\end{array}$ & Self-directed & Focused & Indirect & $\begin{array}{c}\text { Little } \\
\text { emphasis }\end{array}$ & $\begin{array}{l}\text { Daily, } 2 \text { times } \\
\text { 15/20min, }\end{array}$ \\
\hline $\begin{array}{l}\text { Progressive } \\
\text { Muscle } \\
\text { Relaxation }\end{array}$ & Self-directed & Focused & Direct & Emphasis & $\begin{array}{l}\text { Daily or as needed; } \\
\text { no fixed duration }\end{array}$ \\
\hline Biofeedback & $\begin{array}{l}\text { Self-directed with } \\
\text { initial expert } \\
\text { component }\end{array}$ & Focused & Direct & Emphasis & $\begin{array}{l}\text { Supervised sessions } \\
\text { until resolved or as } \\
\text { needed }\end{array}$ \\
\hline $\begin{array}{l}\text { Alexander } \\
\text { Technique }\end{array}$ & Externally directed & Focused & Direct & Emphasis & $\begin{array}{l}\text { Taught lessons until } \\
\text { resolved or as needed }\end{array}$ \\
\hline $\begin{array}{l}\text { Qi Gong/Tai } \\
\text { Chi }\end{array}$ & $\begin{array}{l}\text { Externally directed, } \\
\text { later self directed }\end{array}$ & Focused & Direct & Emphasis & $\begin{array}{l}\text { Taught lesson with } \\
\text { daily practice }\end{array}$ \\
\hline $\begin{array}{l}\text { Life-style } \\
\text { modification }\end{array}$ & $\begin{array}{l}\text { Externally directed, } \\
\text { later self directed }\end{array}$ & Mixed & Indirect & Mixed & Defined programs \\
\hline $\begin{array}{l}\text { Kundalini } \\
\text { Yoga, Hata } \\
\text { Yoga }\end{array}$ & $\begin{array}{l}\text { Externally directed, } \\
\text { later self directed }\end{array}$ & Focused & Direct & Emphasis & $\begin{array}{l}\text { Supervised sessions } \\
\text { with daily practice }\end{array}$ \\
\hline $\begin{array}{l}\text { Mindfulness } \\
\text { Meditation }\end{array}$ & $\begin{array}{l}\text { Externally directed, } \\
\text { later self directed }\end{array}$ & $\begin{array}{l}\text { Initially } \\
\text { focused, later } \\
\text { wide focus }\end{array}$ & Indirect & $\begin{array}{c}\text { Little } \\
\text { emphasis }\end{array}$ & $\begin{array}{c}\text { Supervised programs } \\
\text { with daily practice }\end{array}$ \\
\hline
\end{tabular}

\subsection{Alexander Technique}

This is a method originally developed by the actor Frederick Matthias Alexander (1869-1955) as a self-help treatment for his failures of voice on stage [127]. This technique places a lot of emphasis on correct anatomical posture, mainly of the spine, but also for movements. It uses mental directives or self-suggestions ("my neck is wide and free") on top of teacher-directed movements to foster awareness of unfavorable movement and posture habits and eventually change them. It is suggested to be a helpful technique for all anatomy related pain problems, such as for chronic back pain, neck and shoulder pain or speech disorders. The Alexander Technique (AT) normally necessitates a series of single sessions until old movement patterns and postures have been unlearned and new movements incorporated. Later booster sessions are supposed to be beneficial. It is normally not possible to practice AT alone, except the self-hypnotic directives that are supposed to be integrated into daily movements.

The technique has been researched comparatively little. A recent systematic review uncovered four trials, two of which have some relevance and report promising results in back pain patients and Parkinson patients [128]. Another review found no studies allowing conclusions on the efficacy of Alexander Technique in asthma [129]. Our own randomized single-case study showed good effects in two patients with refractory stuttering [130]. A recent Randomized Controlled Trial study with 597 patients suffering from persistent back pain provided an economic evaluation of 
therapeutic massage, exercise and lessons in the Alexander technique [131,132]. A combination of six lessons in the Alexander technique followed by exercise turned out to be the most effective and cost-effective option.

\subsection{Qi Gong/Tai Chi}

These Chinese movement meditations are thought to be derived from ancient martial arts training, although most forms have been compiled comparatively recently. They rest on assumptions that Chi, considered to be the universal life energy or force, is continuously used and regenerated by the body and has to be balanced between two opposite polar sides. Chi can be regenerated through breathing and moving. Hence certain prescribed sets of motions are used to regenerate Chi and to balance it within the body. Qi Gong uses slow repetitive patterns of movements with a tight coordination of breathing and moving that can be quite taxing on the muscular system, and different types of exercises are adapted for different sets of tasks. Tai Chi uses a certain series of movement figures that continuously follow each other. Depending on school and type, these movements can differ slightly and are conducted at various levels of speed. Qi Gong exercises can be used singly and incorporated into a daily program of only a few minutes. Tai Chi programs are normally longer and would take roughly 15 to $30 \mathrm{~min}$ at least. Due to their intricate patterns and their dependence on correct movements, both techniques need experienced and qualified teachers initially, with tight supervision of correct movements, until students reach some proficiency and can benefit from their own training. Both are supposed to be practiced daily for at least $15 \mathrm{~min}$, although Qi Gong can be also practiced for a shorter period when integrated in one's own private program.

Although old by any modern standard and well accepted as general health promoting, relaxing and integrating exercises, Tai Chi and Qi Gong have not been researched to any notable extent. One systematic review of Tai Chi in patients with rheumatoid arthritis concluded that there was very weak evidence for the effectiveness of Tai Chi. In fact only four trials were included in this review, and only one showed a clear benefit [133].

Another review summarizes Tai Chi used in six bone mineral density studies, but the conclusion is limited by the quantity and quality of these studies [134]. [135] showed that community-based Tai Chi interventions could reduce the fear of older people falling in community-accommodation.

Tai Chi as a complement to existing exercise intervention can be useful in low and intermediate risk patients in cardiac rehabilitation [136] and cancer patients [137]. It appears to have beneficial health effects, but due to the small number of studies and the lack of a theoretical foundation, it is difficult to draw firm conclusions [138]. A recent review analyzing 40 studies where Tai Chi was utilized as a clinical intervention suggested improvements in psychological well-being including reduced stress, anxiety, depression and mood disturbance as well as increased self-esteem [139]. It is also noteworthy that another review based on 13 randomized controlled trials recommended Tai Chi as an alternative treatment in older adults for improving balance and reducing falls, although it was not found to be superior to other interventions [140]. A recent trial proved it effective for fibromyalgia [141]. 


\subsection{Yoga Interventions}

There are large numbers of different programs that are summarized under the heading of Yoga. Yoga literally means union. Some of the yoga programs are more akin to TM or mindfulness meditation programs, as they mainly train attention and awareness whereas other Yoga forms focus more on physical training. In a way, the TM program can be viewed as a derivative and adaptation of an ancient Vedic Yogic meditation technique to modern day requirements. Kundalini Yoga, for example, is a specific type of Yoga practice which emphasizes the awakening/rise of the Kundalini force which is symbolically located as an enrolled serpent at the lower end of the spine. However, in the West, yoga is mostly associated with Hatha Yoga, which emphasizes the overcoming of the physical body limitations as a mirror to the internal mind. Through regular practice of asanas (body positions of stretching and holding) as well as breathing techniques, focusing one's attention and meditation, the union of body and mind is to be achieved. The idea being that this union will have healing and preventive effects, as well as a calming effect on the mind.

Many individual studies exist, some of them promising [142,143] but not followed up, and a bibliography details the earlier research [144]. Two recent reviews conclude that there is too little research for definitive conclusions, but that first results are encouraging [145,146]. Kundalini-Yoga has also shown effects in the treatment of obsessive-compulsive disorder (OCD) [147].

A series of studies document that Yogic meditation has clearly definable effects on the brain as shown in the EEG: mainly the power of lower frequencies (alpha, delta and theta) is enhanced, as is the coherence of the resonators across the brain [148-152].

A systematic review suggests that yoga may reduce insulin-resistant syndrome risk factors for cardiovascular disease, but most of the studies have methodological limitations [153]. There is evidence that meditation techniques (Meditation, Meditative Prayer, Yoga, Relaxation Response) might have health benefits, but that sound methodological studies are missing [154]. However, a recent review that included more than 80 studies found that yoga interventions seemed to be equal or superior to exercise in most outcome parameters measured, except those involving physical fitness [155]. Two recent trials proved Yoga efficient for the treatment of low back pain [156-158].

\subsection{Transcendental Meditation}

Arguably, the best-researched mind-body intervention is Transcendental Meditation. This is a Yogic-Vedic meditation technique introduced in the West by the late Maharishi Mahesh Yogi (1918-2008). Although, strictly speaking, not necessarily dependent on this person, a large community and organization has evolved around this guru and his technique that also drove the research activities. The core of the TM program is a mantra, given out only during personally supervised sessions and supposedly individually chosen. This mantra, consisting of some Sanskrit words, is used to focus attention during the meditation process. The hypothesis is this mantra conveys some subtle spiritual benefit on the meditator, apart from acting as an aid to focus. After some training, which is supposed to consist of two sessions of $20 \mathrm{~min}$ daily training over a period of 10-16 weeks, the meditator is able to reach a state of transcendence of normal consciousness into a blissful state of pure consciousness, thought to be not only psychologically desirable, but also physically healthy [159-161]. 


\section{4}

A large number of studies have been conducted, but overviews and reviews are still not clear about the benefit of the program $[145,162]$. Earlier meta-analyses and reviews comparing randomized studies conducted to date have been largely supportive [163], with moderate to sizeable effect sizes between Cohen's $d=0.33$ to $d=1.5$ [159]. Skeptics sometimes criticize the non-randomized nature of some of the evidence, for instance for less health care use [164-166] or crime prevention $[165,166]$. However, the over-rigid adhesion to allegedly omnivalent quality standards derived from pharmacological trials may sometimes produce false negative conclusions [162] due to the exclusion of studies that are deemed less valid or due to the insufficient expertise of reviewers in the content area itself [167]. Overall, TM seems to be useful in stress reduction and secondarily in the lowering of blood pressure [168] (although this has been doubted [162]), and in the prevention of coronary artery disease [169]. A series of promising single studies has shown the effects of TM on blood pressure and cardiovascular risk factors [170-175]. Some reviews support this [176-178], and a recent review suggested that TM may have the potential to reduce systolic and diastolic blood pressure in a clinically meaningful way [179].

\subsection{The Relaxation Response}

The development and study of the relaxation response seems to be modeled along the lines of spiritual meditation programs, leading to a completely secularized counterpart. The introduction and teaching time was radically shortened. The meditation also focuses on a mantra- like syllable, which, however, is meaningless [180]. Posture is less important and a specific content-less state of mind is not the target of the technique, but simply relaxation. Some of the research shows that even this comparatively reduced program seems to have some effects [181-186]. A recent meta analysis embracing 27 studies found that relaxation training showed a medium-large effect size in the treatment of anxiety [187].

\subsection{Mindfulness Meditation}

Mindfulness Meditation is probably one of the oldest meditation techniques, tracing its inauguration to the historical Buddha himself. It consists in mindfully observing the breath and all mental content, both during the exercise and outside it. Ideally, it should lead to a mindful awareness of one's mental activity and in the long term also to a non-judgmental attitude towards one's own mind and other people's actions [188,189]. Mindfulness is both active (actively observing) and passive (not reacting towards what is observed) and in this and other aspects it is dialectical [188]. While the original practice clearly is religious in intent in that it was supposed to be a means to free oneself from suffering through enlightenment, the modern adoptions often use just the technique without the religious and philosophical background. One of the most popular adoptions is Mindfulness Based Stress Reduction (MBSR)[2] and two further developments, Mindfulness Based Cognitive Therapy (MBCT) [190], which is a program for depression relapse therapy, and Dialectical Behavior Therapy [191], in which the principles of mindfulness have been included into a specialized program of therapy for borderline patients. A common feature of these programs is that they use principles of mindfulness and teach formal mindfulness meditation to patients, urging them to daily practice at least within the eight-week programs. In a meta-analysis 
published in 2003 of studies on MBSR, Baer et al. found an effect size of $d=0.70$ for anxiety and $\mathrm{d}=0.84$ for depression [192]. We found in a meta analysis published in 2004 that MBSR was effective in improving psychological and physical health outcomes across various diseases with an effect size of $d=0.53$, which can be considered a medium effect that is worthwhile, considering the chronicity of the diseases studied [193]. However, a more recent meta-analysis published by Bohlmeijer et al., based on 8 studies of moderate to good quality investigating the effect of MBSR on mental health of adults with a chronic medical disease, found only smaller effect sizes ranging from $d=0.47$ for anxiety and $d=0.26$ for depression [194]. In a similar way, MBCT proved effective in preventing relapse in patients with recurrent depression in controlled studies [195-197] but is at present not seen as a completely reliable intervention by others, as the results of studies are equivocal [198].

Pain patients seem particularly able to profit from mindfulness, although not from pain alleviation as such. Nevertheless, mindfulness seems to install a cognitive distance between the experience of pain and the cognitive reaction towards it. In our study on MBSR in fibromyalgia patients building on an effective pilot study [199,200], one of our patients said: "I have been bossed around by my pain all my life. Now I just don't bother any longer and go on holidays." It was the first time this lady had taken some time out for more than 20 years. She did not go without pain, but with more freedom.

\section{Final Remarks and Conclusions}

Mind-body techniques have a clear place in integrative medical care. They are, together with placebo research, the systematic place where it becomes clear that mental activity, techniques and practices have a clearly recognizable and direct influence on the body [201]. Most mind-body techniques seem to be effective, although conclusive statements cannot be made as yet. They are popular, because patients intuitively want this holistic approach. They seem to understand sometimes more clearly than their physicians that part of their physical problem may be due to some emotional-mental ailment and that treating this mental realm might also be beneficial for their bodies. Although we are only slowly beginning to understand how the interconnections between the psyche and the body operate, due to our greater knowledge of the immunological and endocrinological connections between the brain and the periphery, in principle, we have enough knowledge to understand how stressful and soothing, noci-ceptive and healing reactions and influences can travel either way. Hence, it seems natural also to employ these mind-body techniques as therapeutic options. It is clearly more difficult to study those techniques as they are always complex interventions, operating with an array of potential specific and non-specific effects. Such complex interventions cannot be studied by simple research designs modeled along the lines of pharmaceutical interventions [202,203]. Rather, they need a diligent, stepwise approach in which general effectiveness is established first, before dismantling trials might be able to tackle the question about which component might be important and which component could be dispensed with. A lot of time, money and effort have to be put into research programs like that, and considering the limited amount of funding available it will take a score of years until we have the desired, firm knowledge base. Until then, we will have to rely on proxy-studies and proof of principle evidence. This we have. We have enough knowledge in general to be confident that some 
of the techniques - meditation and mindfulness relaxation, and body work - can be beneficially employed. Here as elsewhere, these techniques will only be beneficial if patients themselves see a point in involving their mental and psychological lives in their healing process. If they do, a mind-body technique might be the first step towards more wholeness and healing, as patients understand that it does not make sense to cure the body without tackling their psychological wounds and vice-versa. We are therefore of the opinion that mind-body techniques constitute a superior approach to attaining holistic health.

\section{Acknowledgments}

Harald Walach and Niko Kohls are grateful for the long standing support of the Samueli Institute, USA. Marie-Louise Gander was supported by the Swiss National Fund at the time this work was conducted.

\section{References and Notes}

1. Latorre, M.A. A holistic view of psychotherapy: Connecting mind, body, and spirit. Perspect. Psychiatr. C. 2000, 36, 67-68.

2. Kabat-Zinn, J. Full Catastrophe Living: Using the Wisdom of Your Body and Mind to Face Stress, Pain, and Illness; Delacorte: New York, NY, USA, 1991.

3. Kabat-Zinn, J. Wherever You Go, There You Are; Hyperion Books: New York, NY, USA, 1994.

4. Walach, H. Mind - body - spirit. Mind Matter 2007, 5, 215-239.

5. Kohls, N.; Benedikter, R. The origins of the modern concept of "neuroscience"-Wilhelm wundt between empiricism and idealism: Implications for contemporary neuroethics. In Scientific and Philosophical Perspectives in Neuroethics; Giordano, J., Gordijn, B., Eds.; Cambridge University Press: Cambridge, UK, 2010; pp. 37-65.

6. Kohls, N. Aussergewöhnliche erfahrungen-Blinder fleck der psychologie? Eine auseinandersetzung mit aussergewöhnlichen erfahrungen und ihrem zusammenhang mit geistiger gesundheit; Lit-Verlag: Münster, Germany, 2004.

7. Du Bois-Reymond, E. Jugendbriefe von emile dubois-reymond an eduard hallmann; Dietrich Reiner: Berlin, Germany, 1918.

8. Churchland, P.S. Neurophilosophy. Toward a Unified Science of the Mind-Brain; MIT Press: Cambridge, MA, USA, 1986.

9. Metzinger, T. Neural Correlates of Consciousness: Empirical and Conceptual Questions; MIT Press: Cambridge, MA, USA, 2000.

10. Wegner, D.M.; Wheatley, T. Apparent mental causation. Sources of the experience of will. Am. Psychol. 1999, 54, 480-492.

11. Libet, B. Do we have free will? J. Conscious. Stud. 1999, 6, 47-57.

12. Damasio, A. The Feeling of What Happens. Body, Emotion, and the Making of Consciousness; Vintage: London, UK, 2000.

13. Laureys, S.; Owen, A.M.; Schiff, N.D. Brain function in coma, vegetative state, and related disorders. Lancet Neurol. 2004, 3, 537-546. 
14. Tononi, G. An information integration theory of consciousness. BMC Neurosci. 2004, 5, 42.

15. Can, R. Are thalamocortical rhythms the rosetta stone of a subset of neurological disorders? Nat. Med. 1999, 5, 1349.

16. Jeanmonod, D.; Schulman, J.; Ramirez, R.; Cancro, R.; Lanz, M.; Morel, A.; Magnin, M.; Siegemund, M.; Kronberg, E.; Ribary, U.; et al. Neuropsychiatric thalamocortical dysrhythmia: Surgical implications. Thalamus Relat. Syst. 2003, 2, 103-113.

17. Kübler, A.; Neumann, N.; Kaiser, J.; Kotchoubey, B.; Hinterberger, T.; Birbaumer, N. Brain-computer communication: Self-regulation of slow cortical potentials for verbal communication. Arch. Phys. Med. Rehab. 2001, 82, 1533-1539.

18. Kübler, A.; Kotchoubey, B.; Hinterberger, T.; Ghanayim, N.; Perelmouter, J.; Schauer, M.; Fritsch, C.; Taub, E.; Birbaumer, N. The thought translation device: A neurophysiological approach to communication in total motor paralysis. Exp. Brain Res. 1999, 124, 223-232.

19. Kim, D.Y.; Camilleri, M. Serotonin: A mediator of the brain-gut connection. Am. J. Gastroenterol. 2000, 95, 2698-2709.

20. Damasio, A. The Feeling of What Happens: Body and Emotion in the Making of Consciousness; Harcourt: New York, NY, USA, 1999.

21. Tang, Y.; Ma, Y.; Fan, Y.; Feng, H.; Wang, J.; Feng, S.; Lu, Q.; Hu, B.; Lin, Y.; Li, J. Central and autonomic nervous system interaction is altered by short-term meditation. P. Natl. Acad. Sci. 2009, 106, 8865-8870.

22. Heitkemper, M.; Burr, R.L.; Jarrett, M.; Hertig, V.; Lustyk, M.K.; Bond, E.F. Evidence for autonomic nervous system imbalance in women with irritable bowel syndrome. Digest. Dis. Sci. 1998, 43, 2093-2098.

23. Petzke, F.; Clauw, D.J. Sympathetic nervous system function in fibromyalgia. Curr. Rheumatol. Rep. 2000, 2, 116-123.

24. Martinez-Lavin, M. The autonomic nervous system and fibromyalgia. J. Musculoskel. Pain 2002, 10, 221-228.

25. Hiramoto, R.N.; Rogers, C.F.; Demissie, S.; Hsueh, C.-M.; Hiramoto, N.S.; Lorden, J.F.; Ghanta, V.K. Psychoneuroendocrine immunology: Site of recognition, learning and memory in the immune system and the brain. Int. J. Neurosci. 1997, 92, 259-286.

26. Kiecolt-Glaser, J.K.; McGuire, L.; Robles, T.F.; Glaser, R. Emotions, morbidity, and mortality: New perspectives fro psychoneuroimmunology. Ann. Rev. Psychol. 2002, 53, 83-107.

27. Ray, O. How the mind hurts and heals the body. Am. Psychol. 2004, 59, 29-40.

28. Mössner, R.; Mikova, O.; Koutsilieri, E.; Saoud, M.; Ehlis, A.C.; MÃ¹/4ller, N.; Fallgatter, A.J.; Riederer, P. Consensus paper of the wfsbp task force on biological markers: Biological markers in depression. World J. Biol. Psychiatry 2007, 8, 141-174.

29. Schins, A.; Dorien, T.; Richel, L.; Gunter, K.; Delanghe, J.; Crijns, H.; Grauls, G.; Stassen, F.; Maes, M.; Honig, A. Inflammatory markers in depressed post-myocardial infarction patients. J. Psychiatr. Res. 2005, 39, 137-144. 
30. Römer, H.; Walach, H. Complementarity of phenomenal and physiological observables: A primer on generalized quantum theory and its scope for neuroscience and consciousness studies. In Neuroscience, Consciousness and Spirituality; Walach, H., Schmidt, S., Jonas, W., Eds.; Springer: Dordrecht, The Netherlands, 2011; pp 97-107.

31. Walach, H.; Römer, H. Generalized entanglement-A nonreductive option for a phenomenologically dualist and ontologically monist view of consciousness. In Neuroscience, Consciousness and Spirituality; Walach, H., Schmidt, S., Jonas, W., Eds.; Springer: Dordrecht, The Netherlands, 2011; pp. 81-95.

32. Giordano, J.; Kohls, N. Spirituality, suffering, and the self. Mind Matter 2008, 6, 179-191.

33. Bendelow, G.; Williams, S. Pain and the mind-body dualism: A sociological approach. Body Soc. 1995, 1, 83-103.

34. Llinás, R.; Ribary, U.; Jeanmonod, D.; Cancro, R.; Kronberg, E.; Schulman, J.; Zonenshayn, M.; Magnin, M.; Morel, A.; Siegmund, M. Thalamocortical dysrythmia i. Functional and imaging aspects. Thalamus Relat. Syst. 2001, 1, 237-244.

35. Llinás, R.; Ribary, U.; Jeanmonod, D.; Kronberg, E.; Mitra, P.P. Thalamocortical dysrhythmia: A neurological and neuropsychiatric syndrome characgterized by magnetoencephalography. Proc. Natl. Acad. Sci. USA 1999, 96, 15222-15227.

36. Nagel, T. What is it like to be a bat? Philos. Rev. 1974, 83, 435-450.

37. Chalmers, D.J. The Conscious Mind. In Search of a Fundamental Theory; Oxford University Press: New York, NY, USA, 1996.

38. Hoche, H. Anthropological Complementarism: Linguistic, Logical, and Phenomenological Studies in Support of a Third Way beyond Dualism and Monism; Mentis: Paderborn, Germany, 2008.

39. Fahrenberg, J.; Cheetham, M. The mind-body problem as seen by students of different disciplines. J. Conscious. Stud. 2000, 7, 47-59.

40. McGinn, C. Can we solve the mind-body problem? Mind 1989, 98, 349-366.

41. Richardson, R.C. The "Scandal" Of cartesian interactionism. Mind 1982, 91, 20-37.

42. Beck, F.; Eccles, J.C. Quantum aspects of brain activity and the role of consciousness. Proc. Natl. Acad. Sci. USA 1992, 89, 111357-111361.

43. Pereira, A. The quantum mind/classical brain problem. NeuroQuantology 2003, 1, 94-118.

44. Hameroff, S.; Penrose, R. Conscious events as orchestrated space-time selections. NeuroQuantology 2003, 1, 10-35.

45. Hameroff, S.; Penrose, R. Conscious events as orchestrated space-time selections. J. Conscious. Stud. 1996, 2, 36-53.

46. Schwartz, J.; Stapp, H.; Beauregard, M. Quantum physics in neuroscience and psychology: A neurophysical model of mindâ€"brain interaction. Philos. Trans. R. Soc. Lond. B Biol. Sci. 2005, 360, 1309-1327.

47. Greyson, B. Dissociation in people who have near-death experiences: Out of their bodies or out of their minds? Lancet 2000, 355, 460-463.

48. Greyson, B. Incidence and correlates of near-death experiences in a cardiac care unit. Gen. Hosp. Psychiatry 2003, 25, 269-276. 
49. Van Lommel, P. About the continuity of consciousness. Adv. Exp. Med. Biol. 2004, 550, $115-132$.

50. Atmanspacher, H.; Filk, T.; Römer, H. Quantum zeno features of bistable perception. Biol. Cybern. 2004, 90, 33-40.

51. Atmanspacher, H.; Primas, H. Epistemic and ontic quantum realities. In Time, Quantum, and Information; Castell, L., Ischebeck, O., Eds.; Springer: Berlin, Germany, 2003; pp. 301-321.

52. Hagan, S.; Hameroff, S.R.; Tuszynski, J.A. Quantum computation in brain microtubules: Decoherence and biological feasibility. Phys. Rev. E 2002, 65, 61901-61911.

53. Penrose, R. Mechanism, microtubules and the mind. J. Conscious. Stud. 1994, 1, 241-249.

54. Beck, F. Quantum mechanics and consciousness. J. Conscious. Stud. 1994, 1, 253-255.

55. Grossberg, S. The complementary brain: Unifying brain dynamics and modularity. Trends Cognit. Sci. 2000, 4, 233-245.

56. Feigl, H. Some crucial issues of mind-body monism. Synthese 1971, 22, 295-312.

57. Feigl, H. The "Mental" And the "Physical". In Minnesota Studies in the Philosophy of Science; Feigl, H., Scriven, M., Maxwell, G., Eds.; Minnesota University Press: Minneaopolis, MN, USA, 1958; Volume 2, pp. 370-497.

58. Shamdasani, S. Jung and the Making of Modern Psychology: The Dream of a Science; Cambridge University Press: Cambridge, UK, 2003.

59. Bohr, N. Causality and Complementarity: Essays 1958-1962 on Atomic Physics and Human Knowledge; Vintage: New York, NY, USA, 1966.

60. Fahrenberg, J. Komplementarität in der psychophysiologischen forschung. Grundsätze und forschungspraxis. In Widersprüchliche wirklichkeit. Neues denken in wissenschaft und alltag: Komplementarität und dialogic; Fischer, E.P., Herzka, H.S., Reich, K.H., Eds.; Piper: München, Germany, 1992; pp. 43-77.

61. Walach, H.; Römer, H. Complementarity is a useful concept for consciousness studies. A reminder. Neuro Endocrinol. Lett. 2000, 21, 221-232.

62. Atmanspacher, H. Mind and matter as asymptotically disjoint, inequivalent representations with broken time-reversal symmetry. Biosystems 2003, 68, 19-30.

63. Kohls, N.; Hack, A.; Walach, H. Measuring the unmeasurable by ticking boxes and actually opening pandoras box? Mixed methods research as a useful tool for thinking out of the box while investigating exceptional human experiences Arch. Psych. Relig. 2008, 30, 155-187.

64. Kohls, N.; Walach, H. Exceptional experiences and spiritual practice-A new measurement approach. Spirit Health Int. 2006, 7, 125-150.

65. Kohls, N.; Walach, H.; Lewith, G. The impact of positive and negative spiritual experiences on distress and the moderating role of mindfulness. Arch. Psych. Relig. 2009, 31, 1-18.

66. Pöppel, E. Complementarity as a generative principle in visual perception. Vis. Cogn. 2005, 12, 665-670.

67. Crabtree, A. Animal Magnetism, Early Hypnotism, and Psychical Research 1766-1925. An Annotated Biography; Kraus International Publishers: White Plains, NY, USA, 1988.

68. Crabtree, A. From Mesmer to Freud: Magnetic Sleep and the Roots of Psychological Healing; Yale University Press: New Haven, CT, USA, 1993. 
69. Florey, E. Ars magnetica. Franz anton mesmer 1734-1815: Magier vom Bodensee; Universitätsverlag Konstanz: Konstanz, Germany, 1995.

70. Ellenberger, H.F. The Discovery of the Unconscious. The History and Evolution of Dynamic Psychiatry; Basic Books: New York, NY, USA, 1970.

71. Makari, G. Revolution in Mind: The Creation of Psycho-Analysis; Harper Perennial: New York, NY, USA, 2009.

72. Tinterow, M. Foundations of Hypnosis: From Mesmer to Freud; Charles C. Thomas: Springfield, IL, USA, 1970.

73. Kohls, N.; Sommer, A. Die akademische psychologie am scheideweg: Positivistische experimentalpsychologie und die nemesis der transzendenz. In Spiritualität, krankheit und heilung-bedeutung und ausdrucksformen der spiritualität in der medizin-Perspektiven, schriften zur pluralität in der medizin und komplementärmedizin; Büssing, A., Ostermann, T., Glöckler, M., Matthiessen, P., Eds.; Verlag für akademische Schriften: Frankfurt, Germany, 2006.

74. Carlson, J.; Maniacci, M. Alfred adler revisited; Routledge: London, UK, 2011.

75. Danzer, G. Body, mind, and psychosomatic medicine. In Embodiment in Cognition and Culture (Advances in Consciousness Research); Krois, M., Rosengren, M., Steidele, A., Westerkamp, D., Eds.; John Benjamins Publishing Co: Amsterdam, The Netherlands, 2007; Volume 71, pp. 185-194.

76. Drack, M.; Wolkenhauer, O. System approaches of weiss and bertalanffy and their relevance for systems biology today. Semin. Cancer Biol. 2011, 21, 150-155.

77. Davidson, M. Uncommon Sense: The Life and Thought of Ludwig von Bertalanffy (1901-1972), Father of General Systems Theory; Tarcher: Los Angeles, CA, 1983.

78. Szent-Gyoergyi, A. Drive in living matter to perfect itself. Synthesis 1974, 12-24.

79. Engel, G.L. The need for a new medical model: A challenge for biomedicine. Science 1977, 196, 129.

80. Engel, G.L. The biopsychosocial model and medical education. N. Engl. J. Med. 1982, 306/13, 802-805.

81. Meyer-Abich, K.M. Wie ganzheitlich ist die gesundheit? Von hippokrates und platon bis zu einer kuenftigen sozio-psychosomatischen situationstherapie. Forsch Komplementarmed Klass Naturheilkd 2003, 10, 35-39.

82. Ader, R.; Cohen, N. Behaviorally conditioned immunosuppression. Psychosom. Med. 1975, 37, 333-340.

83. Ader, R. Behavioral conditioning and immunity. In Immunoregulation; Fabris, N., Garaci, E., Hadden, J., Mitchison, N.A., Eds.; Plenum Press: New York, NY, USA, 1983; pp. 283-313.

84. Ader, R.; Cohen, N. The influence of conditioning on immune responses. In Psychoneuroimmunology, 2nd ed.; Ader, R., Felten, D.L., Cohen, N., Eds.; Academic Press: San Diego, CA, USA, 1991; pp. 611-646.

85. Ader, R. Conditioned immunomodulation: Research needs and directions. Brain Behav. Immun. 2003, 17, 51-57. 
86. Van Stegeren, A.; Wolf, O.; Everaerd, W.; Scheltens, P.; Barkhof, F.; Rombouts, S. Endogenous cortisol level interacts with noradrenergic activation in the human amygdala. Neurobiol. Learn. Mem. 2007, 87, 57-66.

87. Blalock, J.E. The syntax of immune-neuroendocrine communication. Immunol. Today 1994, $15,504-511$.

88. Van Praag, H.M.; de Kloet, R.; van Os, J. Stress, the Brain and Depression; Cambridge University Press: Cambridge, UK, 2004.

89. Hellhammer, D.; Hellhammer, J. Stress: The Brain-Body Connection; Karger: Basel, Switzerland, 2008; Volume 174, 1-108.

90. Padgett, D.; Glaser, R. How stress influences the immune response. Trends Immunol. 2003, 24, 444-448.

91. Pollard, T.M. Adrenaline. In Encyclopedia of Stress; Fink, G., Ed.; Academic Press: San Diego, CA, USA, 2000; Volume 1, pp. 52-58.

92. LaBar, K.; Gatenby, J.; Gore, J.; LeDoux; Phelps, E. Human amygdala activation during conditioned fear acquisition and extinction: A mixed-trial fmri study. Neuron 1998, 20, 937-945.

93. Breiter, H.; Etcoff, N.; Whalen, P.; Kennedy, W.; Rauch, S.; Buckner, R.; Strauss, M.; Hyman, S.; Rosen, B. Response and habituation of the human amygdala during visual processing of facial expression. Neuron 1996, 17, 875-887.

94. Heinrichs, S.C.; Koob, G.F. Corticotropin-releasing factor in brain: A role in activation, arousal, and affect regulation. J. Pharmacol. Exp. Ther. 2004, 311, 427-440.

95. Eriksen, H.R.; Olff, M.; Murison, R.; Ursin, H. The time dimension in stress responses: Relevance for survival and health. Psychiatry Res. 1999, 85, 39-50.

96. Esch, T.; Stefano, G. The neurobiology of stress management. Neuro Endocrinol. Lett. 2010, 31, 19-39.

97. McEwen, B.S. Protective and damaging effects of stress mediators. N. Engl. J. Med. 1998, $338,171-179$.

98. Lazarus, R.S.; Folkman, S. Stress, Appraisal, and Coping; Springer: New York, NY, USA, 1984.

99. Melamed, S.; Ugarten, U.; Shirom, A.; Kahana, L.; Lerman, Y.; Froom, P. Chronic burnout, somatic arousal and elevated salivary cortisol levels. J. Psychosom. Res. 1999, 46, 591-598.

100. Glaser, R.; Rice, J.; Sheridan, J.; Fertel, R.; Stout, J.; Speicher, C.; Pinsky, D.; Kotur, M.; Post, A.; Beck, M.; et al. Stress-realted immune suppression: Health implications. Brain Behav. Immun. 1987, 1, 7-20.

101. Glaser, R.; Rabin, B.; Chesney, M.; Cohen, S.; Natelson, B. Stress-induced immunomodulation. JAMA 1999, 281, 2268-2270.

102. Irie, M.; Miyata, M.; Kasai, H. Depression and possible cancer risk due to oxidative DNA damage. J. Psychiatr. Res. 2005, 39, 553-560.

103. O'Leary, A.; Brown, S.; Suarez-Al-Adam, M. Stress and immune funtion. In Clinical Disorders and Stressful Life; Miller, T.W., Ed.; International Universities Press: Madison, CT, USA, 1997; pp. 181-215.

104. McEwen, B.S. Stress and hippocampal plasticity. Annu. Rev. Neurosci. 1999, 22, 105-122. 
105. Heim, C.; Ehlert, U.; Hellhammer, D. The potential role of hypocortisolism in the pathophysiology of stress-related bodily disorders. Psychoneuroendocrinology 2000, 25, 1-35.

106. Raison, C.L.; Miller, A.H. When not enough is too much: The role of insufficient glucocorticoid signaling in the pathophysiology of stress-related disorders. Am. J. Psychiatry 2003, 160, 1554-1565.

107. Fries, E.; Hesse, J.; Hellhammer, J.; Hellhammer, D.H. A new view on hypocortisolism. Psychoneuroendocrinology 2005, 30, 1010-1016.

108. Meissner, K.; Kohls, N.; Colloca, L. Introduction to placebo effects in medicine: Mechanisms and clinical implications. Philos. Trans. R. Soc. Lond. B Biol. Sci. 2011, 366, 1783-1789.

109. Benson, H. The relaxation response: Its subjective and objective historical precedents and physiology. Trends Neurosci. 1983, 6, 281-284.

110. Benson, H.; Greenwood, M.M.; Klemchuk, H. The relaxation response: Psychophysiologic aspects and clinical applications. Int. J. Psychiatry Med. 1975, 6, 87-98.

111. Aldwin, C.M. Stress, Coping, and Development: An Integrative Perspective; The Guilford Press: New York, NY, USA, 2007.

112. Grossman, P.; Taylor, E. Toward understanding respiratory sinus arrhythmia: Relations to cardiac vagal tone, evolution and biobehavioral functions. Biol. Psychol. 2007, 74, 263-285.

113. Stefano, G.B.; Fricchione, G.L.; Esch, T. Relaxation: Molecular and physiological significance. Med. Sci. Monit. 2006, 12, HY21-HY31.

114. Esch, T. Stress, anpassung und selbstorganisation: Gleichgewichtsprozesse sichern gesundheit und überleben. Forsch Komplementarmed Klass Naturheilkd 2003, 10, 330-341.

115. Tang, Y.; Ma, Y.; Wang, J.; Fan, Y.; Feng, S.; Lu, Q.; Yu, Q.; Sui, D.; Rothbart, M.; Fan, M. Short-term meditation training improves attention and self-regulation. Proc. Natl. Acad. Sci. USA 2007, 104, 17152-17156.

116. Tang, Y.; Posner, M. Attention training and attention state training. Trends Cogn. Sci. 2009, $13,222-227$.

117. Giordano, J. Chronic pain and spirituality. Prac. Pain Manage. 2007, 7, 64-68.

118. Giordano, J. Complementarity, brain/mind, and pain. Forsch Komplementmed 2008, 15, 2-6.

119. Demitrack, M.; Crofford, L. Evidence for and pathophysiologic implications of hypothalamic-pituitary-adrenal axis dysregulation in fibromyalgia and chronic fatigue syndrome. Ann. N. Y. Acad. Sci. 1998, 840, 684-697.

120. Kumar, M. Epidemiology, pathophysiology and symptomatic treatment of sciatica: A review. Int. J. Pharm. Bio. Arch. 2011, 2.

121. Chambers, D.; Bagnall, A.; Hempel, S.; Forbes, C. Interventions for the treatment, management and rehabilitation of patients with chronic fatigue syndrome/myalgic encephalomyelitis: An updated systematic review. JRSM 2006, 99, 506-520.

122. Fries, E.; Hesse, J.; Hellhammer, J.; Hellhammer, D. A new view on hypocortisolism. Psychoneuroendocrinology 2005, 30, 1010-1016.

123. von Känel, R.; Mills, P.; Fainman, C.; Dimsdale, J. Effects of psychological stress and psychiatric disorders on blood coagulation and fibrinolysis: A biobehavioral pathway to coronary artery disease? Psychosom. Med. 2001, 63, 531-544. 
124. Schwartz, J. A role for volition and attention in the generation of new brain circuitry. Toward a neurobiology of mental force. J. Conscious. Stud. 6 1999, 8, 115-142.

125. Le Moal, M.; Koob, G. Drug addiction: Pathways to the disease and pathophysiological perspectives. Eur. Neuropsychopharmacol. 2007, 17, 377-393.

126. Li, C.R.; Sinha, R. Inhibitory control and emotional stress regulation: Neuroimaging evidence for frontal-limbic dysfunction in psycho-stimulant addiction. Neurosci. Biobehav. Rev. 2008, 32, 581-597.

127. Alexander, F.M. The Use of the Self; Methuen \& Co. Ltd.: London, UK, 1932.

128. Ernst, E.; Canter, P.H. The alexander technique: A systematic review of controlled trials. Forsch Komplementarmed Klass Naturheilkd 2003, 10, 325-329.

129. Dennis, J. Alexander technique for chronic asthma. Cochrane Database Syst. Rev. 2000, CD000995.

130. Schulte, D.; Walach, H.F.M. Alexander technique in the treatment of stuttering-A randomized single-case intervention study with ambulatory monitoring. Psychother. Psychosom. 2006, 75, 190-191.

131. Hollinghurst, S.; Sharp, D.; Ballard, K.; Barnett, J.; Beattie, A.; Evans, M.; Lewith, G.; Middleton, K.; Oxford, F.; Webley, F. Randomised controlled trial of alexander technique lessons, exercise, and massage (ateam) for chronic and recurrent back pain: Economic evaluation. Br. Med. J. 2008, 337.

132. Little, P.; Lewith, G.; Webley, F.; Evans, M.; Beattie, A.; Middleton; Barnett, J.; Ballard, K.; Oxford, F.; Smith, P.; et al. Randomised controlled trial of alexander technique lessons, exercise, and massage (ateam) for chronic and recurrent back pain. Br. J. Sports Med. 2008, 42, 965-968.

133. Han, A.; Judd, M.G.; Robinson, V.A.; Taixiang, W.; Tugwell, P.; Wells, G. Tai chi for treating rheumatoid arthritis. Cochrane Database Syst. Rev. 2004, Issue 3, Art. No. CD004849.

134. Wayne, P.M.; Kiel, D.P.; Krebs, D.E.; Davis, R.B.; J., S.-G.; Connelly, M.; Buring, J.E. The effects of tai chi on bone mineral density in postmenopausal women: A systematic review. Arch. Phys. Med. Rehabil. 2007, 88, 673-680.

135. Zijlstra, G.A.; van Haastregt, J.C.; van Rossum, E.; van Eijk, J.T.; Yardley, L.; Kempen, G.I. Interventions to reduce fear of falling in community-living older people: A systematic review. J. Am. Soc. Geriatr. 2007, 55, 603-615.

136. Arthur, H.M.; Patterson, C.; Stone, J.A. The role of complementary and alternative therapies in cardiac rehabilitation: A systematic evaluation. Eur. J. Cardiovasc. Prev. Rehabil. 2006, $13,3-9$.

137. Mansky, P.; Sannes, T.; Wallerstedt, D.; Ge, A.; Ryan, M.; Johnson, L.L.; Chesney, M.; Gerber, L. Tai chi chuan: Mind-body practice or exercise intervention? Studying the benefit for cancer survivors. Integr. Cancer Ther. 2006, 5, 192-201.

138. Wang, C.; Collet, J.P.; Lau, J. The effect of tai chi on health outcomes in patients with chronic conditions: A systematic review. Arch. Intern. Med. 2004, 164, 493. 
139. Wang, C.; Bannuru, R.; Ramel, J.; Kupelnick, B.; Scott, T.; Schmid, C. Tai chi on psychological well-being: Systematic review and meta-analysis. BMC Complement Altern. Med. 2010, 10, 23.

140. Leung, D.; Chan, C.; Tsang, H.; Tsang, W.; Jones, A. Tai chi as an intervention to improve balance and reduce falls in older adults: A systematic and meta-analytical review. Altern. Ther. Health Med. 2011, 17, 40.

141. Wang, C.; Schmid, C.; Rones, R.; Kalish, R.; Yinh, J.; Goldenberg, D.; Lee, Y.; McAlindon, T. A randomized trial of tai chi for fibromyalgia. N. Engl. J. Med. 2010, 363, 743-754.

142. Haslock, I.; Monro, R.; Nagarathna, R.; Nagendra, H.R.; Raghuram, N. Measuring the effects of yoga in rheumatoid arthritis. Br. J. Rheumatol. 1994, 33, 787-788.

143. Harinath, K.; Malhotra; Pal, K.; Prasad, R.; Kumar, R.; Kain, T.C.; Rai, L.; Sawhney, R.C. Effects of hatha yoga and omkar meditation on cardiorespiratory performance, psychologic profile, and melatonin secretion. JACM 2004, 10, 261-268.

144. Monro, R.E.; Ghosh, A.K.; Kalish, D. Yoga Research Bibliography; Yoga Ciomedical Trust: Cambridge, UK, 1989.

145. Krisanaprakornkit, T.; Krisanaprakornkit, W.; Piyavhatkul, N.; Laobaiboon, M. Meditation therapy for anxiety disorders. Cochrane Database Syst. Rev. 2006, CD004998.

146. Ramaratnam, S.; Sridharan, K. Yoga for epilepsy. Cochrane Database Syst. Rev. 2002, CD001524.

147. Shannahoff-Khalsa, D.S. Kundalini yoga meditation techniques for the treatment of obsessive compulsive and oc spectrum disorders. Brief Treat. Crisis Interv. 2003, 3, 369-382.

148. Aftanas, L.I.; Golocheikine, S.A. Human anterior and frontal midline theta and lower alpha reflect emotionally positive state and internalized attention: High-resolution eeg investigation of meditation. Neurosci. Lett. 2001, 310, 57-60.

149. Aftanas, L.I.; Golocheikine, S.A. Non-linear dynamic complexity of the human eeg during meditation. Neurosci. Lett. 2002, 330, 143-146.

150. Aftanas, L.I.; Golosheykin, S. Impact of regular meditation practice on eeg activity at rest and during evoked negative emotions. Int. J. Neurosci. 2005, 115, 433-443.

151. Lehmann, D.; Faber, P.L.; Achermann, P.; Jeanmonod, D.; Gianotti, L.R.R.; Pizzagalli, D. Brain sources of eeg gamma frequency during volitionally meditation-induced, altered states of consciousness, and experience of the self. Psychiatry Res. 2001, 108, 111-121.

152. Lehmann, D.; Faber, P.L.; Gianotti, L.R.R.; Kochi, K.; Pascual-Marqui, R.D. Coherence and phase locking in the scalp eeg and between loreta model sources, and microstrates as putative mechanisms of brain temporo-spatial functional organization. J. Physiol. Paris 2006, 99, 29-36.

153. Innes, K.E.; Bourguignon, C.; Taylor, A.G. Risk indices associated with the insulin resistance syndrome, cardiovascular disease, and possible protection with yoga: A systematic review. J. Am. Board Fam. Med. 2005, 18, 491-519.

154. Arias, A.J.; Steinberg, K.; Banga, A.; Trestman, R.L. Systematic review of the efficacy of meditation techniques as treatments for medical illness. JACM 2006, 12, 817-832.

155. Ross, A.; Thomas, S. The health benefits of yoga and exercise: A review of comparison studies. JACM 2010, 16, 3-12. 
156. Sherman, K.; Cherkin, D.; Erro, J.; Miglioretti, D.; Deyo, R. Comparing yoga, exercise, and a self-care book for chronic low back pain. Ann. Intern. Med. 2005, 143, 849-856.

157. Sherman, K.; Cherkin, D.; Wellman, R.; Cook, A.; Hawkes, R.; Delaney, K.; Deyo, R.A. A randomized trial comparing yoga, stretching, and a self-care book for chronic low back pain. Arch. Intern. Med. 2011, 171, 2019-2026.

158. Tilbrook, H.; Cox, H.; Hewitt, C.; Kang'ombe, A.; Chuang, L.; Jayakody, S.; Aplin, J.; Semlyen, A.; Trewhela, A.; Watt, I. Yoga for chronic low back pain. Ann. Intern. Med. 2011, $155,569-578$.

159. Alexander, C.N.; Rainforth, M.V.; Gelderloos, P. Transcendental meditation, self-actualization, and psychological health: A conceptual overview and statistical meta-analysis. J. Soc. Behav. Pers. 1991, 6, 189-247.

160. Yunesian, M.; Aslani, A.; Vash, J.; Yazdi, A. Effects of transcendental meditation on mental health: A before-after study. Clin. Pract. Epidemiol. Ment. Health 2008, 4, 25.

161. MacLean, C.; Walton; Wenneberg, S.; Levitsky, D.; Mandarino, J.; Waziri, R.; Hillis, S.L.; Schneider, R. Effects of the transcendental meditation program on adaptive mechanisms: Changes in hormone levels and responses to stress after 4 months of practice. Psychoneuroendocrinology 1997, 22, 277-295.

162. Canter, P.H.; Ernst, E. Insufficient evidence to conclude whether or not transcendental meditation decreases blood pressure: Results of a systematic review of randomized clinical trials. J. Hypertens. 2004, 22, 2049-2054.

163. Alexander, C.N.; Robinson, P.; Orme-Johnson, D.; Schneider, R.H.; Walton, K.G. The effects of transcendental meditation compared to other methods of relaxation and meditation in reducing risk factors, morbidity, and mortality. Homeostasis 1994, 35, 243-263.

164. Orme-Johnson, D.W. Medical care utilization and the transcendental meditation program. Psychosom. Med. 1987, 49, 493-507.

165. Alexander, C.N.; Walton, K.G.; Orme-Johnson, D.; Goodman, R.S.; Pallone, N.J. Transcendental Meditation in Criminal Rehabilitation and Crime Prevention; Haworth Press: New York, NY, USA, 2003.

166. Dillbeck, M.C.; Banus, C.B.; Polanzi, C.; Landrith, G.S. Test of a field model of consciousness and social change: The transcendental meditation and tm-sidhi program and decreased urban crime. J. Mind Behav. 1988, 9, 457-486.

167. Orme-Johnson, D.W.; Barnes, V.A.; Hankey, A.M.; Chalmers, R.A. Reply to critics of reearch on transcendental meditation in the prevention and control of hypertension. J. Hypertens. 2005, 23, 1107-1110.

168. Schneider, R.H.; Alexander, D.N.; Wallace, R.K. In search of an optimal behavioral treatment for hypertension: A review and focus on transcendental meditation. In Personality, elevated blood pressure, and essential hypertension, Johnson, E.H.; Gentry, W.D.; Julius, S., Eds.; Hemisphere: Washington, DC, USA, 1992; pp. 291-312.

169. Calderon, R., Jr.; Schneider, R.H.; Alexander, C.N.; Myers, H.F.; Nidich, S.I.; Haney, C. Stress, stress reduction and hypercholesterolemia in african americans: A review. Ethn. Dis. 1999, 9, 451-462. 
170. Alexander, C.N.; Schneider, R.H.; Staggers, F.; Sheppard, W.; Clayborne, B.M.; Rainforth, M.; Salerno, J.; Kondwani, K.; Smith, S.; Walton, K.G.; et al. Trial of stress reduction for hypertension in older african americans. Ii. Sex and risk subgroup analysis. Hypertension 1996, 28, 228-237.

171. Alexander, C.N.; Langer, E.J.; Newman, R.I.; Chandler, H.M.; Davies, J.L. Transcendental meditation, mindfulness, and longevity: An experimental study with the elderly. J. Pers. Soc. Psychol. 1989, 57, 950-964.

172. Barnes, V.A.; Johnson, M.H.; Treiber, F.A. Impact of stress reduction on ambulatory blood pressure in african-american adolescents. Ethn. Dis. 2003, 13, S2-S173.

173. Barnes, V.A.; Treiber, F.A.; Davis, H. Impact of transcendental meditation on cardiovascular function at rest and during acute stress in adolescents with high normal blood pressure. J. Psychosom. Res. 2001, 51, 597-605.

174. Castillo-Richmond, A.; Schneider, R.H.; Alexander, C.N.; Cook, R.; Myers, H.; Nidich, S.; Haney, C.; Rainforth, M.; Salerno, J. Effects of stress reduction on carotid atherosclerosis in hypertensive african americans. Stroke 2000, 31, 568-573.

175. Schneider, R.H.; Alexander, C.N.; Staggers, F.; Orme-Johnson, D.W.; Rainforth, M.; Salerno, J.W.; Sheppard, W.; Castillo-Richmond, A.; Barnes, V.A.; Nidich, S.I. A randomized controlled trial of stress reduction in african americans treated for hypertension for over one year. Am. J. Hypertens. 2005, 18, 88-98.

176. Walton, K.G.; Schneider, R.H.; Nidich, S. Review of controlled research on the transcendental meditation program and cardiovascular disease. Risk factors, morbidity, and mortality. Cardiol. Rev. 2004, 12, 262-266.

177. Walton, K.G.; Schneider, R.H.; Nidich, S.I.; Salerno, J.W.; Nordstrom, C.K.; Bairey Merz, C.N. Psychosocial stress and cardiovascular disease part 2: Effectiveness of the transcendental meditation program in treatment and prevention. Behav. Med. 2002, 28, 106-123.

178. Schneider, R.H.; Walton, K.G.; Salerno, J.W.; Nidich, S.I. Cardiovascular disease prevention and health promotion with the transcendental meditation program and maharishi consciousness-based health care. Ethn. Dis. 2006, 16, S4-15-26.

179. Anderson, J.; Liu, C.; Kryscio, R. Blood pressure response to transcendental meditation: A meta-analysis. Am. J. Hypertens 2008, 21, 310-316.

180. Kutz, I.; Borysenko, J.; Benson, H. Meditation and psychotherapy: A rationale for the integration of dynamic psychotherapy, the relaxation response, and mindfulness meditation. Am. J. Psychiatry 1985, 142, 1-8.

181. Garvin, A.W.; Trine, M.R.; Morgan, W.P. Affective and metabolic responses to hypnosis, autogenic relaxation, and quiet rest in the supine and seated positions. Int. J. Clin. Exp. Hypn. 2001, 49, 5-18.

182. Jorgensen, M. Autonomic and psychological responses to an acute psychological stressor and relaxation: The influence of hypnotizability and absorption. Int. J. Clin. Exp. Hypn. 2000, 48, 388-403.

183. Keefer, L.; Blanchard, E.B. The effects of relaxation response meditation on the symptoms of irritable bowel syndrome: Results of a controlled treatment study. Behav. Res. Ther. 2001, 39, $801-811$. 
184. Peters, R.K.; Benson, H.; Peters, J.M. Daily relaxation response breaks in a workig population. Ii. Effects on bloodpressure. Am. J. Public Health 1977, 67, 954-959.

185. Peters, R.K.; Benson, H.; Porter, D. Daily relaxation response breaks in a working population. I. Effects on self-reported measures of health, perfomrance and well-being. Am. J. Public Health 1977, 67, 946-953.

186. Mandle, C.L.; Jacobs, S.C.; Arcari, P.M.; Domar, A.D. The efficacy of relaxation response interventions with adult patients: A review of the literature. J. Cardiovasc Nurs. 1996, 10, 4-26.

187. Manzoni, G.; Pagnini, F.; Castelnuovo, G.; Molinari, E. Relaxation training for anxiety: A ten-years systematic review with meta-analysis. BMC Psychiatry 2008, 8, 41.

188. Sauer, S.; Lynch, S.; Walach, H.; Kohls, N. Dialectics of mindfulness: Implications for western medicine. Philos. Ethics Humanit. Med. 2011, 6, 10.

189. Kohls, N.; Sauer, S.; Walach, H. Facets of mindfulness-results of an online study investigating the freiburg mindfulness inventory. Pers. Individ. Dif. 46 2009, 46, 224-230.

190. Segal, Z.V.; Williams, J.M.G.; Teasdale, J.D. Mindfulness-Based Cognitive Therapy for Depression: A New Approach to Preventive Relapse; Guilford Press: New York, NY, USA, 2002.

191. Linehan, M.M. Cognitive Behavioral Treatment of Borderline Personality Disorder; Guilford Press: New York, NY, USA, 1993.

192. Baer, R.A. Mindfulness training as a clinical intervention: A conceptual and empirical review. Clin. Psychol. 2003, 10, 125-143.

193. Grossman, P.; Schmidt, S.; Niemann, L.; Walach, H. Mindfulness based stress reduction and health: A meta-analysis. J. Psychosom. Res. 2004, 37, 35-43.

194. Bohlmeijer, E.; Prenger, R.; Taal, E.; Cuijpers, P. The effects of mindfulness-based stress reduction therapy on mental health of adults with a chronic medical disease: A meta-analysis. J. Psychosom. Res. 2009, 68, 539-544.

195. Teasdale, J.D.; Segal, Z.V.; Williams, J.M.G.; Ridgeway, V.A.; Soulsby, J.M.; Lau, M.A. Prevention of relapse/recurrence in major depression by mindfulness-based cognitive therapy. J. Consult. Clin. Psychol. 2000, 68, 615-623.

196. Fjorback, L.; Walach, H. Meditation based therapies: A systematic review and some critical observations. Religions 2012, 3, 1-18.

197. Keng, S.; Smoski, M.; Robins, C. Effects of mindfulness on psychological health: A review of empirical studies. Clin. Psychol. Rev. 2011, 31, 1041-1056.

198. Toneatto, T.; Nguyen, L. Does mindfulness meditation improve anxiety and mood symptoms? A review of the controlled research. Can. J. Psychiatry 2007, 52, 260-266.

199. Grossman, P.; Tiefenthaler-Gilmer, U.; Raysz, A.; Kesper, U. Mindfulness training as an intervention for fibromyalgia: Evidence of postintervention and 3-year follow-up benefits in well-being. Psychother. Psychosom 2007, 76, 226-233.

200. Schmidt, S.; Grossman, P.; Schwarzer, B.; Jena, S.; Naumann, J.; Walach, H. Treating fibromyalgia with mindfulness-based stress reduction: Results from a 3-armed randomized controlled trial. Pain 2010, 152, 361-369. 
201. Kohls, N.; Sauer, S.; Offenbächer, M.; Giordano, J. Spirituality: An overlooked predictor of placebo effects? Philos. Trans. R. Soc. Lond. B Biol. Sci. 2011, 366, 1838-1848.

202. Fonnebo, V.; Grimsgaard, S.; Walach, H.; Ritenbaugh, C.; Norheim, A.J.; MacPherson, H.; Lewith, G.; Launso, L.; Koithan, M.; Falkenberg, T.; et al. Researching complementary and alternative treatments - the gatekeepers are not at home. BMC Med. Res. Methodol. 2007, 7.

203. Boon, H.; MacPherson, H.; Fleishman, S.; Grimsgaard, S.; Koithan, M.; Norheim, A.J.; Walach, H. Evaluating complex healthcare systems: A critique of four approaches. Evid. Based Complement Alternat. Med. 2007, 4, 279-286. 


\title{
Transpersonal Psychology: Mapping Spiritual Experience
}

\section{Dwight Judy}

\begin{abstract}
The first Journal of Transpersonal Psychology was published in 1969. Since this signal event, transpersonal psychology has emerged as a field of theory and application. A way has been made in Western psychology for the appreciation and study of interior subjective awareness, the domain of spiritual experience. One of the most recent contributions, the Wilber-Combs Lattice, offers a typology to account for both developmental processes throughout the human life span, as well as different qualities of spiritual experience.
\end{abstract}

Reprinted from Religions. Cite as: Judy, D. Transpersonal Psychology: Mapping Spiritual Experience. Religions 2011, 2, 649-658.

\section{Introduction}

In the late 1960's, as Abraham Maslow, Huston Smith, Anthony Sutich, and others surveyed psychology as practiced in America (U.S.A.), they found that there was no place for discussion of interior states of awareness, of mystical experience, or of values and their impact on human activity. They felt a need to reclaim American psychology to these tasks through the naming of a new field, transpersonal psychology, and with the establishment of the Journal of Transpersonal Psychology, which was first published in 1969.

In that era, American psychology had veered very far from its originating basis in the writings of William James, for whom the realm of subjective spiritual experience was a proper domain for psychological inquiry, and which he described in depth in The Varieties of Religious Experience (1902) [1]. The behaviorist school of psychology ruled, with its emphasis on empirically observable sensory data and with the focus on stimulus/response patterns. While great insight has come from behaviorism as it has formed the basis for empirical study within psychology, something was dramatically amiss, when the dynamics of the human psyche, with the often unpredictable turns of mystery and complexity were ignored. During my fourteen years of association with the Institute of Transpersonal Psychology, from 1980-1994, I worked with admission process of students for ten years. I frequently encountered mid-life persons reorienting their career aspirations, who said that they had wanted to study the psychology of the human spirit described by transpersonal psychology, but college psychology curriculum in the 1960's and 1970's offered only experimental research on animals. There was not a framework within psychology to study the unique characteristics of the human psyche, so they sought another area of study.

Through the efforts of transpersonal psychology and related fields, much has happened. In 1975, James Hillman's now classic, Re-Visioning Psychology [2], began to bring into more popular view, the power of the psyche to reveal itself through mythological imagery, and assisted to bring those powers articulated by Carl Jung, those powers belonging to the collective unconscious, into more 
popular view. Ken Wilber began his monumental contribution to the understanding of the human psyche in his writings in the late 1970's [3,4]. Stanislav Grof (1987) [5] described a coherent holotropic theory of non-ordinary experience. He has continued research and publishing in this area to the present [6]. Jenny Wade (1996) [7] catalogued emerging models of whole life psychospiritual development. The once enigmatic language of Carl Jung has now become a mainstay of our discourse with one another, with such terms as extroversion, introversion, animus, anima, shadow, persona, Self, forming the basis of our understanding of the human being.

The reductionism produced by a narrow empiricism affected not only psychology. It has created a morass of confusion for all of the human enterprise of the twentieth century, from which we are just beginning to emerge. By "narrow empiricism," I mean the view that the only valid information that could be scientifically studied was that information externally observable by the senses. Of course, this left out of discourse all inherently subjective experience of the human psyche. Transpersonal psychology intentionally included this internal domain of experience in its field of inquiry.

The problem of our "narrow empiricism" has been particularly evident in that arena most closely allied to psychology, namely, religion. In 1980, Jacob Needleman in his book, Lost Christianity, made a shocking indictment of Christianity. The indictment was that Christianity had lost the capacity to guide people in an inner pathway of spiritual development. What Christianity had lost, according to Needleman, was its pathway into the inner life of the individual. Jacob Needleman wrote: "We are seeking to bring back the symbolic power of the idea of the soul, to recover it as a guide to the search for ourselves, our lost selves [8]." "[We must rediscover the] intermediate [human], who alone in the cosmic scheme can care for, or harmonize, or relate all the Forces of creation [9]." In the aftermath of World War II, Carl Jung, made a similarly bold pronouncement, when he declared:

Christian civilization has proved hollow to a terrifying degree: it is all veneer, but the inner [person]

has remained untouched and therefore unchanged. It may easily happen. that a Christian who believes in all the sacred figures is still undeveloped and unchanged in [the] inmost soul because he [or she] has "all God outside" but does not experience [God] in the soul [10].

In my personal searching, I found the same sentiment spoken by Fr. Anthony Morello, a Carmelite monk from Dallas, Texas, who in 1980 taught that even within the Roman Catholic monastic orders the interior way of contemplative prayer had almost been lost within the last generation.

In the last thirty years much has happened in our cultural awareness to help us reclaim the vast reservoir of potentiality that lies within the human psyche. The renewal of contemplative and meditative spiritual practices across religious traditions, as well as the understandings of transpersonal and Jungian psychology and fields such as psychoneuroimmunology in health care, have begun this recovery. We see many signs that the Western soul has begun to be rediscovered. New and more complete models of the human soul are now being described. A new vocabulary of soul-making is emerging. The mystics of Christianity and other world religions are again being read. The power of prayer as a healing force in medicine is publicly acknowledged in certain forces within health care, such as the voices of Larry Dossey (1993) [11] and Jeanne Achterberg (1985) [12]. Many conferences in psychology and spiritual life will now ordinarily discuss themes such as 
energy therapy, dreamwork, visualization, emotional needs, and spiritual development from Eastern and Western sources. An emerging transpersonal vision of the human being is making these discussions possible. How might such a transpersonal vision of the human being contribute to the health of the soul?

\section{Discussion of New Perspectives on Human Consciousness}

The very language of our interior world was frequently ignored and even repressed within the twentieth century. On the one hand, in the silent experience of the human heart, nothing has changed. We still long for meaning, we still dream dreams and are drawn toward the future with vision, yet this vast interior domain of human understanding had to prove the validity of its existence. The first and perhaps the most important gift toward the health of the soul that this emerging transpersonal vision has brought forth is simply to allow us to give credence to our interior sources of information - a new validity of subjective experience. I quote from the Editor's note in the second Journal of Transpersonal Psychology, published in 1969:

"For the time being, at least, it is agreed that an empirical approach seems to be the most suitable one for the phenomena we are dealing with". This approach coincides with what [Willis] Harman calls the "science of ordinary and extraordinary experience". Our journal is primarily concerned with the realm of ultimate phenomena, of course, and as such comes under the purview of extraordinary subjective experience. One of the dominant tasks is "some sort of mapping or ordering of states of consciousness transcending the usual states of conscious awareness" [13].

Two examples of such subjective, spiritual experience will show the importance of the now obvious conclusion that these states of awareness should be validated for study.

In a guided meditation on a healing story of Jesus, a woman found herself remembering one of her most traumatic life-experiences. It was the time of the birth of one of her children. She had previously given birth to another child. She had been alert through that birth. But in this birthing experience, her medical team made the judgment that she needed to be sedated. Through that sedation process, carried out against her personal desires, she had felt great loss of participation consciously in the birthing of that child. The meditation continued to be present with her for several hours that night. In her inner vision experience, Christ was with her. Christ calmed her anxiety as her memories unfolded again of the traumatic encounter in the hospital, and she watched inwardly as she entered the birthing chamber. She relived her physical contractions. Christ comforted and sustained her and in her interior experience gave her the great gift she had longed for, to participate consciously in the birth of that child. Her physical and her emotional life were changed by this visitation of Christ, the healer [14].

In a meditation retreat, a man's attention was drawn to a well known place of chronic tension in his lower back. While focusing attention there, suddenly a perspective opened within his imagination and a knight in full regalia of the time of the crusades appeared. The story unfolded of this man's quest for spiritual surrender through the life of a crusader. The place of tension in the contemporary man's body was the place a sword was thrust into the crusader, killing him. It was only in the moment of death, that the crusader realized that in the ensuing battles, he had lost his purity of motivation and instead had become consumed with the blood lust of battle and of sexual violations in which he had 
participated. He died with great remorse. This "past life" memory helped the meditator to understand an array of his own struggles relating to aggression, sexuality, and life purpose (personal communication to the author).

In these reported spiritual experiences, the individuals have received very helpful information from their own soul's resources. There are countless other examples, such as insight through therapeutic conversation, or clarity for decision processes. I have guided people in meditation or other processes of inner awareness now for thirty years. I have come to expect that when we frame a question or concern from the best of our human understanding, we will be met in our inner world by a source of wisdom that will shift the question, that will enlighten the concern, or that will effect a transformation.

If the first gift of the emerging transpersonal vision is to claim validity again for our own subjective experience, the second gift is to reorient ourselves to the very nature of the psyche itself. What do we think it is? What are its limits? How does our finite human mind relate to the Infinite dimension of reality? We get close here to some theological or metaphysical ponderings. For myself, I have been satisfied to name this sea of information in which our consciousness dwells, "soul," so long as we define it as St. Augustine did: "a cavernous treasury, a confusion and richness, both [15]." The membrane of this soul in relationship to the collective and to the Eternal worlds is very thin. We become, as Needleman sought to restore, the "intermediate [human], who alone in the cosmic scheme can care for, or harmonize, or relate all the Forces of creation."

A useful metaphor for the human psyche or soul is an iceberg. Only the tip of the iceberg floats above the water and the essential character of the iceberg is the same as the cosmic sea surrounding it, yet it has been uniquely constituted into its own separate identity. If the soul or psyche is this cavernous treasury, of the same essential character as the cosmos in which it dwells, have we not perhaps overly objectified those terms Ego, Id, Personal Unconscious, Collective Unconscious? This issue was dramatically illustrated when the works of Freud were translated into English. In the standard translations used in America, Latin terms were substituted for the more intimate German terms. "Ich," "I" in German became the ego in translation [16]. In Jung's original writings, "I" or "Ich" or what we call ego, was simply all of which I am consciously aware in my inner world. For Jung, the "unconscious" was simply the vast sea of information from the interior of which I am not yet aware, the cavernous treasury, which from time to time will reveal more of itself. He was at pains to try to point to a new intermediate condition, in which information from the unconscious is assimilated into the "I." Theoretically, because the Self, this vast container of information is infinitely expandable, so also our "I," as it is made more and more conscious of the vast ocean of consciousness in which it dwells, is capable of infinite expansion. This puts us closer and closer to Needleman's intermediate human. Jung spoke of this new psychological state as a "mid-point of personality." In his Two Essays on Analytical Psychology, he wrote:

It may not be immediately apparent what is meant by a "mid-point of the personality." I will therefore try to outline this problem in a few words. If we picture the conscious mind, with [the "I" or] the ego as its centre, as being opposed to the unconscious, and if we now add to our mental picture the process of assimilating the unconscious, we can think of this assimilation as a kind of approximation of conscious and unconscious. This would be the point of new equilibrium, a new centering of the 
total personality, a virtual centre which, on account of its focal position between conscious and unconscious, ensures for the personality a new and more solid foundation [17].

To use our analogy of the iceberg, we begin adult life primarily identified with that tip of the iceberg that is visible out of the water. This was the totality of the psyche visible to the strict behaviorism and narrow empiricism of the 1950's. As we begin to assimilate more of our interior experience through dreamwork, exploration of emotional complexes, meditation, journal reflections, art process, prayer, or bodywork, our "I" shifts down into the main body of the iceberg. And we may even have glimpses of the fundamental unity of the ice with the ocean!

Culturally, we have advanced in the last thirty years, to expect much more ready access between these previously opposed forces within the psyche, that we ordinarily call the "ego" and the "unconscious." We might do well to envision ourselves much more like this notion of Jung's - that the "I," the conscious part of ourselves, is frequently visited by information from the less conscious but exceedingly dynamic part of ourselves, the cavernous treasury of the soul [18].

Thus, the first task of transpersonal vision has been to reclaim the validity of subjective experience. The second task has been to discover that there is a fluidity of information flowing between the so-called unconscious and the conscious dimensions. The third discovery that we have made is that this soul, or Self, if you wish or simply psyche, actively strives toward health, meaning, and wholeness. There is an active search for health within our psyche. If we ignore our psychological symptoms of quiet desperation or boredom, the quest for meaningful existence rooted deeply within our psyche will manifest in dreams. Or, if we succeed long enough in ignoring those, in physical symptoms, perhaps ultimately in disease. Similarly, if we ignore our desire for meaningful perspective on our existence, if we refuse the metaphysical challenge to struggle toward a coherent philosophy of life, we will subject ourselves also to psychological and perhaps physical distress. Within us is an innate drive toward health, meaning, and wholeness. This dynamic is well attuned to the theme in spiritual practice of a hope for advancement of spiritual life. The term, spiritual formation, points in this direction. There is a telos toward which spiritual life points. This may be named in a variety of ways depending upon each religious tradition. In Christianity, it may be characterized as striving for the "mind of Christ," in Buddhism, there is the hope to dwell in "Buddha mind;" in Hinduism, the aspiration for Samadhi. Our historic religious traditions point us toward a potentiality of human character continuing to form throughout our life. This aspect of human life is illustrated over and over again in the drive toward health and wholeness that we witness in psychological practice.

The fourth discovery made in this era of transpersonal discovery is the nature of the language of this psyche or soul or Self. That language is not the articulated language of reason, it is the language of symbolic manifestations, of emotionality, of imagination, of intuition, and of symptoms of distress or disease. Our fourth task is to learn this language well, if we would maintain the health of our souls. A good transpersonal counselor or spiritual director must be committed to an intimate knowing of one's own unfolding psyche and learning of one's own language of the soul. This self-knowledge gives us humility in listening for the metaphors, symbols, and primary images that clients bring to their spiritual and therapeutic work. This is the arena of spiritual experience. It is captured in the medieval European understanding of "memory," as containing both past and future imagination. 
Various models of interior life developed by transpersonal psychology have brought us closer to medieval European thought on the nature of the individual. In the English writing, The Cloud of Unknowing, we find the intermediate human being that Needleman was seeking. The human being is described in the following way.

Beneath you and external to you lies the entire created universe. Yes, even the sun, the moon, and the stars. They are fixed above you, splendid in the firmament, yet they cannot compare to your exalted dignity as a human being.

The angels and the souls of the just are superior to you inasmuch as they are confirmed in grace and glorious with every virtue, but they are your equals in nature as intelligent creatures. By nature you are gifted with three marvelous spiritual faculties, Mind, Reason, and Will, and two secondary faculties, Imagination and Feeling. There is nothing above you in nature except God.

When you are reading books about the interior life and come across any references to yourself, understand it to mean your whole self as a human being of spiritual dignity and not merely your physical body. As [a person] you are related to everything in creation through the medium of your faculties [19].

In The Cloud of Unknowing, Mind, Reason, Will, Imagination, and Feeling are listed as the human faculties. Mind is the overarching category, perhaps consciousness itself. To this container, the author adds reason, imagination, feeling or emotions, and will. Other medieval writers would have added the senses and named imagination as memory, which has an expanded definition from our present usage. In our time, we might make intuition a unique faculty, as well as kinesthetic information from the body, and also the capacity for moral judgment. These are the "faculties," or "intelligences." "Intelligences" is perhaps preferable in our time, because it implies that we can learn to cultivate each one distinctly. It also implies that we will have natural capacities in some and less developed capacity in others. One of our tasks of soul-work thus becomes cultivating our skills of receptivity with each of the discrete faculties or intelligences. We would not think it proper to educate our children without some development of reasoning skills, but we regularly graduate students without adequate emotional skills, and we even suppress the skills of imagination and intuition, rather than seeing these also as intelligences or faculties to develop. Much of our counseling work, in fact, is remedial work, in simply assisting people to develop their feeling faculty or emotional self-understanding. Through this lens, the faculty of imagination or memory takes on a fascinating aspect.

In some medieval writings, the term memory is used in the way we currently use imagination or symbolic awareness. It was not limited to the past, as we use the term. Bonaventure wrote of it, in the thirteenth century in this way: ". . . the memory retains the past by remembrance, the present by reception and the future by foresight [20]." In other words, memory is not only related to the past, but the function of mind that also envisions the future. This concept of imagination is captured in the provocative title of David Hogue's recent book, Remembering the Future, Imagining the Past [21].

One way of viewing the extraordinary shift in understanding of the human psyche that has taken place through the transpersonal movement is a recovery of the capacity of the human being for the faculty of memory or imagination. Now with ready ease, through a variety of relaxation, 
meditation, or hypnosis techniques, we take as normal, the capacity to recover memory of past psychological states. We are also becoming more sophisticated in its use and are learning that this memory is not necessarily fully trustworthy factually of a past event; however, it is absolutely trustworthy psychologically. Such memory, whether of a crystallizing moment in our childhood or imaginal information from the realms of spirit, gives us information needed for our current movement toward psychological health. The capacity of memory would also then relate to the imagery states in which we receive information relating to future possibility for ourselves, or in which we seek to discern the future that is drawing us toward itself. This imaginal realm has been the classic domain of spiritual experience, which Ken Wilber has designated as subtle level experience. Subtle experience of the divine contains some image of the divine, such as the experience reported earlier of the woman remembering her birthing experience with Christ present. Causal experience in this model would be an experience of the divine without form, such as an experience of divine light or kinesthetically felt divine presence.

Recently Ken Wilber and Allan Combs have made a major contribution to the intersection of transpersonal psychology and spiritual experience in the diagram they call the Wilber-Combs Lattice. This way of differentiating levels of consciousness from kinds of spiritual experience is a major step forward. In Wilber's early works, such as Spectrum of Consciousness (1977) and The Atman Project (1980), this distinction was not made. As we view the Wilber-Combs Lattice, the vertical dimension describes the development of the capacities for individual human consciousness, beginning at the bottom and advancing in complexity as one moves upward on the diagram. The diagram uses categories derived from the work of Jean Gebser. Wilber correlates these categories with similar designations of several theorists on human development, including Sri Aurobindo, Jane Loevinger, Jean Piaget, and James Fowler [22]. For simplicity, I will only compare the stages of Gebser and James Fowler. Thus, Gebser's archaic and magic thinking are associated primarily with infancy and early childhood and relate to James Fowler's magical and mythic-literal stages. In late childhood and our teen years, Fowler's conventional stage may become strong. This category relates to Gebser's mythic stage. Persons operating at this stage of development will be well connected with the dominant worldview of their culture. If our rational process becomes more developed, we will be able to differentiate ourselves from our cultural norms, coming into what Fowler describes as individual-reflexive stage and Gerber calls rational. Persons who have developed spiritual practices with sustained attention to the welfare of all persons in the human family may move into Fowler's conjunctive stage or Gerber's pluralistic stage. The most enlightened individuals of any culture or religious tradition may manifest Gebser's integral or Fowler's universalizing stage. In earlier discussions, Wilber had noted that subtle and causal experience would manifest in a primary way in the more advanced levels of consciousness. While this remains true, it is also possible for a person in early childhood to have a spiritual experience that is causal or even non-dual in nature. The Wilber-Combs Lattice in Table 1 shows us how to make sense of these variations in human experience.

Table 1. Adapted from Wilber-Combs Lattice [23].

\begin{tabular}{ccccc}
\hline Types of Spiritual & Gross & Subtle & Causal & Nondual \\
Experience & Nature & Deity & Formless & Nondual \\
\hline
\end{tabular}




$\begin{array}{ccccc}\text { Levels of Consciousness } & * & * & * & * \\ \text { Super-Integral } & * & * & * & * \\ \text { Integral } & * & * & * & * \\ \text { Pluralistic } & * & * & * & * \\ \text { Rational } & * & * & * & * \\ \text { Mythic } & * & * & * & * \\ \text { Magic } & * & * & * & * \\ \text { Archaic } & *\end{array}$

Types of Spiritual Experience/horizontal axis; Levels of Consciousness/vertical axis.

Types of spiritual experience are noted in the horizontal axis: gross refers to ordinary waking experience; subtle refers to vivid dream-like states or meditative states in which deity is experienced in form; causal describes experiences of formless meditation or deep sleep; "Non-dual awareness. is not so much a state as the ever-present ground of all states (and can be "experienced" as such) [24]." As previously noted, the experience of the woman reliving her experience of childbirth with Christ present would be a subtle level experience. Her own quality of personal functioning, most likely at the pluralistic level, allowed her to gain great personal insight from this experience. Sometimes, because of the dramatic shift of understanding that such an experience might bring, it may instead take many years for a person to fully integrate such experience. In some cases, this has been the experience of persons who may have suffered a near-death experience, in which they were catapulted into the causal or non-dual experience. If their level of ordinary functioning is at the mythic or even rational level, it may be very difficult to make sense of such experience. It may take many years of searching for a new reality structure to accommodate the spiritual experience.

The Wilber-Combs Lattice also helps us in interpreting the often quite confusing world of religious language. For example, a vision of Christ at the crucifixion may be interpreted by a person of mythic understanding to say that all persons must have this kind of experience if they are to be truly Christian. Whereas if a person of pluralistic experience has such a vision, the result will very likely be to observe the metaphoric and universal need for people to understand the role of suffering in human existence. They will look for parallels in other religious traditions.

\section{Conclusions}

We stand at a very exciting threshold, in which the recovery of the faculties or intelligences, together with their skillful use, is enabling us to discover the vast healing potentiality of the treasury of each self. Transpersonal models of consciousness, with attention both to stages of development and to inner states of awareness enable us to have deeply meaningful conversations across the global community. Through skillful use of the Wilber-Combs Lattice, it is possible to appreciate both the differences and similarities of advanced states of spiritual experience, which various religious traditions hold as potentiality for human beings.

We are intermediate humans already. Through the collective human experience, we are finding in fresh ways that we are already dwelling in the unbroken fabric of life. Our health is to so live more and more in conscious cooperation with that unbroken fabric. 


\section{Acknowledgments and Notes on the Author}

Thank you to Frank-Gerald B. Pajonk for the invitation to present this article. We became acquainted during my years of service on faculty of Institute of Transpersonal Psychology. Our interests in the intersection of psychology and spirituality continue.

Dwight H. Judy is Professor of Spiritual Formation at Garrett-Evangelical Theological Seminary in Evanston, Illinois. He received his Ph.D. from the Institute of Transpersonal Psychology in 1984. He served on the faculty of the Institute and director of the off-campus program from 1986-1994. He was president of the Association for Transpersonal Psychology from 1994-2000. He presently serves on the editorial review panel of Presence, the journal of Spiritual Directors International. His most recent book, Discerning Life Transitions: Listening Together in Spiritual Direction, is imprint of Spiritual Directors International.

\section{References and Notes}

1. James, W. The Varieties of Religious Experience: A Study in Human Nature, Being the Gifford Lectures on Natural Religion Delivered at Edinburgh in 1901-1902; Longmans, Green Publisher: New York, NY, USA, 1902.

2. Hillman, J. Re-visioning Psychology; Harper \& Row: New York, NY, USA, 1975.

3. Wilber, K. The Spectrum of Consciousness; Theosophical Publishing House, Quest: Wheaton, IL, USA, 1977.

4. Wilber, K. The Atman Project: A Transpersonal View of Human Development; Theosophical Publishing House, Quest: Wheaton, IL, USA, 1980.

5. Grof, S. The Adventure of Self-discovery: Dimensions of Consciousness and New Perspectives in Psychotherapy and Inner Exploration; State University of New York Press: Albany, NY, USA, 1987.

6. Grof, S.; Grof, C. Holotropic Breathwork: A New Approach to Self-exploration and Therapy; State University of New York Press: Albany, NY, USA, 2010.

7. Wade, J. Changes of Mind: A Holonomic Theory of the Evolution of Consciousness; State University of New York Press: Albany, NY, USA, 1996.

8. Needleman, J. Lost Christianity; Doubleday: Garden City, NY, USA, 1980; p. 189.

9. Ibid.; p. 181.

10. Jung, C.G., Hull, R.F.C., Trans. Psychology and Alchemy. The Collected Works of C.G. Jung, 2nd ed.; Princeton University Press: Princeton, NJ, USA, 1968; Volume 12, paragraph 12.

11. Dossey, L. The Power of Prayer and the Practice of Medicine; HarperCollins: New York, NY, USA, 1993.

12. Achterberg, J. Imagery in Healing: Shamanism and Modern Medicine; Shambhala: Boston, MI, USA, 1985.

13. Editor's Note. J.T.P. 1969, 1, \# 2.

14. Judy, D. Quest for the Mystical Christ: Awakening the Heart of Faith; OSL Publications: Akron, OH, USA, 2003; p. 28.

15. Hillman, J. Re-visioning Psychology; Harper \& Row: New York, NY, USA, 1975; pp. 68-69. 
16. Wilber, K. Integral Spirituality: A Startling New Role for Religion in the Modern and Postmodern World; Integral Books: Boston, MI, USA, 2006; p. 123.

17. Jung, C.G., Hull, R.F.C., Trans. Two Essays on Analytical Psychology. The Collected Works of C.G. Jung, 2nd ed.; Princeton University Press: Princeton, NJ, 1966; Volume 7, paragraph 365 .

18. For more extensive discussion, see chapter 2 of Judy, D., Christian Meditation and Inner Healing; OSL Publications: West Sulphur Springs, VA, USA, 2010.

19. Johnston, W., Ed. The Cloud of Unknowing and the Book of Privy Counseling; Doubleday: Garden City, NY, USA, 1973; pp. 129.

20. Cousins, E., Trans. In Bonaventure; Paulist: Mahwah, NJ, USA, 1978; p. 80.

21. Hogue, D. Remembering the Future, Imagining the Past: Story, Ritual and the Human Brain; Wipf \& Stock Publishers: Eugene, OR, USA, 2009.

22. Wilber, K. Integral Spirituality: A Startling New Role for Religion in the Modern and Postmodern World; Integral Books: Boston, MI, USA, 2006; Figure 2.4, Figure 2.5.

23. Ibid.; p. 90.

24. Ibid.; p. 74. 


\title{
Sacred Psychotherapy in the "Age of Authenticity": Healing and Cultural Revivalism in Contemporary Finland
}

\section{James M. Wilce}

\begin{abstract}
Like other European countries, contemporary Finland has witnessed an explosion of healing modalities designatable as "New Age" (though not without profound controversy, [1]). This paper focuses on Finnish courses in lament (wept song, tuneful weeping with words) that combine healing conceived along psychotherapeutic lines and lessons from the lament tradition of rural Karelia, a region some Finns regard as their cultural heartland. A primary goal of the paper is to explicate a concept of "authenticity" emerging in lament courses, in which disclosing the depths of one's feelings is supported not only by invoking "psy-" discourses of self-help, but also by construing the genuine emotional self-disclosure that characterizes neolamentation as a sacred activity and a vital contribution to the welfare of the Finnish people.
\end{abstract}

Reprinted from Religions. Cite as: Wilce, J. M. Sacred Psychotherapy in the "Age of Authenticity": Healing and Cultural Revivalism in Contemporary Finland. Religions 2011, 2, 566-589.

\section{Introduction/Background}

The relations between religions/spiritualities new and old on the one hand and psychotherapies per se (as opposed to shamanism interpreted as a form of psychoanalytic intervention [2]) are complex and shifting. To grossly oversimplify, early (i.e., nineteenth century) psychiatry clearly reflected its roots in magic while doing its best to distance itself from those roots [3]. During the twentieth century that distancing trend continued in some contexts, while other contexts witnessed a sort of hybridity that is so visible today in what is commonly labeled the "New Age" scene. In a previous article [4], I investigated an example of the magical roots of psychiatric modernism in Bangladesh and its hostile stance toward "superstition." This local form of psychiatric modernism encompasses strict rejection of Islamic medicine at least in the form in which it is now practiced in rural Bangladesh. The article demonstrated that the letters section of Bangladesh's only popular psychiatry/psychology magazine contains discourse structures that help us understand the hostility of Bangladeshi psychiatry and its insecurity. That insecurity may reflect the surprising presence, in the psychiatrist-editors' responses to messages published in the letters column, of poetic, parallelistic formations whose similarities to ritual discourse around the world are striking.

The present paper describes a very different scenario, involving no hostility at all between psychotherapeutic ideas and spiritualities of the self. It concerns examples that typify certain forms of "post-secular" [5] spirituality in blending postmodern "freedom of self-determination" [6] and "humanistic expressivism" [7] - both of which are related to contemporary discourses of authenticity - with an experience of the sacred. The example is the proliferation of healing courses in Finland, and one such course in particular-Hoitava Itku, 'Healing Lament,' courses offered by 
Ä̈nellä Itkijät, 'Those Who Cry With Voice [Words]' (hereafter, ÄI-Lamenters). ÄI may be the only cultural revivalist group in the world to focus on lament, and it certainly is the only one in Finland.

\subsection{Historical Background and Finnish Context of New Spiritualities}

\subsubsection{A Pocket Religious History of Finland}

Finland's earliest exposure to Christianity - roughly a thousand years ago - was to its Eastern Orthodox branch. In the twelfth century, however, Swedish-led Crusades pushed Eastern Orthodoxy back to the eastern part of what is now Finland. In the sixteenth century Swedish influence brought about another change - the country's mass conversion to Lutheranism. ${ }^{24}$ Karelia, in the east, remained largely Orthodox. During the nineteenth century, after Sweden was forced to cede the territory of Finland to Russia, of which it became a Grand Duchy, the Czars began to encourage Finland's version of the romantic nationalism sweeping Europe. In Finland's quest to become a modern nation like Germany, its cultural elites spread out across the territory in search of a body of folklore that would compare to Germany's. They found in Karelia a mythic fons et origo of "Finnish" culture [8] — despite the clear differences between the two, and particularly religious differences. This attribution of sacredness to Karelia is of foundational importance to the Finnish lament "revival" 25 and to "Karelianist" politics ([8-10]) which space does not allow me to describe.

Ketola and Martikainen, in their study of contemporary religious communities in Finland [11], divide these communities into 10 categories, including "Western Esoteric Traditions and the New Age," whose manifestations would include groups/congregations and magazines [12] that develop themes familiar around the world of contemporary religion/spirituality. For example, a Yoga school in Helsinki is said to emanate "spirituality, well-being, individuality, and sociality" [13]. Junnonaho ([14], pp. 88, 93) has found widespread acceptance of what he calls "New Age ideas" both in surveys of Finns and in New Age institutions in Finland-“metaphysical book shops, groups of psychic and mental development, alternative health centers, and practically all possible groups of so-called alternative religiosity." A spiritual eclecticism or "mixing of codes" pervades such institutions and their counterparts elsewhere in the world [15].

Having invoked the label "New Age," it is important to explain why I prefer instead, following Charles Taylor, to speak of ours as the "Age of Authenticity" [16]. ${ }^{26}$ Although some do find a consistent set of core beliefs and practices across the scope of "New Age" phenomena [17,18], 27 for others the sheer diversity of spiritualities, practices, beliefs, etc. that are commonly described under the rubric of "New Age" is a sign that the term is problematic [1]. Moreover, at least in my

24 I am indebted to Junnonaho (1999) for the preceding account of Finland's religious history.

25 I put "revival" in quote marks first because it is a word lament activists themselves use, but also because, to others, their claim to be reviving Karelian lament is controversial.

26 Despite some advantages the phrase "Age of Authenticity" has over "New Age," at least for my purposes here, there is also evidence that our age is one of spectacle, glittering surfaces, and performance that makes authenticity appear merely modern in postmodern times. This critique will be developed in a later publication.

27 For Hanegraaff at least part of that core is "a supposedly university spirituality based on the primacy of personal inner experience." 
recordings, lamenters never self-identified with the New Age, but did speak movingly of their commitment to authenticity.

What I address in this paper is the surprising connection between a value (authenticity) that receives its fullest treatment, perhaps, in the works of psychologist Carl Rogers [19], but that turns out to be regarded by $\ddot{A} I$-Lamenters as sacred. This can just as well be described as the penetration of religious notions into the psychological sphere, or the penetration of psychological notions into the sphere of religion. Kivivuori argued in the 1990s [20] that a psychological mindset was penetrating all social institutions-in Finland as elsewhere. However, more recent work by Utriainen, Hovi, and Broo [5], underscores the mutual interpenetration of sacred and secular discourses pertaining to healing. "Officially secular spaces, such as hospitals have been in a modern north-European country such as Finland, include 'pockets' where religious language (but in a changed form...) or other practices are now increasingly found" ([5], p. 6). Utriainen and her colleagues cite “'therapy', 'holism' and 'spirituality' [as... ] some of the key labels by the use of which religious practices and beliefs enter many ... formerly secular institutions and places" ([5], p. 8). However, the creation of that kind of hybridity relies equally on invocations of "authenticity" as in this advertisement for a course described as an aito identiteettikurssi intense löytäjälle "authentic-identity course to find yourself" ([20], p. 11), translation by the present author).

Before turning to a thorough description of Finnish lament courses, the next major section paints, with large brush strokes, the Western historical context for the emergence of religious and therapeutic hybrids in Finland. That context is the emergence in the West over the last two-and-ahalf centuries of a modern self obsessed tendency, with a very particular sort of "experience" and a very particular kind of "authenticity," and the more recent partial displacement of organized religions by spiritualities. Note that "authenticity" is commonly used in two very different senses by, for example, folklorists [21] (as well as performers) versus sociologists (e.g. Heelas) and anthropologists (Lindholm [22]) of religion. We will be concerned with authenticity as "faithfulness" not to tradition, but "to the self" [23].

\subsubsection{Psychiatry, Psychotherapy, and the Sacred Self: Broader Background}

It is important to acknowledge both the deep historic roots of contemporary religious subjectivism as part of the Western "genealogy of the self" [24], and its relative uniqueness to lateor post-modernity. Thus on the one hand, some features of the modern Authentic Self (features that Heelas, for example [25], labels "New Age") have Augustinian and even classical Greek roots. Yet the emergence in the West of a self that is both source and object of spiritual practice, and the apotheosis of experience and authentic self-expression - started in the seventeenth century and blossomed in the late eighteen century. These flowerings included Pietism in Finland ([26,27], pp. 49-50) and elsewhere ([28], p. 302), and Methodist "experience meetings" ([24], p. 887).

\subsubsection{The Evolution of Psychiatry, Psychotherapies, and the Expressive/Experiential/Authentic} Self in Europe and the U.S.

What Nikolas Rose calls "the psy disciplines," i.e., "the psychosciences and disciplinespsychology, psychiatry, and their cognates"- have become crucial to modern technologies of the 
self, including those reproduced in Finnish lament courses, especially to the extent that they reflect "psy." "It has become impossible to conceive of personhood, to experience one's own or another's personhood, or to govern oneself or others without psy," ([29], pp. 2, 34).

At approximately the same time as Methodist meetings emerged, psychiatry was taking shape in Scotland, Germany, and France [30]. The particular French history invoked here illustrates the interweaving of psychiatry and religion. According to Goldstein, pioneering nineteenth century French psychiatrist Jean-Martin Charcot (1825-1893) worked and wrote at a time of particular religious fervor, focused for example on healing miracles. Charcot's article on the topic, though intended as a pronouncement of psychiatric authority was, "like so much of the activity of the Salpêtrière school, ... a response to religious life in France, in this case the flourishing miracle cult at Lourdes" [31] as cited by [32], p. 381.).

At the time Charcot's article appeared, British psychiatry and its scientific model of the self was also entering into dialogue with popular religious trends like demonology and Pentecostalism. Hayward [3] explores the exchange between these currents in the late nineteenth and early twentieth century. The writings and practices of nineteenth- and twentieth-century spiritualists and Pentecostalists reveal the influence of psychiatry, indeed. However, this was not a simple story of scientific models driving out religious beliefs;

rather, a much more textured process took place in which spiritual practitioners actively incorporated contemporary psychiatric, neurological, and epidemiologic knowledge as part of a general attempt to make sense of their supernatural experiences. The incipient disciplines of psychiatry and biomedicine did not depose religious conceptions of exorcism and possession; instead, psychological and neurological concepts became just one more part of the practical repertoire of techniques upon which demonologists drew in order to achieve their spiritual aims and personal goals. Scientific ideas that might have been formulated to advance the projects of materialism or secularization could always be expropriated by religious practitioners to sustain an antagonistic program of magical or supernatural practice [3], p. 39).

Meanwhile, psychotherapy was largely unknown in the early twentieth-century U.S., but underwent a wild popularization between 1906 and 1910. This historical moment is of interest to us here because it involved an unprecedented collaboration between American psychotherapists and churches. Caplan [33] has shown us that psychotherapy's popularization in the U.S. can be traced, largely, to the "Emmanuel Movement." Originating in Boston's Emmanuel [Episcopal] Church, the movement entailed an "unprecedented medical-pastoral venture." "The psychotherapy movement's appeal transcended denominational boundaries: Baptists, Presbyterians, Congregationalists, Unitarians, and Universalists all enlisted in the cause" [33], p. 290). Notably this tentative merger of interests did not involve the sacralization of the self and its authentic expression. These emerged only with New Age per se, later in the century.

These French, British, and American histories can be seen as predecessors of postmodernity, with its unabashed hybrids of the modern and the traditional, and as foreshadowings of those contemporary ideas of "personal growth" therapy and personal spirituality seen in lament and other healing courses in Finland. In our "Age of Authenticity," "therapies multiply which promise to help you find yourself, realize yourself, release your true self, and so on" [16], p. 475). During the twentieth century, self-control and a high tolerance for role-playing came to be regarded as "self-destructive 
and fraudulent. Instead, we want to discover and express our essential selves in rapturous church services, in charged therapy sessions ... [and] intense personal relationships" [22], p. 65).

We can think of the byways through which what Heelas calls "New Age" thought and practice emerged fully into twentieth-century currents as long roads with origins in the nineteenth century, or as radicalizations of nineteenth-century trends.

The New Age provides a spiritual — and thus radicalized - rendering of the assumptions and values of [nineteenth-century] humanistic expressivism. Humanistic expressivists think in terms of selfdevelopment. They ... concentrate on what it is to be a person ... [and] have faith in what the inner, psychological realm has to offer. Attaching significance to self-exploration and seeking to express all that one can be, their values include "awareness," "insight," "empathy," "creativity," "autonomy," "authenticity," being loving" and seeking "fulfillment" [7], p. 115; emphasis added).

So, despite its historic roots, the massive subjectivization of Western culture-including mass/popular culture, cut off to a large extent from organized religion-only occurred in the twentieth century, as Taylor, Heelas, Lindholm, and others have noted. And it is only with this twentieth-century popularization of new forms of spirituality that religion and its connections with nation-states (see the state religions of Europe, some of which are rapidly losing members) is increasingly being displaced:

[What] Charles Taylor calls "the massive subjective turn of modern culture"-favors those forms of ["subjective-life"] spirituality which resource one's subjectivities and treats them as a fundamental source of significance, and undermines those forms of religion which do not. Experienced as the heart of life and flowing through the unique experiences that comprise personal life, holistic spirituality can appeal to the increasing number of free spirits in the culture - people who exercise their autonomy by trusting their own experience to find ways of "deepening," ${ }^{28}$ thereby "elevating," the quality of their subjective lives, their intimate relationships, their sense of fulfillment and authenticity [34], p. 57, emphasis added).

What Heelas calls "subjective-life spirituality" is not simply individualization by another name. Subjectivism refers to the apotheosis of "forms of spirituality which cater for subjective-life tasks — offering individuals a sense of harmony and serenity, for example" [35], p. 78. However, this "subjectivism" need not be of the Lone Ranger sort.

The direction that subjective-life may take as it extends out beyond its autonomous basis can vary. Our findings suggest that this variation can be thought of in terms of a spectrum between two poles. At one extreme lies what we will call individuated subjectivism and at the other relational subjectivism, with many intermediate positions in between [35], pp. 95-96, emphasis added).

Like "individuated subjectivism," "relational subjectivism" embraces "self-expression and fulfillment ...doing 'what feels right,' 'following your heart,' [and] 'being true to yourself,'” but "relational subjectivity is all about 'the we of me'-developing one's own subjective-life, be/coming oneself, relating to one's life, through one's relationships” ([35], pp. 80, 97).

28 Apart from headers, I have used bold or bold-italic throughout the article to indicate terms that are central to the discourse of Finnish neolamenters and other healers. 
Relational subjectivism is indeed what we find in Finnish lament courses. ÄI-Lamenters invoke something like the concept of relational subjectivism precisely, if seemingly paradoxically, when explaining the sanctity of lamenting in contemporary groups. But the significance of the "relational subjectivism" model becomes even clearer insofar as it helps explain something mentioned again in the Conclusion - the predominance of women in lament courses.

They key to solving the puzzle is that more women than men tend to emphasize relational subjectivelife, and conversely that more men than women tend to emphasize the individuated or distinct variant. Accordingly, since subjective wellbeing culture and the holistic milieu is so relational, their provisions or activities attract subjectively orientated women (in particular) who seek to develop their subjective-lives through associational encounters. ... [More men than women, at least in data collected by Heelas et $a l$ l] seek to develop their subjective-lives by going out into the world to achieve and compete whilst retaining their own boundaries and sense of being in control [35], p. 98.

We have sketched the background of rapidly spreading forms of spirituality, many of which include a healing element, and their Finnish incarnation. It is time now to paint the background of Finnish lament courses in particular, i.e., tracing the history of Karelian lament and adding an ethnographic description of the courses.

\subsection{Fieldwork with ÄI-Lamenters}

This article is based on 11 months of ethnographic fieldwork in 2008-2009, six weeks more in 2010, and shorter trips earlier in the decade focused on the "lament revival" in contemporary Finland and particularly on the revivalist organization, "Those Who Cry With Words" ( $\ddot{I}$-Lamenters, introduced earlier). My fieldwork included participant-observation in, and audio and video recording of, six lament courses; interviews with 12 lament course participants (alumni); four interviews with a group of women, and especially Aino Pusa, who live in the small Finnish town of Ähtäri (in southern Pohjanmaa, the Finnish region whose people are best known for maintaining a stiff upper lip) and who, in the years since they participated in a lament course, have continued as a group of "lament sisters"; and analysis of media coverage of the "revival," including four documentaries on the contemporary Finnish lamenters, including Laurinen's [36], and Härmä's [37].

My investigation, though it builds on excellent earlier work on "the three lives of Karelian lament," the latest being the "revival" [38-40], is unique in several ways. First, English-language ethnographic studies in Finland are quite rare. ${ }^{29}$ Second, as far as I know, only one other investigator of contemporary lament has participated and not just observed or recorded, performing his own laments with others, and that was in Venezuela [41]. Third, this is the first anthropological investigation of a movement referring to itself as a "lament revival." Besides my own ethnographic data, I also draw on archival data interpreted with the help of contemporary folklorists (Heidi Haapoja; ${ }^{30}$ [42,43]; Irma-Riitta Järvinen, personal communication, June 2010) in constructing my argument.

\footnotetext{
29 For an exception, see the rich ethnographic work of Karen Armstrong (2004).

30 Heidi Haapoja served as my research assistant/ expert consultant from September 2008 through June 2010. My debt
} 


\subsubsection{Lament Roots and Contemporary Lament Classes}

One might regard crying with words and melody (lament) as a global tradition, as some teachers regard shamanism. Traditional performances of ritual lament were once extremely widespread [44]. In many societies lamentation served to hasten and safeguard a dead soul's journey to the other world. This and other ritual functions were pervasive in the ancient Near East (see [45], for a description of five millennia of lamenting in Egypt). Crucially for our purposes, a magico-ritual function defined itkuvirret 'laments' in Karelia - an area straddling the Finnish-Russian border (see Figure 1, below) ${ }^{31}$-as well as among Komis, Mordvins, and other Finnic peoples (see Figure 2) - until the 1970's (personal communication: Eila Stepanova, August 2010) when, some 70 years after the disappearance of wedding laments, funerary laments were becoming moribund [21, 46-49].

Laments' performative function — guiding the dead to the afterworld - rendered them sacred for thousands of years, at least in the eyes of women. Their perspective contrasted sharply with the views, for example, of Solon, Plato, and other Greeks who each tried to at least control if not eradicate this women's practice. And from the birth of the Christianity until roughly a century ago, churchly pronouncements against lament became more and more harsh, and the implementation of bans on lament apparently became more violent ([50] and [44]. On the surface it is ironic that an increasing number of Finnish women accept as pyhä, 'sacred,' what churches have for 2000 years attempted to eradicate. But it is in fact not ironic at all, since the sacredness of this women's tradition has probably always been a prime motivation for attacks on it, whether from Christianity, Islam, Hinduism, or the apparent secularism of recently urbanized populations [44].

In many Karelian regions, villagers were baptized members of the Russian Orthodox Church. However, priests were unable to visit these villages more than once a year, at which time babies born in the preceding year would be baptized, weddings would be blessed or sacralized, and funerals over which women had largely officiated — particularly by performing laments — would be recapitulated following Orthodox ritual. In such Karelian villages, kansan ortodoksisuus 'folk Orthodoxy' predominated. This village religion included the following beliefs (interview with Alexandra Stepanova, April 2009):

- "There was some kind of communication between the departed, and the living, those who remained, relatives"

- "The departed hear only lament words" [i.e., they understand only the itkukieli, 'lament register']

- "Of course people knew about God... but there were REALLY a lot of other gods." As one elderly lamenter asked Stepanova, "Well, don't you understand that this is my chief deity and the others are minor ones in submission [alamaisiaan] to God?" RST

Figure 1. Many Karelias (Permission is granted to copy, distribute and/or modify this document under the terms of the GNU Free Documentation License, Version 1.2 or

to her is enormous.

31 There are, as Map 2 shows, many Karelias. Eila Stepanova (personal communication, August 2010) points out that in each, lament had its own life. 
any later version published by the Free Software Foundation; with no Invariant Sections, no Front-Cover Texts, and no Back-Cover Texts. Subject to disclaimers.).

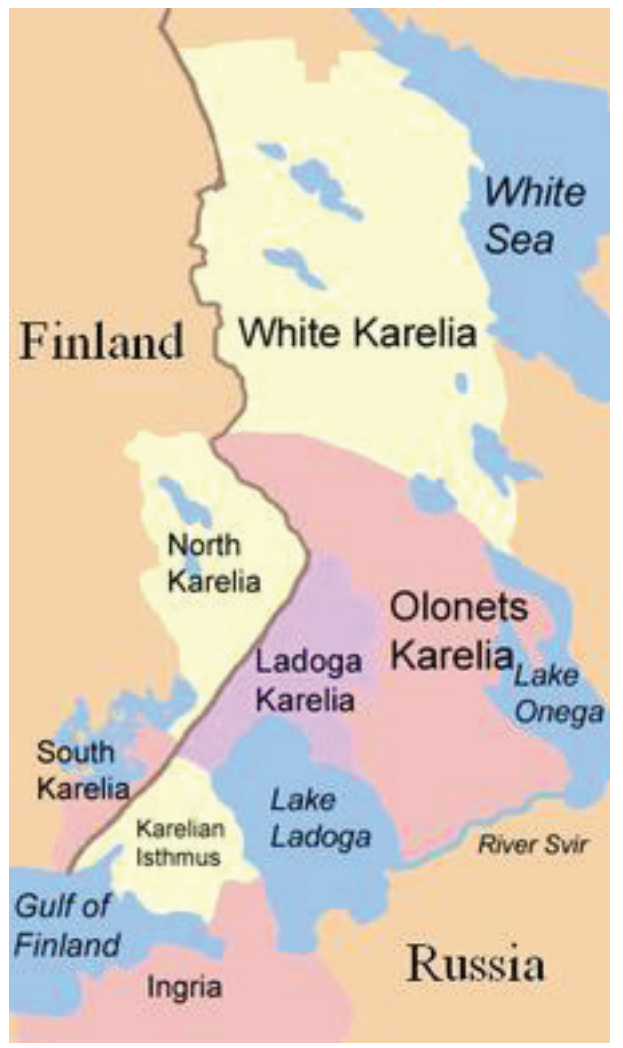


Figure 2. The Finno-Ugric Language Family (permission requested, answer pending).

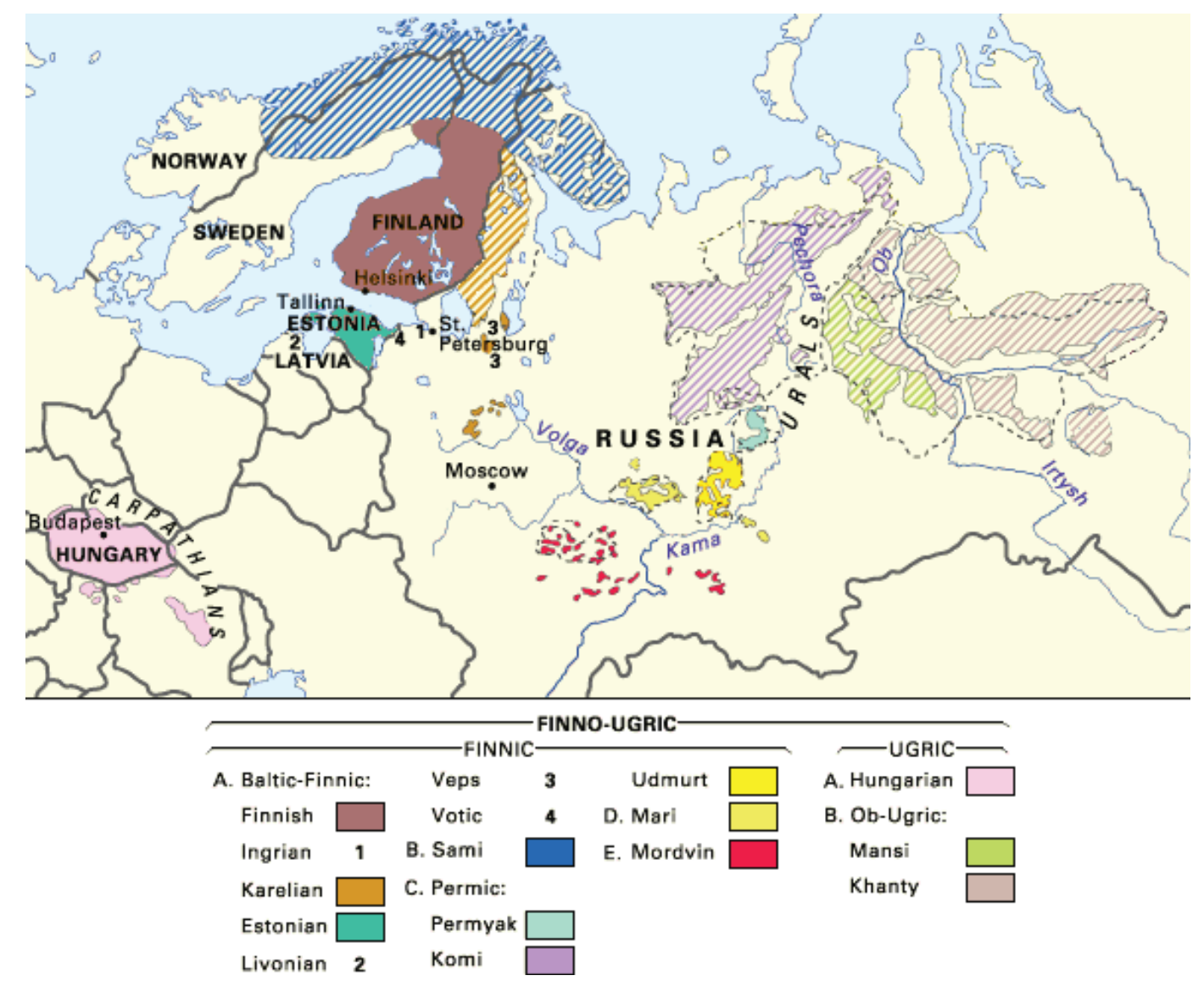

ÄI-Lament courses typically include lectures on Karelia, elaborating on Stepanova's comments about lament in its traditional context.

Scholars like Elizabeth Tolbert have described expert lamenters (itkiänaiset, 'lament women') as "female shamans." Some knew spells as well as they knew the lament register. Also, even if itkijänaiset did not make the soul journey along with the dead in funeral laments (as male shamans might in different circumstances), they could certainly be said to enter trance states. Only thus could their sung-wept feelings take on the magical power through which they blessed the dead, brides, etc., as Tolbert makes clear:

To understand the musical procedures used in the lament [including musical masking], the shamanistic elements in the lament must be kept in mind: magico-religious power associated with lamenting as evidenced in the etymological associations of lamenting with sorcery, verbal descriptions of the power of the lament and its necessity for the success of ritual, the dangers of lament performance and soul loss, and shamanistic cosmological conceptions which show up in the form and function of lament [48], p. 54).

The micro level of [traditional Karelian] lament structure consists primarily of the musical consequences of the icons of crying. They signal and validate the presence of spiritual power by their direct index of emotional involvement. The ritual context of the lament suggests overwhelmingly that the micro-tonal and micro-rhythmic variations are essential to the process of creating an effective performance, and are not merely the result of individual catharsis. These micro-parameters are an 
indication that the lamenter has reached a trance-like state and successfully contacted the other world ([51], p. 90).

The preceding has indicated various reasons that Karelian itkuvirret, 'laments,' would be considered pyhä, 'sacred,' and why it is that I present even a highly modified version of the lament tradition as a spiritual practice. It is to these modified neolaments that we must now turn.

\subsubsection{The Twentieth-Century History, and the Three Lives, of Karelian Lament}

Karelian lament has had "three lives" [39]. The first stretched from an era temporally undefined except by its characterization as one of "tradition" to roughly 1900, when performances of wedding laments disappeared and funeral laments began to decline. The second life began after World War II, when Karelian women lamented the loss of their homes - a loss shared by several hundred thousand Karelians evacuating their villages in territory newly transferred to the Soviet Union (a form of war reparations demanded of Finland). Throughout the first and second lives of Karelian lament, the itkukieli 'lament language [i.e., lament register]' was mandatory for all performances, both ritual and "occasional" or personal/situational laments (personal communication: Eila Stepanova, August 2010). The features of the lament register included free meter, pervasive alliteration, and - most important by far for our purposes - a conventional set of at least 1400 "metaphoric" or "formulaic expressions," "circumlocutions," or "substitute names",32 obligatorily used to avoid addressing the dead, or the bride, etc. "directly," i.e., by kin term [52].

Why this esoteric register of Karelian? As itkijänaiset 'lament women' have explained to at least two generations of researchers, the true addressees of their laments-several classes of spirits - understood only this register. Most mortals had a harder time with it. It is possible that itkijänaiset from interrelated Finnic groups that shared overlapping lament traditions-Ingrians and Vepsians, for example - understood each other (personal communication: Eila Stepanova, August 2010), but that Finns, who may never have had a lament tradition of their own, ${ }^{33}$ would not have understood much at all of old Karelian laments.

Although the idea that a metaphoric and thus "indirect" register would appeal to spirits might strike some as surprising, it is in fact noted in the linguistic anthropological literature. The trick is to take the itkukieli (the traditional Karelian lament register) as one of a class, i.e., as an "honorific register," which is a term intended to include all of the phenomena Silverstein mentions:

Note how all maximally respectful language... mitigates communication. Whether one is talking about speech level phenomena in the classic cases of Japanese, Javanese (Errington 1988), etc., or mother-in-law or similar registers in Aboriginal Australian societies, or speech of-and-to the gods in Yurok (Buckley 1984), all the indexically marked ways of speaking have this attenuated and/or tropic denotational effect, in effect constituting denotation by “hint" and by allusion [53], pp. 34-350).

32 This list of alternative terms for the "circumlocutions" that mark lament registers in the Ingrian (Nenola 2002) and Karelian (A. Stepanova 2003) derives from Eila Stepanova, personal communication, August 2010).

33 The issue of whether or not Western Finns once had their own lament tradition is controversial, with most revivalists affirming and some key scholars denying it. 
This trope - the "I am saying something to you, but not in such a way as to pin you down as addressee"-is at work in the metaphoric indirection of the itkukieli [52].

\subsubsection{Contemporary Lament Classes}

Revivalist lament courses that started in the late 1990s, and particularly courses taught by $\ddot{A}$-Lamenters, represent the third life of Karelian lament. In this third life, the Finnish language - not Karelian - dominates; thus one must speak Finnish to participate in $\ddot{A} I$-lament courses. Most of these courses are gatherings of ten or so women as students, together with Pirkko Fihlman and Tuomas Rounakari, the man who almost always co-teaches courses with Fihlman and a successful musician. The two-and-a-half day weekend courses consist of lectures on the Karelian tradition, the "revival," lament technique, etc.; the playing of archival recordings of old lamenters and a video recording of the very first course (1998); in-class singing and lamenting exercises; homework (polishing the lament that each student performs on Sunday); and, ideally, a debriefing Sunday afternoon as the course ends. Students are middle-class women, i.e., those who can afford both the time and the registration fee. Courses attract people of many professions, but consistently women who practice various forms of therapy-psychodrama, art, and sex therapy, for example — or who have allied professions such as psychiatric nursing. Over the years of offering courses, probably at least $20 \%$ of the 700 trainees have had a strong Karelian background. Finally, it is not unusual to have several students who have taken, if not lament classes, other "healing" courses.

According to my interviews, a minority of lament course alumnae "become lamenters." The path for those who do wish to continue is typically to take more courses. Out of some 750 students who have taken lament courses since the late 1990s, only a dozen or less have later performed in public. It is unclear how many of the 750 continue to lament in private for personal benefit. Somewhat surprisingly, the few who have gone on to perform publicly are neither consistently from the east (Karelia) nor western Finland. Moreover, when those who lack any known Karelian roots and indeed who originate from Pohjanmaa (mentioned above) do become lamenters, the irony of their lives is not lost on them.

What makes the lament courses unique vis-à-vis other healing courses in Finland and elsewhere is the balance struck in lament courses between psychodynamic concepts of therapy or healing and a very particular linguistic-cultural-ritual-musical tradition. ÄI-Lament teachers mention both the sacredness of traditional lamenting and such hybrid phrases such as itkuprossessi, the 'lament process,' which evokes the formation of trust and intimacy in the lament group, the preparation of one's own lament, and the catharsis experienced in lamenting before the group.

Pirkko Fihlman's ideas of language, derived from older generations of lamenters, contrast sharply with those of many psychotherapists and assertiveness trainers in affirming the importance of learning a particular linguistic convention to be used in self-expression - namely, minäviesti or "I-language" [54]. I-language is taught or at least advocated in other Finnish settings, including a graduate program in art therapy (as reported by a student whom I interviewed) and Lutheran confirmation classes [55-56].

Why should ÄI-Lament courses devote substantial amounts of time to teaching about Karelian, rather than Finnish, lamenting? According to Nenola [21,57], there had never been a lament 
tradition in western Finland. This fact accords with a widespread stereotype that tends to be reproduced by Finns and outsiders alike - the stereotype of the "silent" or "emotionally inexpressive Finn" [58-61]. A recent survey I conducted in Finland $(n=200)$ revealed agreement with the stereotype that "Finns" have difficulty expressing their feelings (Wilce, unpublished data). I was taken aback when a focus group of six university students in Jyväskylä not only indicated agreement with the stereotype, but asserted that the situation has not changed with their generation. The stereotype best fits men, and those living in western Finland, the extreme being the region of Pohjanmaa or Ostrobothnia, with a strong Swedish heritage.

Pirkko Fihlman (interview, 2003) has described lament as a tool to help modern people, by which she means modern Finns. According to her ÄI-Lament co-teacher Tuomas Rounakari, one can look at the lament revival as offering to western Finns elements of eastern culture (that of eastern Finns but particularly Karelians, most of whom now live in Russia, not Finland). In lament courses, Fihlman or Rounakari will occasionally draw explicit contrasts between the Karelian cultural tradition they are teaching and western Finnish culture. For example, Rounakari has said more than once that in Karelia people say, "Cry that thing until it's ready/ until the end," while the western Finnish tendency is to tell someone who is upset or crying, "You'll manage, you'll manage-so don't collapse there beside me" (said during the 2009 Annual Meeting of ÄILamenters.).

We return to such representations of Finns in the Conclusion, in discussing the stakes for lament courses. Meanwhile, in section 2 below, I present an analysis of lamenters' discourse, and especially their echoing of other discourses.

\section{Results and Discussion}

\subsection{Tropes of the Experiential Self and their Use in Lament Courses}

\subsubsection{The trope of interiority}

Whatever it might owe to classical Greek and biblical discourse (e.g. Romans 7:22, II Corinthians 4:16), we see a very marked movement in the last several centuries of western discourse toward an embrace of "internalization" and "the trope of interiority" ("compelling metaphors of the spatial distinctions of inner and outer" that enable the imagination of "the internal fixity of the self and... of gender identity [62], p. 171) with the acceleration traceable to the rise and spread of Protestant theologies of the person [63]. Throughout the nineteenth century psy-disciplines played their role, but we can attribute the increasing dominance of the interior model of the self to psychoanalysis in particular (see Wachtel's [64] critical account of this history).

The trope of interiority plays a major role in $\ddot{A} I$-Lament courses. It is not necessarily the case that interiority or internalization per se are valued above exteriority and externalization. In fact, the conviction on the part of ÄI-Lament teachers that the point of lamenting is catharsis, or the authentic expression of what is inside, does not at all threaten the notion of the self's residence in an inner castle of some sort. It is the inner self whose voice or "contents" must be expressed, and that conviction is key to understanding Finnish manifestations of expressivist subjective-spirituality. In the 2009 annual meeting of the ÄI-Lamenters, Paavo Kärkkäinen (a life coach with much 
experience lamenting, and one of the panelists in the annual meeting's featured discussion) described lamenting as both a promising means of purging oneself of very deep feelings, and a practice that must avoid the pitfalls of hörheltäminen, 'psychobabble.' In response to Kärkkäinen, a female Lutheran priest in the audience said that true lamenting "is not verbiage/rhetoric but inner feeling." 34

Pirkko Fihlman of $\ddot{A} I$-Lamenters sometimes depicts "inner feelings" as the object of healing via Hoitava Itku, "Healing Lament," courses). She said, for example, "And this old Karelian lament tradition is that by which we healed those sisäisiä tunteita, inner feelings." Fihlman stresses the link between the Karelian lament tradition and $\ddot{A} I$-classes, asserting that traditional lamentation was about healing inner feelings and that Fihlman's practice is but the latest link in that tradition.

\subsection{2. "The Trope of Depth" ([65], p. 283)}

To be the latest link in a tradition does not mean pure replication. ÄI-Lamenters are innovators and not just replicators. They encourage deep self-expression, not literal faithfulness to traditional forms. From Pirkko Fihlman's perspective, despite making little use of the traditional metaphor corpus, what $\ddot{I}$-Lamenters teach $i$ s the itkukieli-simply modernized. In fact she says that only the itkukieli is capable of reaching and healing "the deep feelings" about which her students compose their laments. Quite often, Fihlman and her co-teacher Tuomas Rounakari use the phrase kuvakieli "picture [pictorial] language" for (their version of) the itkukieli. "The picture-language speaks syvemmin "more deeply" [than everyday Finnish]," said Fihlman during an interview.

In asking Fihlman and others about the semiotic register appropriate to lament, I sometimes broke the register into its component pieces, inquiring about the relative importance of one facet or another in making the register as special as it was/is, and the process of healing. Just speaking one's feelings - the very thing encouraged in courses oriented toward "I-language" in Finland or elsewhere - is for Fihlman inadequate. "The feeling," says Fihlman, "goes deeper with the [addition of the] melody." This statement accurately reflects her central semiotic ideology [66], p. 17) - that the combination of feeling with weeping, melody, and words "heals" at a deep level. "Pure crying doesn't touch that syvintä tunnetta, "deepest feeling," said Fihlman in a February 2009 lament course.

It is not only problems to be healed but also the power to heal that is located in the depths. In the same 2009 course, Tuomas Rounakari said, "And somehow, while crying, of course, one goes like into a deep trance." 35 This description of lament as trance-experience may come particularly easily to Rounakari's mind, given that he engages in shamanistic rituals, and knows very well both from ethnographic work in Siberia and from his own experience just what shamanic trance consists of (and see my discussion of the trance-like experience of traditional Karelian itkijänaiset, lament-women, above.). When other $\ddot{A}$-Lamenters, or others who offer healing courses in Finland,

34 Unless noted otherwise quotations from others such as Pirkko Fihlman are presented in translation. I am enormously grateful to Heidi Haapoja, Elli-Noora Virkkunen, and Pinja Haukkavaara for their help with transcription and translation.

35 Rounakari uses the extremely common impersonal, "missing person," or "zero person" construction here (which I have translated with "one..."). 
refer to "going deeper," they are reflecting a form of discourse that is in widespread use in what Heelas and his colleagues call "subjective-life" (or "inner-life") spirituality. It is crucial, however, to recognize special features of "relational subjectivism" (introduced earlier):

And unlike individuated (let alone life-as) modes of subjective-life, relational subjectivism is associated with the tendency to go deeper: one finds out more about oneself by discussing one's anger with a close friend or by dealing with jealousy with a lover, for example [35], p. 97).

The two tropes discussed thus far-tropes of interiority and depth-overlap, though only partially. To call a feeling deep may denote its intensity; referring to an "inner feeling" rarely if ever directly denotes intensity. And those two overlap with tropes of authenticity.

\subsubsection{Authenticity, Nakedness, and Daring/Courage}

ÄI-Lamenter's way of blending therapeutic jargon and the discourse of cultural revivalism has again and again taken me aback. I have also repeatedly been surprised at $\ddot{A} I$ leaders' insistence not only that lamenting with supportive others is sacred, but that the sacredness is about the shared emotion, the deep connection between people that it produces, as might stories in a therapy group. However, in this Age of Authenticity, the sacralization of transparent emotional "sharing" is not uncommon. Carrie Kemp, writing about "Journey of Reconciliation with Inactive Catholics," asserts that "a church without members who speak from their sacred authenticity will have no soul" ([67] emphasis added). From the perspective of "subjective-life spirituality" and in particular its relational face, "sacred authenticity" (see also [68], pp. 40-41) is something we as humans at least potentially possess. Authentic self-expression requires courage, even daring. Mustering the courage to engage in deep emotional sharing of the kind that defines lament courses is also celebrated in the contemporary American intentional community pseudonymized as "the Aurora Commons." In their article entitled "Performing Authentic Selfhood in an Intentional Community," Holden and Schrock describe "courageous performances, especially those concerned with overcoming fear, were often ritualized to heighten the perceived sacredness of authenticity" [69], p. 210; emphasis added).

As concrete images of the courage required by authentic self-performance ÄI-Lamenters sometimes use the metaphor of daring to be naked or even without skin. We find the same metaphor on self-identified "New Age" websites [70]. ${ }^{36}$ During debriefing at the end of a March 2009 lament course, one student said appreciatively, "Here [in the course], when you are quite naked with your feelings, you are not that beautiful or that clever." We could paraphrase thus: Here we strip off our defenses, our attempts to project invulnerability, and embrace radical openness. This becoming naked is part of what Pirkko Fihlman and Tuomas Rounakari see as the sacredness

\footnotetext{
36 "Allow yourself to unfold into the beauteous creature that you are. Contemplate and reveal the sacredness of your sexuality as the nakedness of that which you are, presents itself in a multitude of ways. Could you stand up on stage in front of all who those you love and be naked? Can you be seen in fullness in the naked truth of all that you have lied about? Will the un-doings of your past re-string you to play a new song, a new note, and a new tune? People will notice that you vibrate differently in the harmonics of your new energy" (GoddessLight March 12, 2008; last accessed July 13, 2011.)
} 
of lament. In a 2010 interview, Rounakari said, "In lament there is that kind of state of spiritual nakedness that IS holy."

Fihlman also uses the metaphor of a threshold one dares to cross, that threshold sometimes being a watery surface below which one dares to dive.

There is a threshold. One must dare to dive somehow under the surface and be without skin. And it's a threshold for many. But when one dares to go ${ }^{37}$ then the [aitous] 'authenticity' comes to the fore. Lament must be always [aito] 'authentic.' The feeling that one transmits to the other person has to be authentic. ... If one faces some other person's feelings in an authentic way it is, it is a great treasure. We have many here who have attended lament courses present here, and you know we are like sisters because we have faced each other authentically. It's that kind of eternal friendship that will last and it's fantastic in these days. 38

In a conversation with two foreigners who had both participated in lament courses (my wife and myself), Fihlman said (in English), "What we have shared, it's holy for us." We hear the same theme in this exchange between Fihlman and a former student (Aino Pusa) who is now a very active, often public lamenter:

Fihlman: Laments are not like things in every other sort of place but they are areas where the deepest feelings a person had are touched. And then lament should always start with that kind of - I start my laments with a prayer.

Pusa: Like I said in the beginning, it's such a sacred thing.

For Pusa, it seems clear that not only a preceding prayer, but the process by which the deepest feelings of performer (and audience) are touched, makes lament "a sacred thing."

We have seen thus far that, as a reflection of relational-subjectivism, neolamenting is both therapeutic and sacred. But if lamenting is some sort of therapy, what sort is it? If we encounter an abundance of psychotherapeutic terms in lament courses, as we do, what school of psychotherapy do they reflect?

\subsection{What Sort of "Psychotherapy" Do These Courses Represent?}

We have touched on the issue of how Finnish lament courses combine therapeutic jargon with talk of a precious cultural heritage that is still sacred to those who participate in it. There is much to say, however, about the more specifically psychotherapeutic discourse manifest in lament courses. Parallels between the courses described herein and group therapy, especially examples like Esalen [71], are obvious. In addition to that, Pirkko Fihlman at least once echoed the jargon of Transactional Analysis: "We have noticed that in lamenting the adult 'me' can go can go to the abandoned wounded child..." The lamenters' emphasis on authenticity also brings to mind

37 Fihlman leaves this "going" underspecified. She might mean "going" "under the surface" or "over the threshold."

38 Note here two indirect invocations of the sacred-being "like sisters" (certainly an expression heard within religious or spiritual groups) and fostering "eternal friendship." These are two tokens of a religious register that also happens to center on authenticity. 
Rogerian therapy [72]. As one alumna said in an interview about her lament course, "One had courage in lamenting to be what one is. One didn't try to be more or less."

But the play of surfaces and depths we have been exploring in the tropes of interiority and depth is a special concern of psychoanalytic thought and practice. The following section thus focuses on jargon used by $\ddot{I} I$-Lamenters that derives from psychodynamic and particularly Freudian therapy.

The trope of depth pervades psychoanalytic discourse and its popular echoes (where one typically hears of the "subconscious" rather than "unconscious" mind). Lament teachers like Pirkko Fihlman refer to the depths as the buried locus of the most recalcitrant feelings, traumas, problems, to be dealt with in context of therapy, course, etc. In a 2009 lament course, Fihlman invokes the alitajunta, 'beneath awareness, subconscious' thus:

With this lament the idea came to me ... how healing this lamenting is. And I was able to get rid of those sorts of things that I never have become 'aware/conscious' [tiedostanut] of those things that happened in childhood - these kinds of bad feelings and fears and agonies.... in our lament courses... one dares to face those feelings that have stayed unconscious [alitajunta].

Lamenters also make indirect reference to repression ("damming up") and catharsis, as when Pirkko said during the same course, "And when I made that lament I realized how healing lament is. Because the kinds of things that I had dammed up came out, and they were related to those fears and depressions/ agonies I experienced as a ... child."

One young course alumna had become exceptionally familiar with the psychological self-help literature and its indirect Freudian roots. She referred to defense mechanisms in our April 2009 interview:

Working through [one's] feelings is the key and the solution. That painful matter can be handled a lot better when using those metaphors through this the defense mechanism will break-it breaks more easily when word-images are used, not in that raw way of [speaking about] things And there I have a personal goal to learn to save oneself [from that]. So one might speak of things more beautifully in order that one might dare then to face those painful things. If I have too much of a habit of speaking too directly and it - it might be - it's one of those defense mechanisms of mine that when one speaks directly. Then one doesn't have to feel [even] if one would speak about one's own. I should speak about things more beautiful and then I would have more courage to face those painful things, a bit more metaphorically [through word-images] facing the feelings would be easier perhaps.

This alumna embraced the lament course on a number of levels, affirming that the course was aptly named (Hoitava Itku 'Healing Lament'), that the traditions of people far to the east of her had much to contribute to Finland, and that the lament course "process" in many ways mimics the ideal process followed by psychodynamically oriented therapists. But the emphasis on metaphor, using metaphoric language in one's lament - a theme, as we have seen, that many lamenters touch on-deserves analytic attention of its own. In the following section we explore the efficacy of metaphor from both magical-traditional and a modernist-psychotherapeutic perspectives. 


\section{Conclusions}

\subsection{What Is Unique About Lament Courses, and What Do They Tell Us About Culture?}

The ÄI-Lamenters' threefold emphasis on a particular cultural-historical tradition, psy-oriented healing, and a hybrid (whether we call it "postmodern" [15,73] or "New Age" [74,75]) of traditional and "post-secular" religion-rural Karelian folk Orthodoxy, Finnish civil religion, and "the sacred-authentic" - is unique. New spiritualities and the courses that help propagate them tend to be eclectic, rather than borrowing-as ÄI-Lamenters do-from one "local" tradition (the problematique of "locality" having being discussed above). Lament courses offer up traditional Karelian laments (and lament-women) as models, but they also evoke various psychotherapies (especially depth/psychoanalytic), albeit not by name. Other courses in Finland-courses that I have attended, or about which I asked a dozen course alumnae in interviews - teach self-help or healing techniques with no particular local or nearby cultural roots. Those other courses use less psy-jargon vis-à-vis ÄI-Lament courses, and lack any particular focus on authenticity. The specific cultural tradition that $\ddot{A I}$ is "reviving" is like nothing else that students of "subjective-life spirituality" have written about, combining music, weeping, words governed by the rules of a traditional register, and traditional beliefs about its sacred function.

In the postmodern supermarket, it might be relatively easy to find courses that mix psychotherapeutic with spiritual discourse and even a discourse on "a cultural tradition" like shamanism. It is much more unusual, if not totally unique, to uncover a course that teaches a cultural tradition: a) that is at least putatively "local" (see discussion above); b) that is already treated with interest and respect in the media (dozens upon dozens of articles and Finnish public radio and television stories going back at least to the 1970s, before the "revival"); c) that appeals to a "psy-ready" constituency (those who believe that weeping means catharsis and catharsis means expressing previously unconscious contents, as Fihlman has said); but d) that also had a sacred function that revivalists are incorporating into their teaching and their public and private claims about lamenting.

As I have just indicated, ÄI-Lament courses commonly address "culture", but "culture" is a complex signifier in $\ddot{A I}$ representations. It is associated with territory as well as emotional styles (remember Rounakari's contrast). Although little Karelian territory still belongs to Finland-most of it being Russian - it is fairly common in lament course discussions to blur the international boundary. The categories "Finland" and "Finns" could thus either exclude or include "Karelians." Course participants and alumni might therefore represent "Karelian culture" as Self or Other. Because of this complexity, the question of "locality," and especially whether or not to count Karelia as "local," is vexing. 39

The fact that $\ddot{A} I$-Lamenters invest much time in talking about culture reminds us of something Urban [76] has emphasized-i.e., that culture is a layered semiotic phenomenon, and that metacultural reflections are exceedingly important in the ongoing reproduction (or lack thereof) of cultural forms. The explicit reflections in lament courses on the meaning of the very signifiers that

39 As one reviewer put it, "The 'locality' of these traditions appears to be as much of a local (!), cultural conception as it appears to be an analytic one." 
constitute neolaments ("culture," "authenticity") is indeed striking. Beyond neolament circles, I have noted above that Finns engage in metacultural discourse, joining others in self-stereotyping. One lament course alumna interviewed in 2009 said, "We have created a quiet and fine culture, but on the other hand, inside of that culture people are longing...[saying,] 'I would like to let loose!'” Do Finns resist authentic emotional disclosure of the type that defines lament courses (as per the stereotype), or so they secretly long for it, as the interviewee indicated? I would argue that the point is not what the right answer is, or which is true; the point, rather, concerns both as examples of metacultural discourse that is significant in itself.

How so? ÄI-Lament leaders engage in similar metacultural discourse, as the example from Tuomas Rounakari illustrated, and such representations justify intervening in the evolution of Finnish culture, challenging the purported tendency Finns have to resist such things as lamenting. Their representations define the moral-religious stakes of intervening. Revivalist lamenting is not simply and straightforwardly therapeutic; the role that psychotherapeutic notions play in this drama is not simply about individual needs and individual decisions (to seek help or not). Rather, $\ddot{A} I$ 's goal is as much to effect a cultural transformation as it is to offer psy-oriented healing.

\subsection{Metaphors, Indirectness, and Authenticity}

ÄI-Lamenters agree with other voices in the Finnish lament revival on the importance of authentic performance, and regard the metaphoric register that characterizes modern as well as traditional laments as a key part of the healing quality of lamenting. Yet questions surrounding the itkukieli or 'lament register' and its metaphoric nature are among the most divisive within the larger circle of those who make the Karelian lament tradition their concern. This includes Finno-Karelian revivalists who remain separate from $\ddot{A} I$-Lamenters, as well as scholars, some of whom are ethnic Karelians. $\ddot{I}$ rejects the others' strict ("authentic") interpretation of the old corpus of metaphors, emphasizing the sense of "authenticity" as faithfulness to one's inner experience, while not rejecting the indirectness cultivated by metaphoric speech. The old corpus was traditionally followed exclusively, not used as set of models on which to improvise, as it is in $\ddot{A I}$ courses. Yet $\ddot{A} I$ nonetheless locates authenticity, in part, in the metaphoric nature of the "new" itkukieli. Such complexities deserve more investigation.

Here we find what may be most interesting about this phenomenon-whereas psy-discourse typically equates authenticity (which it values highly) with directness, ÄI-Lamenters and course alumni speak of metaphoric indirectness as at the very least a strategic aid to deep, effective, and authentic self-expression. As noted above, one course alumna considers direct speech a "defense mechanism" vis-à-vis the potentially more emotional "beautiful speech." Given the increasing hegemony of ideologies of directness [63,72,77], ÄI-Lamenters seem to have found a via media between what is perceived as the overly rigid and personally distanced corpus of traditional indirect forms and the modern-everyday register of Finnish that Pirkko Fihlman considers abrupt and thus impolite or uncaring. 


\subsection{The Sacredness of Lament vis-à-vis a Psy-Influenced Vision of Authenticity}

There are several sources for the putatively sacred nature of even neolamentation. The first would be its traditional counterpart with its religious function, connecting singer(s) and spirits. Indeed, whatever may be their perspective on the therapeutic quality of neolamenting and on the traditional metaphor corpus, the two women who have played the biggest role in the lament revival have in dreams, like their forebears, experienced contact with the recent dead and with other ancestors. But it is the attribution of the sacredness of lament to a second phenomenon - the ability of the "lament process" unfolding over the three-day period of a lament course to facilitate emotionally authentic "sharing," which is itself deemed sacred-that is especially striking (Striking, that is, despite the fact that this attribution of sacredness reflects other popular manifestations of the Age of Authenticity, including philosophical work, [78], p. 20, where "I-Thou," which Buber calls simply "relation," is "holy"). Indeed even the founder of ÄI-Lamenters, Pirkko Fihlman, has expressed surprise at the intensity of interpersonal connections achieved in "the lament process."

The features of the lament register as used traditionally, especially metaphoric indirection, had a strongly if not exclusively sacred function-establishing communication with the spirits. Psychoanalysis has always concerned itself with metaphors and other tropes, and newly emerging psychodynamic therapies include one centrally concerning itself with metaphors ([79-81]. However, tropes arising in dream narratives, for example, serve to simultaneously obscure and reveal psychic significance - not to link analysands with the spirit world.

Nonetheless, any implication that the spiritual and psychotherapeutic dimensions of lamenting with metaphoric language are mutually exclusive is false. ÄI-Lamenters reject literal faithfulness to the Karelian lament register, yet produce their own consistently metaphoric register. The latter answers to the call to produce discourse that is an authentic self-expression-the call that, for Charles Taylor, defines ours as the Age of Authenticity [16]. Although leaders like Pirkko Fihlman credit her laments with helping her communicate with the dead - the realm of the traditional-sacred in Karelia - the expressive function of the distinct Finnish-Karelian neolament register ÄI-Lamenters are crafting may be just as sacred, but for a different reason. Even the use of metaphors in modern laments is sacred to Fihlman insofar as it helps produce in (and between) lamenter and audience a deep emotional resonance. But metaphors alone cannot produce such resonance in audiences. If they are to produce a sacred form of intersubjectivity laments must reflect authentic feelings. The production of such feelings in lament courses simultaneously reflects the apotheosized "subjectivelife" (in which courses contributing to the growth of the self play a major role) and the subjectivized spiritual life. And it is because of this hybridity of the spiritual and the therapeutic that the stakes of the "lament revival" from the perspective of $\ddot{A}$ I-Lamenters - nothing less than helping Finns express the feelings that they ostensibly hold within, to their detriment - are so high.

Hence, the healing quality of lament practice is not $a$ value, but somehow connected to what is now, in the Age of Authenticity, ultimate value [35]. From a slightly different perspective, if the practice of naked authenticity is sacred, as revivalist leaders claim, then the disposition of Finnish people toward that practice (something with which $\ddot{A} I$ leaders are very concerned) cannot be a matter of indifference. Despite the concern that $\ddot{A} I$ leaders have about Finnish men, it is not 
surprising that group lamenting appeals mainly to (middle-class Finnish) women. The conclusion of Heelas et al ([35], p. 98) fits the Finnish case: "more women than men tend to emphasize relational subjective-life, and conversely ... more men than women tend to emphasize the individuated or distinct variant."

Presently, there is too little theoretical work in anthropology on authenticity as faithfulness to one's own experience, particularly in the context of religion (Lindholm's work being an exception [22]). The finding that, in the lament groups, authenticity potentiates a kind of I-Thou encounter that is sacred, and the uncovering of an ideological struggle among activists in the larger lament movement (beyond the confines of $\ddot{A}$-Lamenters) over two definitions of authenticity-one oriented toward transmission of a tradition, the other oriented to the experiential and reflexively authentic self - may stimulate the anthropology of religion to look again at "authenticity." The internal debates among lamenters, and the apparent durability of both definitions, sometimes locked in a dialogue as is the case among Finnish lamenters, indicate the level of sophistication required in our theorizing of authenticity.

It is hoped that this article will help jump start anthropological work on authenticity and healing under the umbrella of sacredness in today's world. Future work should address, among other things, the contrast and tension between the two versions of authenticity in relation to Urban's [76] distinction between metacultures of tradition (under which would fall "authenticity-as-faithful-replication) $v s$. metacultures of newness (under which would fall “authenticity-as-faithfulness-to-inner-self”).

\section{Acknowledgments}

This material is based upon work supported by the National Science Foundation under Grant No. 0822512. Any opinions, findings, and conclusions or recommendations expressed in this material are those of the author and do not necessarily reflect the views of the National Science Foundation.

Support also came from Michael Stevenson, George Gumerman IV, and Robert Trotter at Northern Arizona University, and to Pertti Anttonen and the Department of Folkloristics at Helsinki University. My heartfelt gratitude goes to all those in Finland who gave generously of their time, advice, instruction, correction, etc.

Finally, thanks to the editors of Religions and to the three anonymous reviewers, whose comments were enormously helpful. Whatever flaws remain in the argument are solely the author's responsibility.

\section{References}

1. Wood, M. Possession, Power and the New Age: Ambiguities of Authority in Neoliberal Societies; Ashgate: Aldershot, UK, 2008.

2. Lévi-Strauss, C. The effectiveness of symbols. In Structural Anthropology; Basic Books: New York, NY, USA, 1963; pp. 186-205.

3. Hayward, R. Demonology, neurology, and medicine in edwardian britain. Bull. Hist. Med. 2004, 78, 37-58. 
4. Wilce, J.M. Scientizing bangladeshi psychiatry: Parallelism, enregisterment, and the cure for a magic complex. Lang. Soc. 2008, 37, 91-114.

5. Utriainen, T.; Hovi, T.; Broo, M. The post-secular position and enchanted bodies. In Religion and the Body; Ahlbäck, T., Dahla, B., Eds.; Donner Institute for Research in Religious and Cultural History: Åbo, Finland, 2011.

6. Taylor, C. The malaise of Modernity; House of Anansi: Concord, Canada, 1991.

7. Heelas, P. The New Age Movement: The Celebration of the Self and the Sacralization of Modernity; Blackwell Publishers: Oxford, UK, 1996.

8. Anttonen, P.J. Tradition through Modernity: Postmodernism and the Nation-State in Folklore Scholarship; Finnish Folklore Society: Helsinki, Finland, 2005; Volume 15.

9. Anttonen, P.J. Folklore, history and the "story of finland". In Dynamics of Tradition: Perspectives on Oral Poetry and Folk Belief (Essays in Hounour of Anna-Leena Siikala on Her 60th Birthday 1st January 2003); Tarkka, L., Ed.; Finnish Literature Society: Helsinki, Finland, 2003; Volume 13, pp. 48-66.

10. Vento, U. The role of the kalevala in finnish culture and politics. Nord. J. Afr. Stud. 1992, 1, 82-93.

11. Ketola, K.; Martikainen, T. The religion in finland project. In Religion \& Society: CrossDisciplinary European Perspectives; Mortensen, V., Ed.; University of Aarhus: Aarhus, Danmark, 2006; pp. 81-89.

12. Mikkonen, P. New age in finland: A view through finnish new age magazines. In Beyond the Mainstream: The Emergence of Religious Pluralism in Finland, Estonia and Russia; Kaplan, J., Ed.; SKS: Helsinki, Finland, 2000; pp. 255-272.

13. Rautaniemi, M. Henkisyys, hyvinvointi, yksilöllisyys ja sosiaalisuus helsingin astanga joogakoulussa [Spirituality, Well-Being, Individuality, and Sociality in the Ashtanga Yoga School of Helsinki]; Helsingin Yliopisto: Helsinki, Finland, 2010.

14. Junnonaho, M. On the finnish present-day religiosity and the new age thought. Stud. Folklore Popular Relig. 1999, 3, 87-94.

15. Jencks, C. What is postmodernism? Academy Editions/St. Martin's Press: London, UK, New York, NY, USA, 1989.

16. Taylor, C. The age of authenticity. In A Secular Age; Taylor, C., Ed.; Harvard University Press: Cambridge, MA, USA, 2007; pp. 473-504.

17. Hanegraaff, W.J. New age religion and secularization. Numen 2000, 47, 288-312.

18. Urban, H.B. The cult of ecstasy: Tantrism, the new age, and the spiritual logic of late capitalism. Hist. Relig. 2000, 39, 268-304.

19. Rogers, C. Client-Centered Therapy: Its Current Practice, Implications, and Theory; Houghton Mifflin Company: Boston, MA, USA, 1951.

20. Kivivuori, J. Psykokulttuuri: Sosiologinen näkökulma arjen psykologisoitumisen prosessiin [psychoculture: A sociological viewpoint to the psychologisation of everyday life]; Hanki ja jää: Tampere and Helsinki, Finland, 1991.

21. Nenola, A. Inkerin itkuvirret-Ingrian laments; Finnish Literature Society: Helsinki, Finland, 2002.

22. Lindholm, C. Culture and Authenticity; Blackwell Publishers: Malden, MA, USA, 2008. 
23. Trilling, L. Sincerity and Authenticity; Harvard University Press: Cambridge, MA, USA, 1972.

24. Desjarlais, R.R. Struggling along: The possibilities for experience among the homeless mentally ill. Am. Anthropol. 1994, 96, 886-901.

25. Heelas, P. Spiritualities of Life: New Age Romanticism and Consumptive Capitalism; Wiley-Blackwell: Malden, MA, USA, 2008.

26. Ollila, D.J. The Formative Period of the Finnish Evangelical Lutheran Church in America or Suomi Synod. Theology Doctorate, Boston University, Boston, MA, USA, 1963.

27. Kivisto, P. Immigrant Socialists in the United States: The Case of Finns and the Left; Fairleigh Dickinson University Press: Rutherford, NJ, USA, 1984.

28. Taylor, C. Sources of the Self: The Making of the Modern Identity; Harvard University Press: Cambridge, MA, USA, 1989.

29. Rose, N. Inventing Ourselves: Psychology, Power, and Personhood; Cambridge University Press: Cambridge, UK, 1996.

30. Pinel, P. A Treatise on Insanity, in Which are Contained the Principles of a New and More Practical Nosology of Maniacal Disorders than Has Yet Been Offered to the Public [Original Title: Traité médico-philosophique sur l'aliénation mentale, ou la manie.]; Todd: Sheffield, UK, 1806.

31. Charcot, J.M. La foi qui guérit. Rev. Hebd. 1892, 1892, 112-132.

32. Goldstein, J. Console and Classify: The French Psychiatric Profession in the Nineteenth Century; Cambridge University Press: New York, NY, USA, 1987.

33. Caplan, E. Popularizing american psychotherapy: The emmanuel movement, 1906-1910. Hist. Psychol. 1998, 1, 289-314.

34. Heelas, P. Challenging secularization theory: The growth of "new age" spiritualities of life. Hedgehog Rev. 2006, 8, 46-58.

35. Heelas, P.; Woodhead, L.; Seel, B.; Szerszynski, B.; Tusting, K. The Spiritual Revolution: Why Religion is Giving Way to Spirituality; Blackwell Publishing: Malden, MA, USA, 2005.

36. Laurinen, T.; Leinonen, M. Martta kuikka - aito itkijä; Videotallenne: Helsinki, Finland, 2001.

37. Härmä, I. Huomisen muistoja [tomorrow's memories]. In $T B C$; Guerillafilms Ltd., Finnish Film Foundation: Helsinki, Finland, 2004; 28 min.

38. Tenhunen, A.-L. Itku on nykynaiselle hoitomuoto: Itkuvirsikursilla ripsivärit jäävät kotiin [lament is for contemporary women a form of therapy: Mascara at a lament workshop challenges the validity of home. Uusi Kansanmusiikki 1999, 3, 13-15

39. Tenhunen, A.-L. Itkuvirren kolme elämää: Itkuvirsien käytön muuttuminen [the three lives of lament: Transformations in lament behavior]; SKS: Helsinki, Finland, 2006.

40. Tenhunen, A.-L. Times change, laments revive. Fin. Music Q. 2007, 2007, 30-36.

41. Briggs, C. Theorizing modernity conspiratorially: Science, scale, and the political economy of public discourse in explanations of a cholera epidemic. Am. Ethnol. 2004, 31, 164-187.

42. Stepanova, E. Reflections of Belief Systems in Karelian and Lithuanian Laments: Shared Systems of Traditional Referentiality? Conference on Baltic Worldview: From Mythology to Folklore, Vilnius, Lithuania, 8-10 July 2009; Harris, J., Lyle, E., Eds.; Institute of Lithuanian Literature and Folklore: Vilnius, Lithuania, 2009. 
43. Stepanova, E. Itkukielen metaforat ja itkujen dramaturgia [the metaphors of lament register and the dramaturgy of lament. In Kantele, runolaulu, ja itkuvirsi (juminkeon julkaisuja, nro 76); Huttu-Hiltonen, P., Frog; Seppänen, J., Stepanova, E., Eds.; Juminkekko: Jyväskylä, Finland, 2009; pp. 13-25, 113.

44. Wilce, J.M. Crying Shame: Metaculture, Modernity, and the Exaggerated Death of Lament; Blackwell Publishers: Malden, MA, USA, 2009.

45. Wickett, E. "For our destinies": The funerary lament of upper egypt. Ph.D. Thesis, University of Pennsylvania, Philadelphia, PA, USA, 1993.

46. Honko, L. Balto-finnic lament poetry. In Studia Fennica 17; Finnish Literature Society: Helsinki, Finland, 1974.

47. Konkka, U. Ikuinen ikävä: Karjalaiset riitti-itkut [eternal longing: Karelian ritual laments]; Suomalaisen Kirjallisuuden Seura (SKS): Helsinki, Finland, 1985; Volume 428.

48. Tolbert, E. Magico-religious power and gender in the karelian lament. In Music, Gender, and Culture; Herndon, M., Zigler, S., Eds.; International Council for Traditional Music, Florian Noetzel Verlag: Wilhelmshaven, Germany, 1990; Volume 1, pp. 41-56.

49. Tolbert, E.D. The voice of lament: Female vocality and performative efficacy in the finnishkarelian itkuvirsi. In Embodied Voices: Representing Female Vocality in Western Culture; Dunn, L.C., Jones, N.A., Eds.; Cambridge University Press: New York, NY, USA, 1994; pp. 179-194.

50. Ó'Súilleabhaín, S. Irish Wake Amusements (caitheamh aimsire ar thórraimh); Mercier Press: Dublin \& Cork, Ireland, 1967.

51. Tolbert, E. Women cry with words: Symbolization of affect in the karelian lament. Yearb. Tradit. Music 1990, 22, 80-105.

52. Wilce, J. Karelian itkukieli as honorific register. Unpublished work.

53. Silverstein, M. "Direct" and "indirect" communicative acts in semiotic perspective. J. Pragmat. 2010, 42, 337-353.

54. Cottler, S.B.; Guerra, J.J. Assertion Training: A Humanistic-Behavioral Guide to Self-Dignity; Research Press: Champaign, IL, USA, 1979.

55. Aalto, M.P. Elämän puu: Rippikoululaisen kirja [the tree of life: A book for confirmation class students]; Kirjapaja: Tampere, Finland, 2007.

56. Evangelical-Lutheran-Church-of-Finland Surun kohtaaminen (facing sorrow/grief). Available online: http://www.evl.fi/kkh/to/kkn/koulu/suru.htm (accessed on 17 February 2009).

57. Nenola, A. Studies in Ingrian Laments; Finnish Academy of Sciences: Helsinki, Finland, 1982; Volume 234.

58. Lehtonen, J.; Sajavaara, K. The silent finn. In Perspectives on Silence; Tannen, D., Saville-Troike, M., Eds.; Ablex: Norwood, NJ, 1985; pp. 193-201.

59. Sajavaara, K.; Lehtonen, J. The silent finn revisited. In Silence: Interdisciplinary Perspectives; Jaworsky, A., Ed.; Mouton de Gruyter: Berlin, Germany, 1997; pp. 263-283.

60. Tulviste, T.; Mizera, L.; de Geer, B.; Tryggvason, M.-T. A silent finn, a silent finno-ugric, or a silent nordic? A comparative study of estonian, finnish, and swedish mother-adolescent interactions. Appl. Psycholinguist. 2003, 24, 249-265. 
61. Tryggvason, M.-T. Communicative behavior in family conversation: Comparison of amount of talk in finnish, swedish-finnish, and swedish families. J. Pragmat. 2006, 38, 1795-1810.

62. Butler, J. Gender Trouble: Feminism and the Subversion of Identity; Routledge: New York, NY, USA, 1990.

63. Keane, W. From fetishism to sincerity: On agency, the speaking subject, and their historicity in the context of religious conversion. Comp. Stud. Soc. Hist. 1997, 39, 674-693.

64. Wachtel, P.L. The surface and the depths: The metaphor of depth in psychoanalysis and the ways in which it can mislead. Contemp. Psychoanal. 2003, 39, 5-26.

65. Donoghue, D. Review: Hannah arendt's "the life of the mind". Hudson Rev. 1979, 32, 281-288.

66. Keane, W. Christian Moderns: Freedom and Fetish in the Mission Encounter; University of California Press: Berkeley and Los Angeles, CA, USA, 2007.

67. Kemp, C. Catholics Can Come Home Again!: A Guide for the Journey of Reconciliation with Inactive Catholics; Paulist Press: Mahwah, NJ, USA 2001.

68. Creditor, R.M. Living in the dream. In Walking with Life; Artson, R.B.S., Silver, D., Eds.; Ziegler School of Rabbinic Studies, American Jewish University: Bel Air, CA, USA, 2009.

69. Holden, D.; Schrock, D. Performing authentic selfhood in an intentional community. In Authenticity in Culture, Self, and Society; Vannini, P., Williams, J.P., Eds.; Ashgate: Surrey, Burlington, UK, 2009; pp. 203-218.

70. GoddessLight. The quantum awakening update. Available online: http://www.myspace.com/ sevelinaasenova/blog (accessed on 9 October 2011).

71. Holloman, R. Ritual opening and individual transformation: Rites of passage at esalen. Am. Anthropol. 1974, 76, 265-280.

72. Smith, B. Ideologies of the speaking subject in the psychotherapeutic theory and practice of carl rogers. J. Ling. Anthropol. 2005, 15, 258-272.

73. Walter, J.A. The Revival of Death; Taylor \& Francis/Routledge: Florence, KY, USA, 1994.

74. Myers, F. Culture making: Performing aboriginality at the asia society gallery. Am. Ethnol. 1994, 21, 679-699.

75. Hill, M. Inca of the blood, inca of the soul: Embodiment, emotion, and racialization in the peruvian mystical tourist industry. J. Am. Acad. Relig. 2008, 76, 251-279.

76. Urban, G. Metaculture: How Culture Moves through the World; University of Minnesota Press: Minneapolis, MN, USA, 2001.

77. Rosaldo, M.Z. I have nothing to hide: The language of ilongot oratory. Lang. Soc. 1973, 2, 193-223.

78. Buber, M. I and Thou; Continuum: London, UK, 2004.

79. Kopp, R.R. Metaphor Therapy: Using Client-Generated Metaphors in Psychotherapy; Brunner/ Mazel: Brisol, PA, USA, 1995.

80. Adams, M.V. Metaphors in psychoanalytic theory and therapy. Clin. Soc. Work J. 1997, 25, 27-39.

81. Dwairy, M. Culture analysis and metaphor psychotherapy with arab-muslim clients. J. Clin. Psychol. 2009, 65, 199-209. 
MDPI AG

Klybeckstrasse 64

4057 Basel, Switzerland

Tel. +41616837734

Fax +41613028918

http://www.mdpi.com/

Religions Editorial Office

E-mail: religions@mdpi.com

http://www.mdpi.com/journal/religions 



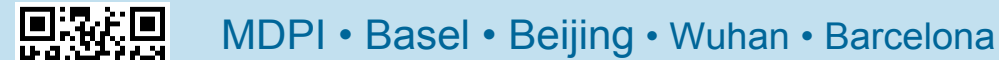
158 ISBN 978-3-906980-78-2 